\title{
TECTÓNICA, VOLCANISMO Y SEDIMENTACIÓN EN LA CUENCA TRIÁSICA DEL GRUPO PUESTO VIEJO (TRIÁSICO MEDIO-SUPERIOR), PROVINCIA DE MENDOZA, ARGENTINA
}

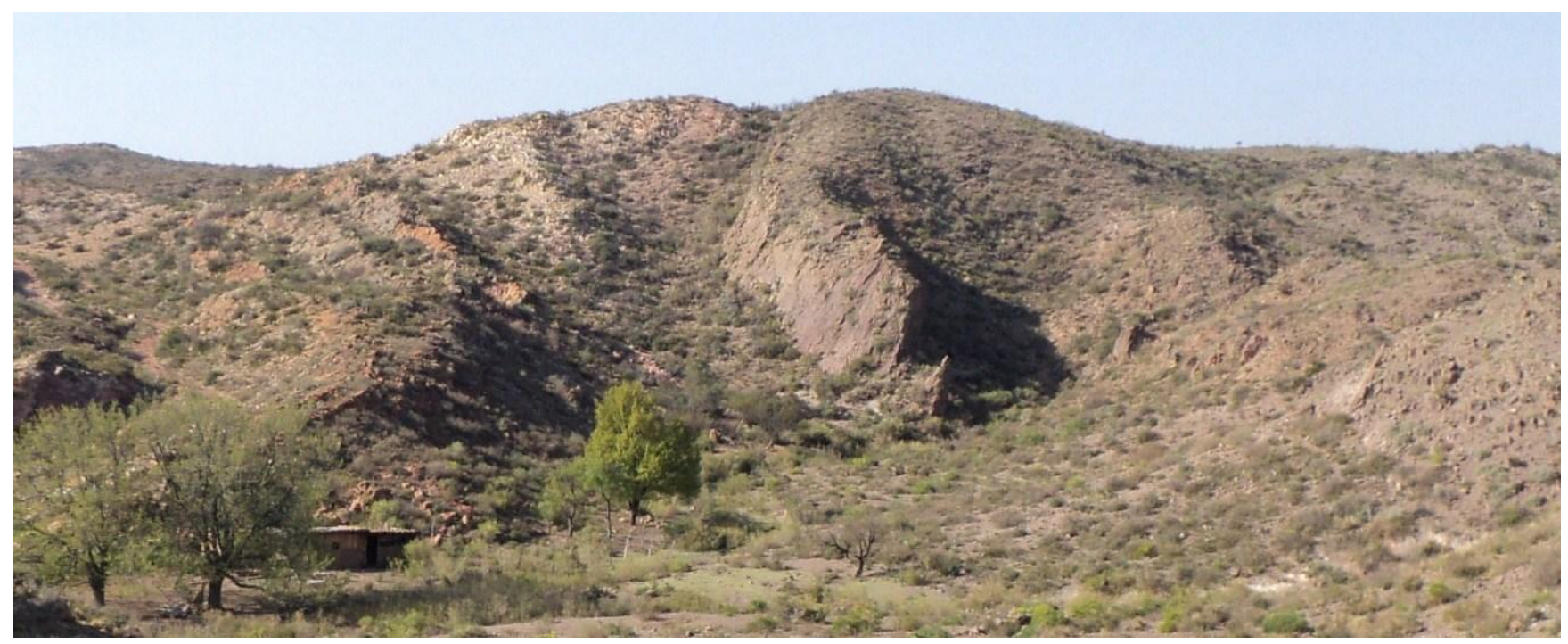

Autora Lic. Mariana Monti

Directores Dr. Juan R. Franzese

Dra. Ana M. Zavattieri

Facultad de Ciencias Naturales y Museo. Universidad Nacional de La Plata, Buenos Aires.

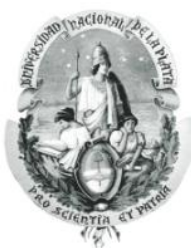


"...Se hace camino al andar..."

Miguel Hernandez

A mi mamá, Alicia ya mi hija, Camila. 


\section{ÍNDICE}

Agradecimientos iv

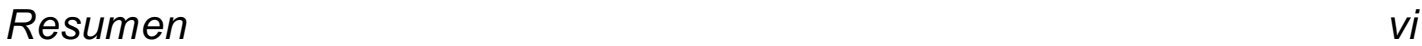

Abstract ix

Capítulo 1. Introducción y Antecedente s............................................. 2

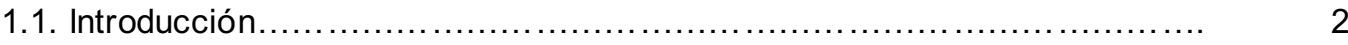

1.2. Marco geológico de las acumulaciones triásicas en San Rafael.............. 4

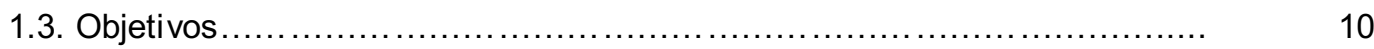

1.4. Estratigrafía del Bloque de San Rafael................................... 12

1.4.1. Estratigrafía pre-triásica................................................ 12

1.4.2. Estratigrafía triásica................................................ 13

1.4.3. Contenido paleontológico triásico ..................................... 15

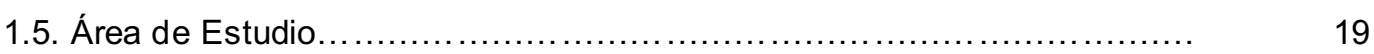

Capítulo 2. Metodología........................................................ 22

2.1. Trabajos de campo ...................................................... 22

2.1.1. Mapeo geológico................................................. 22

2.1.2. Perfiles litológicos y estratigráficos .................................. 23

2.1.3. Relevamiento de datos estructurales ................................ 23

2.1.4. Recolección de muestras ................................................. 24

2.2. Trabajos de gabinete ................................................. 24

2.2.1. Análisis de facies, asociaciones de facies y ambientes.................. 25

2.2.2. Análisis petrográfico y geoquímico ..................................... 25

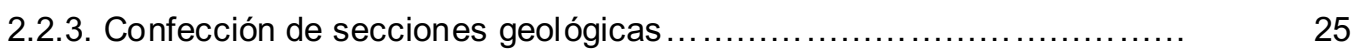

Capítulo 3. Estructura s triá sica s............................................. 27

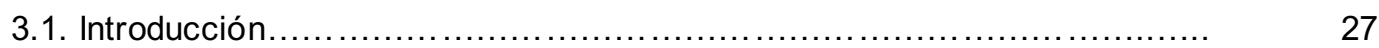

3.1.1. Fallas Principales .................................................. 30

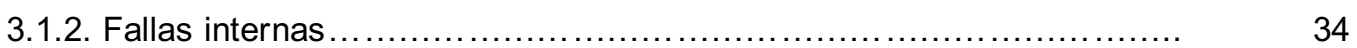

3.1.3. Fallas Menores.................................................... 39

3.1.4. Zona de acomodación del Río Seco de la Quebrada...................... 41

3.1.5. Descripción de los pliegues........................................ 43

3.2. Etapas de estructuración................................................ 48

3.2.1. Etapa I: Generación del espacio de acumulación inicial .................. 49

3.2.2. Etapa II: Desarrollo de las estructuras internas del depocentro ........... 51 
3.2.3. Etapa III: Reactivación y crecimiento de las estructuras internas ........

3.2.4. Etapa IV: Último evento de reactivación de las estructuras internas .... 55

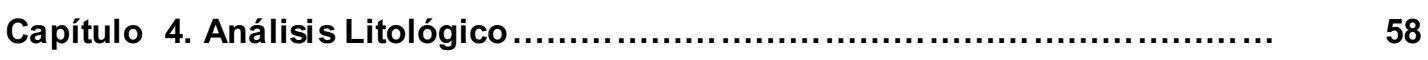

4.1. Análisis de litofacies del Grupo Puesto Viejo ............................ 59

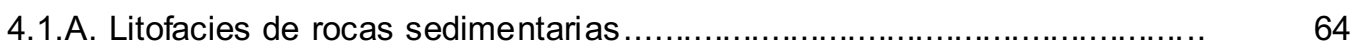

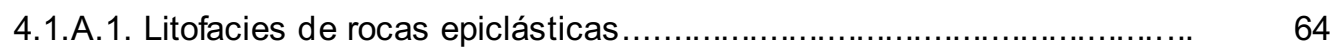

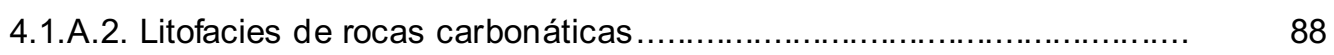

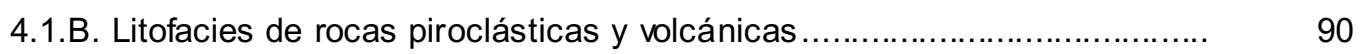

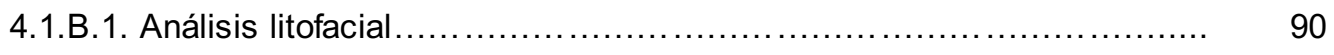

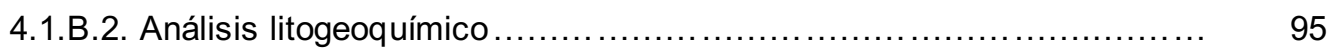

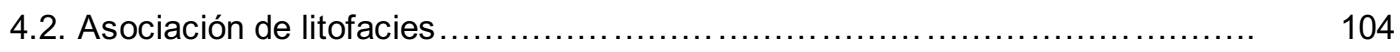

4.2.1. Análisis de las asociaciones de rocas sedimentarias .................... 105

4.2.2. Análisis de las asociaciones de rocas piroclásticas $\ldots \ldots \ldots \ldots \ldots \ldots \ldots \ldots \ldots \ldots$

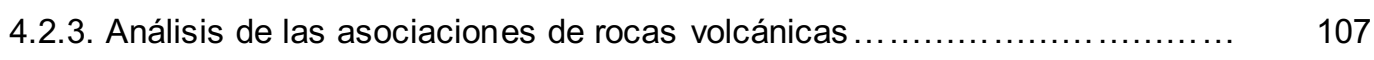

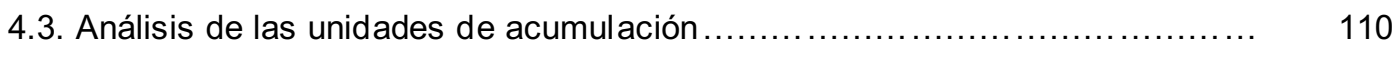

4.3.1. Abanicos aluviales ....................................................... 111

4.3.2. Sistema fluvial meandroso de baja sinuosidad $\ldots \ldots \ldots \ldots \ldots \ldots \ldots \ldots \ldots \ldots \ldots \ldots$

4.3.3. Sistema fluvial meandroso de alta sinuosidad........................ 118

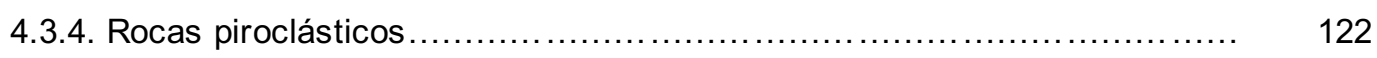

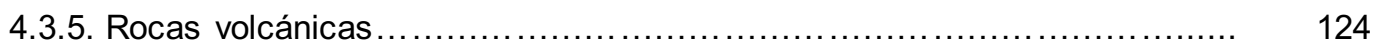

Capítulo s 5. Análisis del relleno del depocentro del Grupo Puesto Viejo......... 129

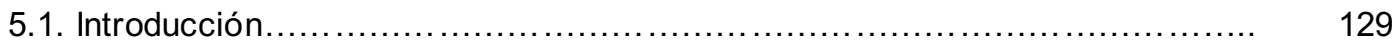

5.2. Relleno de la etapa I: Generación del espacio de acumulación inicial. Niveles basales del Grupo Puesto Viejo (Formación Quebrada de los Fósiles)........ 130

5.2.1. Unidades de acumulación que definen la Etapa I..................... 131

5.3. Relleno de etapa II. Desarrollo de espacios de acumulación internos. Niveles inferiores del Grupo Puesto Viejo (Formación Quebrada de los Fósiles)...... 136

5.3.1. Unidades de acumulación que definen la Etapa II....................... 138

5.4. Relleno de la etapa III. Reactivación y crecimiento de las estructuras internas. Nivel medio del Grupo Puesto Viejo (Fm Río Seco de la Quebrada)........... 148

5.4.1. Unidades de acumulación que definen esta etapa..................... 149

5.5. Relleno de la etapa IV. Generación y colmatación de los espacios de acumulación finales. Nivel superior del Grupo Puesto Viejo (Fm Río Seco de la Quebrada). 
5.5.1. Unidades de acumulación que definen esta etapa.

Capítulo 6. Discusión de los resultados.

6.1. El depocentro del Grupo Puesto viejo en el contexto de la extensión triásica... 164

6.2. Características tecto-sedimentarias del depocentro del Grupo Puesto........... 169

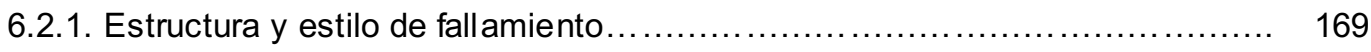

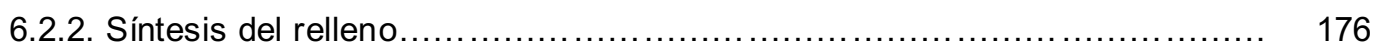

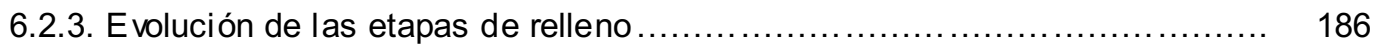

6.3. Evolución tectónica del depocentro que alberga al Grupo Puesto Viejo en el marco de las cuencas triásicas vecinas

6.4. Discusión sobre la edad del Grupo Puesto Viejo y sus connotaciones bioestratigráficas

Capítulo 7. Conclusione s........................................................... 200

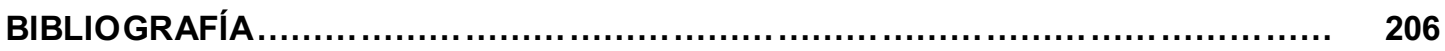

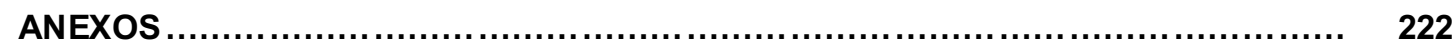




\section{AGRADECIMIENTOS}

Agradezco en primer lugar a mi director, Dr. Juan Rafael Franzese por su confianza, sus enseñanzas, su paciencia, dedicación y por su amistad. A mi segunda directora Dra. Ana María Zavattieri, por su interés y apoyo durante todo el desarrollo de esta tesis doctoral.

Al Dr. Marcelo de la Fuente, Dra. Claudia Marsicano y el Dr. Guillermo Ottone por darme la oportunidad de iniciar esta tesis doctoral mediante el proyecto BID-PICT 2007-00373, en el Museo de Historia Natural de San Rafael, Mendoza.

Imprescindibles quienes me acompañaron y ayudaron en los trabajos de campo Dra. Gisel Peri (UBA), Lic. Eleonora Espin (UNSJ), Lic. Lucas Muñoz (UNSL) y Lic. Nicolás Scivetti (UNLP). También a la Dra. Analia Forasiepi y el Dr. Leandro D'Elia por acompañarme durante las primeras etapas de reconocimiento de la zona estudiada.

A la famila Hernandez y la familia Magioni por su constante predisposición para abrir las tranqueras de sus campos, acompañarnos y darnos refugio en sus puestos.

A todos los becarios con los cuales pude compartir charlas sobre las diferentes temáticas que se abordaron en esta tesis doctoral y sobre muchas cosas más. A los investigadores del Centro de Investigaciones Geológicas que mostraron un gran interés sobre esta temática y brindaron su ayuda. En particular a la Dra. Ana Sato de nuestra casa de estudios y a la Dra. Amancay Martinez de la Universidad Nacional de San Luis.

A los técnicos del Centro de Investigaciones Geológicas por su predisposición, colaboración y amistad.

A mi familia y amigos por acompañarme durante estos cinco años. En especial a mi mamá que dejó todo por cuidar de mi hija y hacer posible que hoy puedan estar leyendo esta tesis doctoral.

A CONICET por darme la oportunidad de terminar esta tesis doctoral.

Al Instituto Argentino de Nivología y Glaciología de Mendoza por apoyarme en cada una de las decisiones que tomé. 
Al Centro de Investigaciones Geológicas de La Plata y todo su personal por incorporarme y brindarme todo para que pueda llevar adelante esta tesis doctoral.

A los jurados de esta tesis doctoral Dra. Silvia Japas, Dr. Luis Spalletti y Dr. Victor Ramos por su dedicación e interés, sus contribuciones y correcciones aportaron claridad y calidad a este manuscrito. 


\section{RESUMEN}

El Grupo Puesto Viejo constituye una unidad continental de edad triásica localizada en el bloque de San Rafael, al oeste de las principales acumulaciones de esa edad del ámbito cuyano.

Su conocimiento está basado en estudios regionales, sedimentológicos y bioestratigráficos. Alberga un importante contenido paleontológico de restos fósiles vertebrados, restos fósiles vegetales, registros palinológicos y de invertebrados, ampliamente estudiados.

En este trabajo se presenta un análisis tectonoestratigráfico del Triásico de San Rafael, integrando información estructural, sedimentológica y geocronológica de modo de brindar un panorama del origen y evolución de la cuenca en la que se depositó. Las tareas fueron llevadas a cabo en un área de estudio limitada dentro de los afloramientos del Grupo Puesto Viejo, en la cual las relaciones entre estructuras y relleno permitieron verificar que integran un único depocentro convenientemente preservado de las inversiones tectónicas andinas.

A través de estudios de campo y gabinete, se pudo constatar que la estructura del depocentro estudiado responde a la geometría de un graben NO-SE, con estructuras internas oblicuas ONO-ESE. Las fallas que bordean el depocentro registraron movimientos de rumbo y normales, mientras que las internas fueron fallas casi puramente normales. Dentro del graben se han preservado otras estructuras internas como zonas de acomodación y pliegues amplios. Algunas de las fallas internas generaron flexuras monoclinales. Las estructuras se observan a la escala de algunos kilómetros y hasta la de pequeñas fallas centimétricas.

La estructura del graben se desarrolló en sucesivas etapas, en las cuales se generaron grábenes y hemigrábenes rellenos por sedimentitas y volcanitas triásicas. En este trabajo se subdividieron cuatro etapas principales de estructuración. En la primera se habría generado el espacio general del graben, con amplio desarrollo areal y escasa subsidencia. En las siguientes etapas, la 
acción de las fallas internas creó espacios estructurales ligados a la subsidencia mecánica, observándose que las mismas secuencias triásicas se encuentran afectadas por fallamiento en las etapas III y IV.

El relleno del depocentro se encontró fuertemente condicionado por la estructura y el magmatismo. A partir del análisis estratigráfico, sedimentológico y geoquímico de las unidades que lo componen se pudieron agrupar asociaciones de facies que derivaron en la definición de unidades de acumulación. Se identificaron cinco unidades de acumulación que se definieron como abanicos aluviales, sistemas fluviales, flujos piroclásticos, efusiones lávicas e intrusivos. La composición magmática es de carácter bimodal, con productos volcánicos andesiitco/basálticos y piroclásticos riolíticos.

Cada una de las etapas estructurales tiene su correlato en una etapa de relleno, cada una de las cuales posee características particulares. La etapa inicial muestra el desarrollo de abanicos aluviales que son cubiertos por flujos piroclásticos. La etapa II está caracterizada por el desarrollo de sistemas fluviales meandrosos de alta sinuosidad y también finaliza con la aparición de mantos de flujos piroclásticos. La etapa III se caracteriza por la presencia de depósitos de sistemas meandrosos de baja sinuosidad y finaliza con episodios volcánicos, tanto efusivos como intrusivos. La etapa $\mathrm{N}$ se caracteriza por la presencia de un sistema de abanicos aluviales que se intercala con flujos piroclásticos.

La geometría del depocentro, tanto como su evolución y la cinemática de las estructuras permiten definir que se trata de una cuenca de carácter extensional, que puede ser caracterizada como un rift oblicuo. La disposición general del depocentro copia la dirección de las estructuras heredadas de la historia orogénica paleozoica del Bloque de San Rafael (orogenia Sanrafaelica) y la disposición de las estructuras internas son compatibles con un régimen de extensión con dirección de máxima elongación ENE-WSW. La cinemática de las estructuras puede ser explicada por una baja a moderada oblicuidad y alta partición de la deformación. Recientes edades radimétricas ( $245 \mathrm{Ma}-\sim 235$ Ma) ubican a los procesos del Grupo Puesto Viejo dentro del marco geocronológico general de la extensión triásica del oeste de la Argentina, cuyas 
etapas de rift evolucionaron durante el Triásico Medio. Estas edades permiten reconocer que no existe continuidad estratigráfica entre los últimos procesos del Pérmico y que puede ser necesaria una revisión bioestratigráfica parcial de la unidad. 


\section{ABSTRACT}

The Puesto Viejo Group constitutes a Triassic continental unit located in the San Rafael Block, to the west of the main Triassic accumulations of the Cuyo area.

The knowledge of the Puesto Viejo Group is based on regional, sedimentological y biostratigraphic studies. This group has a widely studied paleontological contain of vertebrates fossils, plant fossils, pollen records and invertebrates.

In this work, a tectostratigraphic analysis of the Triassic accumulations in San Rafael is presented, integrating structural, sedimentological y geochronological information to give a picture of the origin and evolution of the depositional basin. The tasks were carried out in a study area where structural y filling relationships are conveniently preserved.

Fieldwork y laboratory analysis allowed to conclude that the studied depocenter respond to a NW-SE graben, with WNW-ESE internal oblique structures. The boundary faults register strike-slip y normal movements while the internal system shows almost normal pure movements. Into the graben, there were preserved another internal structures such as accommodation zones and wide folds. Some internal faults generated monoclinal flexures. The structures are observed at scales of a few kilometers to small centimetric faults.

The graben structure was developed in successive stages. In these stages grabens and hemigrabens filled by sedimentites and Triassic volcanics were originated. Four main structural stages were identified. The first stage, with wide areal developement and scarce subsidence, generated the full graben space. In the next stages, the movements of the internal faults created structural depressions where the main infill was deposited.

The depocenter fill was strongly conditionated by faulting and magmatism. The stratigraphic, sedimentological and geochemical analysis allowed to define different facies associations, which led identify several accumulation units. Five 
accumulation units were identified as alluvial fan, fluvial systems, pyroclastic flows, lavic effusives and intrusives. The magmatism has a bimodal signature and is composed by yesitic/basaltic volcanics and rhyolitic pyroclastics.

Each structural stage has a correlated filling stage, each one with particular features. The initial stage shows the development of alluvial fans that are covered by pyroclastic flows. The stage II is characterized by the development of high sinuosity meyering fluvial systems and also ends with the occurrence of pyroclastic flows. The stage III is characterized by the presence of low sinuosity meyering fluvial systems and ends with volcanic episodes, both efussive and intrusive. The stage $\mathrm{N}$ is characterized by the presence of a distal alluvial system that is intercalated with pyroclastic flows.

The depocenter geometry y evolution $y$ the kinematic analysis of the faults allow us to define that it is an extensional basin, which can be characterized as an oblique rift. The general disposition of the depocenter copy the strike of the inherited Paleozoic orogenic history of San Rafael Block (San Rafel Orogeny) and the dispositions of the internal structures are consistent with an ENE-WSW extensional regimen. The kinematics of the structures can be explained by a low to moderated obliquity and a high partitioned deformation. Recent radiometric ages ( $\sim 245 \mathrm{My}-\sim 235 \mathrm{My}$ ) allow us to integrate the Puesto Viejo Group into the general geochronological context of the Triassic extension of westerh Argentina, whith a main rift stage that evolved during the Middle Triassic. These ages led us to recognize that there is not a stratigraphic continuity between the last Permian processes and therefore could be necessary a partial biostratigraphic revision of the Puesto Viejo Group. 


\section{CAPÍTULO 1}

\section{INTRODUCCIÓN Y ANTECEDENTES}




\section{Capítulo 1. Introducción y Antecedentes}

\subsection{Introducción}

El Triásico conforma un Período muy bien registrado en la estratigrafía de Argentina y conocido desde los albores del desarrollo de las geociencias en nuestro país. Numerosos trabajos han documentado su estudio desde distintas disciplinas, tales como la estratigrafía, la geología estructural, la sedimentología y la paleontología (Bonaparte, 1966; González D íaz, 1964, 1967; Artabe, 1985; Kokogián y Mancilla, 1989; Ottone y García 1991; Baez et al., 1993; Ramos, 1993; Spalletti, 1999; Llamb ías et al. 1993; entre otros). El Triásico argentino se depositó mayormente en cuencas extensionales de tipo rift alargadas en sentido NO-SE (Figura 1.1). Su relleno sedimentario estuvo acompañado por un importante magmatismo representado por lavas y rocas piroclásticas de flujo y de caída. El componente volcánico y piroclástico forma parte del Ciclo Magmático Choiyoi, distribuido ampliamente entre el Pérmico y el Triásico en el centro-oeste argentino (Llambías et al., 1993; Kleiman y Japas, 2009). Algunas de estas cuencas extensionales llegaron a tener una larga duración que incluyó casi todo el Triásico (Spalletti, 1999). El régimen tectónico bajo el cual se generaron las cuencas extensionales triásicas ha sido motivo de diversas interpretaciones basadas en general, en consideraciones regionales. La posibilidad de formación de cuencas triásicas por transcurrencia ha sido considerada por Uliana et al. (1989), Rapela et al. (1992) y Tankard et al. (1995). Criado Roqué et al. (1981) proponen un mecanismo de transtensión a escala regional, resultante del cese de la subducción en el margen occidental, y en particular postulan un origen transtensional para la cuenca Cuyana y su prolongación a la cuenca de Alvear por movimientos de transcurrencia y tracción a lo largo de fallas pre-existentes. Señalan, además, que la tectónica de rumbo produjo, durante el Triásico, la rápida subsidencia de depocentros angostos, con geometría de hemigrábenes. En ese sentido trabajos llevados a cabo en el bloque de San Rafael vinculan la apertura de la cuenca que alberga al Grupo Puesto Viejo a un origen transtensional (Spalletti, 1999; Japas, et al., 
2008a; Kleiman y Japas; 2009). En contraposición Moreno Peral y Salvarredi (1984), Uliana y Biddle $(1987,1988)$ y Uliana et al. (1995) entre otros, refieren un origen por colapso extensional del orógeno pérmico. Ramos y Kay (1991) y Ramos (1992) describen el desarrollo de un rifting episutural de retroarco, relacionándolo con un modelo de extensión a lo largo de un despegue basal (modelo de cizalla simple).

El bloque de San Rafael es una unidad morfoestructural pericordillerana, ubicada casi en su totalidad en el departamento de San Rafael, al suroeste de la Cuenca Cuyana, entre las latitudes $34^{\circ}$ y $36^{\circ} \mathrm{S}$ de la provincia de Mendoza, Argentina (Figura 1.1). Está compuesto por metamorfitas asignadas al Precámbrico, una serie sedimentaria de edad ordovícica a carbonífera y extensos afloramientos de secuencias de volcanitas, sedimentitas y cuerpos hipabisales del Pérmico y del Triásico. En el bloque se registra la acción de eventos de deformación del Ciclo Gondwánico (Fase San Rafael y Fase Huárpica; Azcuy y Caminos, 1987) y su conformación actual se debe a la tectónica Andina. El rumbo general de sus estructuras es noroeste, coincidente con una antigua franja de fracturación sobre la sutura de terrenos anexados a la placa sudamericana durante el Paleozoico (Ramos, 1993).

En este trabajo se aborda el análisis tecto-sedimentario del depocentro de San Rafael con la finalidad de discutir las características geológicas y geodinámicas asociadas con la generación y evolución del Grupo Puesto Viejo y la tectónica del bloque de San Rafael, en el contexto geológico en que se desarrollaron las cuencas triásicas del oeste de Argentina. A tal fin, se ha seleccionado un área de trabajo dentro del Grupo Puesto Viejo en la cual, la íntima relación entre las estructuras y el relleno pueden ser convenientemente visualizados. 


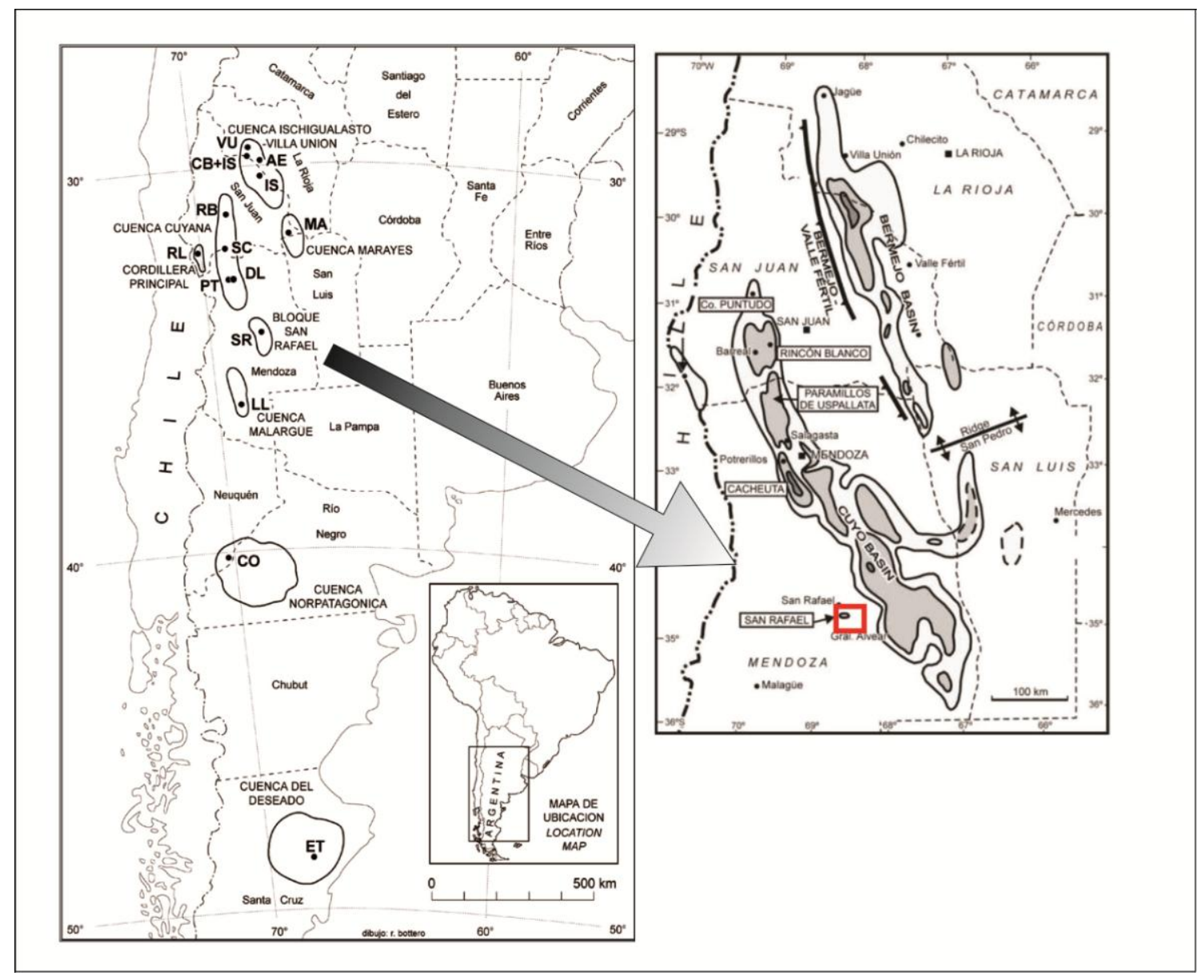

Figura 1.1. Distribución de las cuencas triásicas argentinas. Detalle de la distribución de la cuenca Cuyana y la ubicación del bloque de San Rafael (según Spalletti, 1999).

\subsection{Marco geológico de las acumulaciones triásicas en San Rafael}

En el bloque de San Rafael se registra la acción de varios eventos de deformación. Los movimientos Chánicos producidos por la colisión de un terreno alóctono (Chilenia) contra el margen occidental de Precordillera (margen SO de Gondwana) en el paleozoico inferior marcan el comienzo del ciclo diastrófico gondwánico (Ramos, 1984). Con la subducción oblicua (Azimut $30^{\circ}$ ) de la placa paleo-Pacífico (ca. $280 \mathrm{Ma}$; Kleiman y Japas 2009) a partir de movimientos transpresionales dextrales N-NO se deformaron las cuencas de antepaís carboníferas tanto en el bloque de San Rafael como en Precordillera (Cuenca de Uspallata), que evolucionan a cuencas de retroarco y actualmente 
se encuentran desmembradas por la orogenia Ándica (Ramos, 1993). Durante el Pérmico Temprano, luego del desarrollo de un arco magmático que produjo un importante volcanismo calco-alcalino (Choiyoi Inferior), se registra una rotación del campo de esfuerzos por la progresiva somerización de la placa subducida, con el desarrollo de movimientos transpresionales sinestrales ONO asociados a la migración hacia el este del arco magmático (Kleiman y Japas, 2009). Este evento, atribuido a la Fase Sanrafaélica (ca. $265 \mathrm{Ma}$ ) que tuvo un amplio desarrollo en el bloque de San Rafael, culminó a los $36^{\circ} \mathrm{S}$ como una región de subducción plana con el desarrollo de un evento extensional (Postorógeno San Rafael), el emplazamiento del volcanismo felsítico (Choiyoi Superior) y el desarrollo de cuencas extensionales tipo rift durante el Triásico (Kleiman y Japas 2009). En ese marco se generó la cuenca que alberga al Grupo Puesto Viejo dentro del Bloque San Rafael. Durante su desarrollo fueron eruptadas riolitas y basaltos tipo OIB (Kleiman y Salvarredi, 2001). Los procesos extensionales continuaron hacia el este y hacia el sur, llegando hasta el Jurásico Temprano (Martin et al., 1999; Franzese y Spalletti, 2001; Kleiman y Japas, 2009).

En diversos trabajos de carácter regional se abordó el origen, evolución y relleno de este depocentro (González Díaz, 1964; Valencio, 1975; Spalletti, 1999; Sepúlveda et al., 2007; Kleiman y Japas, 2009; Domeier et al., 2011, entre otros). Otros trabajos de carácter local se han desarrollado en la zona de estudio y alrededores, principalmente con fines estratigráficos, sedimentológicos y paleontológicos, tales como los de Spalletti (1994) y Spalletti et al.,1996), Kusiac (1993), Kleiman y Salvarredi (2001), Stipanicic (2001), Zavattieri (2002), Martinelli et al. (2009), Tassi et al. (2013), Ottone et al. (2014a y b), entre otros. Desde el punto de vista tectónico y paleomagnético, los trabajos realizados en la zona se han abordado desde su evolución paleogeográfica como margen suroeste de Gondwana durante el Paleozoico tardío (Tomezzoli et al., 2005; Kleiman y Japas, 2009). Con el objetivo de conocer la distribución de las mineralizaciones presentes en el bloque de San Rafael, Japas et al. (2008b; 2013) se refirieron al control estructural. La inversión producida por la tectónica Andina durante el Cenozoico en el bloque de San Rafael fue tema de interés para Ramos y Kay (1991). Otros autores que abordaron el tema fueron González Díaz (1964); Bastías et al. (1993); Narciso 
et al. (2001); Costa et al. (2004). De esta revisión se puede concluir que no hay hasta la actualidad trabajos con la finalidad de estudiar las estructuras triásicas que permitan definir la conformación original de la cuenca, así como los procesos de acumulación operantes durante la extensión, constituyendo por ende, uno de los objetivos principales de esta tesis.

El Grupo Puesto Viejo constituye el término final del ciclo de sedimentación y magmatismo del bloque de San Rafael (Criado Roque, 1972). Hasta el momento, el Grupo Puesto Viejo se consideraba como una unidad volcanosedimentaria que se desarrolló en el sur de la provincia de Mendoza durante el Triásico Inferior a Medio (Figura 1.2). Fue reconocida previamente mediante diversas denominaciones y asignada a diferentes edades: Groeber (1952) la denominó como la "Serie Porfírica Supratriásica Choiyoilitense" y Dessanti (1956) la separó en las "Tobas y volcanitas del Triásico" y las "Areniscas y conglomerados del Rincón del Atuel", entre otros. La asignación como Formación Puesto Viejo se debe a los trabajos de González Díaz (1964; 1967; 1972) quien adscribió su edad al Triásico Inferior por los hallazgos de vertebrados y megaflora. Posteriormente, Stipanicic et al. (2007) reasignaron esta unidad como Grupo Puesto Viejo reconociendo dos unidades diferentes en base a datos paleontológicos, sedimentológicos y bioestratigráficos. La unidad inferior, llamada Formación Quebrada de los Fósiles, caracterizada por sedimentos de grano fino, color gris verdoso, intercalados con ignimbritas y basaltos. La unidad superior, denominada Formación Río Seco de la Quebrada, compuesta por depósitos clásticos de grano grueso de color rojo intercalados con coladas basálticas. 


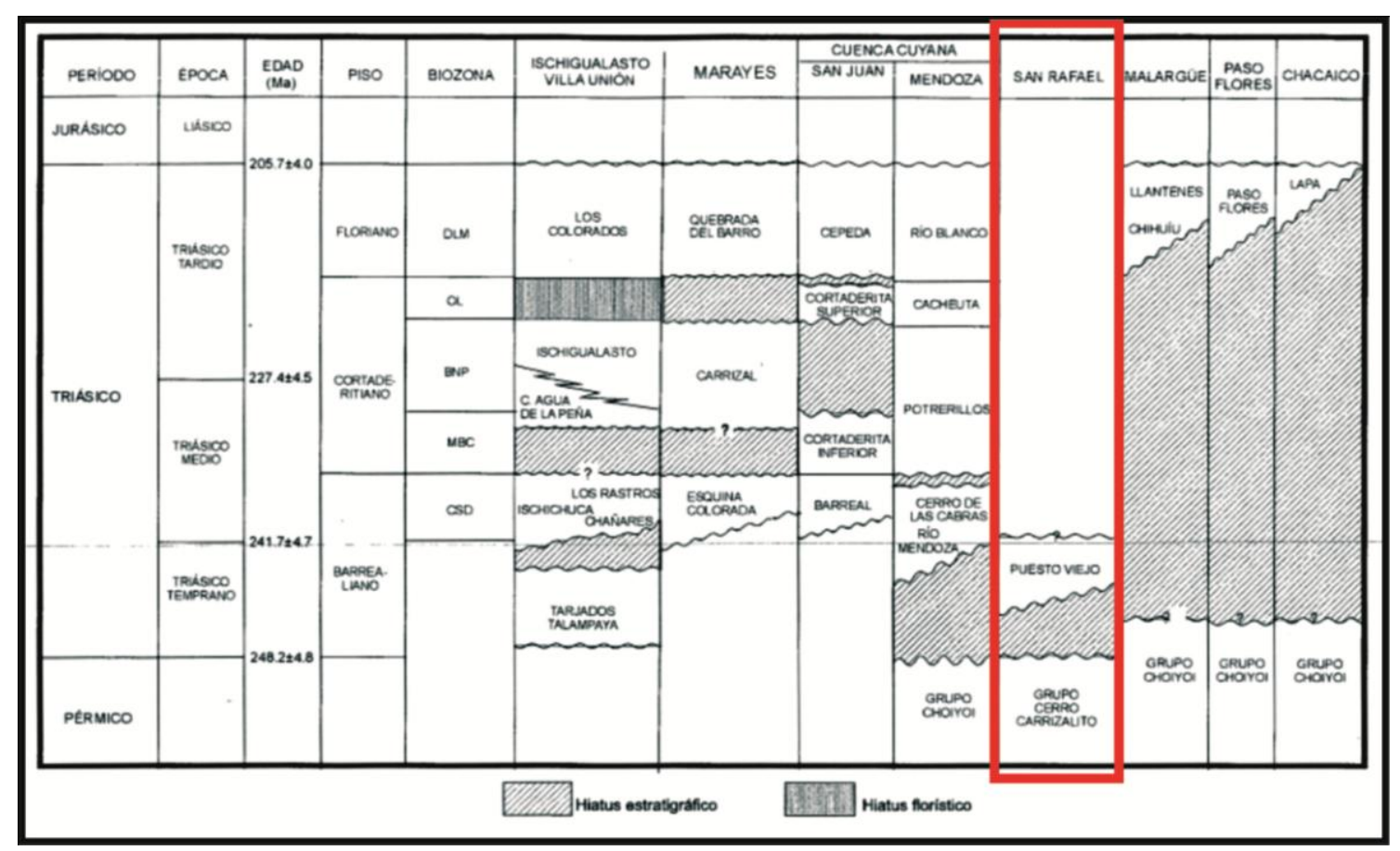

Figura 1.2. Cuencas Triásicas (según Spalletti, 1994).

Los datos radimétricos disponibles $\mathrm{K}$-Ar sobre rocas volcánicas y piroclásticas han proporcionado edades de $230 \pm 10$ a $232 \pm 10$ Ma para la Formación Quebrada de los Fósiles y de $232 \pm 10$ a $236 \pm 10$ Ma para la Formación Río Seco de la Quebrada (Valencio et al., 1975), las que indicarían una edad triásica tardía baja (Carniano) coincidentes con lo determinado por Domeier et al. (2011). Una reciente datación U-Pb SHRIMP en una ignimbrita emplazada entre las formaciones Quebrada de los Fósiles y Río Seco de la Quebrada dio como resultado $235,8 \pm 2,0 \mathrm{Ma}$ (Carniano), otorgyo un nuevo marco depositacional para el Grupo Puesto Viejo (Ottone et al., 2014a y b). Sin embargo, el contenido paleontológico del Grupo Puesto Viejo indicaría una edad más antigua (Triásico Inferior-Medio), por lo cual existe una incertidumbre que debería ser reanalizada. La edad de las unidades que hoy integran el Grupo Puesto Viejo fue dada primeramente por su contenido de tetrápodos (Bonaparte, 1966a, b; 1967; 1969), cuyos hallazgos impulsaron el interés de los paleontólogos por este depocentro, ya que fueron los primeros restos de tetrápodos continentales registrados en el Triásico de América del Sur, permitiendo la correlación bioestratigráfica y paleobiogeográfica a nivel mundial. El conocimiento sobre la diversidad y contenido de restos fósiles se incrementó notablemente en las últimas décadas. La mayoría de los registros 
paleontológicos hallados provienen de la Formación Quebrada de los Fósiles. Existen aún desacuerdos concernientes a la edad de las dos unidades que integran este grupo en base a su contenido paleontológico (Morel et al., 2001). En términos generales, los restos paleontológicos recuperados de la Formación Quebrada de los Fósiles señalan una edad triásica inferior a triásica media temprana para la unidad inferior, mientras que los vertebrados de la Formación Rio Seco de la Quebrada la ubicaron en el Triásico Medio (Anisiano), como se analiza en detalle más abajo (Sección 1.4.3). Las nuevas edades radimétricas plantean un nuevo marco para la sedimentación del Grupo Puesto Viejo y para la edad de sus tetrápodos que, aunque comparten taxones con las faunas de Sudáfrica, se registrarían alrededor de 10 Ma más tarde (Ottone et al., 2014 a y b).

Los afloramientos del Grupo Puesto Viejo se extienden unos $20 \mathrm{~km}$ de largo por $4 \mathrm{~km}$ de ancho, limitados por estructuras NNO-SSE (Figura 1.3). La composición del Grupo Puesto Viejo fue definida como una sucesión volcaniclástica en la que se intercalan mantos de ignimbritas y rocas basálticas (González Díaz, 1964; Spalletti, 1994; Spalletti et al., 1996; Kokogian et al., 1999; 2001). Las sedimentitas fueron depositadas en un ambiente continental, de abanicos aluviales en condiciones áridas (Kusiak, 1993), con al menos una estación húmeda a subhúmeda (González Díaz, 1972) en cuyas condiciones se desarrollaron sistemas fluviales meyriformes de alta y baja sinuosidad, con desarrollo de planicies de inundación (Spalletti, 1994; Spalletti et al., 1996). Hacia el tope de la secuencia se asocian a depósitos piroclásticos (Kokogian et al., 2001; Spalletti, 1994).

Las estructuras asociadas a la generación de la cuenca triásica del Grupo Puesto Viejo se encuentran parcialmente invertidas (González Díaz, 1972; Sepúlveda et al., 2002) a través de fallas de entre $5 \mathrm{~km}$ y $30 \mathrm{~km}$ de longitud, con orientación preferencial NNO-SSE. Los estudios previos indican que esas fallas habrían sido, originalmente, la respuesta a procesos extensionales o transtensionales (Spalletti, 1994; 1999) acaecidos en la base del Triásico (discordancia Huárpica). Estudios realizados sobre las rocas volcánicas (basaltos e ignimbritas) son indicativos de secuencias bimodales compatibles con un marco tectónico de rift continental (Kleiman y Salvarredi, 2001). Afloramientos menores del Triásico se pueden observar en el sector norte de la 
región (en la Cuesta de los Terneros y al norte del Rincón del Atuel; González Díaz, 1964; Spalletti, 1994) y en el sector suroccidental de la región, en las inmediaciones del Cañón del Atuel (Kusiac, 1993). Depósitos cenozoicos cubren indistintamente toda el área con una inclinación predominante hacia el este.

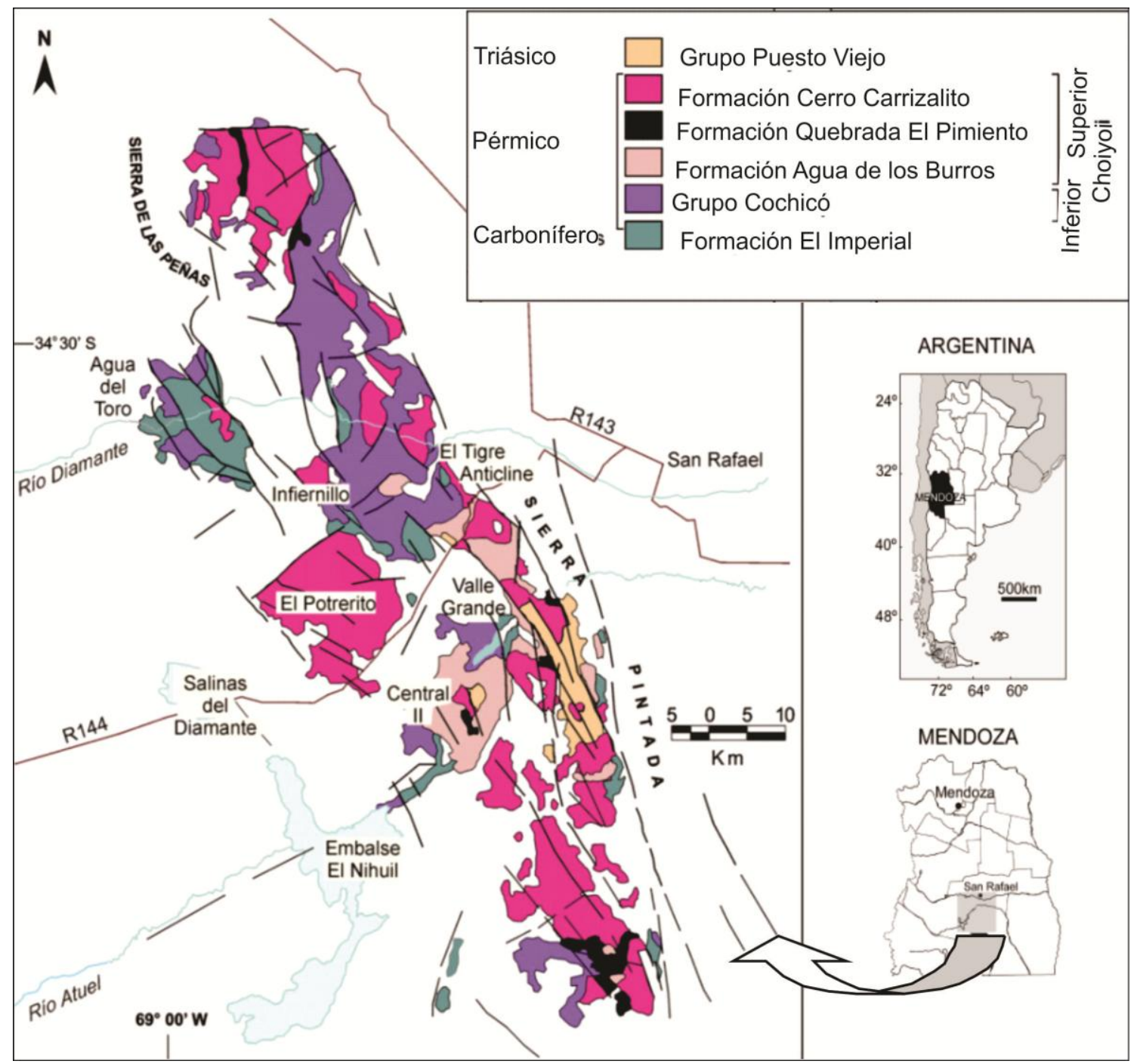

Figura 1.3. Mapa del Bloque de San Rafael donde se indica la distribución del Grupo Puesto Viejo (según Kleiman y Japas, 2009).

El Grupo Puesto Viejo constituye una unidad muy acotada en el tiempo y en el espacio, que registra el final de una historia tectónica particular dentro del Bloque San Rafael. Si bien sus características composicionales están definidas de manera general, muchos aspectos quedan planteados como interrogantes que merecen ser considerados. El relleno sedimentario ha sido vinculado con el 
desarrollo de sistemas fluviales cambiantes en el tiempo. Esta caracterización ha sido realizada en forma amplia y poco se conoce sobre las posibles variaciones laterales de esos ambientes, la existencia de polaridades y cambios de espesor y la relación de esas variaciones respecto de sus límites depositacionales o del área depocentral. Aunque se ha distinguido internamente la intercalación de unidades lávicas y piroclásticas, no hay un conocimiento acabado de su distribución areal, ni de su interrelación con los procesos sedimentarios. Estos aspectos se abordan en esta tesis.

La caracterización del área depositacional como parte del relleno de sin-rift de una cuenca extensional se ha realizado sobre la base de escasa información estructural (fallas invertidas no estudiadas en detalle), de las características generales del relleno o de la composición de su magmatismo. Todas esas características por sí solas no alcanzan para una definición tectonoestratigráfica precisa. Particularmente, los aparentemente reducidos espesores del Grupo Puesto Viejo (no más de $450 \mathrm{~m}$ ) comparados con los gryes espesores registrados en las cuencas triásicas vecinas (por ejemplo, más de 2000 m en la Cuenca Cuyana), su abrupta y temprana finalización y la falta de registro de cambios súbitos de espesor asociados a las fallas que limitan los afloramientos, son rasgos que merecen ser explicados en el contexto regional.

\subsection{Objetivos}

\section{Objetivos generales}

El plan de trabajo presentado para el desarrollo de esta tesis tiene como objetivo principal estudiar y actualizar el conocimiento de las secuencias sedimentarias y volcánicas triásicas del Grupo Puesto Viejo (Stipanicic et al., 2007 ) en el Bloque San Rafael, ubicado al sur de la provincia de Mendoza (Fig. 1.3) y definir su contexto tectonoestratigráfico y la geodinámica evolutiva. En su desarrollo se previó realizar estudios estratigráficos de detalle, mapeo, confección de secciones estructurales y estratigráficas, análisis sedimentológicos y petrográficos y estudios de la composición y distribución de las rocas volcánicas y piroclásticas con el fin de ampliar y rediscutir la 
asignación cronoestratigráfica de las unidades que integran el Grupo y el contexto paleoambiental de esta unidad.

Objetivos específicos

- Definir una estratigrafía interna de la cuenca que permita analizar la interrelación entre las unidades sedimentarias y volcánicas así como sus variaciones de espesor.

- Determinar los ambientes sedimentarios y de sus variaciones espaciales y temporales asociadas a sus límites y al área depocentral.

- Referenciar los nuevos hallazgos de restos fósiles, así como también los niveles fosilíferos ya conocidos para la unidad, rediscutiendo el esquema bioestratigráfico.

- Analizar la composición de las unidades volcánicas y piroclásticas.

- Revisar las principales estructuras asociadas con la generación de la cuenca y con su inversión.

- Evaluar los controles geológicos sobre el relleno, en especial de la interacción de los procesos magmáticos y tectónicos que influyeron en la composición y distribución del relleno de la cuenca.

- Generación de un modelo de evolución geológica de la cuenca desde su inicio hasta su inversión.

- Revisión del significado tectónico de la cuenca en el marco de la historia tectosedimentaria del Pérmico - Triásico y su comparación con otras cuencas triásicas argentinas. Análisis y discusión de los mecanismos generadores de cuencas durante esa etapa. 


\subsection{Estratigrafía del Bloque de San Rafael}

\subsubsection{Estratigrafía pre-triásica}

El basamento del Bloque de San Rafael aflora principalmente en la parte occidental. Se trata de filitas, esquistos y metacuarcitas en facies de esquistos verdes, denominados como Formación La Horqueta, del Ordovícico-Silúrico (González Díaz, 1972). Estas metamorfitas responden a un plegamiento apretado de escasa longitud de onda, ca. Az. 080'. En el valle del Río Atuel aflora una franja de la Formación Río Seco de Los Castaños (Devónico) con rumbo aproximado NO. Consiste de sedimentitas depositadas en un ambiente marino (Sepúlveda, 1999). En forma aislada aflora la Formación El Imperial de edad carbonífera superior - pérmica inferior, a lo largo del frente orogénico del bloque. Sus depósitos tienen orígenes diversos, desde glacimarinos hasta fluviodeltaico y marino somero para terminar en un ambiente fluvial. La estructuración de estas rocas está caracterizada por pliegues de amplio rango y rumbo norte aproximadamente, fallados y erosionados (Núñez, 1976; Llamb ías et al., 1993).

El magmatismo pérmico-triásico manifiesto en la comarca es representado por una asociación volcano-plutónica de rocas efusivas e hipabisales que se apoyan en discordancia angular sobre las unidades pre-pérmicas. Los movimientos de la fase diastrófica Sanrafaélica originaron una estructuración en bloques. En el Pérmico Inferior se formaron dos cubetas con orientación meridiana, separadas por un umbral, denominadas cuenca oriental y cuenca occidental. En ellas se depositó la secuencia volcano-hipabisal de composición dacítica y yesítica correspondiente a la Formación Cerro de las Yeguas y el Grupo Cochicó, con características relacionadas a un margen continental activo (ambiente de arco volcánico). Durante el Pérmico Inferior alto y Triásico Inferior ocurre un nuevo proceso efusivo-intrusivo en un ambiente de transición que va del régimen compresional previo hacia otro distensivo cortical post orogénico (Kleiman y Salvarredi, 1989). Este nuevo evento está representado por los grupos Choiyoi s.s. y El Portillo. El Grupo Choiyoi tiene amplia difusión en el Bloque San Rafael. Se conforma por una sección inferior dacítico-yesítica 
representada por la Formación Agua de los Burros, una sección superior de composición predominantemente basáltica intrusiva correspondiente a la Formación Quebrada del Pimiento y otra riolítica constituyendo a la Formación Choique Mahuida. Rocha-Campos et al. (2010) dataron rocas de esta formación por U-Pb SHRIMP obteniendo edades de 251,9 \pm 2,7/6,6 Ma, cercanas al límite Lopingiano/Triásico. Esta sección superior, según Salvarredi (1996) representa un volcanismo de tendencia bimodal. El Grupo El Portillo corresponde a un conjunto intrusivo hipabisal a plutónico, de naturaleza silícea distribuido ampliamente en la región.

\subsubsection{Estratigrafía triásica}

El Grupo Puesto Viejo (Stipanicic et al., 2007) se encuentra representado en la región por una secuencia sedimentaria continental (Figura 1.4) con interdigitaciones de basaltos olivínicos levemente alcalinos, yesitas e ignimbritas riolíticas (Kleiman y Salvarredi, 2001). El grupo se asienta sobre una asociación volcanogénica constituida por tobas, lapillitas soldadas y brechas piroclásticas pumíceas de composición riolítica pertenecientes a los estadíos finales del ciclo magmático Choiyoi. El magmatismo Gondwánico en el Bloque de San Rafael está representado por dicho ciclo, de edad permotriásica, que puede dividirse en una sección inferior, vinculada a un régimen de subducción y una sección superior transicional entre un ambiente de arco y uno de intraplaca (Kleiman 1993, 1999). La discordancia basal del Grupo Puesto Viejo se observa cuyo las sedimentitas triásicas adoptan una relación de traslape u onlap sobre un paleorelieve elaborado en las volcanitas y piroclastitas ácidas pérmicas (Spalletti, 1994). La discontinuidad entre estos dos grupos se debe la fase diastrófica Huárpica.

La cuenca donde se depositó el Grupo Puesto Viejo está limitada por fracturas

de orientación NO (Spalletti, 1994). El fallamiento pre-terciario que afecta a estas rocas es directo y constituye bloques inclinados de orientación NO y E-O, con rechazos que alcanzan los $1000 \mathrm{~m}$ en algunas localidades (Kleiman y Salvarredi, 1989; Kleiman y Salvarredi, 2001). Ramos y Kay (1991) y Ramos (1993) proponen un origen extensional primario para las cuencas triásicas. Por 
otra parte, Criado Roque et al. (1981) y Spalletti (1994) coincidieron en opinar que la apertura del depocentro tuvo relación con fenómenos de transcurrencia, en especial a lo largo de las megafracturas de Valle Fertil- Desaguadero y Atuel.

Spalletti (1994) propone una depositación general para el grupo dominada por sistemas fluviales, con sistemas de transporte y depositación mixtos, siendo característica la coexistencia de abundante carga de lecho, suspensiva y de lavado circundado por un relieve volcánico con actividad explosiva ácida, en un clima de carácter húmedo a subhúmedo con una progresiva aridización. La sedimentación estaría controlada por factores externos o alocíclicos.

Originalmente, González Díaz $(1964 ; 1967 ; 1974)$ sugirió que la sección basal de la sucesión triásica (Formación Quebrada de los Fósiles) se compone de material clástico de la Formación Agua de los Burros (Pérmico), mientras que las rocas fuentes para la sección superior (Formación Río Seco de la Quebrada) eran en su mayoría, las riolitas de la Formación Cerro Carrizalito (Pérmico). Jenchen y Rosenfeld (2002) también sugirieron una doble procedencia para los sedimentos del Puesto Viejo, con una parte superior enriquecida en componentes riolíticos debido a la ocurrencia de una ignimbrita en la parte superior de la Formación Agua de los Burros. 


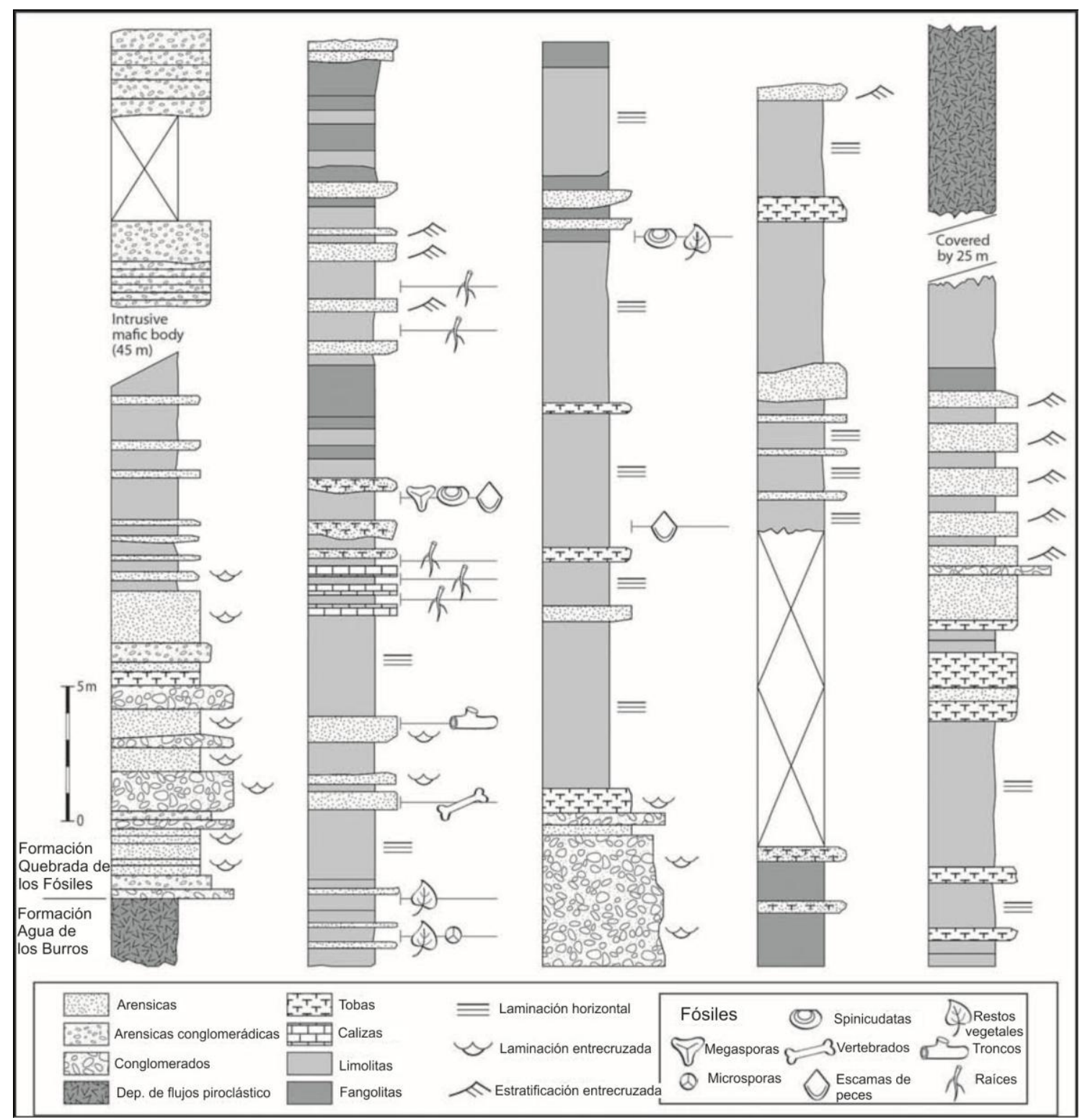

Figura 1.4. Perfil estratigráfico del Grupo Puesto Viejo (Formación Quebrada de los Fósiles). Según Tassi et al., (2013); modificado de Spalletti, (1994).

Stipanicic et al. (2007) sugirieron que el límite entre las Formaciones Quebrada de los Fósiles y Río Seco de la Quebrada fue discordante, lo que sugiere la presencia de un hiato temporal entre las dos unidades, tema que es analizado $\mathrm{y}$ rediscutido en la presente tesis doctoral.

\subsubsection{Contenido paleontológico triásico}

El contenido paleontológico perteneciente a este grupo ha sido motivo de controversia para paleontólogos de vertebrados, paleobotánicos y palinólogos. 
Dos asociaciones faunísticas se describieron para ambas unidades del Grupo (Stipanicic et al., 2002). De la Formación Quebrada de los Fósiles provienen escasos restos de terápsidos dicinodontes (Rechinisaurus sp. y dicinodonte indet.) y un arcosauriforme basal (probable proterosuquio) indet. (Bonaparte, 2002). Esta asociación fue tradicionalmente conocida como "Fauna Local de Agua de Los Burros" (Bonaparte, 1981, 1982; Domnanovich y Marsicano, 2009; Ezcurra et al., 2010) correlacionándola con la Zona Asociación de Lystrosaurus (AZ) de Sudáfrica. Esta fauna local fue referida al Triásico Temprano o cercana al límite Pérmo-Triásico (Bonaparte, 1981; 2000; Báez et al., 1993; Abdala et al., 2009; Martinelli, 2010). De la unidad superior, Formación Río Seco de La Quebrada, se conocen los dicinodontes kannemeyéridos, Kannemeyeria argentinensis y Vinceria sp. y los cinodontes Pascualgnathus polanskii, Cynognathus crateronotus y Diademodon tetragonus (Bonaparte, 1966a, b, 1969; Abdala, 1996; Martinelli y De la Fuente, 2008; Abdala et al., 2008; Martinelli et al., 2009). Esta asociación faunística se la denominó "Fauna Local Puesto Viejo" y se la correlacionó a la Zona de Cynognathus (AZ) de Sudáfrica (Bonaparte, 1982), la que fue asignada alternativamente al Olenekiano (Bonaparte, 1982; Lucas, 1998) o al Anisiano (Bonaparte 1966c, 1967). Recientemente fue correlacionada con las subzonas B (Anisiano Temprano) y C (Anisiano Tardío) de dicha bio-Zona africana, basada exclusivamente en su contenido de cinodontes (Abdala et al., 2008; Martinelli et al., 2009, Martinelli, 2010). Abdala et al. (2008) analizaron y correlacionaron cinco asociaciones faunísticas para el Triásico de Sudamérica (3 en Argentina y 2 o posiblemente 3 para Brasil) asignyo a la fauna de la unidad superior del Grupo Puesto Viejo al Anisiano o probablemente Anisiano Tardío por la presencia de cinodontes traversodóntidos (Figura 1.5). Asimismo, analizaron la posible equiparación y contemporaneidad de la Fauna Local de Puesto Viejo con la fauna de la Formación Cerro de Las Cabras de la localidad de Potrerillos, Cuenca Cuyana (= Fauna Local Río Mendoza) (Bonaparte 1982; 2000; 2002; Zavattieri y Arcucci, 2007) por la presencia en ambas unidades de cinodontes traversodóntidos. En base al análisis de las últimas dataciones radimétricas realizadas de las unidades del Grupo Uspallata (Ávila et al., 2006; Spalletti et al., 2008; Abdala et al., 2008) concluyen que ambas asociaciones 
de tetrápodos comparten elementos en común y las refieren al Anisiano (sensu Gradstein y Ogg, 2004).

\begin{tabular}{|c|c|c|c|c|c|}
\hline \multirow{2}{*}{228} & & $\begin{array}{c}\text { SAN } \\
\text { RAFAEL }\end{array}$ & CUYO & ISCHIGUALASTO & PARANA \\
\hline & Carnian & & & Ischigualasto & Hyperod. AZ \\
\hline 237. & Ladinian & & & $\begin{array}{l}\text { Los Rastros } \\
\text { Chañares }\end{array}$ & $\begin{array}{l}\text { Santa Cruz } \\
\text { Dinodon. AZ }\end{array}$ \\
\hline & Anisian & $\begin{array}{c}\text { Puesto } \\
\text { Viejo }\end{array}$ & $\begin{array}{l}\text { Cerro de } \\
\text { las Cabras }\end{array}$ & & ?Mariante \\
\hline 249.7 & Olenekian & & & & \\
\hline
\end{tabular}

Figura 1.5. Edad y correlación de la Fauna Local Puesto Viejo (= Asociación de tetrápodos de la Formación Río Seco de la Quebrada) con la Fauna de Cerro de Las Cabras (= Fauna Local Río Mendoza) en base a las edades de la escala geológica de tiempo de Gradstein y Ogg (2004). Según Abdala et al., 2008).

Los primeros restos fósiles vegetales del Grupo Puesto Viejo fueron mencionados por Trumpy (1940) y posteriormente, González Díaz (1964; 1967) reubicó los niveles con plantas fósiles en la unidad inferior del grupo. En distintos niveles de la Formación Quebrada de Los Fósiles se describieron restos de megaflora correspondientes a la "Flora de Pleuromeia" (Stipanicic, 1969; Morel y Artabe, 1993; 1994), género que aparece a partir del Triásico Temprano, aunque es común en el Triásico Medio y alcanza el Triásico Tardío (Retallack, 1977). La asociación de Pleuromeiales fue referida a la Biozona CSD (parte inferior) del Piso Barreliano, definido por Spalletti et al. (1999) y asignado al intervalo temporal Eotriásico-Mesotriásico Temprano (Zamuner et al., 2001; Morel et al., 2003). Recientemente, Coturel et al. (2012) hallaron nuevos niveles con restos de floras fósiles en la localidad tipo de la Formación Quebrada de Los Fósiles con impresiones-compresiones de tallos decorticados 
y micrófilos asignables a la Familia Pleuromeiaceae (Lycophyta), fragmentos de tallos de equisetales (Sphenophyta) y dos estróbilos incompletos de afinidad incierta, además de megasporas silicificadas de licópsidas (Arce y Lutz, 2010), troncos de posibles coníferas y semillas de clasificación indeterminada (Gallego et al., 2009). La presencia de licófitas y esfenófitas es común en los depósitos del Triásico Inferior, mundialmente reconocido por la pobreza de las asociaciones y la predominancia de pteridofitas, en contraposición a la dominancia de pteridospermas en los ecosistemas del Pérmico y del Triásico Medio a Tardío. Consecuentemente, los registros paleobotánicos hallados exclusivamente en la unidad inferior, indicarían para esta unidad portadora un rango de edad comprendido entre el Triásico Temprano y el Triásico Medio.

En relación a los estudios microflorísticos, los primeros registros palinológicos los realizaron Ottone y García (1991) quienes asignaron una palinoflora poco diversificada al Eotriásico, por presentar elementos comparables con el Eotrías (Zona de Protohaploxypinus samoilovichii) y del Eo a Mesotríasico Medio e incluso Superior (Zona de Triplexysporites playfordii) de Australia. Zavattieri y Batten (1996) rectificaron las citas de las palinozonas australianas mencionadas originalmente y las refirieron exclusivamente al Triásico Inferior. Zavattieri et al. (2003) analizaron asociaciones palinológicas de las localidades Quebrada de Los Fósiles y del Río Seco de la Quebrada encontryo formas típicas del Pérmico gondwánico, junto a elementos comunes en el Triásico Medio y Superior de Argentina, concluyendo que la base del Grupo Puesto Viejo, podría haber comenzado a depositarse en el límite Pérmico-Triásico. Estas mostrarían diferencias composicionales con asociaciones tanto meso y neotriásicas como aquellas meso y neopérmicas de la Argentina (Zavattieri et al., 2003; Sepúlveda et al., 2007; Stipanicic et al., 2007). Recientemente, Vázquez (2012) estudió una asociación microflorística poco diversificada de los afloramientos de esta unidad en el Rio Seco de la Quebrada, concluyendo que contiene elementos similares a los presentes en asociaciones del Lopingiano y Triásico Temprano de Australia y asignó dicha palinoflora al intervalo temporal Induano-Olenekiano por la alta abundancia de esporas que tienen similitudes con las asociaciones del Triásico Temprano de Australia (Zona de Protohaploxypinus samoilovichii). Por el momento, los datos 
palinológicos de la unidad inferior del Grupo indican una edad triásica temprana.

Los primeros registros de invertebrados de la Cuenca San Rafael proceden también de la Formación Quebrada de los Fósiles y consisten de valvas de conchóstracos y ostrácodos y escamas de peces indeterminados (Gallego et al., 2009). Tassi et al. (2013) describieron una nueva especie de spinicaudatos (Crustacea, Diplostraca), Cornia martinsnetoi. Este género tiene amplia distribución en secuencias del Paleozoico superior y Triásico Inferior de Gondwana. Del análisis bioestratigráfico, los autores sugieren una edad triásica temprana (Induano-Olenekiano) y constituyen la especie de spinicuadados más antigua registrada en el Triásico de Sudamérica.

\section{5. Área de Estudio}

La zona de estudio forma parte de los afloramientos sudorientales del área de distribución del Grupo Puesto Viejo. Esta área se encuentra en el departamento de San Rafael, sur de la provincia de Mendoza, en la Sierra Pintada (Figura 1.6). El área se ubica entre los $34^{\circ} 45^{\prime}$ y los $34^{\circ} \mathrm{S}$ y los $68^{\circ}$ y $68^{\circ} 30^{\prime} \mathrm{W}$.

El área de estudio se seleccionó debido a que presenta la estratigrafía completa del Grupo Puesto Viejo y conserva el marco estructural que permite correlacionar los eventos tectónicos, magmáticos y sedimentarios. Además, incluye buena parte de los niveles fosilíferos clásicos. Esta área será utilizada como un caso de estudio de un depocentro tipo del Grupo Puesto Viejo. 


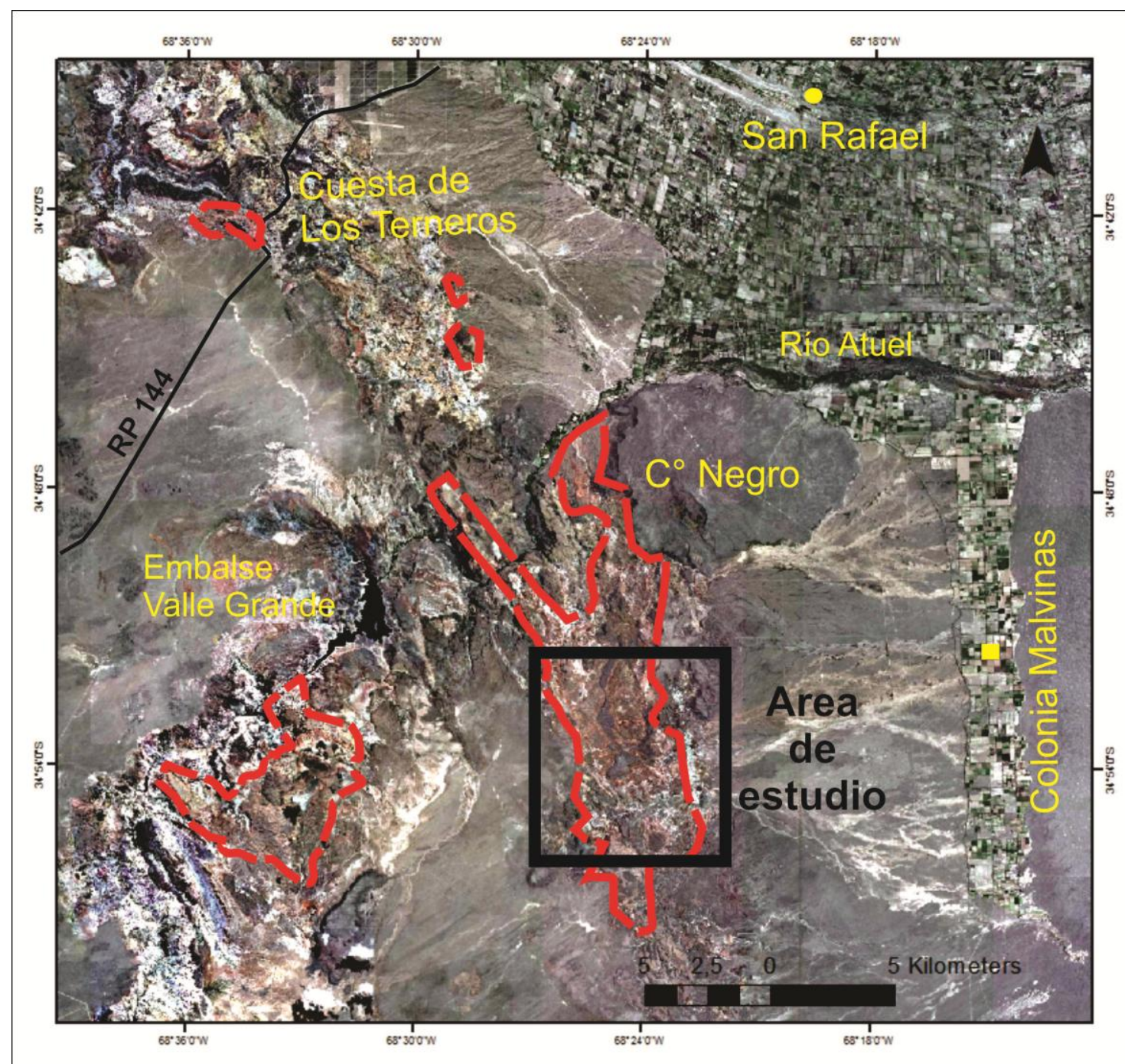

Figura 1. 6. Mapa de la distribución de afloramientos del Grupo Puesto Viejo (lineas punteas rojas). En recuadro negro se delimita el área de estudio. 
CAPÍTULO 2

METODOLOGÍA 


\section{Capítulo 2. Metodología}

A lo largo del desarrollo de esta tesis doctoral los trabajos de campo y de gabinete se llevaron a cabo de manera alternante en función de los avances y los objetivos alcanzados. A continuación se describen las metodologías y los materiales utilizados para la elaboración del presente trabajo:

\subsection{Trabajos de campo}

Los trabajos de campo consistieron en: mapeo estructural y geológico de detalle, levantamiento de perfiles sedimentológicos y estratigráficos y muestreo con fines bioestratigráficos, geoquímicos, petrográficos y geocronológicos. Las estructuras fueron medidas con brújula tipo Brunton y cinta en estaciones determinadas durante el mismo trabajo de campo.

\subsubsection{Mapeo geológico}

Para las tareas de mapeo se utilizaron imágenes satelitales Lysat TM尺 e imágenes Google Earth de alta resolución (obtenidas bajo licencia del Centro de Investigaciones Geológicas de Google Earth Pro) como base para el mapeo en el campo impresas en papel fotográfico a escalas 1:50.000 y 1:25.000. Se utilizó además, GPS con barómetro para obtener datos de localización precisa en las tres dimensiones del espacio. El mapeo en el campo se hizo sobre papel de acetato y la información fue ingresada luego en un sistema de información geográfica (GIS) donde se incluyeron datos de composición litológica, tipos de contactos, rumbo e inclinación de las capas, posición y rumbo e inclinación de las estructuras deformacionales y sedimentológicas. 


\subsubsection{Perfiles litológicos y estratigráficos}

Con el fin de caracterizar las sucesiones que componen a las secuencias depositacionales, se relevaron perfiles de detalle a escala 1:100. Estos incluyen tanto a rocas clásticas como lávicas a fin de poseer el mismo grado de detalle de los distintos procesos que ocurren en uno y otro tipo litológico. Se utilizó para esto cinta métrica y báculo de Jacob. La elección de los sitios elegidos para levantar los perfiles se hizo en base a la mejor calidad de exposición posible, cercanía a estructuras deformacionales, cambios faciales y composicionales. Se tuvo principal interés en identificar las variaciones litofaciales vinculadas a las estructuras, por ello se levantaron perfiles sedimentológicos adyacentes a los planos de falla y alejados de ellos para una misma unidad. En algunas localidades, donde se registró una intensa interrelación entre estructura y sedimentación se procedió de forma diferente: se realizaron 7 paneles con un promedio de 2 perfiles sedimentológicos de detalle por panel (Capitulo 5). En los casos que no fue posible realizar sedimentología de detalle por la calidad de los afloramientos o por su inaccesibilidad se procedió a la medición de espesores y una caracterización estratigráfica. Con el objetivo de sistematizar lo más posible la toma de datos, se utilizó un mismo modelo de libreta de campo para levantar los perfiles litológicos.

\subsubsection{Relevamiento de datos estructurales}

Se tomaron mediciones sistemáticas de rumbo e inclinación de todas las estructuras deformacionales a fin de poder obtener una base de datos lo más completa posible. Se midieron planos de fallas, estrías de falla, raques, rechazos, flancos y ejes de pliegues. Se empleó brújula geológica de tipo Brunton $®$ para medir rumbo e inclinación. Se utilizó también cinta métrica para los casos en que los rechazos de las fallas no superaban la decena de metros. El análisis de los datos recogidos se elaboró fundamentalmente mediante los programas (Open Stero) Stereonet $\AA$ y Stereowin $®$. Con ellos se confeccionaron diagramas de rosas y estereográficas de diagramas pi y beta 
para estimar relaciones entre las distintas estructuras extensionales y compararlas entre sí en las diversas localidades.

\subsubsection{Recolección de muestras}

Se seleccionaron niveles de los cuales se recolectaron muestras representativas de rocas para realizar posteriormente análisis petrográfico, geoquímico, bioestratigráfico, con el propósito de conocer sus características texturales y mineralógicas a microescala.

Las muestras recolectadas para obtener un control bioestratigráfico fueron preparadas y estudiadas por los paleontólogos del Museo de Historia Natural de San Rafael y de la Universidad de Buenos Aires responsables del Proyecto PICT 07-373 ANPCyT "Las faunas de tetrápodos continentales en el intervalo Pérmico-Triásico de la Cuenca de San Rafael, provincia de Mendoza". En el marco de dicho proyecto se realizaron dataciones radimétricas de los sectores inferiores y superiores de la Formación Puesto Viejo para aceptar o rechazar la cronología relativa de estas unidades realizadas en base a correlaciones biostratigraficas entre las faunas locales de tetrápodos del Grupo Puesto Viejo con las biozonas de la Cuenca del Karoo, datos que podrán ser utilizados en este trabajo.

\subsection{Trabajos de gabinete}

Para el desarrollo este trabajo se realizó, en una primera instancia, la recopilación, lectura y análisis bibliográfico y cartográfico de la información disponible (topografía digital, satelital, fotografías aéreas, etc.).

Las tareas de gabinete consistieron en la preparación de mapas temáticos, perfiles y bloques diagrama sedimentológicos y estratigráficos, desarrollo de paneles de correlación y distinción de facies con sus respectivos ambientes. Se prepararon muestras para su análisis geoquímico y petrográfico. Se trabajó con programas sencillos de análisis y otros específicos (2DMOVE). 


\subsubsection{Análisis de facies, asociaciones de facies y ambientes}

Esta fase se caracterizó por la interpretación de las facies volcánicas, piroclásticas y sedimentarias que constituyen el relleno del Grupo Puesto Viejo. De manera jerárquica fueron determinadas unidades elementales (facies). Posteriormente, en función de asociaciones de facies y las confecciones de paneles de correlación se determinaron unidades de acumulación para el relleno.

\subsubsection{Análisis petrográfico y geoquímico}

Para los análisis petrográficos se realizaron cortes delgados y las muestras fueron analizadas mediante el empleo de microscopios petrográficos del Laboratorio del Centro de Investigaciones Geológicas (CIG, La Plata). Para estudios geoquímicos se analizaron diez muestras de origen volcánico, para lo cual se trituraron mediante un molino de myíbulas del CIG las que fueron enviadas al Laboratorio Actlabs $\AA$ en Canadá para determinar valores de elementos mayoritarios, minoritarios y trazas por análisis de FUS-ICP e ICPMS (Fusion Inductively Coupled Plasma y Fusion Inductively Coupled Plasma Mass Spectrometry).

\subsubsection{Confección de secciones geológicas}

La elección de los sitios donde realizar las diversas secciones geológicas fue hecha sobre la base de la información adquirida en el campo a partir de las sucesivas campañas realizadas.

Se eligieron localidades donde se pudiera estimar el efecto de las estructuras extensionales y la actividad volcánica sobre el desarrollo del relle no de los depocentros. Para su elaboración se valió además de los medios empleados para el mapeo y levantamiento de los perfiles, datos sobre la topografía del lugar (modelos de elevación digital de terreno - DEMs). 


\section{CAPÍTULO 3}

\section{ESTRUCTURAS TRIÁSICAS}




\section{Capítulo 3. Estructuras triásicas}

\subsection{Introducción}

En este Capítulo, se analizarán los aspectos estructurales que dieron lugar a la generación y evolución del depocentro en el cual se depositó el Grupo Puesto Viejo en el área de estudio. Tal como se planteó en el Capítulo 1.2, las principales estructuras de la región se desarrollaron en diferentes etapas durante el Paleozoico, Mesozoico y Cenozoico. En esta sección se analizarán las estructuras generadas en el Triásico, discriminándolas de aquellas que pudieron haber sido herencia de la tectónica paleozoica y teniendo en cuenta que muchas de ellas fueron reactivadas o invertidas en fases posteriores, tal como se señaló en el Capítulo 1.2 .

Las principales estructuras reconocidas fueron fallas de diversa magnitud y morfología y, en menor proporción, pliegues o flexuras. La Figura 3.1 muestra un mapa del área de trabajo en el que se han volcado las estructuras mayores reconocidas. El mapa muestra que la distribución de la estratigrafía tiene un control estructural regional, ya que se aprecia el predominio de las rocas del basamento hacia el norte-noroeste de la región, mientras que en los sectores central y sur presentan menor desarrollo, limityo la distribución geográfica de los afloramientos triásicos con orientación NO-SE. Los mayores espesores del Grupo Puesto Viejo se observan hacia el borde oriental, donde se preservan las secciones estratigráficas más completas (450 metros). Los menores espesores se registran en el borde occidental (160 metros).

A los fines de obtener un panorama de las estructuras que generaron y condicionaron las acumulaciones triásicas, el estudio de la geometría y cinemática de las fallas triásicas se ha realizado donde los efectos de la inversión post-triásica son menores. Las observaciones de campo representadas en el mapa permiten reconocer diferentes jerarquías del fallamiento. En los contactos de los depósitos triásicos con el basamento, las estructuras de fallamiento muestran una importante magnitud y continuidad, lo que las caracteriza como fallas principales. En el área dominada por los 
afloramientos del Grupo Puesto Viejo, fallas de menor longitud pueden ser visualizadas como fallas internas, subordinadas a los límites impuestos por las fallas que circunscriben la estratigrafía triásica. Otras estructuras observadas en afloramiento no se muestran en este mapa por razones de escala. Además de fallas, en menor medida se identificaron flexuras monoclinales de gran escala y de pequeña escala, tema que se desarrollará más adelante en este Capítulo . 


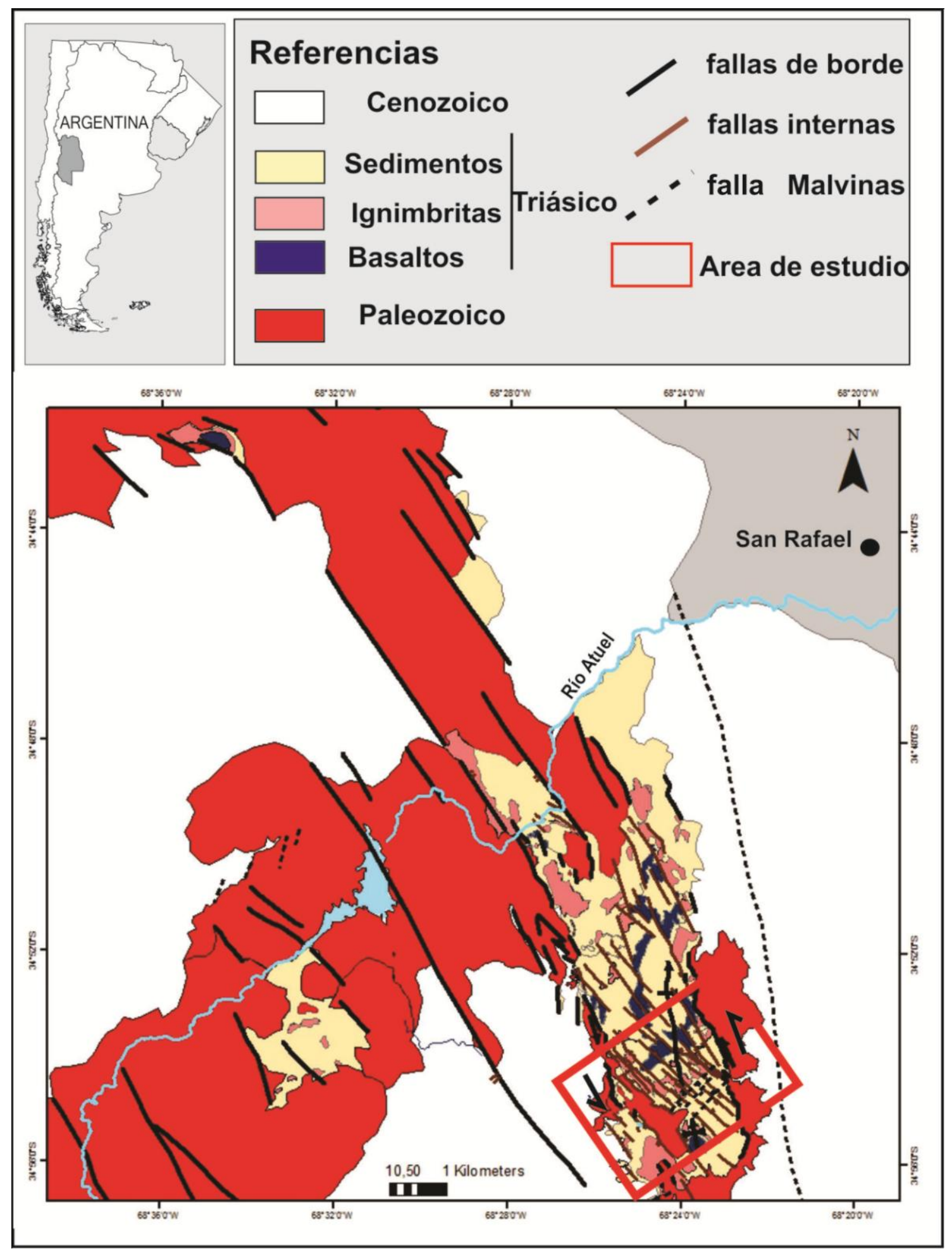

Figura 3.1. Mapa del área de trabajo.

A los efectos de ordenar la descripción estructural, se han subdividido las estructuras reconocidas en cinco categorías: 1. fallas principales de borde, que limitan los afloramientos triásicos y atraviesan toda el área de estudio; 2. fallas internas, las que se desarrollan dentro del área del estudio delimitadas 
por las principales; 3. fallas menores, que se distribuyen delimitadas por las secundarias; 4. zona de acomodación, desarrollada en el extremo sur del depocentro y 5 . plieques $y$ flexuras monoclinales.

\subsubsection{Fallas Principales}

Estas fallas, previamente reconocidas por González D íaz (1964), se identifican con claridad en el campo. Constituyen el borde de cuenca para el Grupo Puesto Viejo en el área de estudio. Se trata de sistemas de fallas segmentadas, paralelas a los ejes del depocentro que limitan la estratigrafía del Triásico en el área de estudio (Figura 3.1.). El Grupo Puesto Viejo se encuentra contenido por estas fallas que lo ponen en contacto lateral con rocas del basamento pérmico en ambas márgenes del depocentro estudiado (Figura 3.1 y 3.4).

Las fallas principales se pueden trazar a lo largo de, aproximadamente, $30 \mathrm{~km}$, aunque la extensión de cada segmento de falla es variable, pudiéndose reconocer desde aquellos que tienen $200 \mathrm{~m}$ de longitud hasta los de $6 \mathrm{~km}$ de extensión (Figura 3.1 y 3.4). A partir del histograma de longitud (Figura 3.2), se observa que las fallas presentan mayor frecuencia en el valor de $1 \mathrm{~km}$ de longitud. Los segmentos de falla en la región al norte del Río Atuel son más continuos pero con trazos irregulares y presentan una orientación preferencial NO-SE. Hacia el sur del Río Atuel adoptan una disposición NNO-SSE y conforman un sistema de fallas con un patrón complejo que muestra segmentación, con fallas dispuestas en echelón y generando un trazo en zigzag (Figura 3.1 y 3.4 ) 


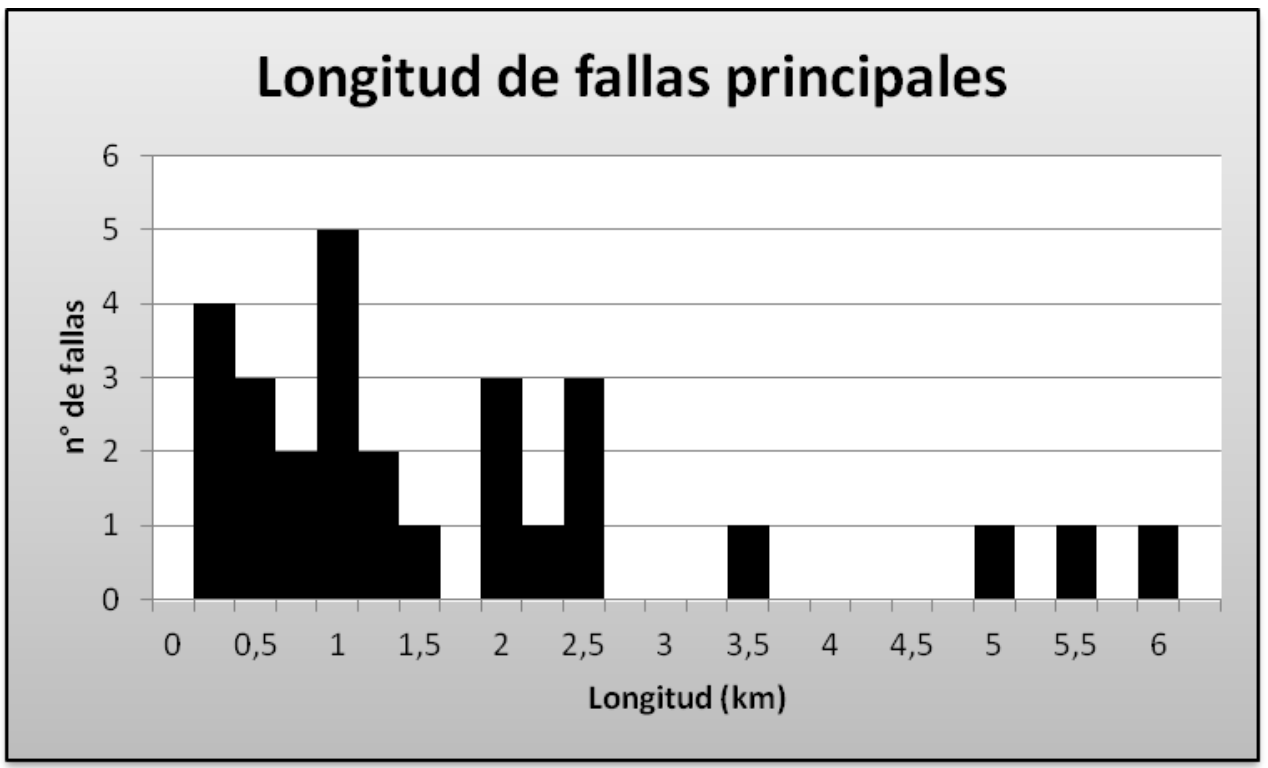

Figura 3.2. Histograma de longitudes de fallas de borde.

Las fallas poseen superficies planas algo irregulares, comúnmente con alto ángulo de inclinación, entre $65^{\circ}$ y $89^{\circ}$ (véase Anexo 1). En el borde oriental del depocentro, los planos de falla muestran una orientación preferencial NO-SE, con inclinación al sudoeste. En estos planos de falla se observaron estrías que presentan rakes horizontales y de $10^{\circ} \mathrm{SE}$ (véase Anexo 1; Figura 3.3). En el borde occidental ocurre la misma orientación preferencial NO-SE y el contacto con rocas del basamento pérmico es neto, presentando inclinación hacia el noreste. En este caso, las estrías de falla poseen rake horizontal o con $10^{\circ} \mathrm{NO}$ (Figura 3.3). Los planos de falla en el sector suroeste y noreste de la zona de estudio son difusos o inferidos, porque el contacto entre los depósitos del Triásico y el basamento pérmico se encuentra cubierto por depósitos cuaternarios.

El patrón que presentan las fallas principales con rakes de $10^{\circ}$ medidos en ambos bordes de la cuenca las caracteriza como fallas de rumbo. Teniendo en cuenta las inclinaciones medidas (algunas de ellas en el orden de los $65^{\circ}$ ) y el hecho de que limitan áreas con pocos centenares de metros de relleno triásico, podrían definirse como fallas de rumbo con componente extensional. El movimiento en el sentido del rumbo debió haber sido discreto, ya que se encuentra subdividido en varias estructuras en las que no se observaron evidencias de largos desplazamientos de rumbo. 


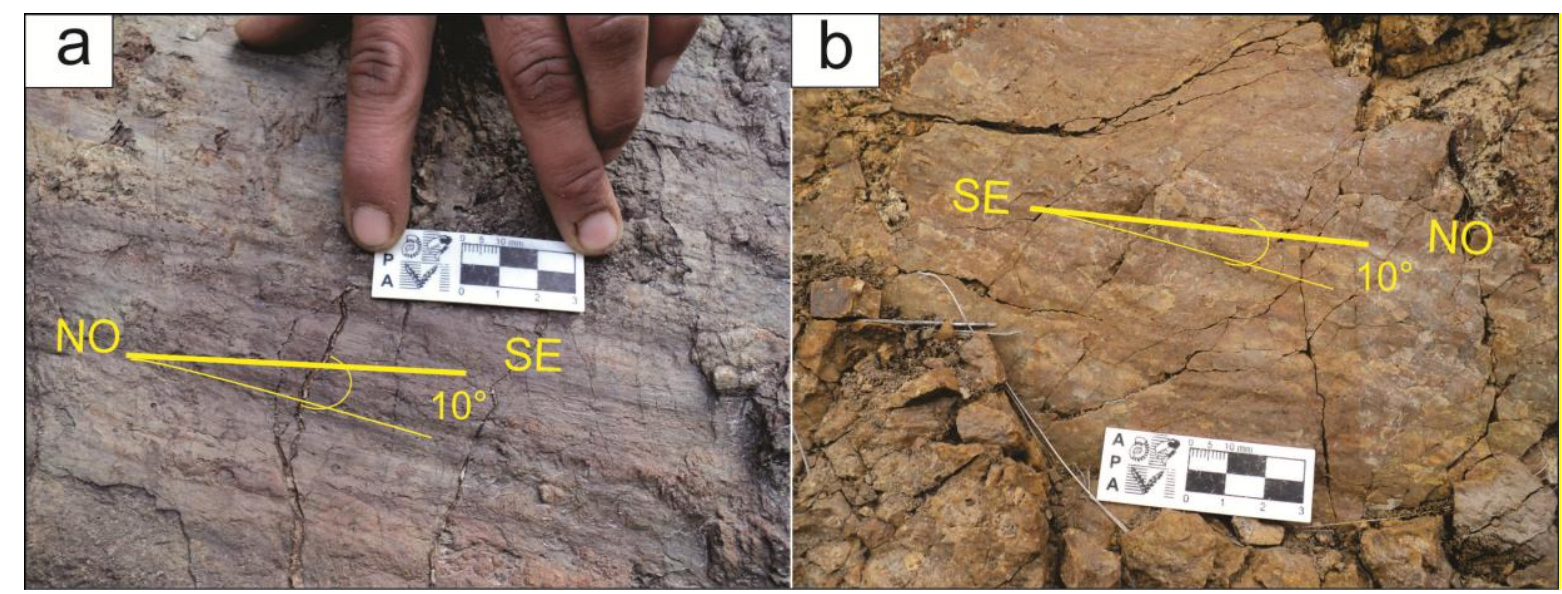

Figura 3.3. Indicadores de dirección de desplazamiento medidos sobre planos de falla de borde.

La tectónica cenozoica vinculada a las fallas principales se ve reflejada en la inversión y consecuente levantamiento de los niveles estratigráficos triásicos basales, actualmente en contacto lateral con rocas del basamento (Figura 3.4). La zona de borde se encuentra afectada localmente por fallas con inclinaciones bajas de entre $45^{\circ}$ a $55^{\circ}$ (véase Anexo 1), con cinemática inversa, que arrastran y deforman las capas triásicas sobre el basamento pérmico. 


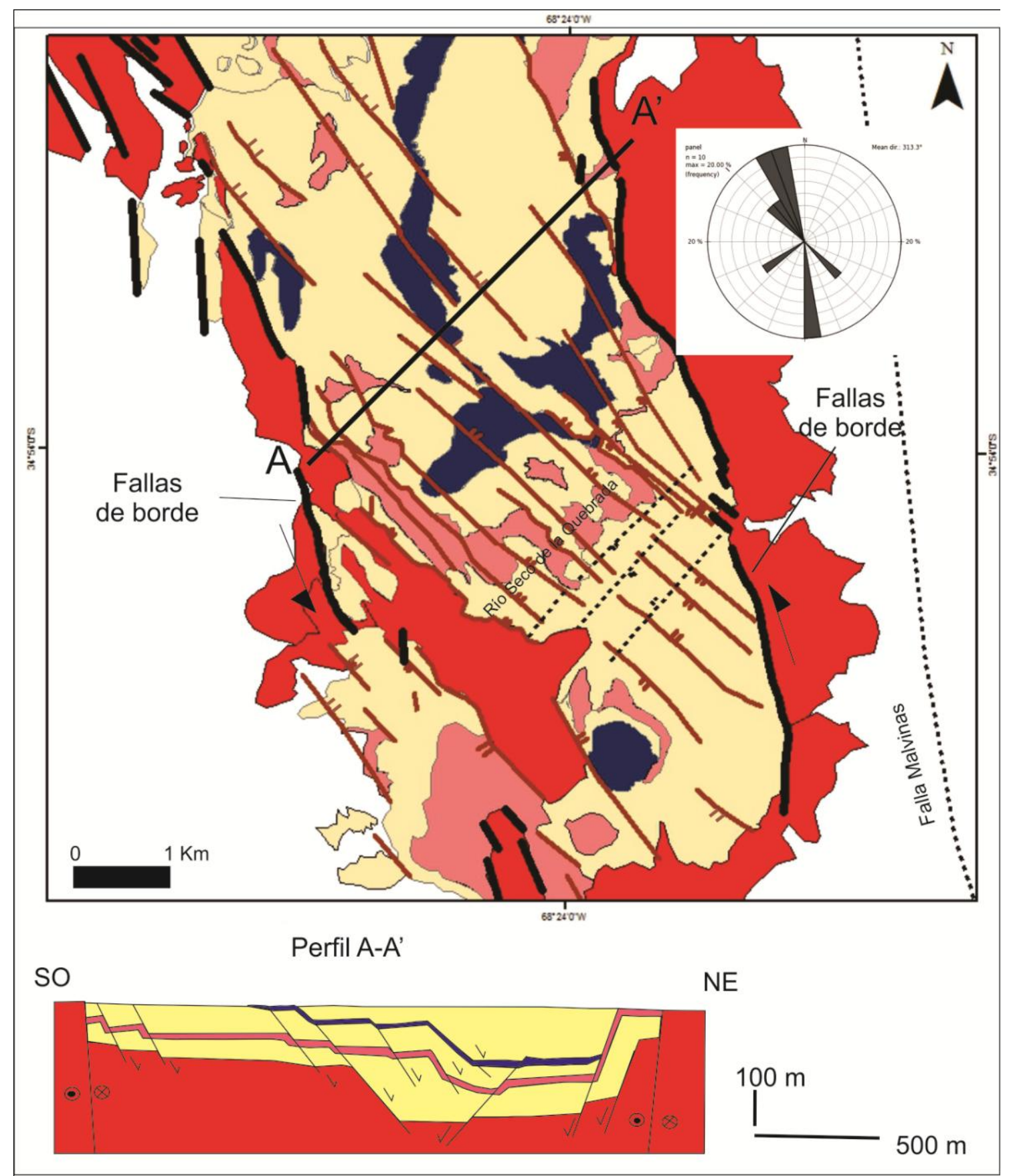

Figura 3.4. Mapa de la zona de estudio con la ubicación del perfil geológico (Quebrada El Puntano) que muestra la disposición de las fallas de borde de la cuenca. El diagrama de rosas muestra el rumbo general de estas fallas. 


\subsubsection{Fallas internas}

Las fallas internas se encuentran contenidas por las fallas de borde del depocentro. Se distribuyen dentro del área de estudio como fallas planas no rotacionales, con una disposición mayormente paralela entre sí y un espaciado que varía de 150 a $300 \mathrm{~m}$. Su extensión es menor que la de las fallas de borde, siendo posible reconocerlas en tramos continuos de $250 \mathrm{~m}$ y hasta de $4 \mathrm{~km}$ de longitud. La Figura 3.4 permite visualizar que la mayoría de las fallas tiene menos de $2 \mathrm{~km}$, con su mayor frecuencia en los 1,5 km de longitud (Figura 3.5). Presentan muy buena exposición en el sector sureste del área de estudio (Figura 3.4) donde fue posible su medición y mapeo. Hacia el noroeste, los planos de fallas son inferidos (Figura 3.1b) dado que los depósitos triásicos más modernos las cubren parcialmente.

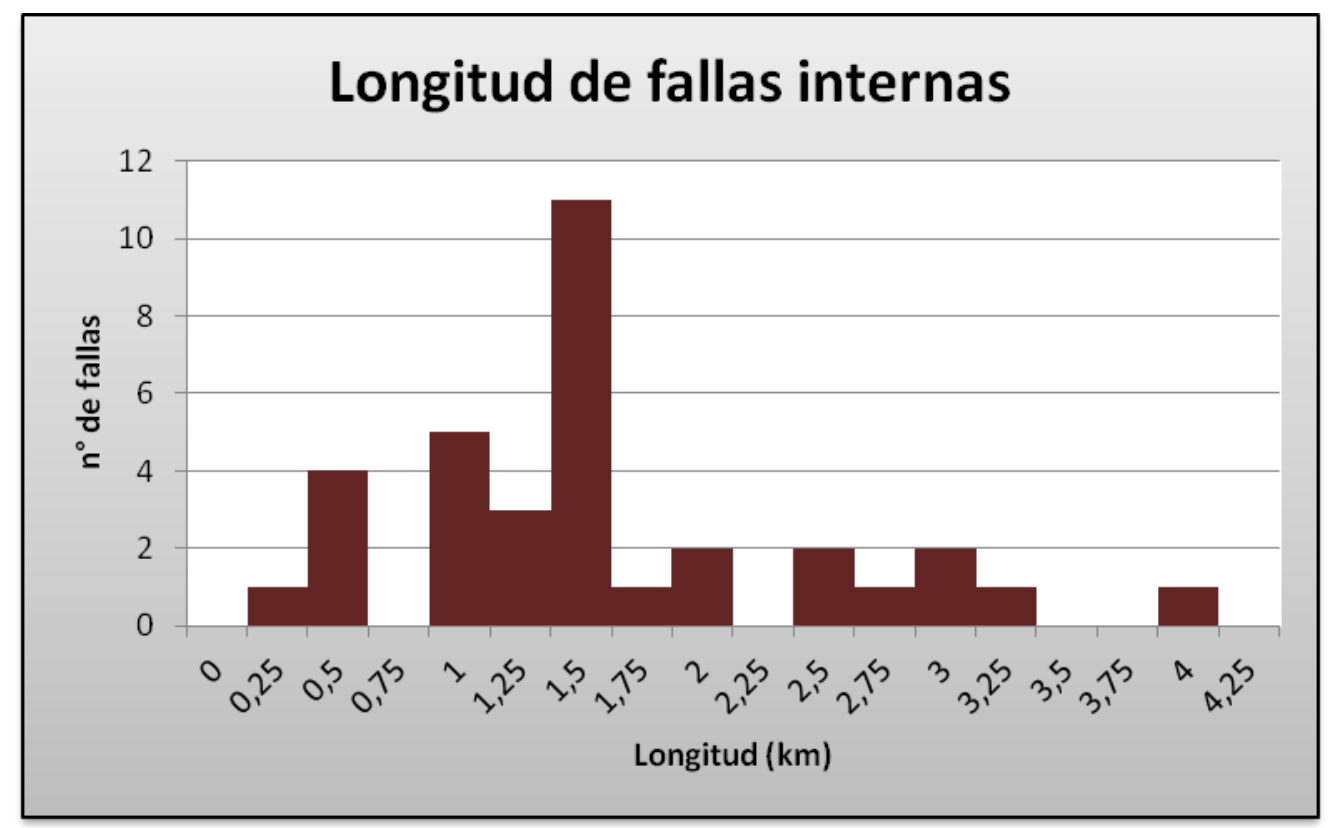

Figura 3.5. Histograma de longitudes de fallas internas.

A partir de la medición de los planos de falla que presentan buena exposición, se reconocieron dos grupos de orientaciones diferentes que inclinan tanto al noreste como al suroeste: un primer grupo de fallas NO-SE coincidente con la orientación preferencial de las fallas principales de borde de cuenca. Este grupo se distribuye cerca de ellas, en el sector norte del área de estudio (Figura 3.7). El segundo grupo de fallas directas, mayormente sintéticas entre sí, 
presenta una orientación preferencial ONO-ESE con marcada disposición oblicua a los límites de la cuenca y se distribuye principalmente hacia el interior de la cuenca (Figura 3.7). Todas las fallas internas se identificaron como fallas normales, con inclinaciones que oscilan entre $50^{\circ}$ y $80^{\circ}$ (véase Anexo 1). En ocasiones fue posible identificar y medir, sobre el plano de falla de bloques colgantes, indicadores del movimiento relativo de los bloques. En estos casos se midieron rakes de entre $30^{\circ}$ y $70^{\circ}$ al NO (véase Anexo 1; Figura 3.6) para las fallas oblicuas al borde de la cuenca. Esta disposición del desplazamiento de las fallas las caracteriza como fallas normales sinestrales.

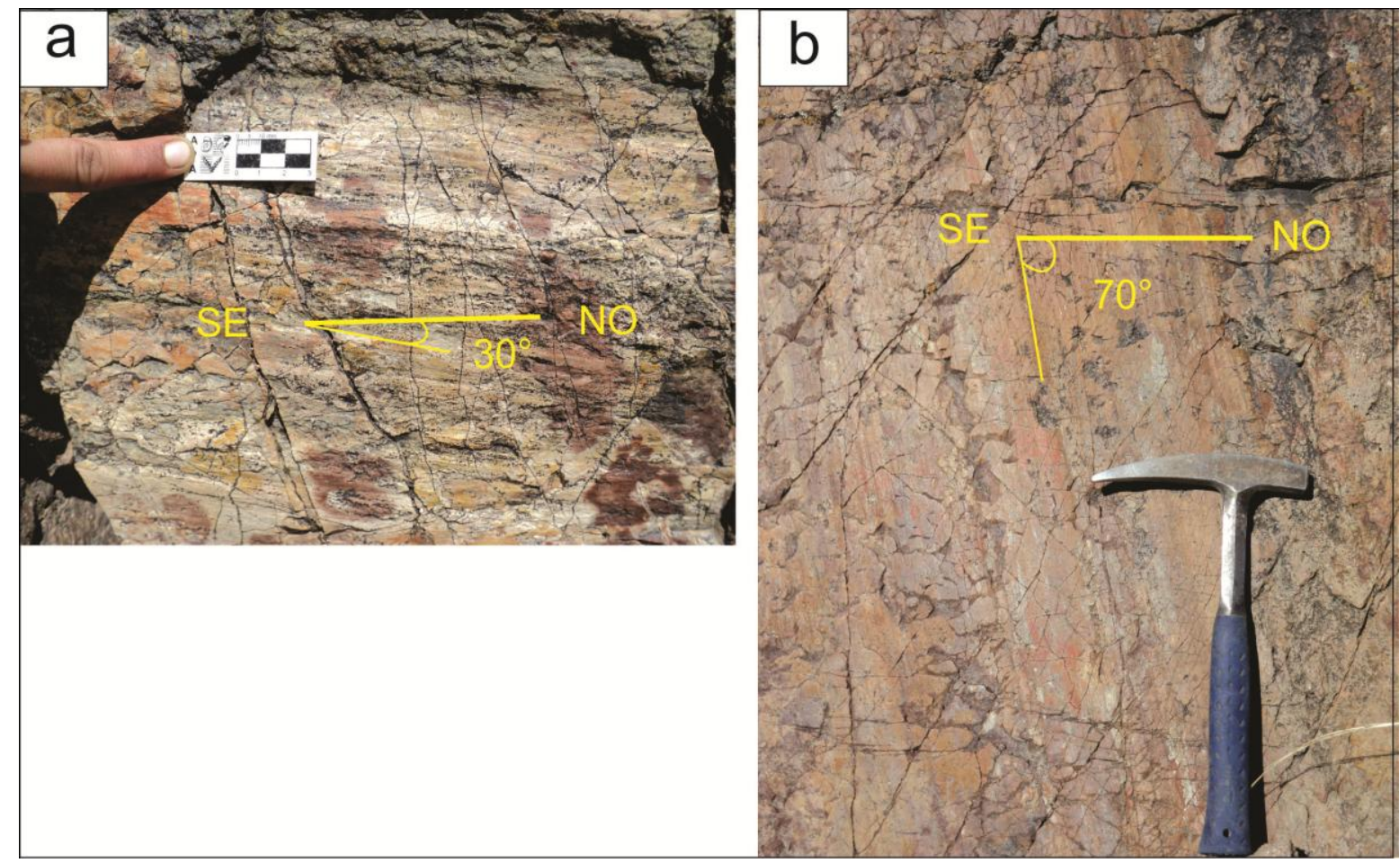

Figura 3.6. Indicadores de dirección de desplazamiento medidos sobre planos de fallas internas.

Las fallas internas constituyen un sistema de estructuras triásicas que actuaron durante la evolución del depocentro del Grupo Puesto Viejo bajo un régimen esencialmente extensional. Es posible observar que limitan grábenes y hemigrábenes rellenos por diferentes unidades continentales y volcanigénicas generando etapas sucesivas de relleno controladas por la actividad tectónica. La actividad de estas fallas parece durar toda la historia deposicional, pudiéndose reconocer toda una secuencia de eventos de deformación 
extensional. Las estructuras internas más antiguas son las fallas directas que afectan a los niveles triásicos inferiores, evidenciadas por la deformación de potentes bancos de ignimbrita que actúan como niveles guía de ese tramo estratigráfico (Figura 3.7). La acción de esas fallas internas iniciales alcanza rechazos verticales de hasta $50 \mathrm{~m}$ y rechazos horizontales menores a 20 metros, dando lugar a la generación de hemigrábenes menores y nuevos espacios internos de acumulación. La reactivación y propagación de estas fallas directas iniciales dio lugar a una segunda secuencia tectónica que resultó en la depositación de los niveles triásicos más modernos en espacios de acumulación que siguen también la geometría de hemigrábenes (Figura 3.7). El desplazamiento máximo medido es de $2,5 \mathrm{Km}$. Las fallas internas responden, por lo tanto, a un modelo de fallas de crecimiento desarrolladas durante el Triásico, que controlaron la estratigrafía del Grupo Puesto Viejo con cada incremento en su desplazamiento, generando nuevos espacios de acumulación internos que aumentaron el espesor y volumen del depocentro principal tal como es común observar en otros depocentros extensionales (Schlische, 1991; Morley 1995; Corti 2012). Más adelante se analizará esta evolución en conjunto con la secuencia de relleno en el área de estudio. 


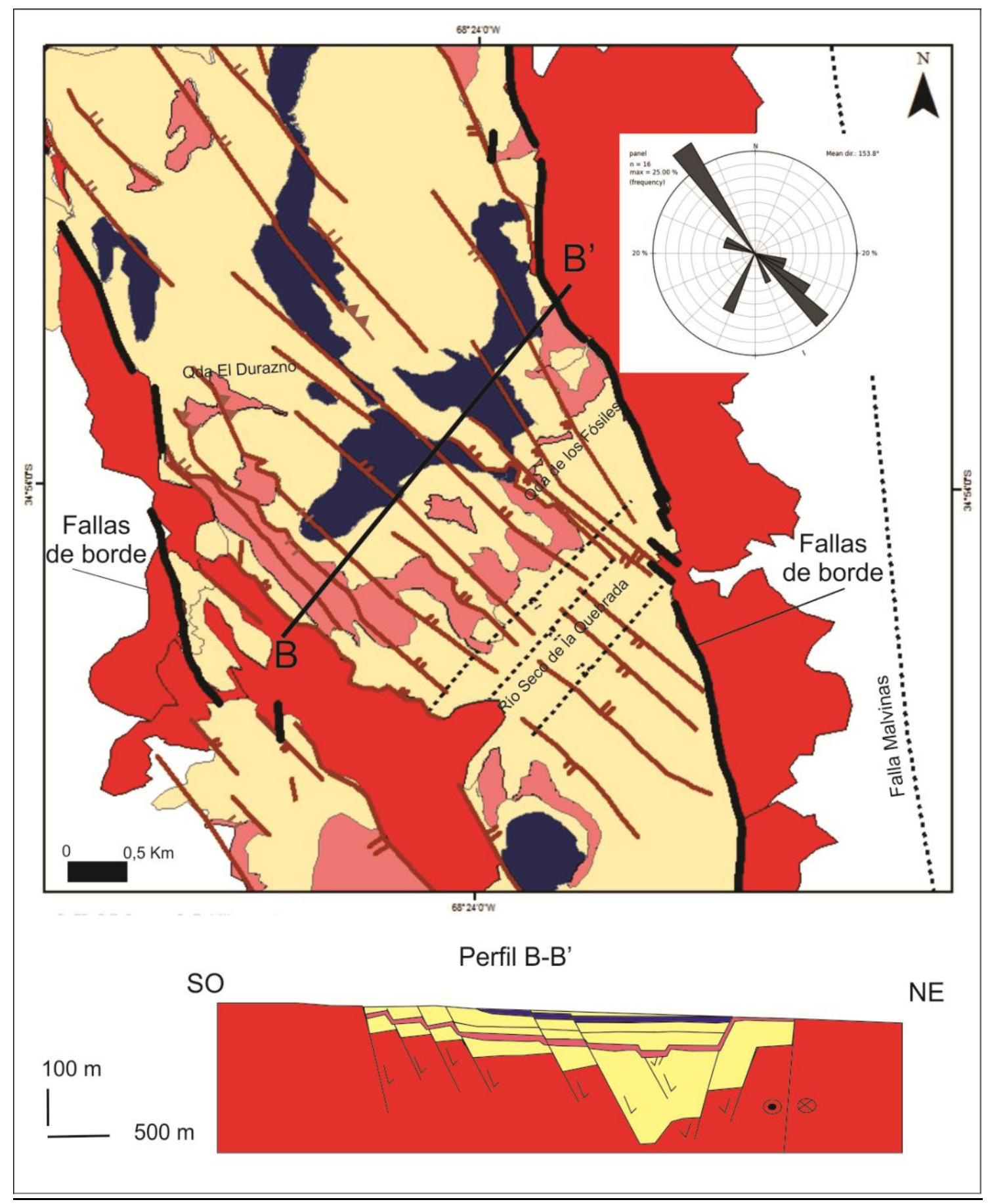

Figura 3.7. Mapa de la zona de estudio con la ubicación del perfil geológico (Quebrada de los Fósiles) que muestra la disposición de las fallas internas de la cuenca. El diagrama de rosas muestra el rumbo general de estas fallas.

En la región, las estructuras que dieron lugar al desarrollo interno de la cuenca se encuentran selectivamente modificadas por la tectónica cenozoica (Figura 3.8) (p.e. reactivación, inversión, etc.). Los rasgos de inversión observados en 
los niveles triásicos a partir de indicadores cinemáticos medidos sobre planos de falla internas inicialmente directas, muestran un desplazamiento de tipo inverso (véase Anexo 1; Figura 3.8a). Además se observan algunas fallas inversas con bajo ángulo de inclinación, sintéticas entre sí y a las preexistentes, que producen la superposición de los niveles afectados (Figura 3.8b). Es importante destacar que la inversión cenozoica no afecta la distribución general de los grábenes triásicos y sólo se observa en los alrededores de los bordes de cuenca.

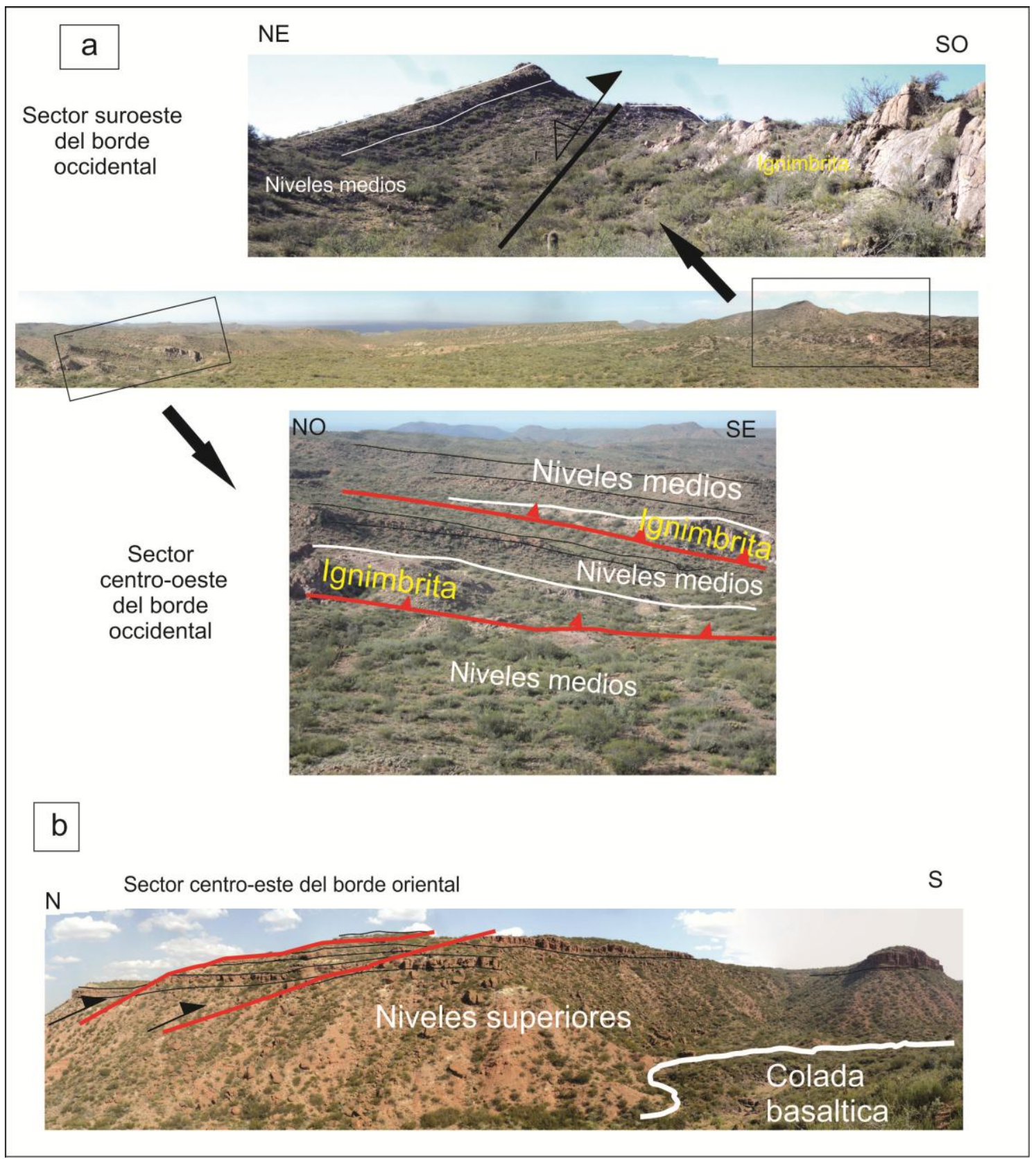


Figura 3.8. a) Fallas normales invertidas en el borde oeste de localidad El Durazno. b) Fallas inversas cenozoicas producen superposición de niveles triásicos afectados en el borde este de la localidad El Durazno. Véase ubicación en la Figura 3.7.

\subsubsection{Fallas Menores}

Estas fallas se observan a escala de afloramiento, delimitando pequeños grábenes dentro de los hemigrábenes mayores generados por las fallas internas. Constituyen estructuras que se extienden desde centímetros hasta centenares de metros y fueron observadas especialmente en el extremo sureste del área de estudio, a lo largo de la localidad Río Seco de La Quebrada (Figura 3.9). Se trata de fallas normales cuya orientación es variable. Las más importantes presentan dos orientaciones: NO-SE paralelas a los bordes de cuenca y ONO-ESE oblicuas a las anteriores. Ambas direcciones son coincidentes con la de las fallas internas descriptas en el inciso anterior. Con menor frecuencia se midieron fallas con orientación NE-SO con inclinaciones al noroeste y al sudeste. En términos generales las fallas normales menores poseen inclinaciones altas, de entre $60^{\circ}$ y $85^{\circ}$ (véase Anexo 1; Figura 3.9).

La superficie de los planos de falla, en la mayoría de los casos, no se encuentra expuesta. Al recorrer los afloramientos es posible observar que consisten en fallas normales que controlan la estratigrafía del Triásico, desplazando estructuras previas y generando espacios menores de acumulación como grábenes y hemigrábenes, en los cuales se depositan niveles más modernos del mismo Triásico. Capas guía y conjuntos de estratos de variable espesor y composición en la sucesión triásica deformada, junto con indicadores cinemáticos asociados a la zona de falla, han permitido identificar el desplazamiento directo sinestral (véase Anexo 1; Figura 3.9).

Vinculados a los planos de falla con orientación ONO-ESE, se midieron pequeños rechazos menores a $1 \mathrm{~m}$ en los niveles inferiores que aumentan progresivamente a rechazos menores a 3 metros en los niveles más altos (Figura 3.9), indicando una fuerte interrelación entre el aporte volcanosedimentario y la actividad tectónica. Un rasgo característico de algunas de 
estas fallas es que su techo se encuentra plegado por flexión de falla (rollover), mientras que esa geometría no fue observada en las estructuras de mayor envergadura.

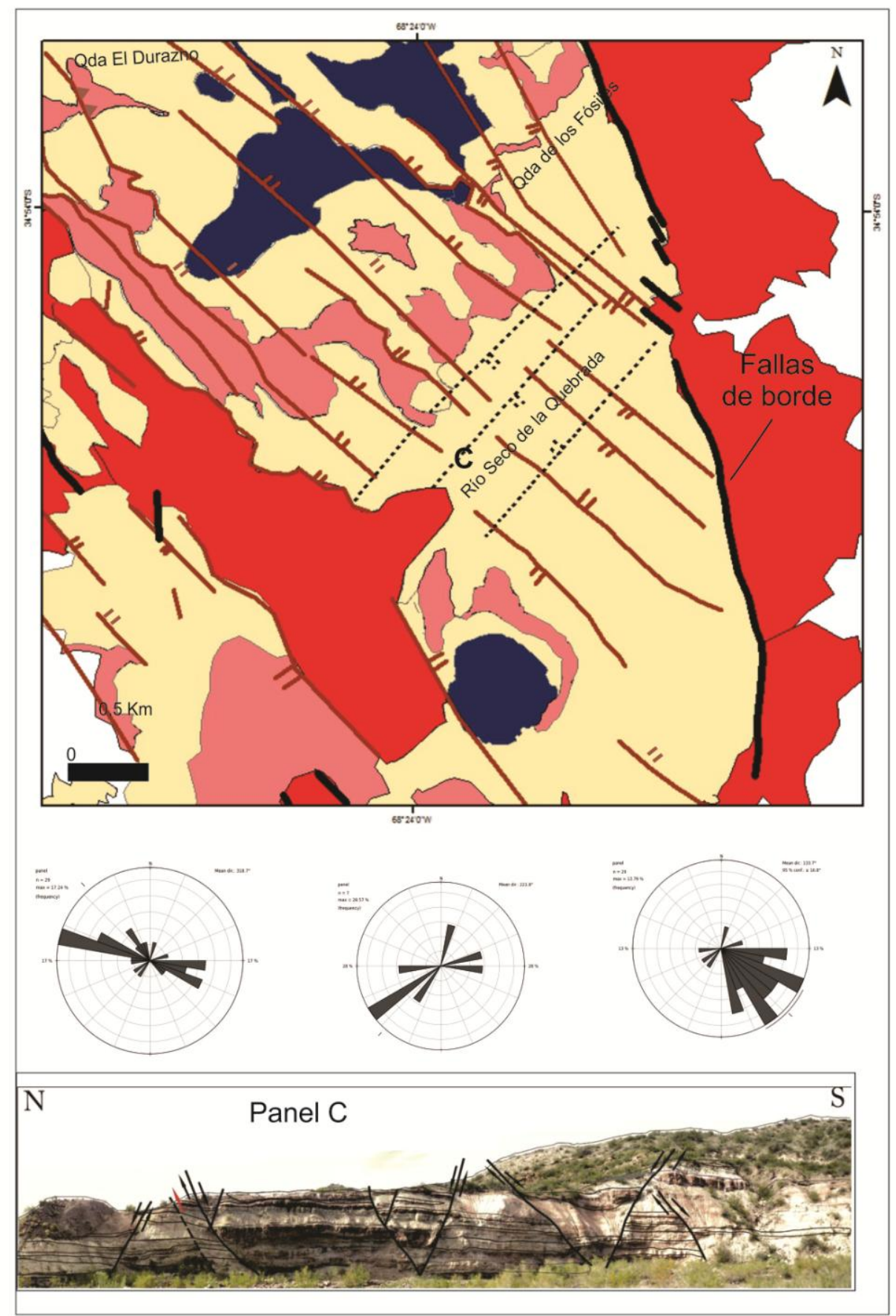

Figura 3.9. Mapa de la zona de estudio con ubicación del panel que muestra el fallamiento normal asociado a esta escala. Fotos tomadas en la localidad Río Seco de la Quebrada. 
Estas estructuras menores también muestran rasgos de inversión tales como atajos con muy bajo ángulo $\left(30^{\circ}\right.$ a $\left.45^{\circ}\right)$ o fallas directas invertidas localmente (véase Anexo 1; Figura 3.10). En términos generales la inversión de estas estructuras es escasa y se ha preservado una elevada proporción de fallas normales no invertidas por la tectónica cenozoica.

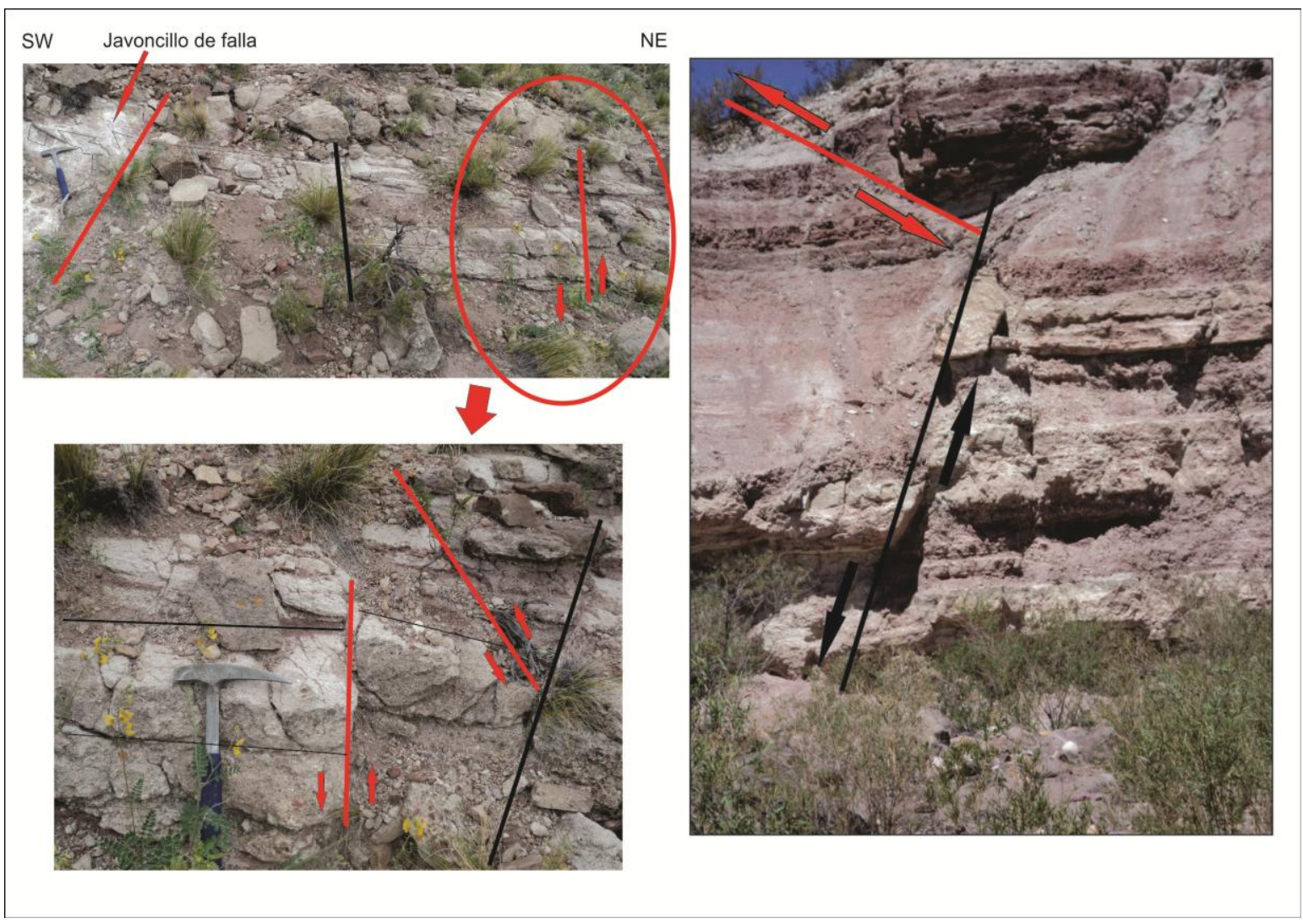

Figura 3.10. Fallas inversas cenozoicas a escala de afloramientos en los alrededores de Río Seco de la Quebrada.

\subsubsection{Zona de acomodación del Río Seco de la Quebrada}

En el extremo sur del depocentro de San Rafael se identificaron y midieron fallas menores con orientación NE-SO que forman un ángulo alto (mayor a $60^{\circ}$ ) con las estructuras principales del rift NO-SE y coinciden con un cambio sustancial en la geometría de las fallas ONO-ESE (Figura 3.11). En este sector de la zona de estudio se observa una segmentación ligeramente fuera de secuencia (en offset) de las fallas ONO-ESE, lo que produce una zona de fallas conjugadas parcialmente superpuestas. 
La sección transversal de la Figura 3.11 muestra el cambio de polaridad que se generan en los hemigrábenes con desplazamiento del eje principal hacia el borde occidental. Esta nueva disposición es evidenciada por el desarrollo de un alto de basamento con geometría de horst alargado en sentido ONO-ESE, limitado por fallas internas de inclinación opuesta en el extremo suroeste del área de estudio. Estas características responden a un modelo de zona de acomodación en el sentido de Morley (1999) y McClay et al. (2002). Las zonas de acomodación son rasgos comunes en depocentros extensionales (Corti et al., 2007) y suelen estar controladas por estructuras heredadas de la historia tectónica previa (Morley, 1999). En este caso, se trataría de una zona de acomodación de alto relieve (Faulds y Varga, 1988). 


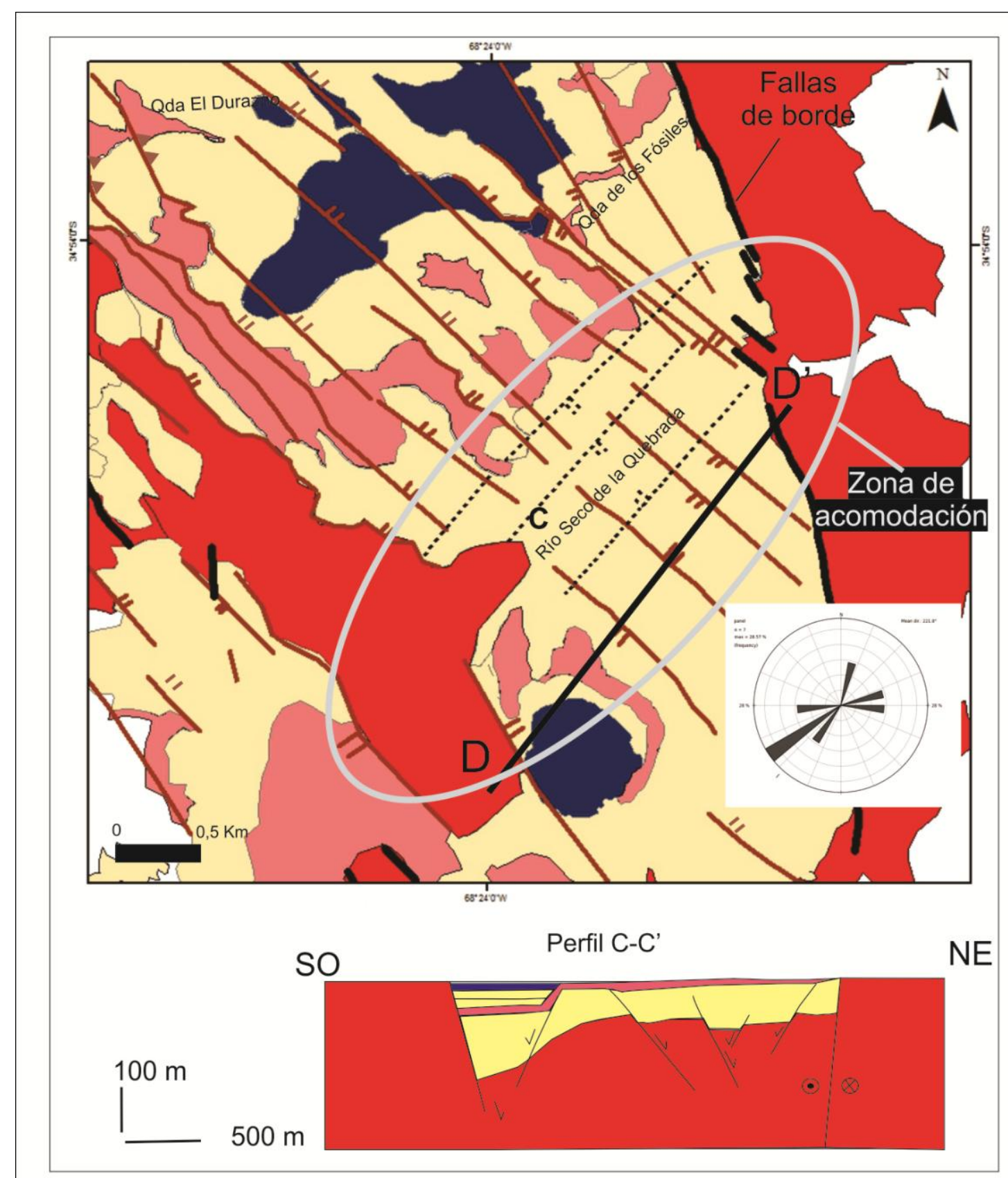

Figura 3.11. Mapa de la zona de estudio con la ubicación del perfil geológico de los afloramientos al sur de la quebrada Río Seco de la Quebrada. Zona de acomodación. El diagrama de rosas muestra el rumbo de estas fallas.

\subsubsection{Descripción de los pliegues}


La zona de estudio ha sido caracterizada desde las primeras descripciones como un amplio sinforme delimitado por las fallas principales de borde de cuenca (Capítulo 1.2; Figura 3.12). Este rasgo es fácilmente detectado al recorrer la zona de estudio en sentido este-oeste, a pesar de que el conjunto de la estratificación triásica presenta muy baja inclinación $\left(2^{\circ}-20^{\circ}\right.$; véase Anexo 1b). La estructura de la región divide al área de estudio en dos pliegues sinformes evidenciados por la preservación de los niveles triásicos más jóvenes (coladas basálticas) aflorantes en el seno de los mismos. El de mayor dimensión se ubica al norte del Río Seco de la Quebrada con eje NNO-SSE, con flancos que inclinan hacia el E-NE en el sector occidental y hacia el NO en el sector oriental (Figura 3.12). El segundo pliegue sinforme se localiza al sur del Río Seco de la Quebrada (Figura 3.12) con eje NNO-SSE y flancos que inclinan hacia el NE en el sector occidental y hacia SO en el sector oriental.

La disposición de los ejes de ambos sinformes en dirección longitudinal a las estructuras con leve inclinación hacia el norte, su amplia distribución afectando la totalidad de los afloramientos en el área de estudio y la forma simétrica de los pliegues con planos de estratificación muy cercanos a la horizontal (Figura 3.13) limitados por fallas internas normales y adyacente a la superficie de la falla en los bloques piso (Figuras $3.3 ; 3.5$ y 3.7 ), son características que permiten clasificarlos como pliegues de arrastre (Slische, 1995, Khalil y McClay, 2002) formados como resultado del crecimiento de fallas normales durante la extensión triásica. El cambio de inclinación de los flancos orientales de los sinformes con inclinaciones opuestas a ambos lados de la zona de acomodación, sugiere la presencia de un antiforme (Faulds, et al., 2002) evidenciado por los niveles triásicos más antiguos que afloran en ese sector (Figura 3.12). Durante el Cenozoico, el plegamiento fue modificado o acentuado localmente producto de la inversión selectiva característica en la zona de estudio. 


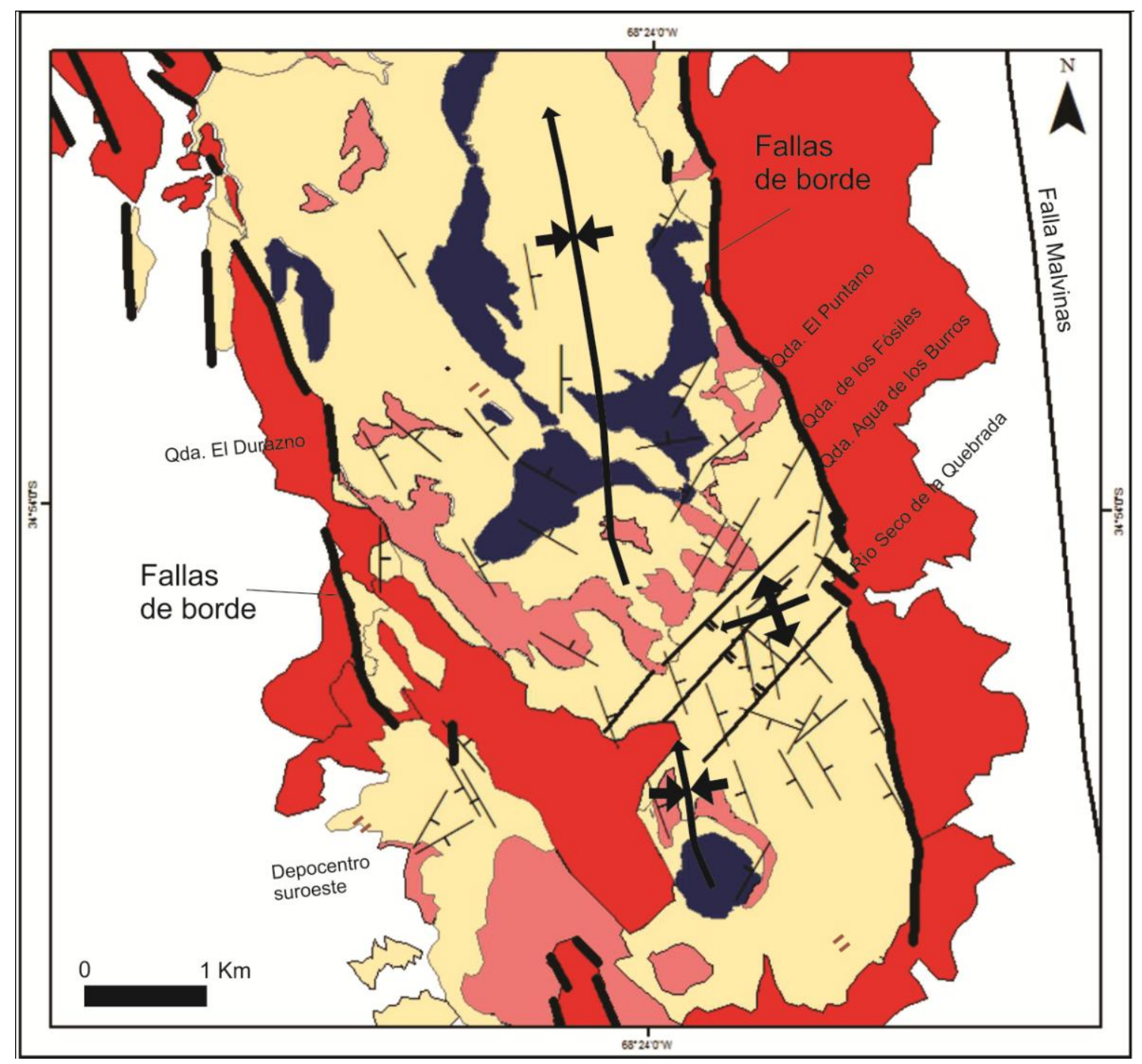

Figura 3.12. Mapa de la zona de estudio con la ubicación los pliegues sinformes al norte y al sur de la zona de acomodación; y del pliegue antiforme en el Río Seco de la Quebrada. 


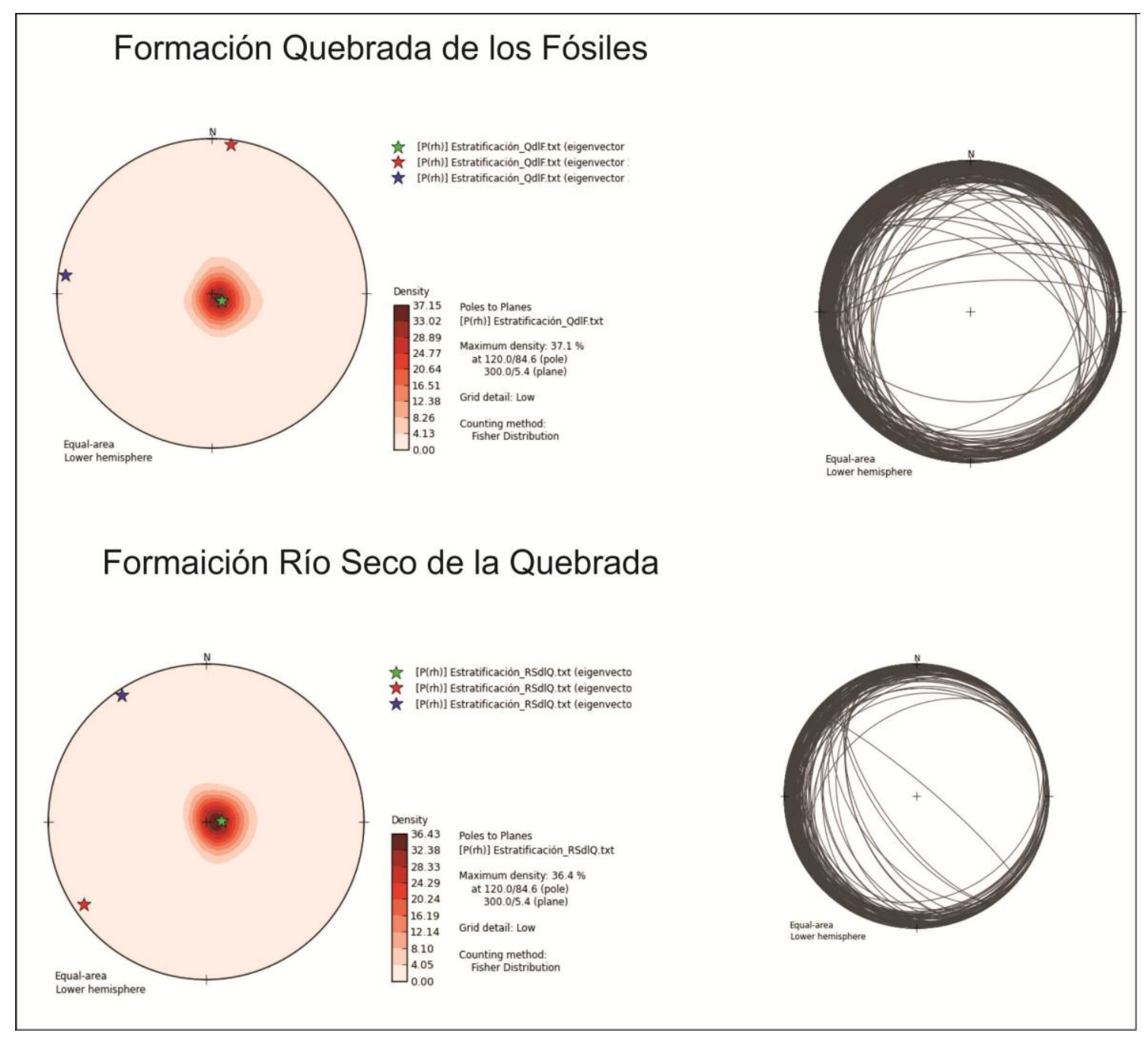

Figura 3.13. Posición casi horizontal de los flancos de pliegues.

La estructuración triásica controlada por las fallas internas con desplazamiento normal ha generado también el desarrollo de flexuras monoclinales como producto de la propagación de dichas fallas. Esta geometría de deformación implica la acción de fallas normales que no alcanzan la superficie y producen la flexión de los niveles inmediatamente por encima del extremo de la falla (Slische, 1995). Los problemas de espacio generados por el desplazamiento a lo largo de estos tramos con distinta inclinación se resuelven por medio de pliegues de arrastre, flexión de fallas y fallas secundarias antitéticas de ajuste (Figura 3.14). Las flexuras monoclinales se observan afectando bancos ignimbríticos que coronan las secuencias inferiores del Grupo Puesto Viejo (Figura 3.15). 


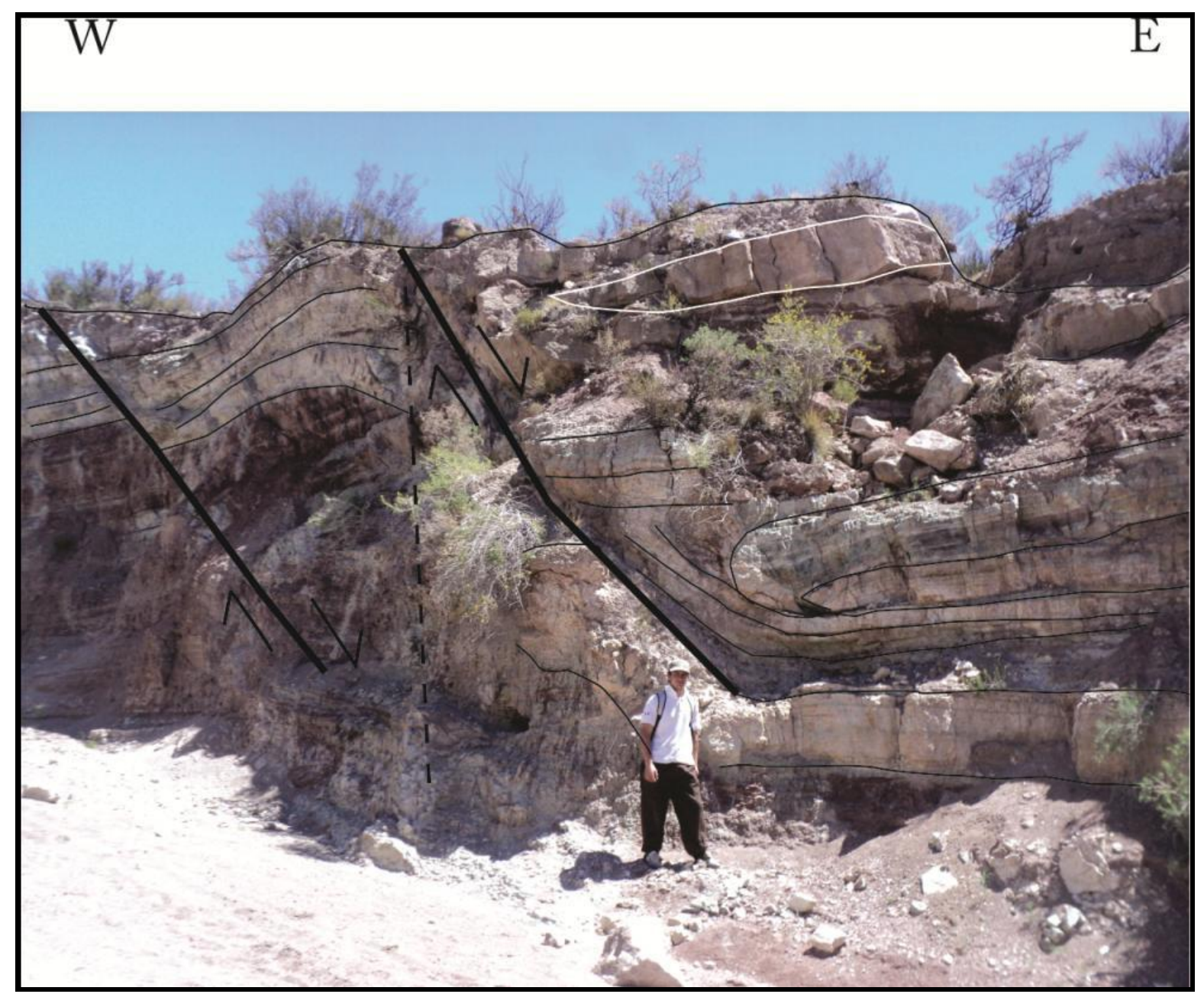

Figura 3.14. Plegamiento por arrastre (roll-over) de fallas normales. Afloramiento en la localidad Río Seco de la Quebrada (ubicación en Figura 3.12). 


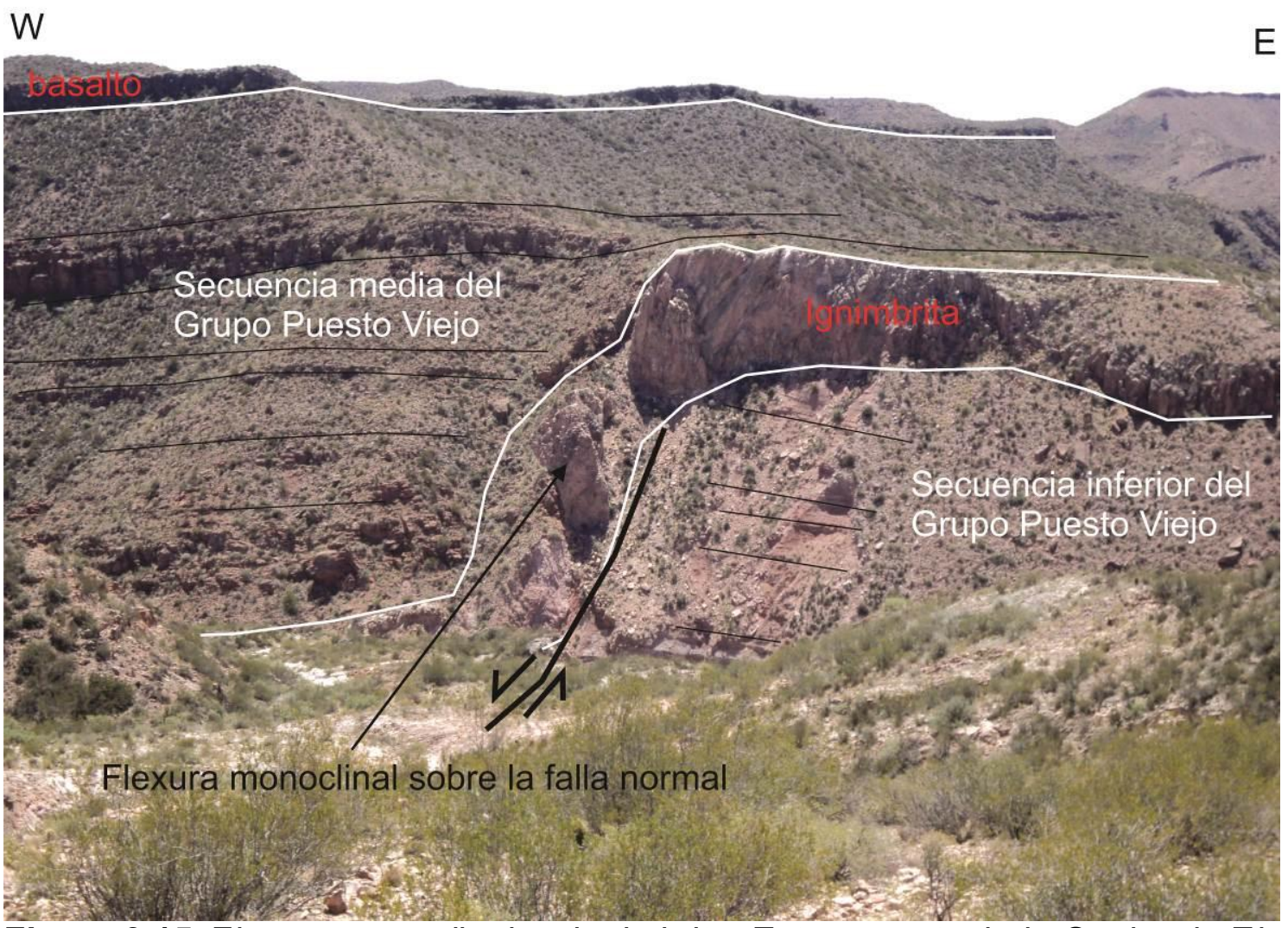

Figura 3.15. Flexura monoclinal en ignimbrita. Extremo este de la Quebrada EI Puntano (ubicación en Figura 3.12).

\subsection{Etapas de estructuración}

La observación de las estructuras relevadas muestra que el depocentro en el cual se depositó el Grupo Puesto Viejo en el área de estudio fue estructurado en sucesivas etapas con características particulares. La gran geometría del depocentro responde a una fosa elongada en sentido NNO-SSE limitada por las fallas de borde en tramos segmentados (Figura 3.4). Estas fallas de borde transtensivas poseen un sistema interno con desplazamientos casi puramente extensionales, representado por las fallas internas descriptas en la sección 3.1.6. Este sistema extensional es oblicuo a los bordes (Figura 3.7) y estaría controlado por el desplazamiento de las fallas de borde. La evolución de la gran estructura del depocentro del área de estudio puede ser dividida en 4 etapas de actividad relativamente continua. Una etapa inicial, que dio origen a la cuenca, se vincula a desplazamientos discretos sinestrales en las fallas de 
borde. Posteriormente, el desarrollo de las fallas fallas internas, vinculadas a extensión pura, puede ser subdividido en tres etapas.

\subsubsection{Etapa l: Generación del espacio de acumulación inicial}

Las fallas de borde, que no alcanzan a desarrollar un desnivel estructural grye ni muestran la geometría de hombros rotados típica de muchas fallas de borde en sistemas extensionales, se caracterizan por mostrar desplazamiento de rumbo (Figura 3.4). Se desconoce la magnitud de ese desplazamiento, ya que no se observaron marcadores que la permitieran medir, aunque, tal como se ha comentado, no hay evidencias para implicar la existencia de importantes movimientos horizontales. Los primeros desplazamientos de las fallas de borde, tuvieron un carácter transtensional, y habrían generado el espacio de acumulación general en el área de estudio. Estas fallas se pueden observar en el mapa (Figuras 3.1 y 3.4) con orientación principal NO-SE en tramos rectos y continuos que se cortan en segmentos y en ocasiones conformyo fallas cortas en echelón. Con la información disponible, no es posible establecer certeramente si la disposición de los planos de falla medidos en superficie presenta continuidad en profundidad o no, dificultyo la posibilidad de establecer con certeza a qué modelo responden.

Los depósitos de borde de cuenca se pueden observar muy bien preservados en el extremo sur de la zona de estudio, adyacentes a los planos de falla del borde oriental (Figura 3.16) y occidental (Figura 3.17). Estos depósitos constituyen los niveles triásicos basales cuyas características se desarrollarán en el siguiente Capítulo . 


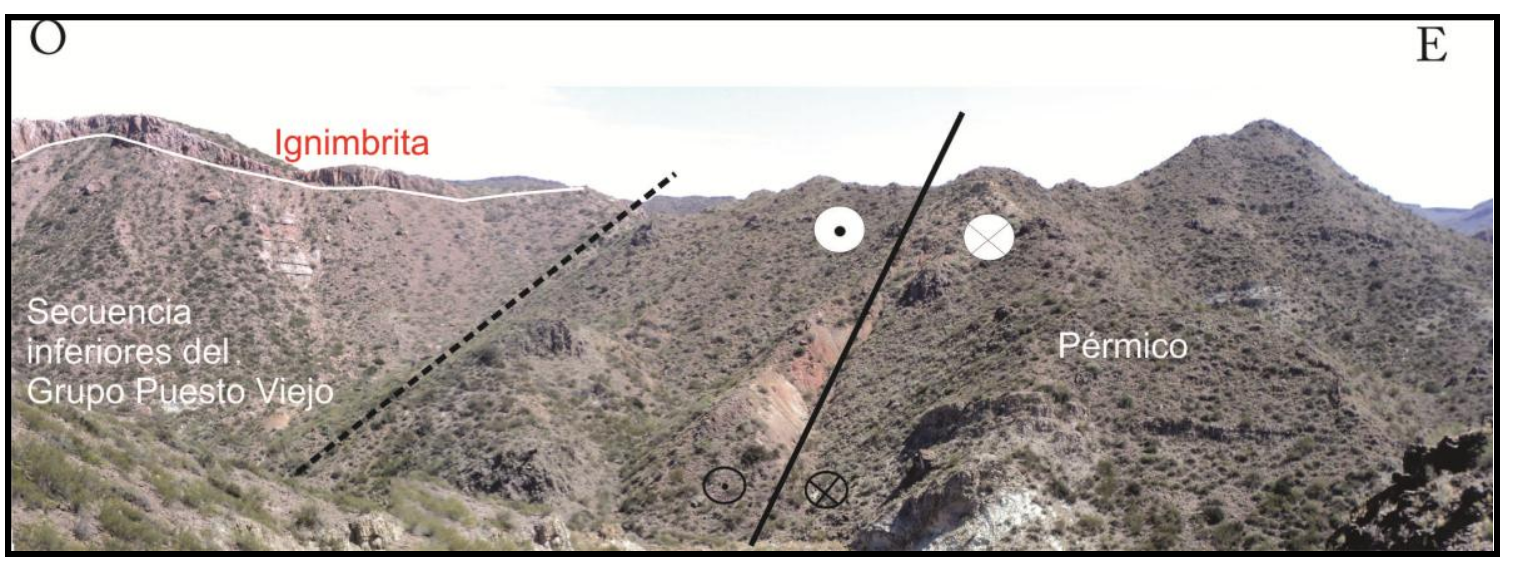

Figura 3.16. Vista hacia el norte del borde oriental de la cuenca, en la quebrada de los Fósiles (ubicación en Figura 3.12).

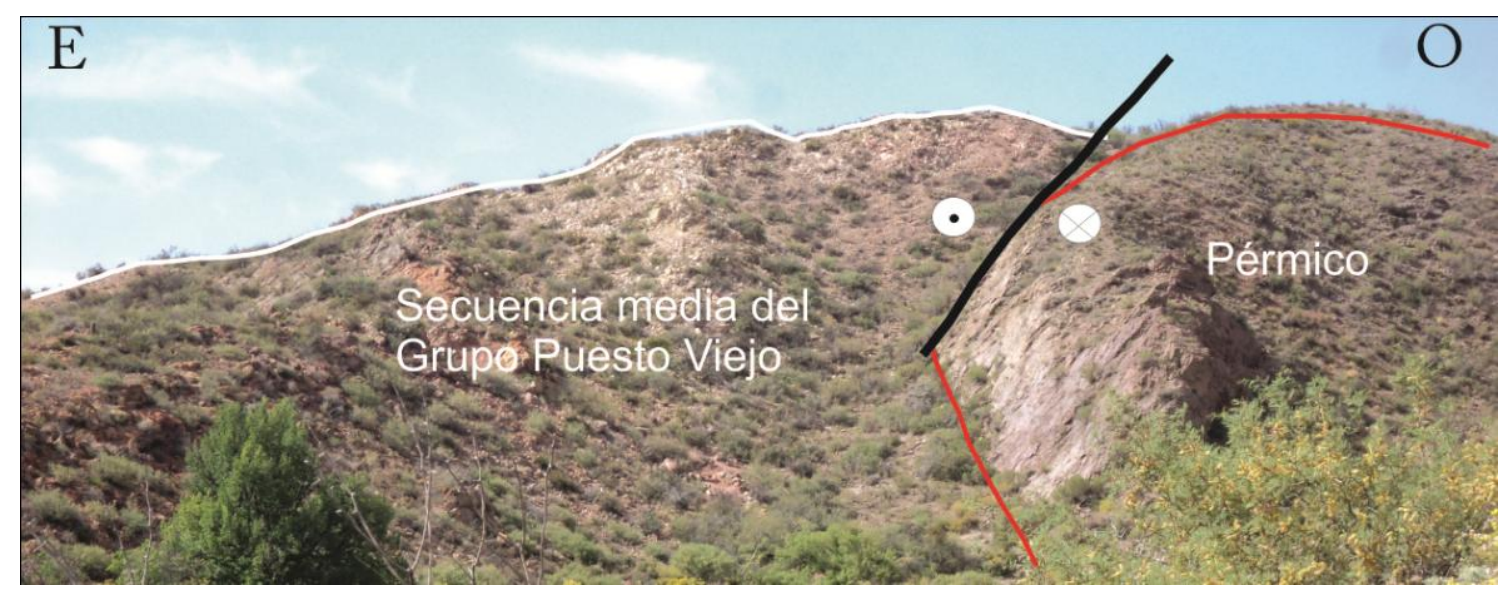

Figura 3.17. Vista hacia el sur del borde occidental de la cuenca, en la quebrada El Durazno (ubicación en Figura 3.12).

El espacio de acumulación generado en esta etapa es amplio ya que abarca todo el depocentro y no muy profundo, ya que los rechazos verticales no superan los 40 metros. No se han registrado estructuras internas en el basamento del techo de toda la secuencia, por lo cual se puede concluir que el depocentro no se encontraba mayormente segmentado en su etapa inicial (Figura 3.18). 


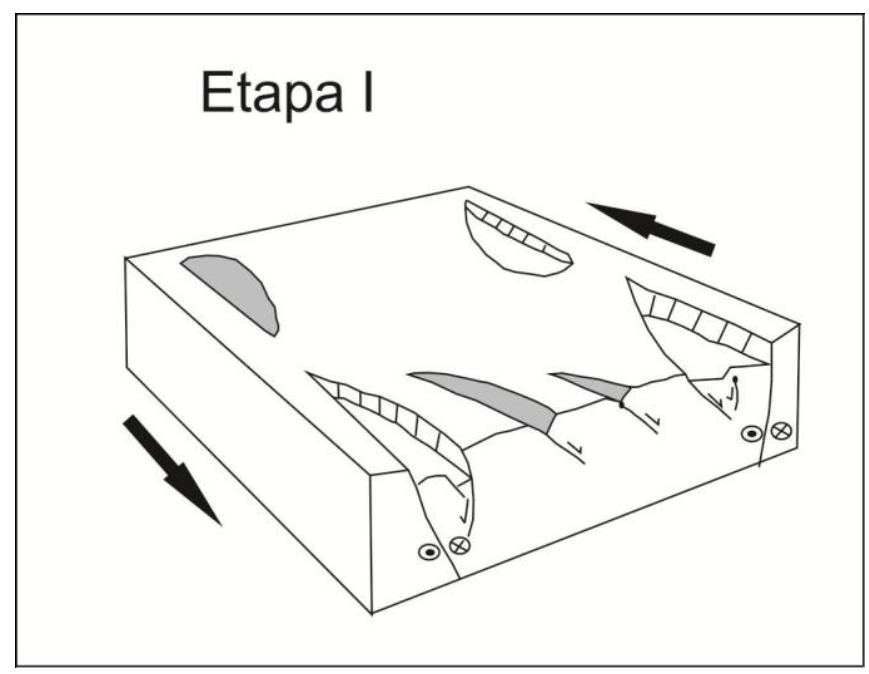

Figura 3.18. Bloque diagrama muestra la configuración de la cuenca para la Etapa I.

\subsubsection{Etapa II: Desarrollo de las estructuras internas del depocentro}

La actividad extensional generalizada que se desarrolla durante esta etapa se ve reflejada en el crecimiento de las estructuras internas que generó una segmentación de la cuenca. El registro de la las fallas menores descriptas para el sector sureste del área de estudio corresponde a esta etapa, donde se desarrolla un conjunto de fallas normales de variada orientación (NO-SE; ONOESE; NE-SO) y poca magnitud. El desarrollo de fallas directas sintéticas entre sí con orientación ONO-ESE oblicuas al borde de cuenca fue prolongada en el tiempo y generó espacios internos de acumulación como grábenes y hemigrábenes donde se depositaron niveles inferiores del Grupo Puesto Viejo (Figuras 3.9 y 3.19). En cambio, la actividad de las fallas con orientación NOSE, sintéticas a los bordes de cuenca, generó espacios incipientes en las inmediaciones de los márgenes de la cuenca en respuesta a la distribución de la extensión en los hemigrábenes mayores (Figura 3.21a) 


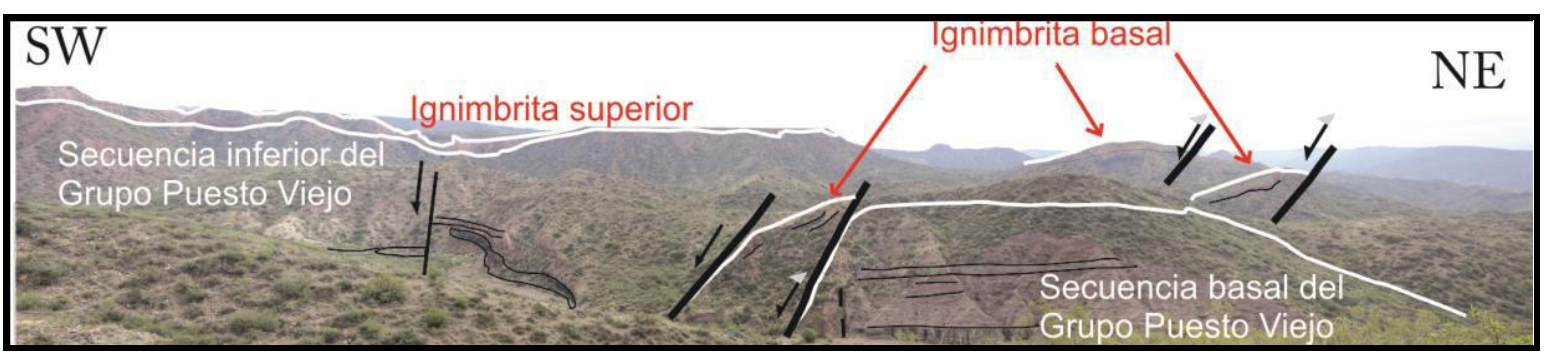

Figura 3.19. Extremo este de la quebrada Río Seco de la Quebrada (ubicación en Figura 3.12), donde afloran los niveles inferiores de la Formación Quebrada de los Fósiles.

Las fallas con orientación NE-SO, anómalas para la geometría general del depocentro, se desarrollaron durante esta etapa a lo largo de la localidad Río Seco de la Quebrada (Figura 3.20) cortyo a las fallas ONO-ESE y NO-SE con un ángulo relativamente alto (entre $60^{\circ}$ y $90^{\circ}$ ). Estas fallas generaron un cambio de polaridad en los grábenes y hemigrábenes de la etapa II (Figura 3.21b) generando una zona de acomodación (Faulds y Varga, 1988; Morley, 1999; McClay et al. 2002).

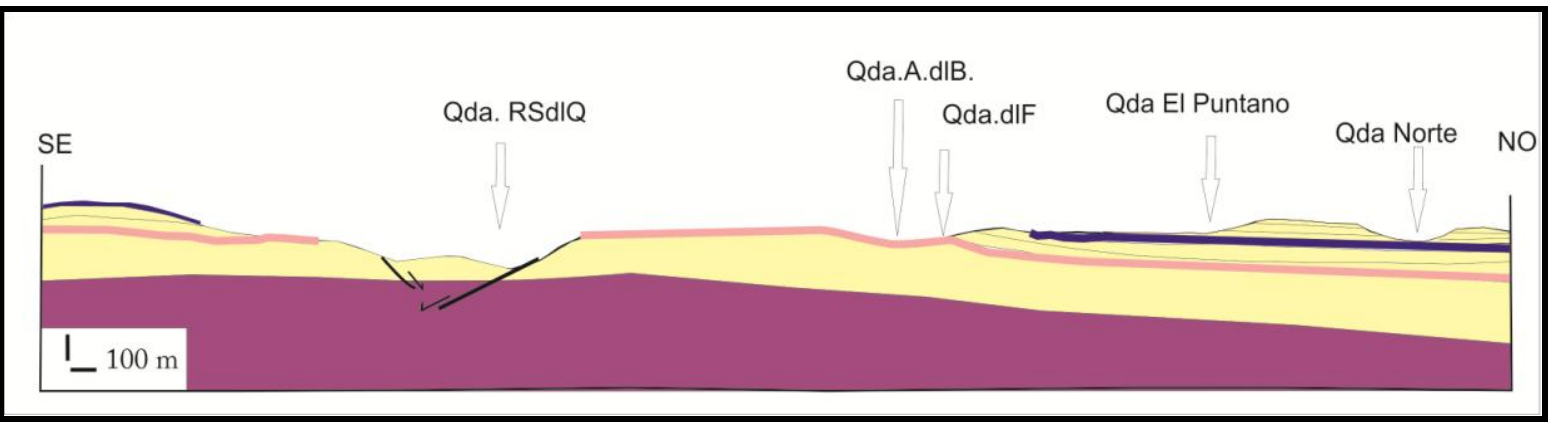

Figura 3.20. Perfil geológico SE-NO que muestra la disposición de las fallas NE-SO en el Río Seco de la Quebrada. 


\section{Etapa II}

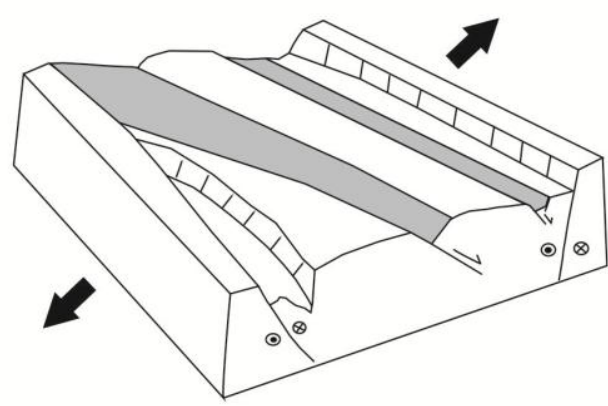

Zona de acomodación

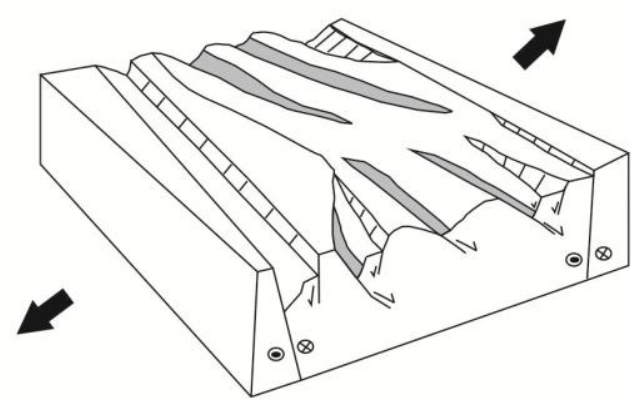

Figura 3.21.a) Bloque diagrama muestra la configuración de la cuenca para la Etapa II. b) Zona de acomodación del Río Seco de la Quebrada.

\subsubsection{Etapa III: Reactivación y crecimiento de las estructuras in ternas}

En esta etapa, la continuidad en la actividad de fallas internas más longevas generó una reestructuración de la cuenca, condicionada, entre otros factores, por la localización de la zona de acomodación del Río Seco de la Quebrada. La reactivación y propagación de algunas de las fallas internas ONO-ESE produjeron nuevos espacios para el relleno en la forma casi simétrica de grábenes donde se depositaron niveles triásicos medios del Grupo Puesto Viejo, tal como se observa en la Figura 3.7. Algunas de estas estructuras ONOESE generaron las flexuras monoclinales descriptas en la sección 3.1.4 a medida que el desplazamiento se propagó hacia la superficie, limityo un espacio de acumulación que no entra en contacto con el plano de falla principal (Figuras 3.15 y 3.22 ). 


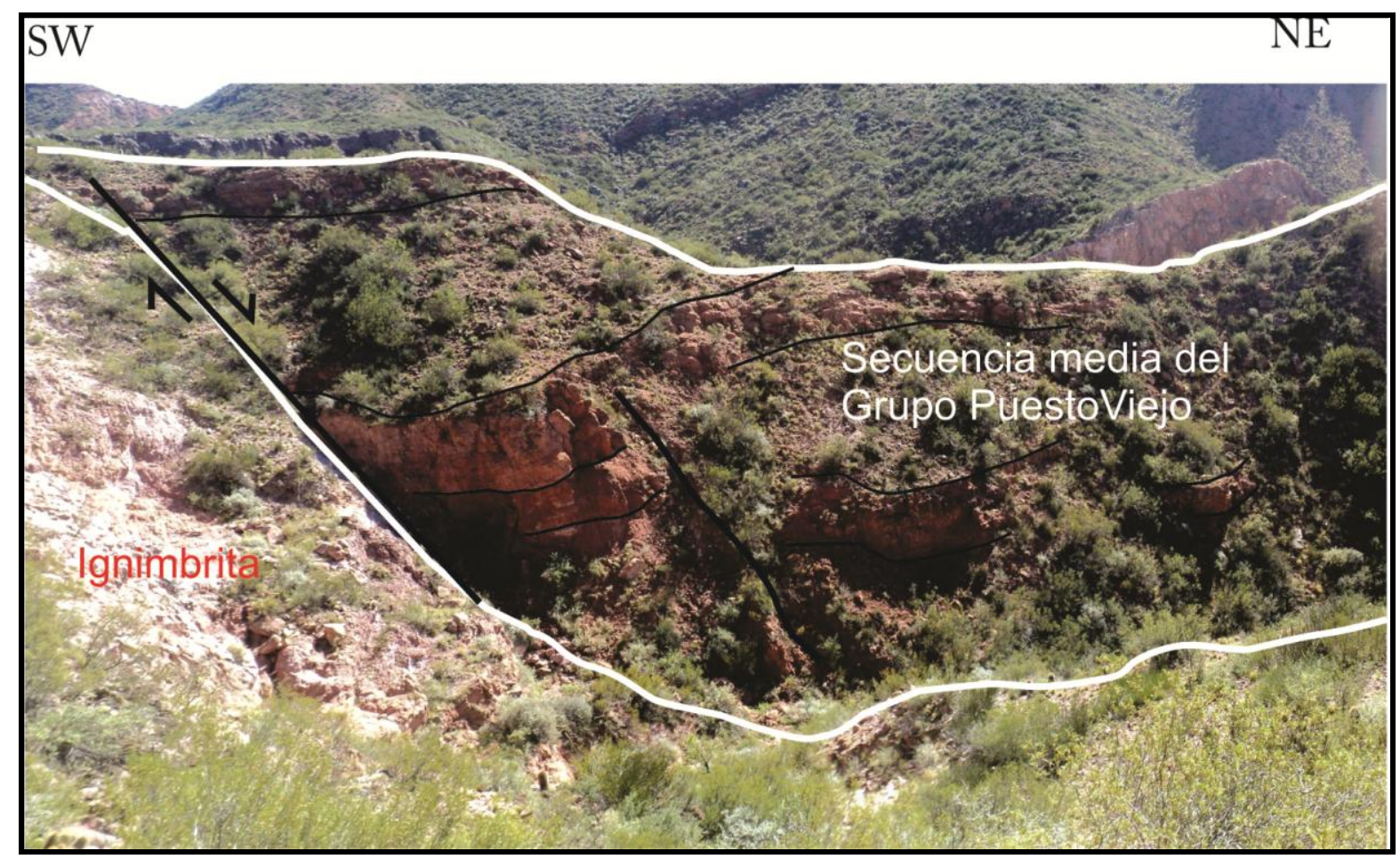

Figura 3.22. La reactivación de fallas internas afecta a los niveles de ignimbritas que dan lugar a la depositación de los niveles medios. Localidad: Quebrada Agua de los Burros (ubicación en Figura 3.12).

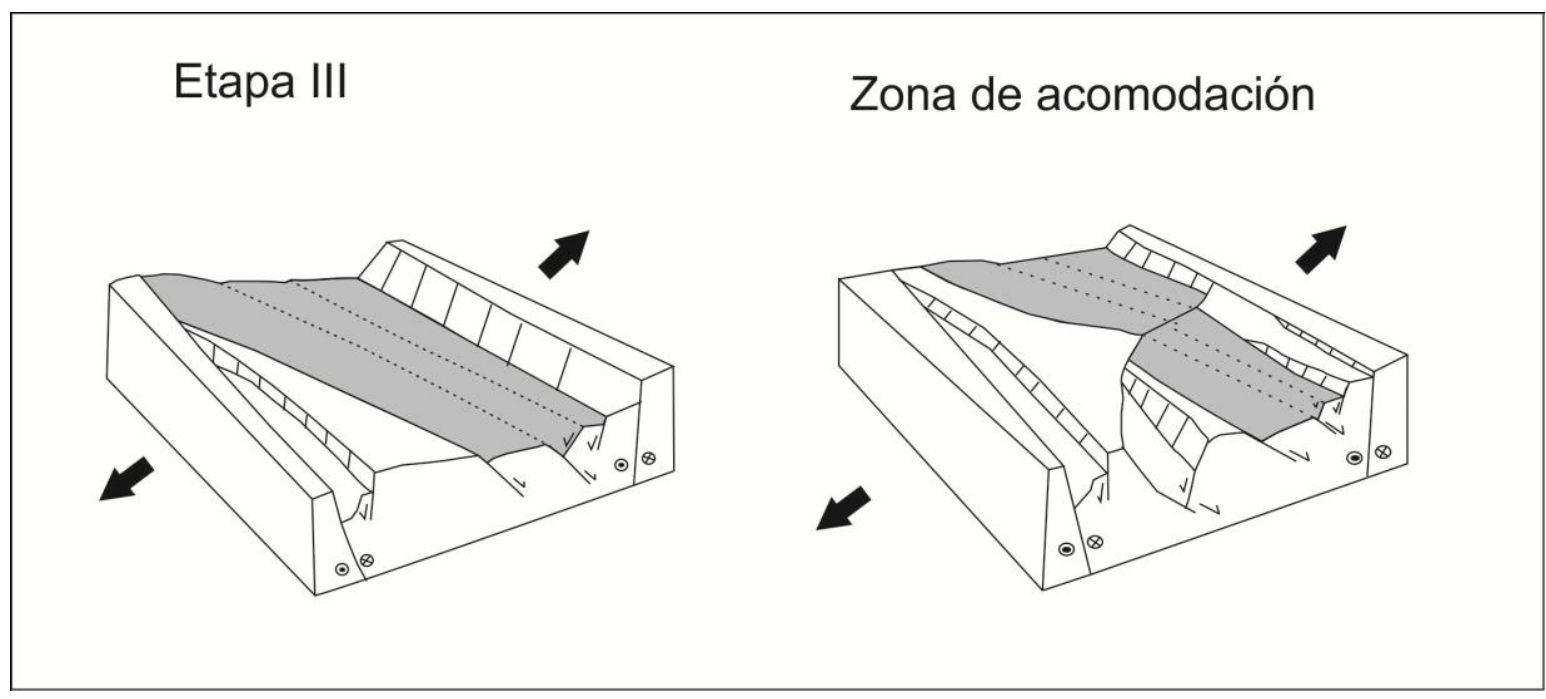

Figura 3.23. Bloque diagrama muestra la configuración de la cuenca para la Etapa III. 


\subsubsection{Etapa IV: Último evento de reactivación de las estructuras internas}

Esta etapa constituye el último evento de reactivación de las fallas internas más longevas que modificó la configuración del sector norte de la cuenca. La reactivación y propagación selectiva de algunas de las fallas internas ONOESE con alto grado de inclinación produjeron nuevo espacio acomodación fuertemente asimétrico en la forma de hemigrábenes localizados hacia el borde oriental del depocentro, donde se depositaron los niveles triásicos más modernos. Esta actividad se identifica en el campo por la disposición de las coladas basálticas en los niveles triásicos superiores del Grupo Puesto Viejo, como se observa en las Figuras 3.4 y 3.24. Los espacios de acumulación generados durante esta etapa fueron poco profundos y estrechos, constituyendo la última forma estructural de la historia tectónica del depocentro.

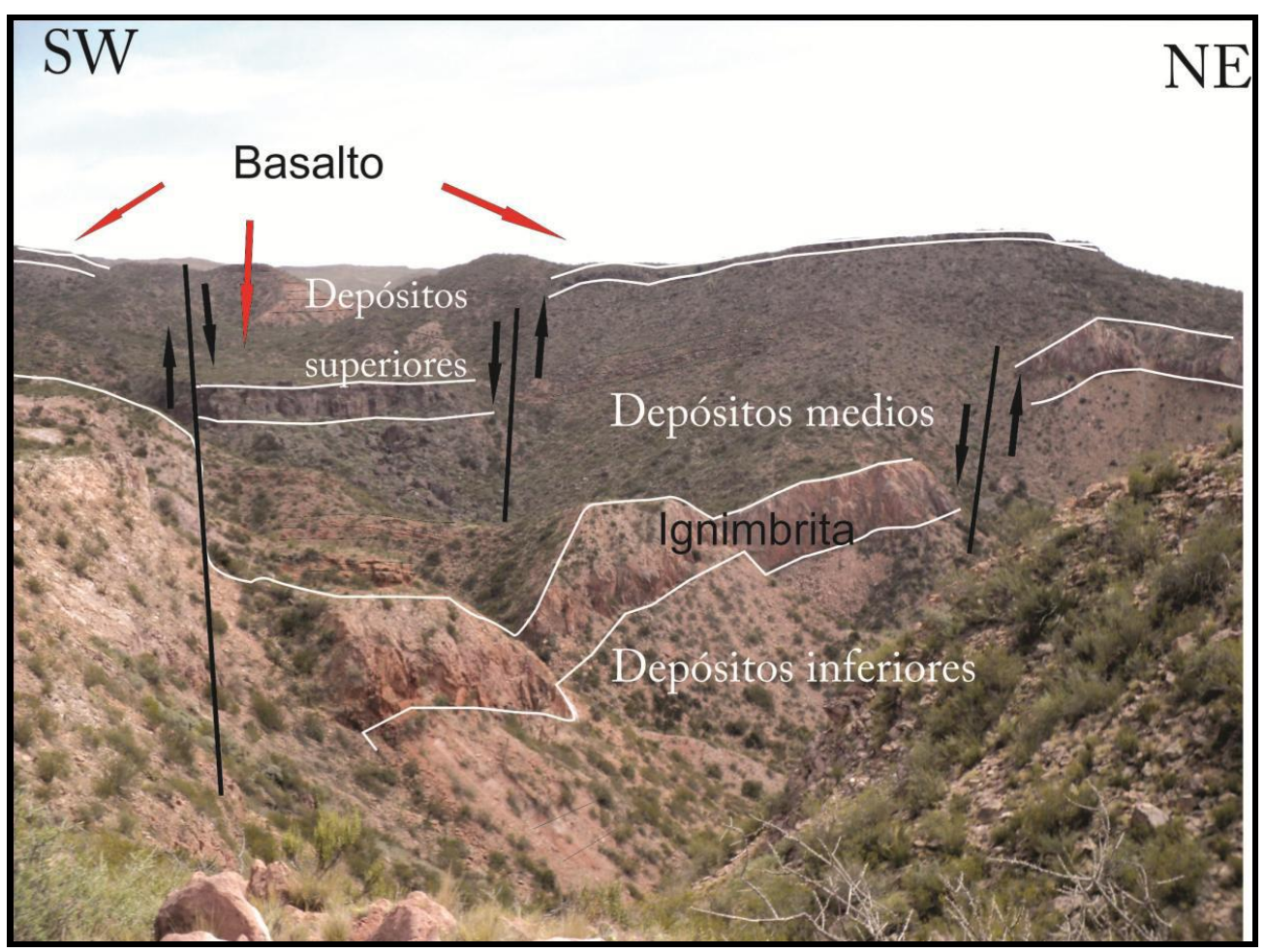

Figura 3.24. La reactivación de fallas internas afecta a los niveles de coladas basálticas que dan lugar a la depositación de los niveles superiores. Unión de las quebradas Agua de los Burros y Quebrada de los Fósiles (ubicación en Figura 3.12). 


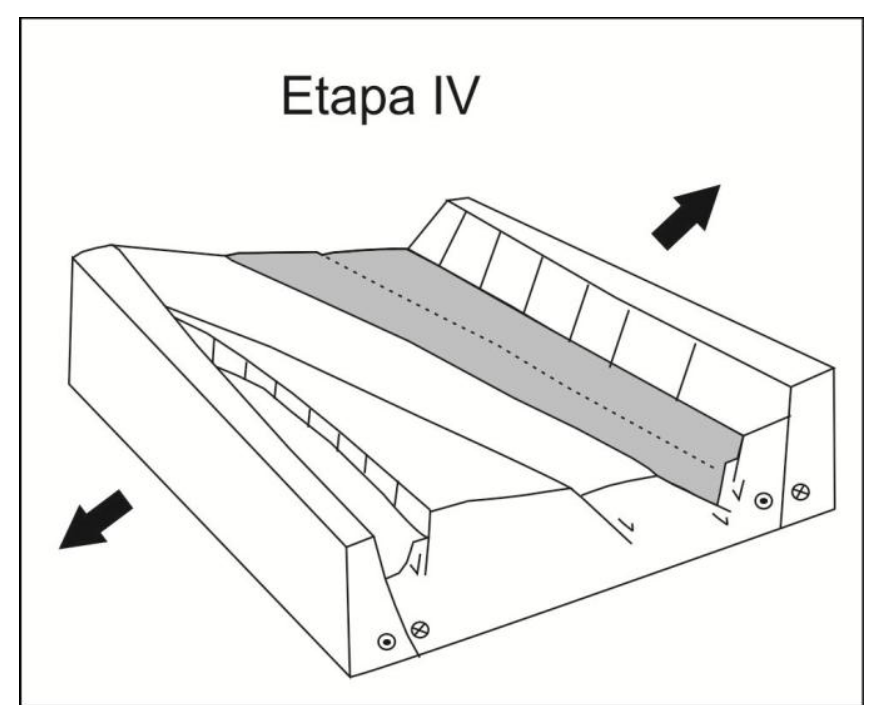

Figura 3.25. Bloque diagrama muestra la configuración de la cuenca para la Etapa IV. 
CAPÍTULO 4

ANÁLISIS LITOLÓGICO 


\section{Capítulo 4. Anális is Litológico}

El Grupo Puesto Viejo está constituido por rocas sedimentarias, piroclásticas y volcánicas depositadas en un ambiente continental. La sucesión, referida como tal por Stipanicic et al. (2007) incluye a la Formación Quebrada de los Fósiles para los depósitos basales principalmente finos de planicie de inundación de color gris verdoso y a la Formación Río Seco de la Quebrada para los depósitos superiores más gruesos, de canal, color rojizo. Su historia es registrada por espesores que no superan los 450 metros, de depósitos dominados por sistemas fluviales, acompañados por momentos con actividad volcánica (Spalletti, 1994).

La estratigrafía del Grupo Puesto Viejo presenta homogeneidad a lo largo de toda el área de trabajo, habiéndose depositado dentro de un depocentro relativamente estrecho documentado estructuralmente en el Capítulo 3 (Estructuras Triásicas). El área estudiada registra los máximos espesores hacia el sector centro-este del depocentro. Allí, en el borde oriental se puede observar la estratigrafía más completa del Grupo Puesto Viejo con un espesor de $440 \mathrm{~m}$ (Figura 4.1). Los menores espesores registrados afloran localmente en el borde suroeste del depocentro, representados por $140 \mathrm{~m}$ de espesor (Formación Quebrada de los fósiles). 


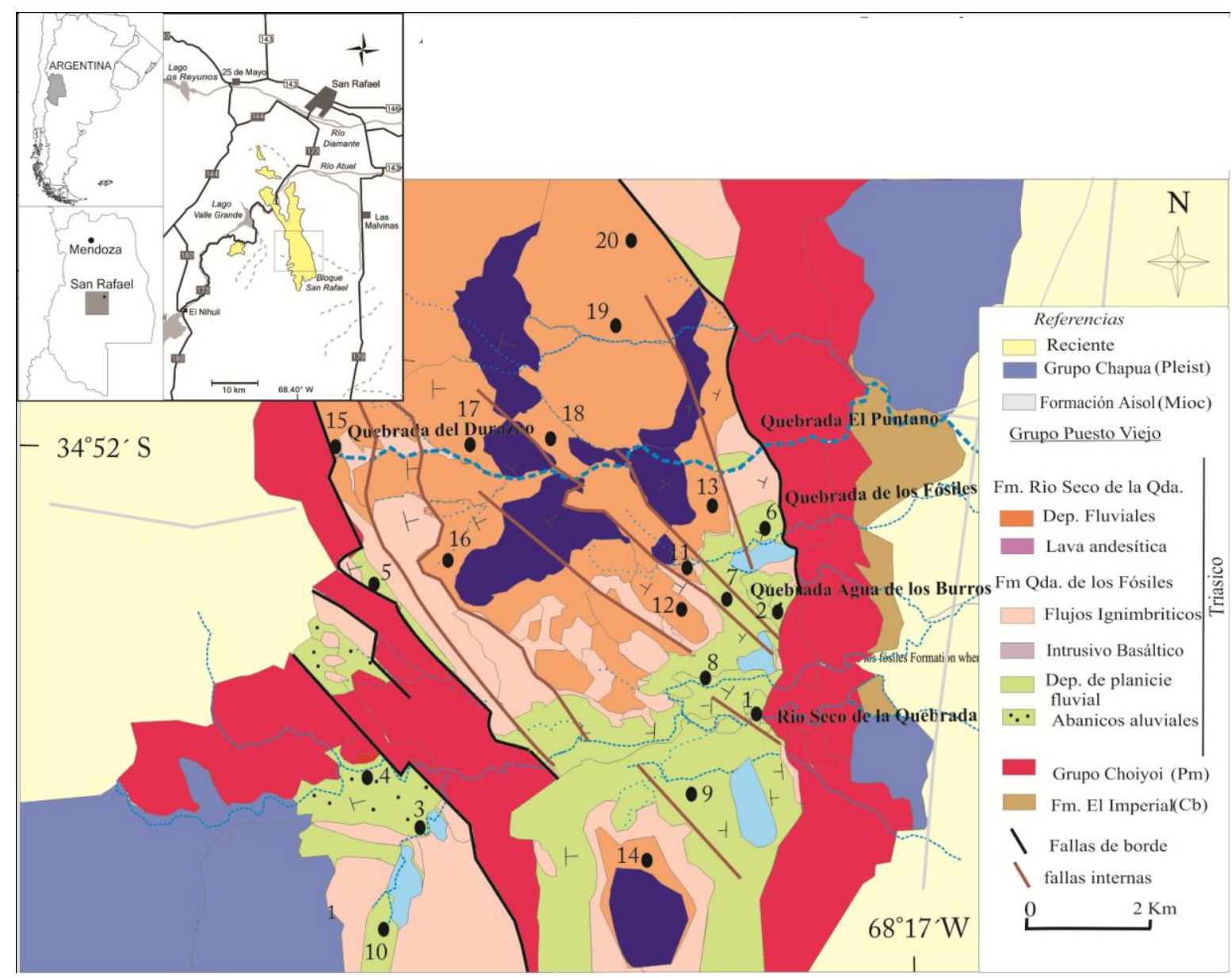

\begin{tabular}{|c|c|c|c|}
\hline 1- RSdIQ & 6- QdIF & 11- AdIB I & 16- El Durazno VI \\
\hline 2- Pequeña qda. & 7- Pequeña qda & 12- AdIB II & 17- El Durazno VII \\
\hline 3-dep. SO & 8- RSdIQ & 13- El Puntano III & 18-El Durazno 1 \\
\hline 4-oeste RSdIQ & 9- sur RSdIQ & 14-sur RSdIQ IV & 19- qda. Norte 2 \\
\hline 5-sur Puesto Viejo & 10- dep. SO & 15-El Durazno V & 20- qda. Norte 3 \\
\hline
\end{tabular}

Figura 4.1. Mapa geológico de la zona de estudio con la ubicación de los perfiles sedimentológicos. Abajo tabla de referencia para los perfiles sedimentológicos del Anexo 2.

\subsection{Análisis de litofacies del Grupo Puesto Viejo}

En esta sección se analizan las litofacies que constituyen los depósitos del Grupo Puesto Viejo con la finalidad de determinar los ambientes sedimentarios registrados durante su evolución, sus variaciones espaciales y temporales y los procesos que les dieron origen. Esta caracterización fue realizada a partir del 
levantamiento de columnas estratigráficas y perfiles sedimentológicos (véase Anexo 2) y a través del análisis de textura, estructura y composición de las diferentes litologías registradas en el Grupo Puesto Viejo. Los resultados obtenidos apuntan a determinar la estratigrafía interna del área de acumulación y la interrelación entre las unidades sedimentarias y volcánicas para establecer la historia del relleno de la Cuenca de San Rafael durante su evolución tectosedimentaria.

Con la finalidad del análisis detallado del relleno triásico, fueron levantados 20 perfiles sedimentológicos de detalle (véase Anexo 2) a escala 1:100 en diferentes localidades de la zona de estudio (Figura 4.1). La selección del lugar donde se levantó cada perfil estuvo en función de la ubicación y calidad de los afloramientos. Se priorizaron las secciones tipo (véase Capitulo 1) y otras donde se identificó un registro completo y continuo de cada unidad.

A continuación (siguiendo a Miall, 1992 y Bridge, 1993, con modificaciones) se describen las 30 litofacies identificadas a partir del análisis sedimentológico. 
Tabla 1. Litofacies establecidas para el Grupo Puesto Viejo.

\begin{tabular}{|c|c|c|c|c|c|}
\hline Roca & Litofacies & Código & Es tructura & Dimensiones & Procesos \\
\hline \multirow{7}{*}{ EPICLASTICAS } & \multirow{3}{*}{$\begin{array}{l}\text { Conglo merados } \\
\text { matriz-sostén }\end{array}$} & Gt & $\begin{array}{l}\text { Estratificación entrecruzada en } \\
\text { artesa. Internamente cada set } \\
\text { presenta gradación normal (Gmg) }\end{array}$ & $\begin{array}{l}\text { Cuerpos lenticularres con base neta y erosiva. } \\
\text { Espesores de } 1,5 \text { maislados hasta } 8 \mathrm{~m} \\
\text { agrupados. Conformado por sets de } 1 \mathrm{~m} \text { de } \\
\text { espesor. }\end{array}$ & $\begin{array}{l}\text { Régimen de flujo intemedio a bajo. Barras gravosas 3D } \\
\text { Colmatación de canales menores }\end{array}$ \\
\hline & & Gmg & Estratificación gradada normal & $\begin{array}{l}\text { Geometría del cuerpo lenticular a tabular, } \\
\text { con base erosiva. Espesor de cada set aislado } 1 \\
\mathrm{~m} \text {, hasta } 8 \mathrm{~m} \text { agrupados. }\end{array}$ & Flujo de detritos pseudoplástico (baja resistencia, viscoso). \\
\hline & & $G p$ & Estratificación entrecruzada plana & $\begin{array}{l}\text { Cuerpo lenticular con base erosiva. Espesores } \\
\text { de } 3 \mathrm{~m} \text { a } 4 \mathrm{~m} \text {. Formados por sets } \text { de } 0,60 \mathrm{~m} \text { a } \\
1,7 \mathrm{~m} .\end{array}$ & $\begin{array}{l}\text { Bajo régimen de flujo, barras 2D marginales o de frente de } \\
\text { longitudinales }\end{array}$ \\
\hline & \multirow[b]{2}{*}{$\begin{array}{l}\text { Conglo merados } \\
\text { clasto-sostén }\end{array}$} & Gh & Estratificación horizontal & $\begin{array}{l}\text { Cuerpo tabular con base erosiva a plana. } \\
\text { Espesores de } 0,4 \mathrm{~m}-0,6 \mathrm{~m} \text {. }\end{array}$ & $\begin{array}{l}\text { Corriente ácuea de régimen intermedio a alto. Depósitos de } \\
\text { sieve. }\end{array}$ \\
\hline & & Gcm & Masivo & $\begin{array}{l}\text { Cuerpo lenticular de } 4 \mathrm{~m} \text { de ancho y base } \\
\text { erosiva. Espesores de } 0,2 \mathrm{~m} \text { a } 1 \mathrm{~m} \text {. }\end{array}$ & $\begin{array}{l}\text { Corrientes concentradas, baja fluidez, alto rég imen. } \\
\text { Flujo de detritos pseudoplástico (carga de fondo inercial, } \\
\text { flujo turbulento) }\end{array}$ \\
\hline & \multirow{2}{*}{ Sabulitas } & $S G t$ & $\begin{array}{l}\text { Estratificación entrecruzada en } \\
\text { artesa }\end{array}$ & $\begin{array}{l}\text { Cuerpo lenticul ar con techo neto a ondulado y } \\
\text { base erosiva cóncava. Espesor de } 0,2 \mathrm{~m}\end{array}$ & Barras areno-gravosas de bajo régimen de flujo \\
\hline & & $S G p$ & Estratificación entrecruzada planar & $\begin{array}{l}\text { Cuerpo lenticular con base erosiva. Espesores } \\
\text { de } 0,6 \mathrm{~m} \text { a } 1 \mathrm{~m} \text {. }\end{array}$ & $\begin{array}{l}\text { Estructuras sedimentarias transversas o lenguiformes } \\
\text { (dunas 2D). Traccionales }\end{array}$ \\
\hline
\end{tabular}


Continuación Tabla 1

\begin{tabular}{|c|c|c|c|c|c|}
\hline Roca & Litofacies & Código & Es tructura & Dimensiones & Procesos \\
\hline \multirow{8}{*}{ EPICLASTICAS } & \multirow{5}{*}{ Areniscas } & $S m$ & Masiva & $\begin{array}{l}\text { Forma del cuerpo tabular. Techo y base neta. } \\
\text { Espesores de } 0,1 \text { hasta } 9 \mathrm{~m} \text { (variaciones: } \\
0,25 \mathrm{~m}-1 \mathrm{~m}-4 \mathrm{~m})\end{array}$ & $\begin{array}{l}\text { Depósitos de desbordamiento. Modificación por acción } \\
\text { biogénica. }\end{array}$ \\
\hline & & $S h$ & Laminada & $\begin{array}{l}\text { Forma de cuerpo tabular- lenticul ar con } \\
\text { techo plano. Espesores de } \\
0,3 \mathrm{~m} \mathrm{a} 1 \mathrm{~m} .\end{array}$ & Capas planas de alto régimen de flujo \\
\hline & & $S l$ & $\begin{array}{l}\text { Estratificación entrecruzada planar } \\
\text { de bajo angulo }\end{array}$ & $\begin{array}{l}\text { Forma del cuerpo tabular. Espesores de } 0,6 \mathrm{~m} \\
\text { a } 1 \mathrm{~m} \text {. }\end{array}$ & $\begin{array}{l}\text { Tope de barras (point bar) o depósitos de canales de } \\
\text { crevasse en plancie de inundación. }\end{array}$ \\
\hline & & $S p$ & Estratificación entrecruzada planar & $\begin{array}{l}\text { Forma tabular a lenticular con base erosiva } \\
\text { Set con base conglomerádica de } 2 \mathrm{~cm} \\
\text { Espesores de } 1 \mathrm{~m} \text { hasta } 6 \text { magrupados. }\end{array}$ & Barras transversales o lenguiformes (dunas 2D) \\
\hline & & St & $\begin{array}{l}\text { Estratificación entrecruzada en } \\
\text { artesa }\end{array}$ & $\begin{array}{l}\text { Base erosiva. Espesores de } 1,2 \mathrm{~m} \text { co mo set } \\
\text { aislado y hasta } 7 \mathrm{~m} \text { agrupados }\end{array}$ & $\begin{array}{l}\text { Barras arenosas y areno-gravos as de bajo régimen de flujo. } \\
\text { (Dunas de cresta sinuosa y lenguiforme 3D) }\end{array}$ \\
\hline & \multirow{3}{*}{ Areniscas tobáceas } & $S T m$ & Masiva & Forma del cuerpo tabular. Espesor $1,3 \mathrm{~m}$. & $\begin{array}{l}\text { Decantación subaérea (loessico) Depósitos poco } \\
\text { canalizado. } \\
\text { Con modificación por acción biogénica. }\end{array}$ \\
\hline & & $S T h$ & Laminada & $\begin{array}{l}\text { Forma del cuerpo tabular con base y techo } \\
\text { neto a irregular. Espesor } 0,8 \mathrm{~m}\end{array}$ & $\begin{array}{l}\text { Decantación subácua y subaérea (loessico) retrabajada por } \\
\text { corrientes ácuas de alto régimen de flu jo. }\end{array}$ \\
\hline & & $S T p$ & Estratificación entrecruzada planar & $\begin{array}{l}\text { Forma del cuerpo tabular con base neta a } \\
\text { erosiva y techo neto. Espesor } 2 \mathrm{~m}\end{array}$ & $\begin{array}{l}\text { Depósitos de canales de crevasse en plancie de } \\
\text { inundación. }\end{array}$ \\
\hline
\end{tabular}




\section{Continuación Tabla 1}

\begin{tabular}{|c|c|c|c|c|c|}
\hline Roca & Litofacies & Código & Es tructura & Dimensiones & Proces os \\
\hline \multirow{8}{*}{ EPICALSTICAS } & \multirow{4}{*}{ Pelitas } & $F$ & \multirow[t]{2}{*}{ Fangolita y arcillita laminada } & \multirow[t]{2}{*}{ Espesores que varían de $0,1 \mathrm{~m}$ hasta $4,5 \mathrm{~m}$} & \multirow{2}{*}{$\begin{array}{l}\text { Procesos de decantación a partir de suspensiones ácueas en } \\
\text { Llanura de inundación o canales abandonados }\end{array}$} \\
\hline & & Fsl & & & \\
\hline & & Fsm & Limolitas masivas & Espesores de $0,1 \mathrm{~m}$ a $0,9 \mathrm{~m}$ & $\begin{array}{l}\text { Modificación por acción biogénica. } \\
\text { Pantano o canal abandonado. }\end{array}$ \\
\hline & & $\operatorname{Fr}(P)$ & $\begin{array}{l}\text { Limolitas bioturbadas y/o con } \\
\text { marcas de raices. Paleosuelos }\end{array}$ & $\begin{array}{l}\text { Forma del cuerpo tabular. Espesores de } 0,5 \mathrm{~m}- \\
0,6 \mathrm{~m}\end{array}$ & $\begin{array}{l}\text { Acción biogénica. } \\
\text { Capa de reíces, suelo incipiente. }\end{array}$ \\
\hline & \multirow{4}{*}{ Pelitas tobáceas } & \multirow{2}{*}{ FTrf } & \multirow{2}{*}{$\begin{array}{l}\text { Fangolitas ricas en materia } \\
\text { orgánica con fisilidad }\end{array}$} & Forma de 1 cuerpo tabular. & Procesos de decantación a partir de suspensiones ácueas. \\
\hline & & & & Espesores de $0,2 \mathrm{ma} 1,6 \mathrm{~m}$. & Capa de ra íces, suelo incipiente. \\
\hline & & FTm & Limolitas y fangolitas masivas & $\begin{array}{l}\text { Forma del cuerpo tabular. Espesores de } 0,7 \mathrm{~m} \\
\text { a } 4 \mathrm{~m}\end{array}$ & $\begin{array}{l}\text { Modificación por acción biogénica } \\
\text { Llanura de inundación o canales }\end{array}$ \\
\hline & & FTl. & $\begin{array}{l}\text { Limotita s y fangolitas laminada con } \\
\text { ondulitas }\end{array}$ & $\begin{array}{l}\text { Banco tabular con contactos netos. Espesores } \\
\text { de } 0,7 \mathrm{~m} \text { a } 1,4 \mathrm{~m}\end{array}$ & $\begin{array}{l}\text { Procesos de decantación a partir de suspensiones ácueas en } \\
\text { llanura de inundación. }\end{array}$ \\
\hline CARBONATICAS & $\begin{array}{l}\text { Calizas/fango } \\
\text { calcáreos }\end{array}$ & $\mathrm{Cl}$ & Calizas laminada (estro matolitos) & $\begin{array}{l}\text { Cuerpo tabular, espes ores } 0,2 \\
\mathrm{~m} \text { a } 0,5 \mathrm{~m}\end{array}$ & Precipitación subácua. \\
\hline \multirow{3}{*}{ PIROCALSTICAS } & \multirow{3}{*}{ Piroclasticas } & $T m$ & Tobas masiva & $\begin{array}{l}\text { Cuerpos tabularres. Delgadas capas de } 0,1 \mathrm{~m} \mathrm{a} \\
0,2 \mathrm{~m} .\end{array}$ & $\begin{array}{l}\text { Depósitos de caída subaérea a partir de plu mas } \\
\text { piroclásticas. }\end{array}$ \\
\hline & & $m L s$ & $\begin{array}{l}\text { Lapillita masiva con alto grado de } \\
\text { soldamiento. }\end{array}$ & \multirow{2}{*}{$\begin{array}{l}\text { Mantos tabulares con espesores individuales } \\
\text { de } 8 \mathrm{~m} \text {. Superpuestos alcanzan espesores de } \\
35 \mathrm{~m}\end{array}$} & \multirow{2}{*}{ Depósitos de flujos piroclásticos } \\
\hline & & $M l$ & Lapillita masiva poco soldada & & \\
\hline \multirow{3}{*}{ VOLCANICAS } & \multirow{3}{*}{ Volcanitas } & $P p$ & Peperitas & Espesores variables que no superan $1 \mathrm{~m}$. & $\begin{array}{l}\text { Producto del contacto entre un cuerpo ígneo en sedimentos } \\
\text { inconsolidados y húmedos. }\end{array}$ \\
\hline & & $B i$ & Inrusivosbasalticos & $\begin{array}{l}\text { Cuerpos tabulares de } 9,2 \mathrm{~m} \text { de espesor. } \\
\text { Formas dómicas de ca. } 40 \mathrm{~m} \text { de espesor } \\
\text { med ido. }\end{array}$ & Cuerpos hipabisales (criptodomos y filones capa) \\
\hline & & $L A B$ & Lavas andesiticas/basalticas & Mantos tabulares con espesores de 5 a $15 \mathrm{~m}$. & Flujos de lava \\
\hline
\end{tabular}




\subsection{A. Litofacies de rocas sedimentarias}

La información obtenida a partir del análisis de los perfiles de detalle (véase Anexo 2) y del análisis petrográfico, ha sido sintetizada en un sistema de litofacies simple que apunta a reconocer y definir los principales procesos de formación de las rocas sedimentarias. De acuerdo a ello, se han dividido las litofacies según su granulometría, estructura y composición, y se las caracteriza teniendo en cuenta otros parámetros tales como la geometría de los cuerpos, textura y selección del depósito y sus espesores típicos.

\subsection{A.1. Litofacies de rocas epiclás ticas}

\section{Litofacies Conglomerádicas (G)}

Esta facies se encuentra principalmente en posición basal e intercala a distintos niveles del Grupo Puesto Viejo, con una composición variada, dependiendo de la posición en la que se encuentra.

Conglomerados clasto sostén con estratificación horizontal (Gh).

Constituyen cuerpos conglomerádicos de forma tabular a lenticular con base erosiva o neta. Conforman sets de 0,5 $\mathrm{m}$ de espesor con estructura horizontal gradada normal (Figura 4.3). Los clastos son subredondeados a subangulosos y de tamaños variados, $0,1 \mathrm{~cm}$ a $3 \mathrm{~cm}$ (promedio: $0,5 \mathrm{~cm}$ ). La composición de los clastos mayores está integrada por líticos pelíticos rojos y verdes y volcánicos (riolitas); algunos menores son de cuarzo. Poseen cemento silíceo. A escala microscópica se confirma en la Figura 4.2 una composición polimíctica con abundantes líticos volcánicos (Lv), pelíticos (Lp), cristales de cuarzo (Qtz).

Interpretación: debido a su estructura sedimentaria de tipo horizontal, se interpreta como producto de alto régimen de flujo (flujo supercrítico). Se encuentran siempre asociados depósitos de flujos de detritos. Se interpretan 
como depósitos de sieve fomados en condiciones de régimen de flujo intemedio a alto (Miall, 1996).

Conglomerados masivos clasto soportados ( $\mathrm{Gcm})$.

Cuerpos de forma tabular de 0,6 a $1 \mathrm{~m}$ de espesor, $4 \mathrm{~m}$ de ancho y base erosiva con mala selección. Los clastos son subangulosos a redondeados con un tamaño de 0,5 a $3 \mathrm{~cm}$ y alcanzan hasta $10 \mathrm{~cm}$, ocasionalmente (Figura 4.3). La composición de los clastos está integrada por $80 \%$ de pelitas rojas y $20 \%$ de líticos volcánicos de riolita y, subordinadamente, ignimbritas y areniscas verdes. El cemento es silíceo. Pasa hacia arriba, a arenisca conglomerádica, moderada a mal seleccionada, con estratificación planar y niveles conglomerádicos finos intercalados.

Interpretación: Debido a que se presentan como cuerpo tabulares, no canalizados, generalmente aparecen aislados y son de pequeñas dimensiones constituidos por clastos gruesos mal seleccionados, podrían ser producto de flujos densos de detritos, bajo un alto régimen de flujo (Smith y Lowe 1991; Miall, 1996).

Conglomerados con estratificación entrecruzada en artesa (Gt),

Constituyen cuerpos de geometría lenticular y base erosiva que superpuestos alcanzan $8 \mathrm{~m}$ de espesor de conglomerado mal seleccionado, con tamaño de clastos desde 1 hasta $10 \mathrm{~cm}$. Internamente, se identifican set de hasta $1 \mathrm{~m}$ de espesor, con gradación normal (Figura 4.3).

Los clastos de la facies Gt en los niveles basales del Grupo Puesto Viejo se encuentran redondeados, y están compuestos por líticos volcánicos de riolita y líticos piroclásticos procedentes de la secuencia pérmica, con cemento calcáreo. En cambio, los conglomerados con artesas de los niveles superiores contienen clastos subangulosos a subredondedados compuestos por líticos de riolita, basalto, ignimbritas triásicas, areniscas verdes, pelitas y cuarzo, cementados por sílice. La matriz es de arena gruesa a media con clastos subredondeados y moderada selección, de composición tobácea. 
A escala microscópica se observa en la Figura 4.2: a) Niveles superiores con matriz de arena de composición tobácea. (Qtz: cuarzo, T: material vítreo). b) Niveles basales con abundantes líticos volcánicos (Lv), subordinados cuarzo (Qtz) y feldespatos $(\mathrm{FI})$ y cemento calcáreo $(\mathrm{C})$.

Interpretación: la forma lenticular de los cuerpos, con base erosiva y techo plano, constituido a partir de la migración de megaóndulas "3D" permite interpretar a esta facies como depósitos traccionales de canal bajo un régimen de flujo intermedio (Leeder, 1999, Bridge, 2003).

Conglomerados con estratificación entrecruzada planar de bajo ángulo, matriz sostenida (Gp).

Constituyen cuerpos lenticulares con base erosiva de variadas dimensiones, conformados por sets internos de hasta $1 \mathrm{~m}$ de espesor con arreglo granodecreciente y estratocreciente (Figura 4.3).

Los conglomerados son mal seleccionados y están compuestos por clastos de $1 \mathrm{~cm}$ a $3 \mathrm{~cm}$ en promedio y alcanzan tamaños máximos hasta $10 \mathrm{~cm}$. Los clastos son redondeados a subangulosos, principalmente de líticos volcánicos (riolitas) y sedimentarios (pelitas). En los niveles superiores del Grupo Puesto Viejo, la facies Gp incorpora líticos de basalto, ignimbrita y areniscas tobáceas verde amarillentas, con formas angulosas. El cemento es calcáreo y en ocasiones silíceo. La matriz es arena fina a gruesa con moderada selección y compuesta de líticos volcánicos (riolíta) y cuarzo con formas redondeadas a subredondeadas.

A escala microscópica se observa en la Figura 4.2: a) Niveles inferiores compuesta por líticos volcánicos (Lv), sedimentarios (Ls) y abundantes cristales de cuarzo (Qtz) cementados por calcita (C). b) niveles superiores compuesta por líticos volcánicos (Lv) de ignimbritas (claros) y de basaltos (negros), y cristales de cuarzo (Qtz).

Interpretación: Se interpretan como producto de la migración de megaóndulas "2D" es decir de crestas rectas, las cuales se agrupan conformyo barras 
longitudinales formadas en condiciones de bajo régimen de flujo (Miall, 1996; Leeder, 1999; Bridge, 2003).

Conglomerados con estratificación gradada normal, matriz sostenida (Gmg).

En ocasiones se presenta en cuerpos de geometría lenticular a tabular, con base erosiva y estratificación gradada normal. Los conglomerados se encuentran mal seleccionados, con clastos cuyo tamaño medio es $5 \mathrm{~cm}$ pero varían de 1 a $10 \mathrm{~cm}$ de diámetro. Los clastos son redondeados a subredondeados, de líticos volcánicos de riolitas e ignimbritas. La matriz es de arena media a gruesa compuesta por clastos de cuarzo y líticos volcánicos, moderadamente seleccionados (Figura 4.3). Esta facies también se describe en la base del Grupo Puesto Viejo como bancos conglomerádicos de forma tabular, con espesores individuales de aproximadamente $2 \mathrm{~m}$ que en conjunto alcanzan los $14 \mathrm{~m}$. Está compuesto principalmente por clastos redondeados de riolita, ignimbrita, toba, areniscas verdes provenientes del basamento. Su tamaño varía entre 1 a $10 \mathrm{~cm}$, hasta tamaño de bloques. La matriz es de arena gruesa a sabulita de igual composición, en ocasiones areno-pelítica dominante cementada por sílice y/o calcita, lo que le otorga un aspecto gris blanquecino.

A escala microscópica se observa en la Figura 4.2: a) Matriz de conglomerados superiores compuesta por abundantes cristales de cuarzo (Qtz) y líticos volcánicos (Lv), con cemento calcáreo (C). b) Matriz de comglomerados basales con abundantes líticos volcánicos (Lv) y cristales menores de cuarzo (Qtz), cementados por sílice (S).

Interpretación: la forma principalmente tabular de estos cuerpos de variadas dimensiones, compuesta por clastos de distinta granulometría y mal seleccionados formados en condiciones de intermedia a alta energía de flujo, permite interpretar a estas litofacies como derivadas de flujos de detritos pseudoplásticos con baja resistencia, viscosos (Miall, 1996; Leeder, 1999; Bridge, 2003). 


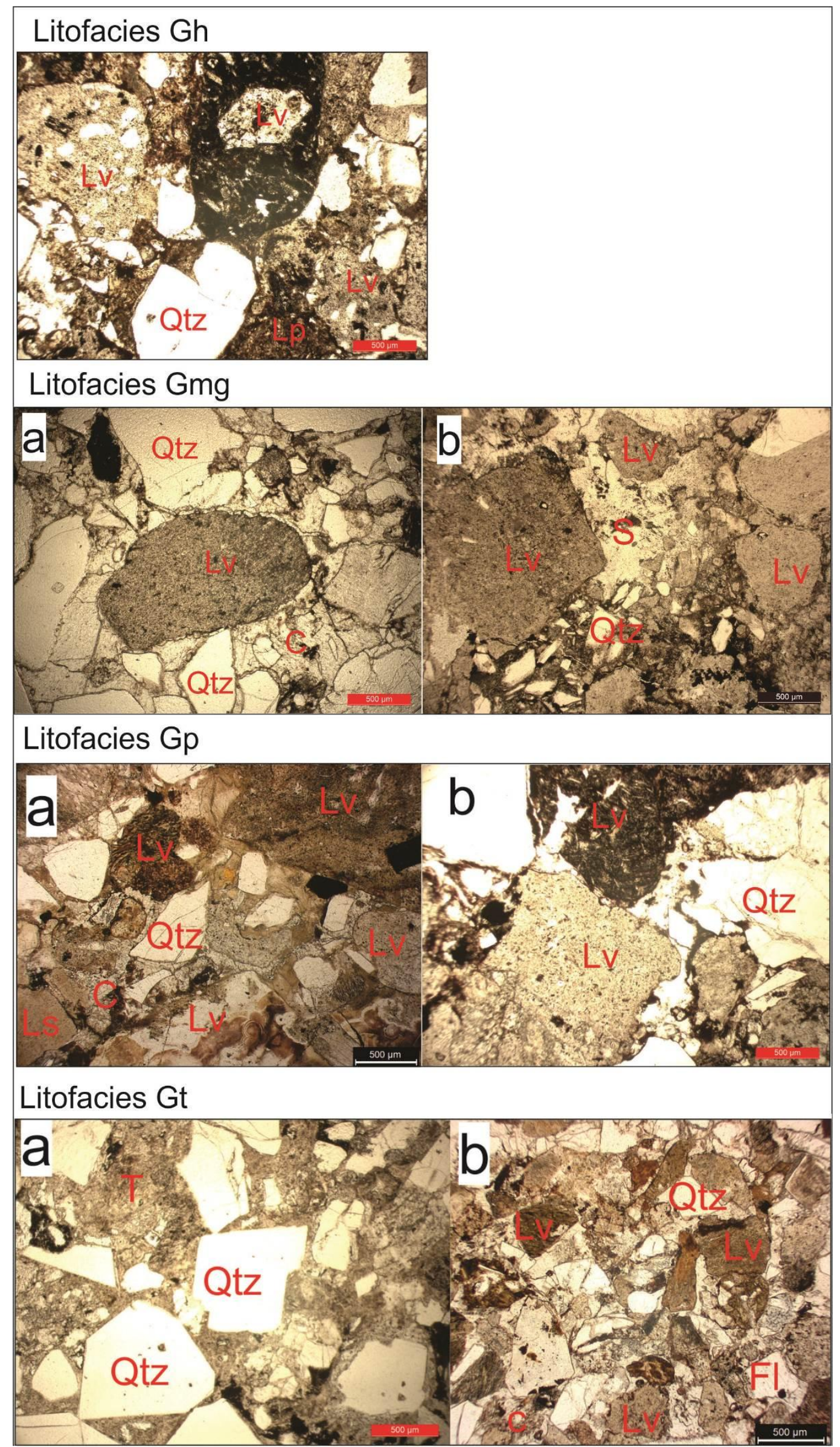


Figura 4.2. Petrografía de litofacies conglomerádicas.

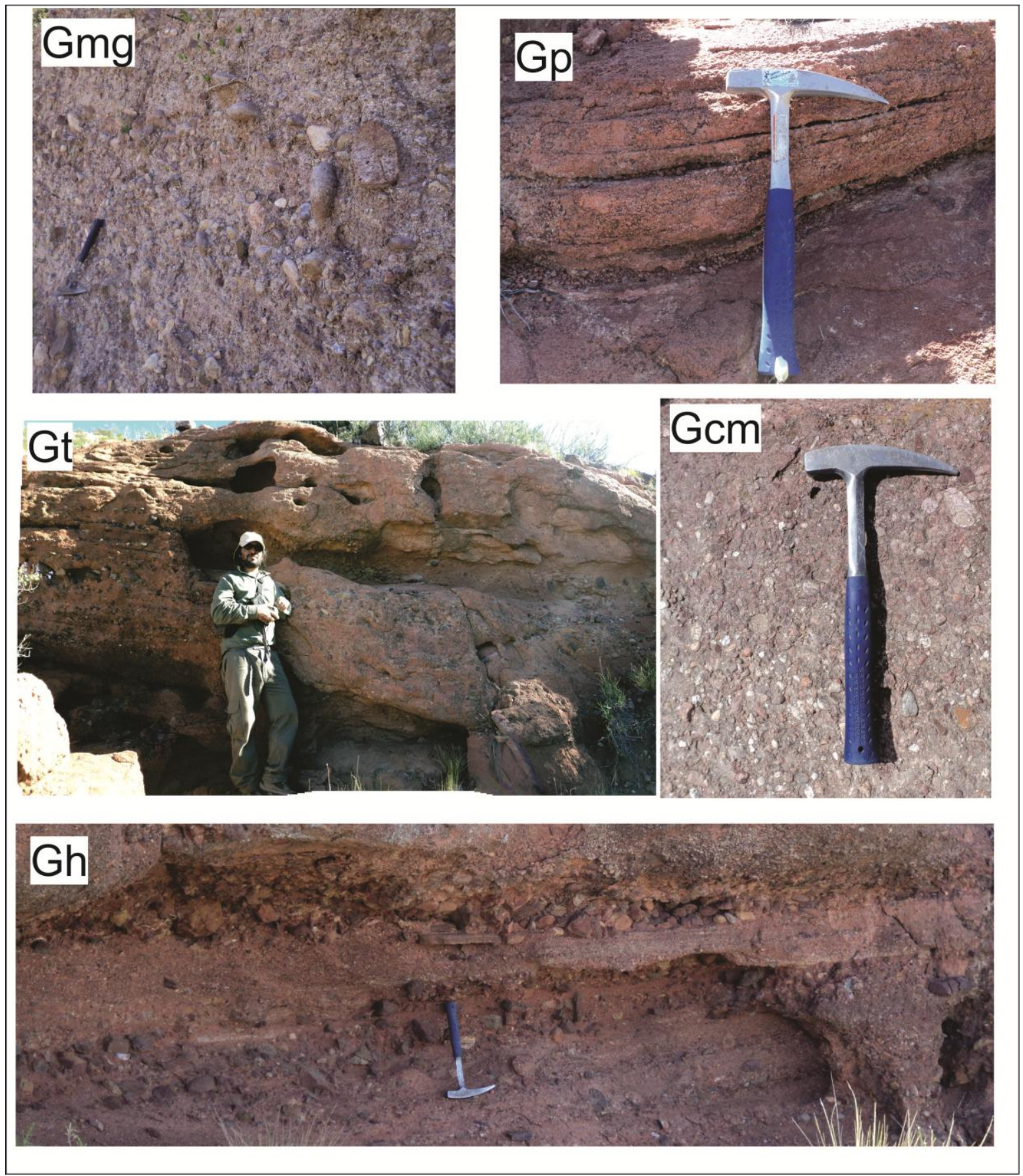

Figura 4.3. Litofacies conglomerádicas.

\section{Litofacies Sabulíticas (SG)}

La distribución de estas litofacies es local, y comúnmente se encuentran asociadas a litofacies conglomerádicas.

Sabulitas con estratificación entrecruzada en artesa (SGt) 
Conforman cuerpos de forma lenticular y techo neto a ondulado y base erosiva de poco espesor (0,2 metros). Internamente presentan estatificación entrecruzada en artesa formada por delgados sets con gradación normal y textura clasto sostén (Figura 4.5). Consiste en una sabulita con moderada a mala selección, con clastos subredondeados a redondeados de líticos volcánicos. El tamaño de los clastos alcanza los $3 \mathrm{~cm}$ de diámetro siendo su tamaño medio $1 \mathrm{~cm}$. Algunos niveles se encuentran cementados por calcita.

A la escala microscópica se observan en la Figura 4.4 líticos volcánicos (Lv) principalmente piroclásticos, abundantes cristales de cuarzo (Qtz) euhedrales hasta muy fragmentados y fuerte impregnación de óxidos de hierro (Ox).

Interpretación: la forma lenticular de los cuerpos de escasas dimensiones, con base erosiva y techo plano, constituido a partir de la migración de megaóndulas "3D" permite interpretar a esta litofacies como depósitos de canal, traccionales formados en condiciones de bajo régimen de flujo (Miall, 1996; Leeder, 1999; Bridge, 2003)

Sabulitas con estratificación entrecruzada planar (SGp)

Conforman cuerpos lenticulares con base erosiva de 0,6 a 1 metro de espesor. Internamente presentan estratificación entrecruzada planar formada por sets estratodecrecientes. Consiste en una arenisca conglomerádica con mala selección (Figura 4.5). El tamaño máximo de los clastos supera los $10 \mathrm{~cm}$ de diámetro, con formas subangulosas a redondeadas, de líticos de riolitas, ignimbritas, basalto y areniscas verdes provenientes del basamento pérmico y también cristales de cuarzo.

A escala microscópica se observan en la Figura 4.4 abundantes líticos volcánicos (Lv) de variada composición y escasos cristales de cuarzo (Qtz).

Interpretación: la forma lenticular de sus cuerpos con base erosiva e internamente conformada por capas planas producto de la migración de megaóndulas "2D" permite interpretar a esta litofacies como depósitos de 
barras areno-gravosas de bajo régimen de flujo (Miall, 1996; Leeder, 1999; Bridge, 2003).

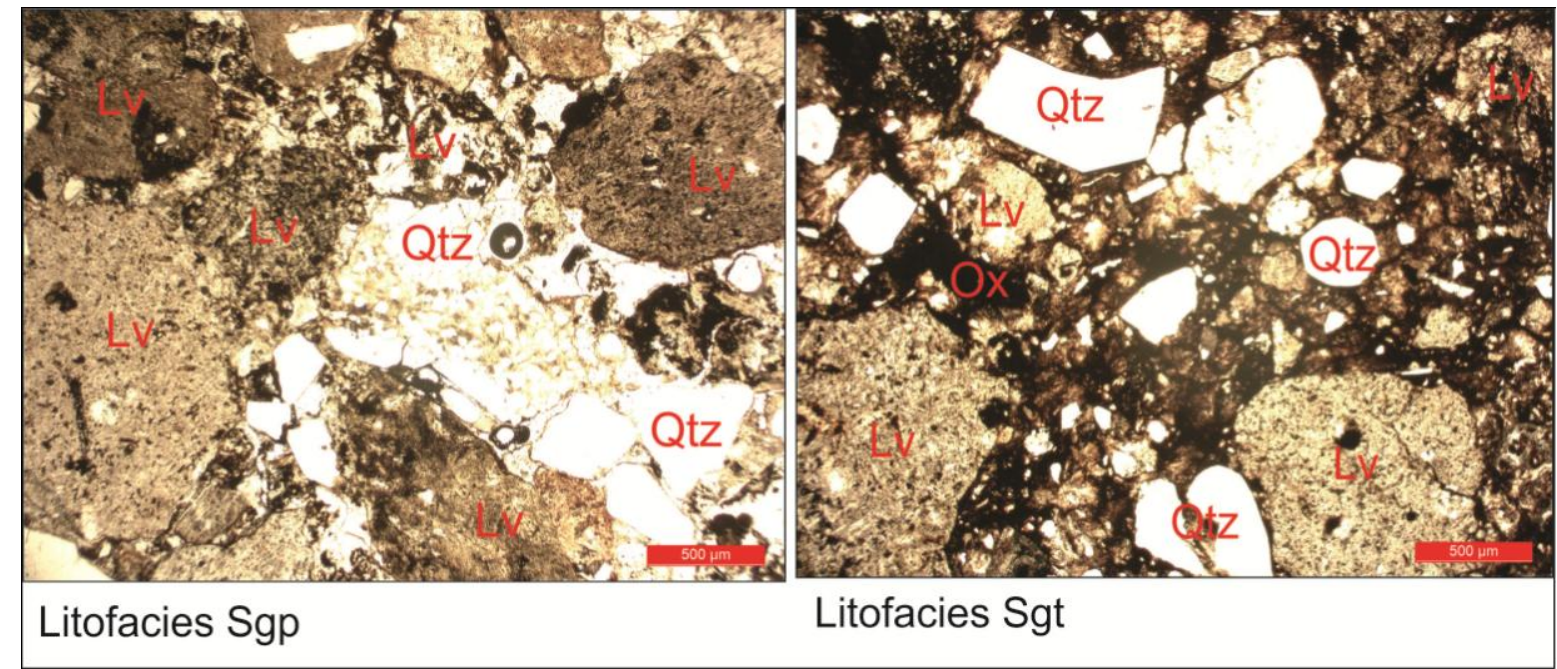

Figura 4.4. Petrografía de litofacies sabulíticas 


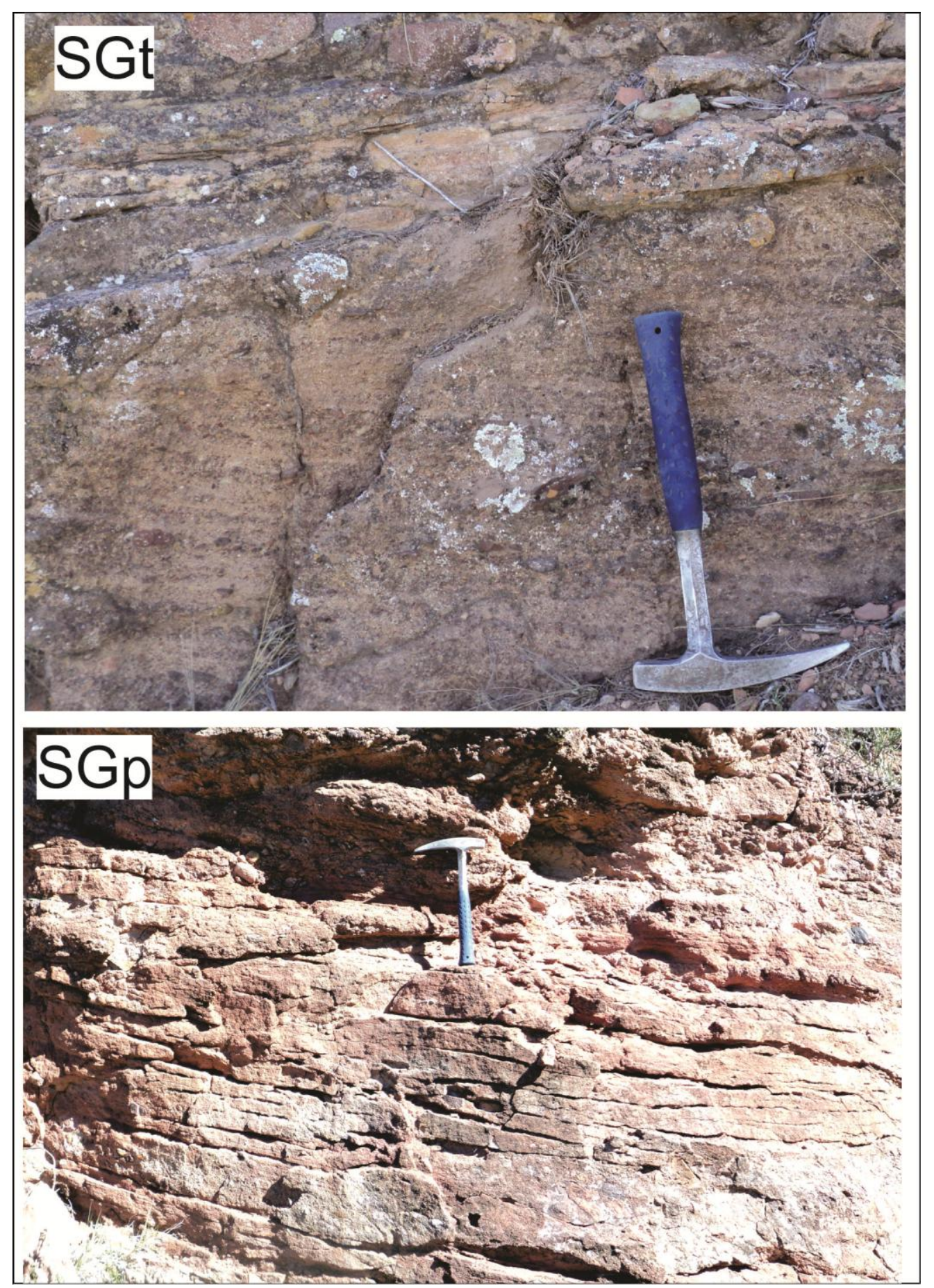

Figura 4.5. Liofacies sabulíticas.

\section{Litofacies de Areniscas (S)}

Estas litofacies son ampliamente distribuidas en la cuenca con variable granulometría y tonos rojizos a verdosos. 
Conforma cuerpos tabulares de techo y base neta y estructura interna masiva. Consiste en una arenisca fina a media, roja, con textura clasto sostén. Presenta buena selección de sus clastos, con formas redondeadas a subredondeadas, de líticos volcánicos de riolitas, cristales de cuarzo y de feldespato, además de líticos alterados indiferenciados. La consolidación de esta litofacies puede estar dada por la presencia de cemento calcáreo y/o silíceo, pero en ocasiones es friable. (Figura 4.7). En los niveles estratigráficos superiores esta litofacies se desarrolla como niveles de arenisca media a gruesa verdosa que intercala con niveles de arenisca fina arcillosa roja. Los clastos presentan moderada selección y están compuestos principalmente por líticos negros y verdes indiferenciados.

A escala microscópica se observa en la Figura 4.6: a) niveles inferiores compuestos por abundantes cristales de cuarzo (Qtz), cristales de feldespato (FI), líticos volcánicos (Lv) e indiferenciados (L), cementados por sílice (S). b) Niveles superiores más gruesos con abundantes cristales de cuarzo (Qtz) y líticos indiferenciados (L).

Interpretación: estos cuerpos arenosos de forma tabular con base y techo plano, que se presentan de manera aislada dentro de planicies fluviales pelíticos, se interpretaron como depósitos de crevasse splay producidos a partir de episodios de desbordamiento de canal. Su aspecto masivo se puede deber a modificación por acción biogénica (Miall, 1996; Leeder, 1999).

Areniscas laminadas (Sh)

Arenisca roja clasto sostén que constituye cuerpos de forma tabular a lenticular con techo plano. La estructura interna es laminada a entrecruzada planar, conformada por láminas espaciadas de arenisca con arreglo interno granodecreciente. (Figura 4.7). Consiste en una arenisca media a muy fina, bien seleccionada, los clastos son subredondeados a redondeados de cristales de cuarzo, líticos pelíticos y volcánicos. En ocasiones la consistencia de esta litofacies es friable o se encuentra consolidada por cemento silíceo. 
Interpretación: la presencia de cuerpos arenosos con estructura laminar asociados siempre al tope de barras son interpretados como capas planas generadas bajo un alto régimen de flujo (Miall, 1996; Leeder, 1999).

Areniscas con estratificación entrecruzada planar de bajo ángulo (SI)

Consisten en cuerpos tabulares con estratificación entrecruzada planar de bajo ángulo. Internamente cada set está formado por delgadas láminas continuas de areniscas finas a limolitas de color blanquecino producto del cemento calcáreo, que alternan con láminas de arenisca finas, de color rojo, cementadas por sílice (Figura 4.7). Los niveles blanquecinos presentan clastos muy bien seleccionados, de composición tobácea. En cambio, los niveles rojizos están compuestos por clastos subredondeados de líticos volcánicos.

Hacia los niveles estratigráficos superiores esta litofacies se caracteriza por presentar un mayor tamaño de grano conformyo una arenisca media a gruesa con clastos de hasta $5 \mathrm{~cm}$ de diámetro. Los clastos son subangulosos a subredondeados, de líticos de riolitas, ignimbritas, areniscas verdosas y cristales de cuarzo.

Interpretación: la presencia de cuerpos arenosos de forma tabular, internamente estratificados a partir de la migración de crestas planas se interpretan como depósitos de canales de crevasse en planicie de inundación producidos a partir de procesos de desbordamiento o descarga. En los niveles superiores podría corresponder a point bars (Miall, 1996; Leeder, 1999).

Areniscas con estratificación entrecruzada en artesa (St)

Las areniscas con estratificación entrecruzada en artesa se presentan en cuerpos aislados de forma lenticular con base erosiva de hasta 1,2 $\mathrm{m}$ de espesor. Internamente, los cuerpos están conformados por la agradación de sets formyo un bajo ángulo y con arreglo estrato y granodecreciente. Consisten en areniscas clasto sostén de variada granulometría. Se pueden diferenciar niveles con tamaño de arena muy fina a fina; fina a media y gruesa. Los clastos 
son subredondeados a redondeados, de cuarzo y líticos volcánicos y el cemento es silíceo (Figura 4.7).

Hacia los niveles superiores del Grupo Puesto Viejo esta facies pasa a una arenisca gruesa a muy gruesa, moderadamente seleccionada. Los clastos son subredondeados a subangulosos de líticos volcánicos y cristales de cuarzo. Contiene niveles conglomerádicos con clastos de hasta $10 \mathrm{~cm}$ de riolitas, ignimbritas, areniscas verdes y basaltos.

A escala microscópica se observan en la Figura 4.6 abundantes cristales de cuarzo (Qtz) y líticos volcánicos (Lv).

Interpretación: la forma lenticular de los cuerpos con base erosiva y techo plano, constituido a partir de la migración de megaóndulas "3D" permite interpretarla como depósitos de barras arenosas y areno-gravosas o bien como depósitos de canal, traccionales formadas en condiciones de bajo régimen de flujo (Leeder, 1999; Bridge, 2003).

Areniscas con estratificación entrecruzada planar (Sp)

Esta facies se desarrolla principalmente en los niveles superiores del Grupo Puesto Viejo. Las areniscas con estratificación entrecruzada planar se presentan en cuerpos de forma tabular a lenticular con base neta a erosiva, con espesores de hasta 7 metros, conformados por la superposición de cuerpos de 1 a 1,5 metros de espesor con techo erosionado. Individualmente los cuerpos están conformados por la agradación y migración de delgados sets planares con arreglo interno granodecreciente que se cortan con ángulo relativamente bajo. Consiste en areniscas media a gruesa, roja, de base conglomerádica, con moderada a buena selección y clastos subangulosos a subredondeados de líticos de ignimbrita que alcanzan los $10 \mathrm{~cm}$ de diámetro, areniscas verdes, pelitas y cuarzo (Figura 4.7). De manera subordinada, se presenta como una arenisca fina a media, moderadamente seleccionada con sus clastos subredondeados a subangulosos, de líticos pelíticos y volcánicos de hasta 3 $\mathrm{cm}$ cementados por calcita y cristales de cuarzo. Intercalan niveles rojos 
cementados por sílice con clastos de hasta $5 \mathrm{~cm}$ conformyo una arena conglomerádica de la misma composición.

A escala microscópica se observan en la Figura 4.6 abundantes cristales de cuarzo (Qtz), líticos volcánicos (Lv) y sedimentarios (Ls).

Interpretación: estos cuerpos se interpretan como producto de la migración de megaóndulas "2D", las cuales se agrupan conformyo barras transversales 0 lingüiformes formadas en condiciones de bajo régimen de flujo (Leeder, 1999; Bridge, 2003).

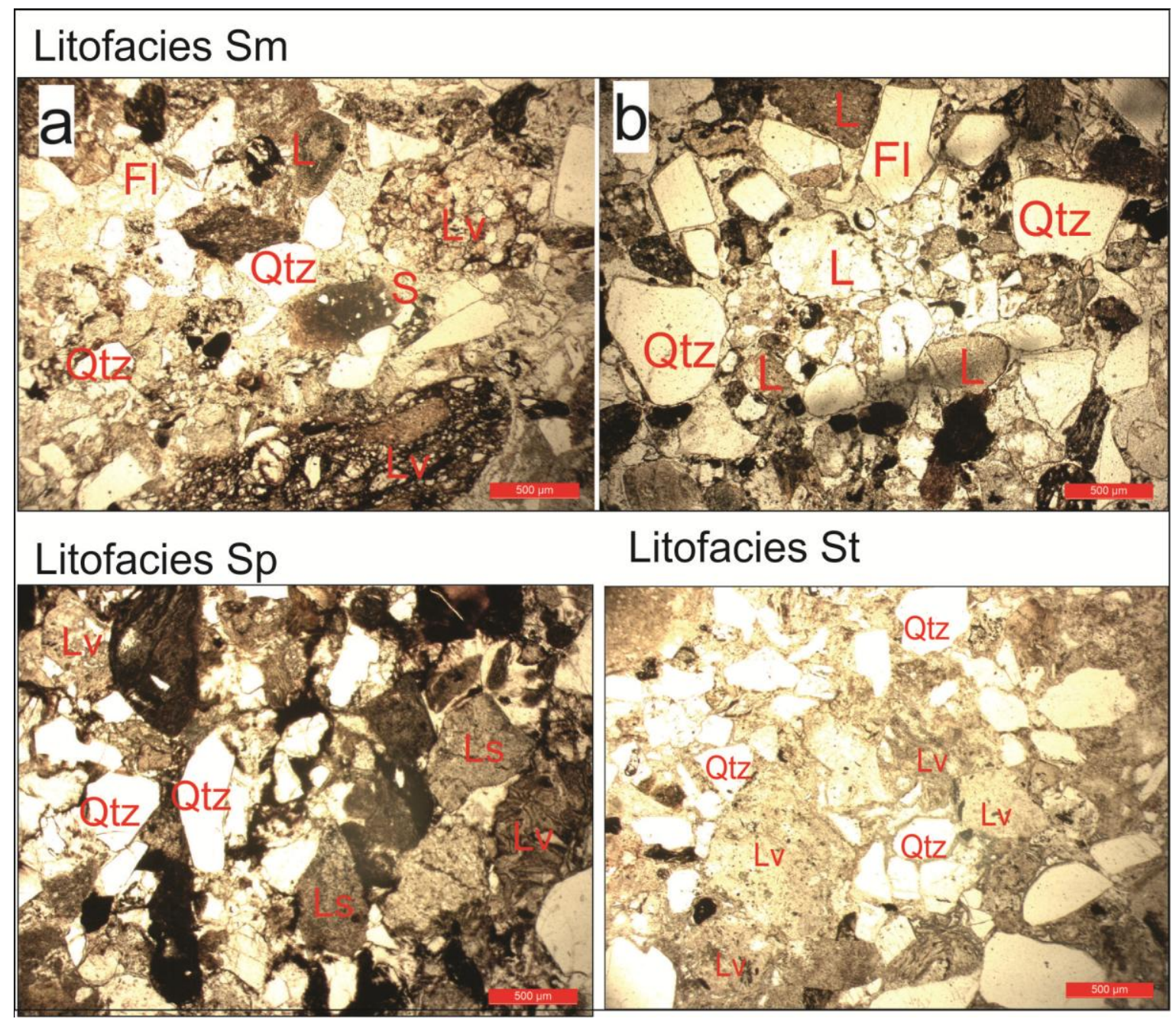

Figura 4.6. Petrografía de litofacies arenosas. 


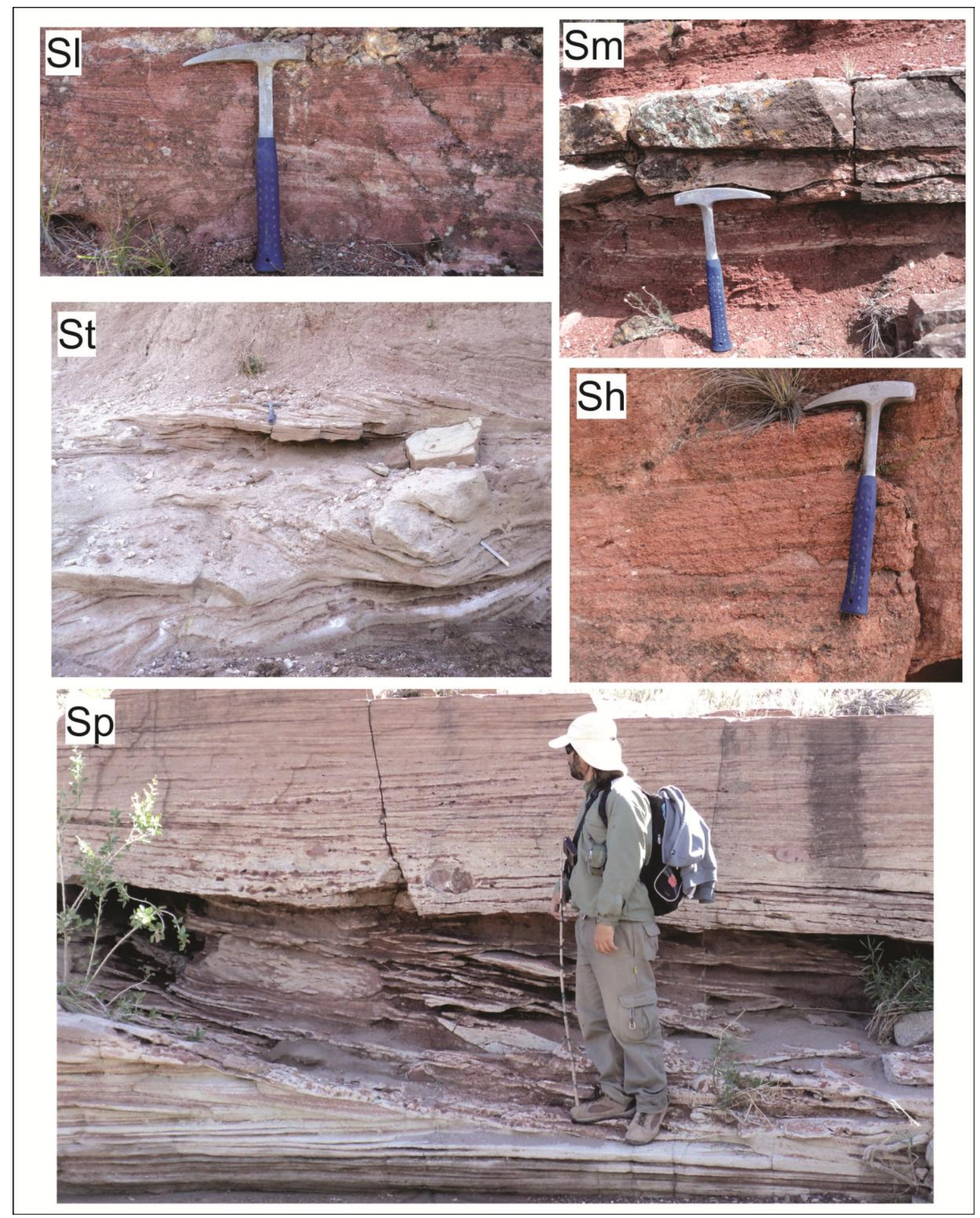

Figura 4.7. Litofacies arenosas.

\section{Litofacies de aren iscas tobáceas (ST)}

Conforman estratos finos a medianos, formados por psamitas volcaniclásticas (McPhie, 1993) gruesas a medianas con importante material limoso intersticial. La composición de esta litofacies es principalmente tobácea, con abundantes 
fragmentos de vidrio volcánico como trizas vítreas y en ocasiones fragmentos pumíceos. En general presenta color verde amarillento con tonalidad clara.

Arenisca tobácea masiva (STm)

Conforma delgados cuerpos de geometría tabular de arenisca fina a media con moderada selección. Su composición tobácea le otorga color blanquecino. Sus clastos son subangulosos a redondeados de cuarzo, líticos pelíticos y piroclásticos en una matríz tobácea (pómez y vidrio volcánico). El cemento es silíceo (Figura 4.9).

A escala microscópica se confirma una composición tobácea con cristales de cuarzo (Qtz) redondeados, líticos pelíticos (Lp) y abundante material vítreo (Mv) como trizas (Figura 4.8).

Interpretación: estos cuerpos arenosos tabulares, de composición tobácea desarrollados en forma aislada se interpretan como depósitos de decantación subaérea (loéssico) retrabajados y redepósitados por eventos de desbordamiento poco canalizado en planicies de inundación. Su aspecto masivo se puede deber a modificación por acción biogénica (McPhie et al., 1993; Leeder, 1999).

Areniscas tobáceas laminadas (STh)

Cuerpos de forma tabular, con base y techo neto a irregular. Es una arenisca muy fina de composición tobácea, con estructura ondulítica y laminar (Figura 4.9). Presenta abundantes marcas de raíces perpendiculares al plano de estratificación. Dentro de los cuerpos hay delgadas intercalaciones de fangolita roja (1 $\mathrm{cm}$ de espesor).

A escala microscópica se observa en la Figura 4.8 la composición tobácea constituida por cristales de cuarzo (Qtz), líticos (L) y material vítreo intersticial (Mv).

Interpretación: estos cuerpos tabulares arenosos de composición tobácea con base y techo neta se interpretan como depósitos loéssicos producidos por 
decantación subaérea, retrabajados por corrientes ácueas y redepositados como capas planas en condiciones de alto régimen de flujo (Miall, 1996; Leeder, 1999).

Areniscas tobáceas con estratificación entrecruzada (STp)

Consiste en cuerpos de forma tabular con base neta a erosiva y techo neto. Intercalan niveles de arenisca media a gruesa color blanquecina y roja. Presenta buena selección y sus clastos son subredondeados. Incorpora clastos tamaño bloque de hasta $50 \mathrm{~cm}$ de la ignimbrita superior del Grupo Puesto Viejo (Capítulo 1.2; Figura 4.9).

A escala microscópica se observa en la Figura 4.8 una composición tobácea con abundantes cristales de cuarzo (Qtz) euhedrales y subredondeados, líticos (L) y material vítreo (Mv) intersticial.

Interpretación: la presencia de cuerpos arenosos de forma tabular, internamente estratificados a partir de la migración de crestas planas se interpreta como depósitos de canales de crevasse o canales pequeños de descarga o chutes de sistema fluvial, en planicie de inundación producidos a partir de procesos de desbordamiento o descarga (Miall, 1996). 


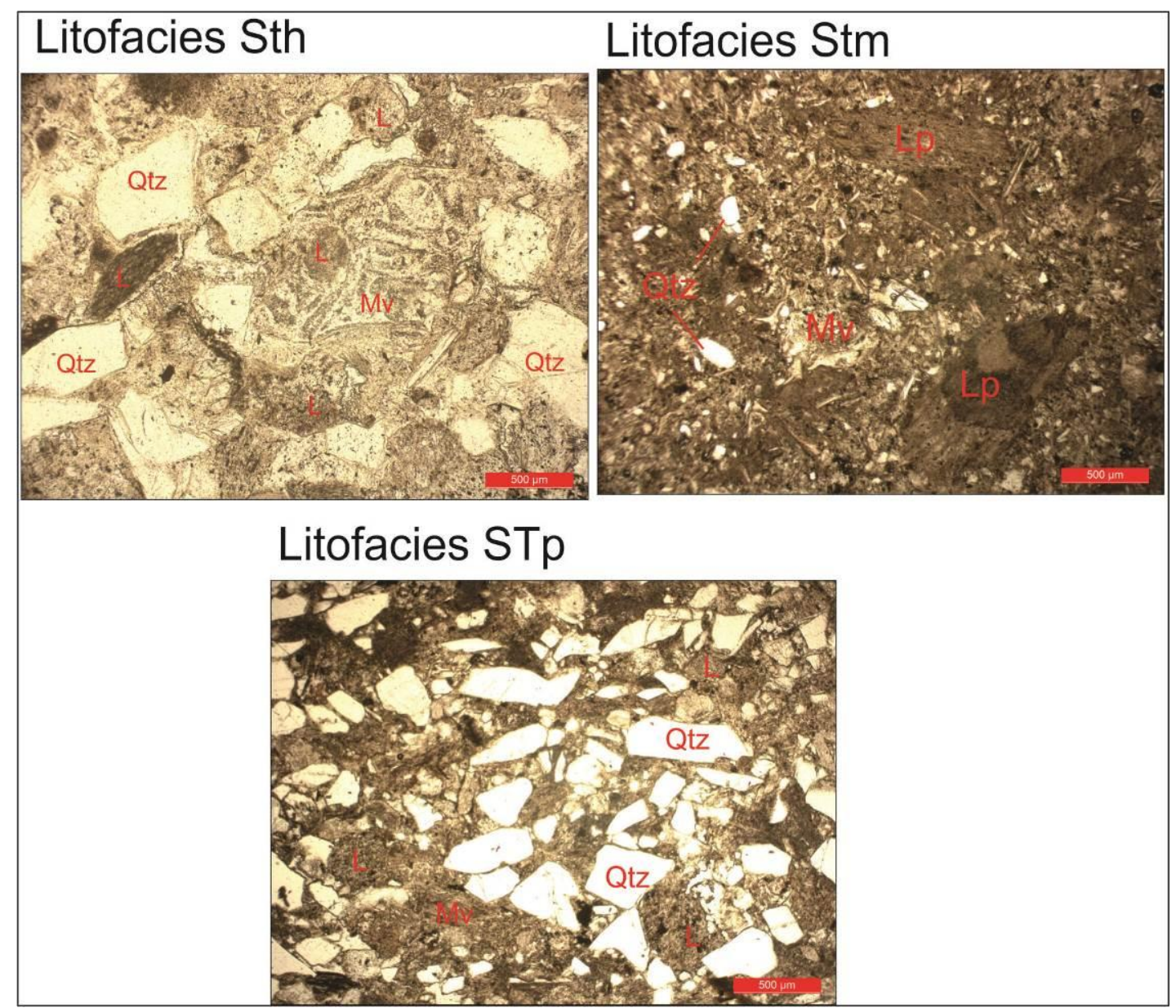

Figura 4.8. Petrografía de areniscas tobáceas. 


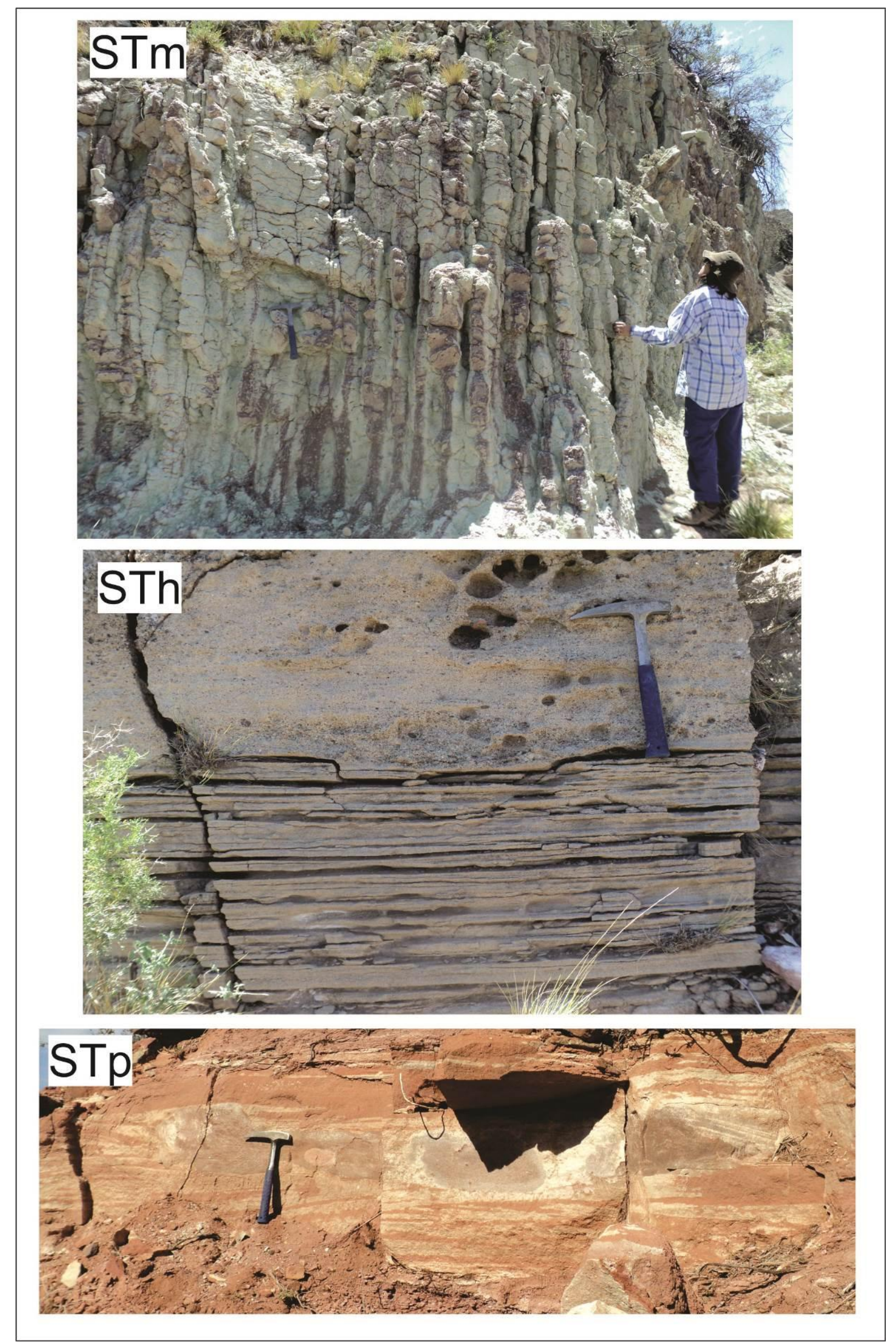

Figura 4.9. Litofacies areniscas tobáceas. 


\section{Litofacies pelíticas (F)}

Esta litofacies posee amplia distribución, constituyendo tanto niveles espesos como delgadas interestratificaciones, con colores rojos, verdes y localmente negros. Los estratos pelíticos son comúnmente macizos y homogéneos en ocasiones producto de bioturbación. Los niveles pelíticos laminados por decantación se hallan subordinados. Se han descripto rasgos, como marcas de raíces, que sugieren la existencia de paleosuelos.

Fangolitas y arcillitas laminadas (FI) y Limolitas laminadas (Fsl)

Constituyen cuerpos tabulares de pelitas moradas y rojas laminadas con espesores que varían de 0,1 a 4,5 metros. Intercalan con lentes masivos de pelitas que contienen abundantes intraclastos y relleno intraestratal (Figura 4.11). En ocasiones alternan con niveles de limolitas verdosas y niveles de arenisca muy fina a fina que presenta láminas o parches calcáreos color gris. A escala microscópica se observan en la Figura 4.10 delgadas láminas de materia orgánica (Mo) deformadas alternyo con láminas más gruesas de material silicoclástico.

Interpretación: cuerpos pelíticos tabulares, internamente laminados, posiblemente formados por decantación a partir de suspensiones ácueas en llanuras de inundación o canales abandonados (Blair y McPherson, 2008).

Limolitas masivas (Fsm)

Cuerpos tabulares de pelita arcillosa color verde grisácea y morada. Presentan espesores de 0,1 a 0,9 metros, con escasas marcas de raíces (Figura 4.11). A escala microscópica se observa en la Figura 4.10 material silicoclástico con materia orgánica (o) intersticial.

Interpretación: la forma tabular de estos cuerpos pelíticos masivos y con marcas de raíces indica que posiblemente fueron formados por decantación 
subácuea en pantanos o canales abandonados y modificados por acción biogénica.

Limolitas bioturbadas y/o con marcas de raíces (Fr) / Paleosuelos (P)

Consisten en delgados bancos de pelitas con forma tabular cuyos espesores varían de 0,5 a 0,6 metros. Se encuentran constituidas por limolitas verdosas y moradas de aspecto masivo, con cemento silíceo y abundantes marcas de raíces (Figura 4.11).

A la escala microscópica se observa en la Figura 4.10 abundante materia orgánica (Mo) y restos vegetales indiferenciados.

Interpretación: por su yacencia (asociada al techo de niveles carbonáticos), su alto grado de bioturbación y su alto contenido de marcas de raíces se los asocia a desarrollo incipiente de paleosuelos (Retallack, 2001). 


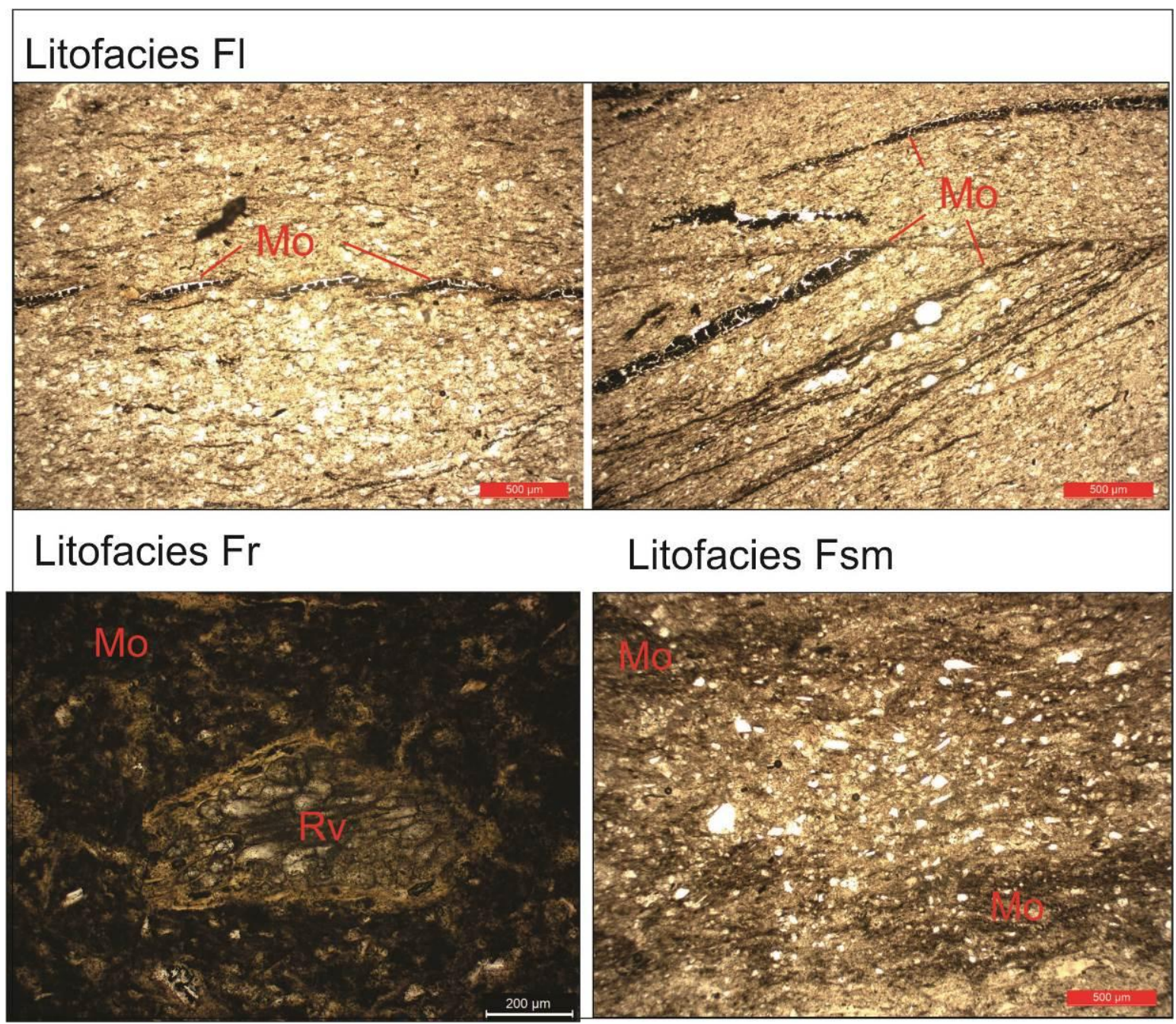

Figura 4.10. Petrografía de litofacies pelíticas. 


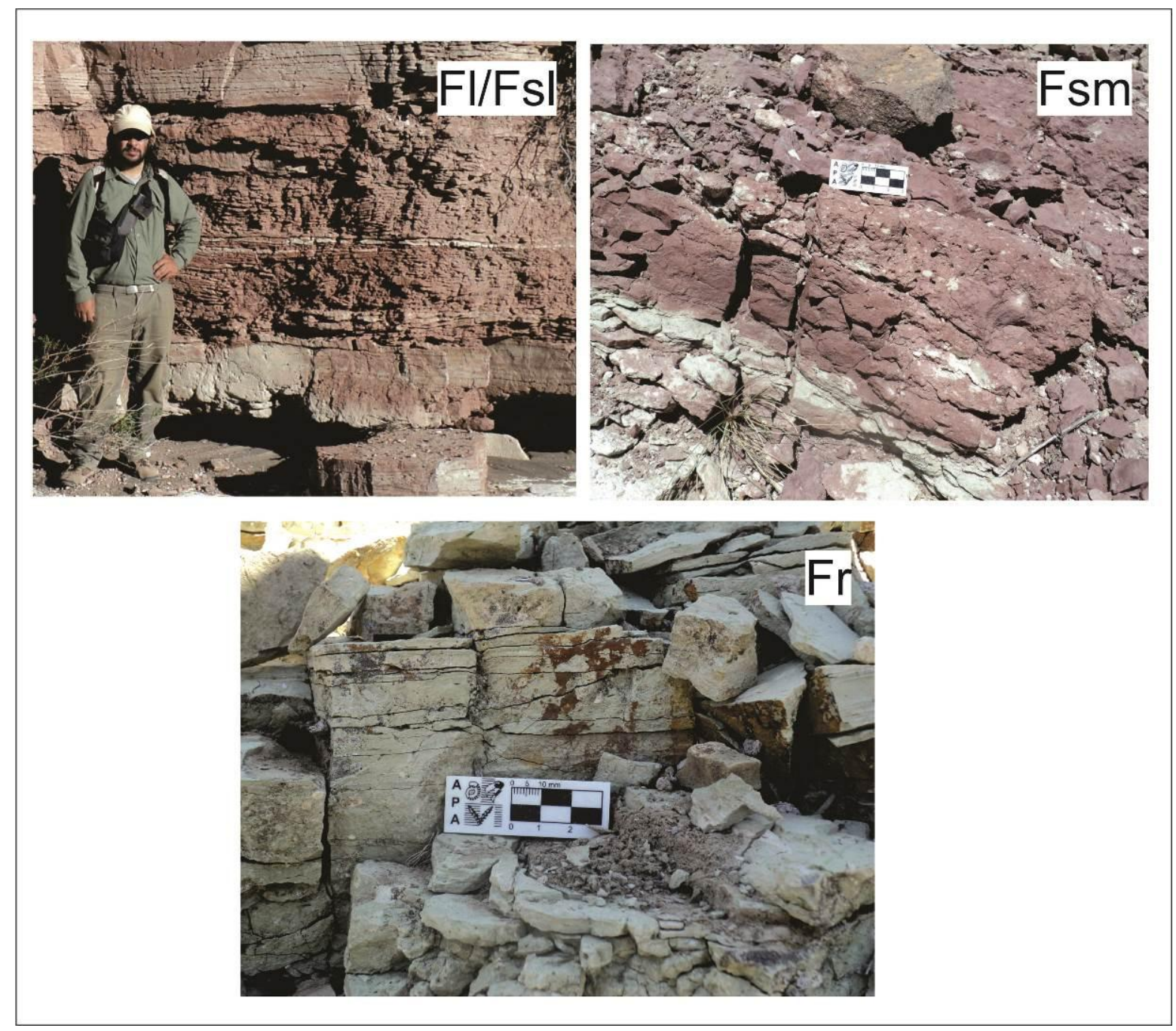

Figura 4.11. Litofacies pelíticas.

\section{Litofacies de pelitas tobáceas (FT)}

Pelitas ricas en vidrio volcánico, macizas o laminadas en capas que van de 0,2 a 4 metros de espesor. Asociados a estos depósitos se han preservado niveles plantíferos, enriquecidos en materia orgánica, que les otorga un tono grisáceo y fisilidad.

Fangolitas tobáceas ricas en materia orgánica con fisilidad (FTrf)

Esta facies constituye cuerpos tabulares de 0,2 a 1,6 metros de espesor de pelita tobácea con marcada fisilidad. Presenta en forma alternante delgadas láminas color gris oscuro y amarillo muy finas ( $<2 \mathrm{~mm}$ ). Se distinguen láminas 
color negro dado por el contenido de materia orgánica (Figura 4.13), restos de equisetales y de licópsidas (posibles pleuromeias).

A escala microscópica se observa en la Figura 4.12 fisilidad dada por la alternancia de delgadas láminas de materia orgánica (Mo) y láminas de material volcaniclástico $(\mathrm{Mv})$.

Interpretación: la presencia de estos restos de vegetales podría indicar áreas de inundación periódica con colonización de equisetales y licópsidas, con desarrollo de paleosuelos.

Limolitas y fangolitas tobáceas masivas (FTm)

Esta facies se presenta en bancos masivos, de forma tabular de hasta 4 metros de espesor. Se halla compuesta por material tobáceo, con cemento silíceo y en ocasiones calcáreo. Se observan comúnmente marcas de raíces (Figura 4.13). A escala microscópica se observa en la Figura 4.12 material volcaniclástico (Mv) con láminas de materia orgánica (Mo) y crustácesos identificados como conchostracos (Co).

Interpretación: la forma tabular de estos cuerpos pelíticos con marcas de raíces, materia orgánica y restos de invertebrados permite interpretar que se trata de depósitos formados por decantación subácuea en una llanura de inundación o en canales abandonados, modificados por acción biogénica. Posiblemente se encuentran asociados al desarrollo de cuerpos de agua someros (Plint y Browne, 1994).

Limolitas y fangolitas tobáceas laminadas con ondulitas (FTI).

Esta litofacies conforma cuerpos tabulares con contactos netos y amplia continuidad lateral, cuyos espesores varían de 0,7 a 1,4 metros. Consiste en limolitas/fangolitas con suave laminación ondulítica asimétrica, de color verde a blanquecina que alternan con niveles silicificados anaranjados. Constituye una superficie con abundantes restos vegetales, materia orgánica, marcas de ra íces y bioturbación (Figura 4.13). 
A escala microscópica se observan en la Figura 4.12 abundantes restos vegetales (Rv) indiferenciados con fuerte silicificación (S).

Interpretación: cuerpos pelíticos de forma tabular con estructura ondulítica, ricos en restos vegetales, materia orgánica, marcas de raíces y bioturbación, características que permiten interpretarlos como depósitos formados por decantación subácuea en planicies de inundación asociados al desarrollo de cuerpos de agua someros (Plint y Browne, 1994).

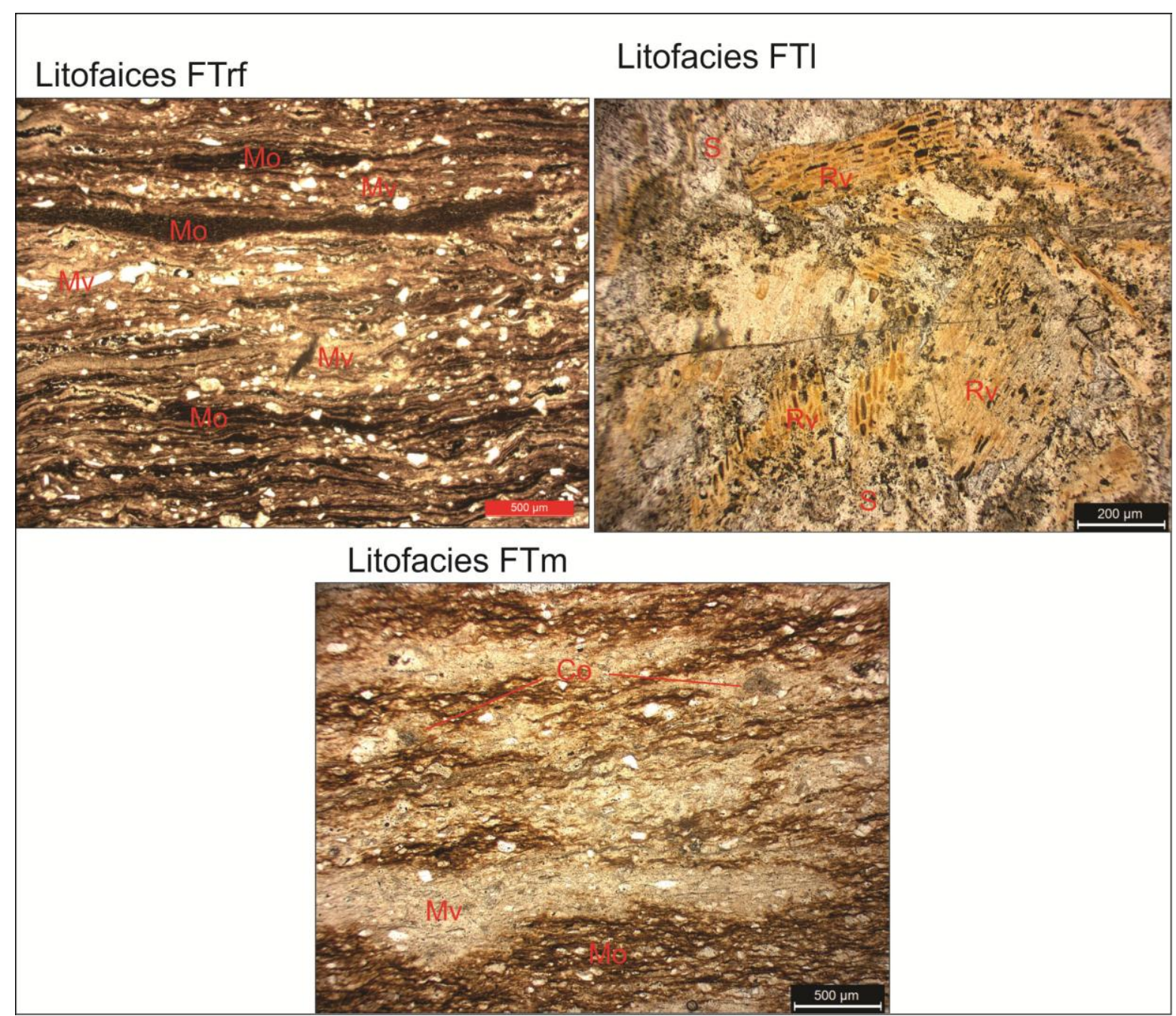

Figura 4.12. Petrografía de litofacies pelitas tobáceas. 


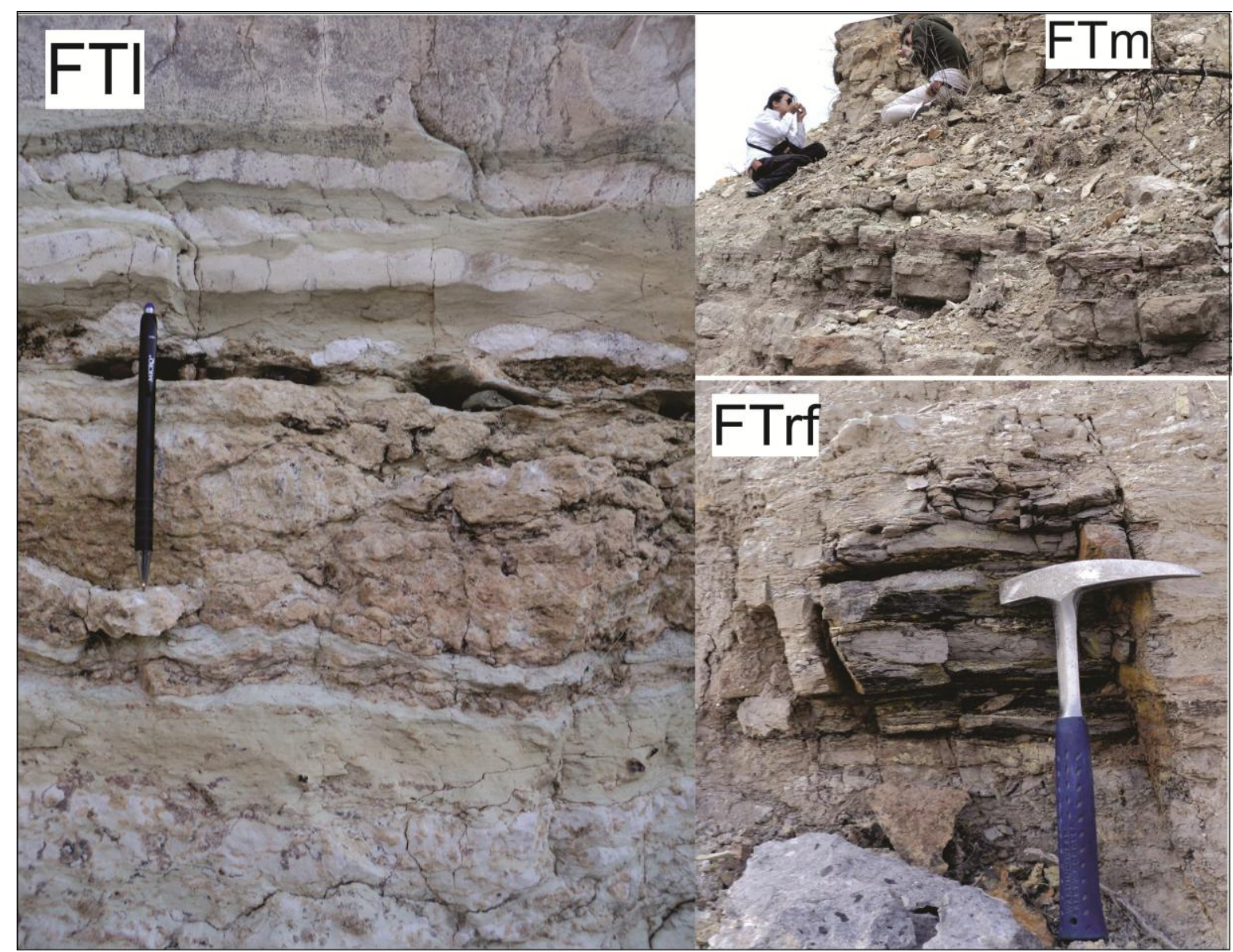

Figura 4.13. Litofacies pelitas tobáceas.

\subsection{A.2. Litofacies de rocas carbonáticas}

Calizas / fango calcáreo $(\mathrm{Cl})$

Se distribuyen localmente como cuerpos de forma tabular con espesores de 0,2 a 0,5 metros, con estructura laminada (estromatolitos). En general presentan tonos amarillentos a ocres y localmente presentan láminas más claras de forma irregular. En algunos niveles se observa bioturbación en el techo. Intercalan con delgados niveles pelíticos (arcillosos) de color verdoso (Figura 4.15).

A escala microscópica se observa en la Figura 4.14 la laminación producida por algas (a). En algunos sectores las láminas se encuentran deformadas (b).

Interpretación: formas de crecimiento algal fijadoras de carbonatos de calcio desarrolladas en cuerpos de agua someros (Tucker, 2001). 


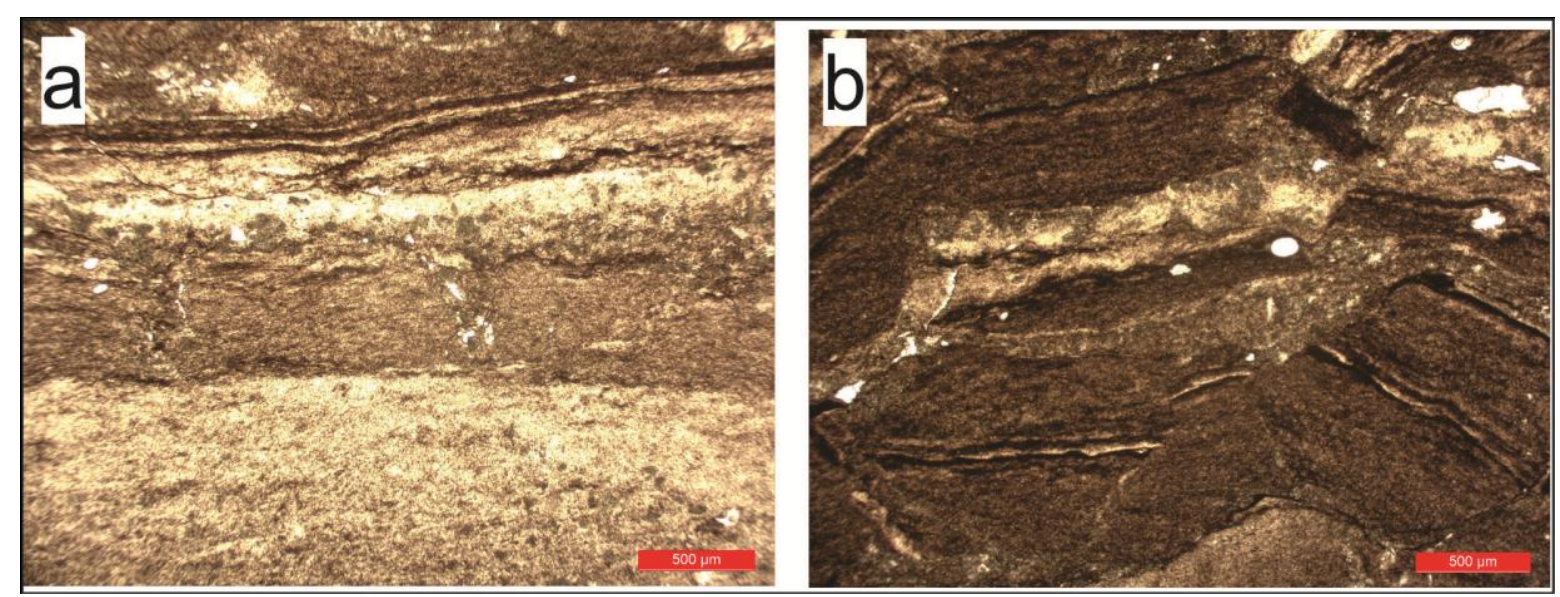

Figura 4.14. Petrografía de litofacies carbonáticas.

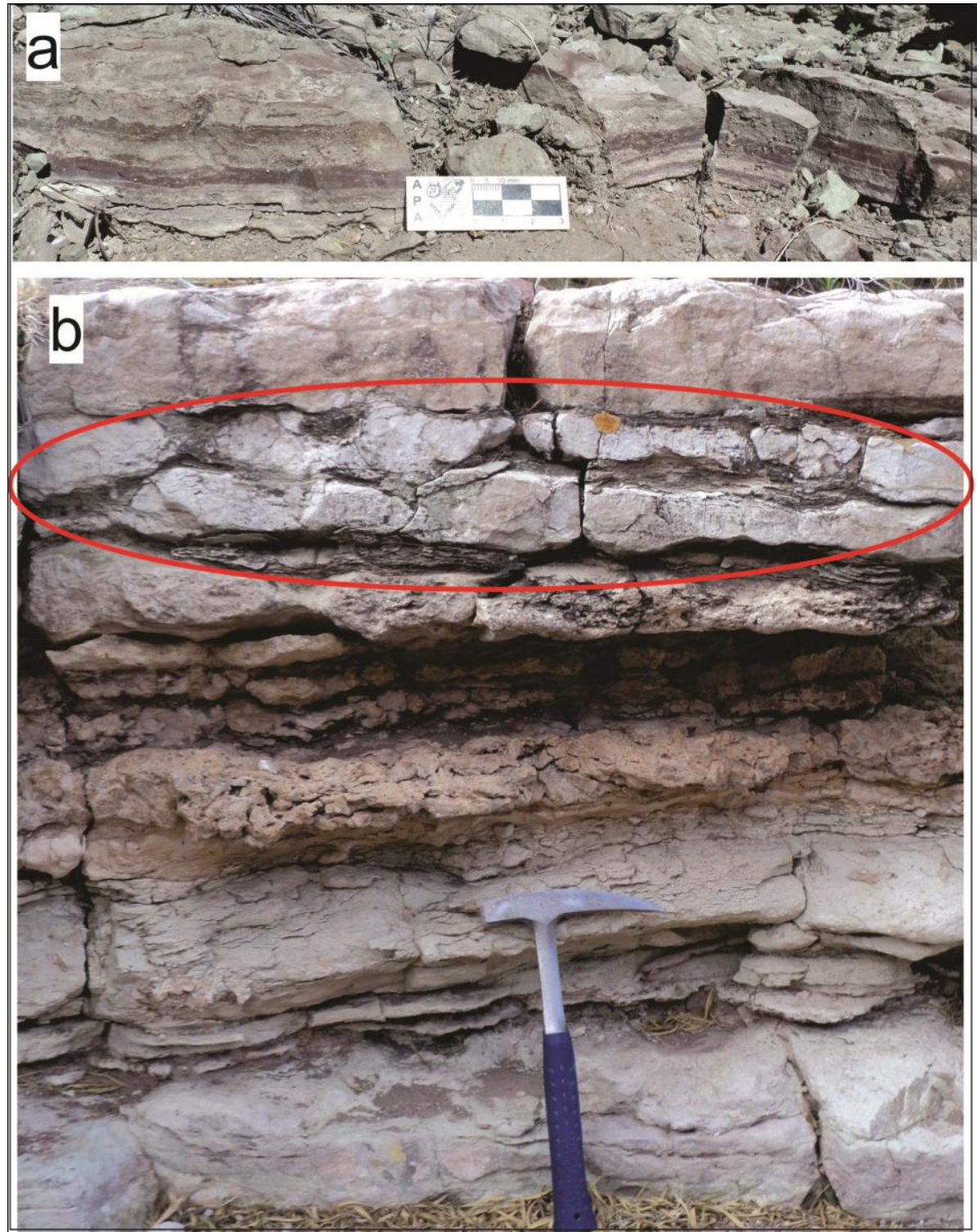

Figura 4.15. Niveles carbonáticos. a) se observa la laminación que presentan estos niveles en la localidad Quebrada de los Fósiles (ubicación en la Figura 4.1). b) nivel de caliza con aspecto 
masivo irregular en asociación con niveles lacustres epiclásticos en la localidad Río Seco de la Quebrada.

\subsection{B. Litofacies de rocas piroclásticas y volcánicas}

Para realizar el análisis de las litofacies de naturaleza piroclástica y volcánica se optó por analizar de forma integrada las características texturales, composicionales y su génesis y mecanismo de sedimentación/emplazamiento a partir del análisis petrográfico y geoquímico en conjunto con las observaciones de campo. En base a la clasificación genética propuesta por McPhie et al. (1993) se identificaron los siguientes procesos: Efusivos con flujos de lava e intrusivos subvolcánicos asociados a depósitos autoclásticos localizados. Extrusivos como flujos piroclástico soldados y no soldados; de forma muy subordinada se identificaron depósitos de ceniza volcánica (no soldada) formados a partir de suspensión. Se dejaron de lado en esta sección los depósitos generados por residementación ya que fueron analizados dentro de las litofacies sedimentarias en el inciso anterior.

A pesar de la variabilidad de procesos involucrados, la escasa distribución areal y temporal que constituye el Grupo Puesto Viejo y el bajo volumen que presentan estos materiales en el depocentro, se han identificado facies muy homogéneas.

Los códigos utilizados para las litofacies fueron elegidos en función de los procesos de depositación/emplazamiento. Para las rocas piroclásticas los códigos utilizados fueron basados y modificados de Branney y Kokelaar (2002) y para las rocas volcánicas fueron creados para una rápida y fácil identificación.

\subsection{B.1. Análisis litofacial}

\section{Litofacies piroclásticas}

Estas litofacies se reconocen como depósitos primarios de caída subaérea formyo delgados cuerpos tabulares y macizos de tobas. Como depósitos 
primarios de flujo se observan mantos de flujos de ignimbritas cuyas características se describen a continuación.

Depósitos primarios de tobas masivas de caída (Tm)

Delgados cuerpos tabulares con techo irregular de 0,1 a 0,2 $\mathrm{m}$ de espesor. Consisten en tobas de color blanquecino, con alto grado de alteración a arcillas. Se identifican abundantes vitroclastos cementados por calcita. Presentan intercalaciones de niveles pelíticos.

A escala microscópica se observan en la Figura 4.16 trizas vítreas (Tv) monocuspidales, bicuspidales y tricuspidales como principal componente, escasos cristalocalstos de cuarzo (Qtz) y fuerte alteración a arcillas (Ar).

Interpretación: depósitos de caída subaérea a partir de plumas piroclásticas posiblemente depositadas por decantación subácuea en cuerpos de agua someros, lo que permitió su conservación (Fisher y Schminche, 1984; Branney y Kokelaar, 2002).

Depósitos primarios de flujos ignimbríticos soldados $(\mathrm{mLs})$ y poco soldados $(\mathrm{mL})$

Constituyen mantos tabulares de ignimbritas de composición riolítica, con variado grado de soldadura. Se presentan como unidades de flujo con espesor individual de 5 a $6 \mathrm{~m}$ de o forman depósitos superpuestos potentes con más de $30 \mathrm{~m}$ de espesor.

Se diferencian zonas caracterizadas por presentar bajo grado de soldamiento $(\mathrm{mL})$ y aspecto masivo (Figura 4.17a), con pasta vítrea afanítica que le otorga un color amarillo a castaño claro. Está constituida principalmente por vitroclastos como trizas vítreas (Tv) bicuspidales y tipo blocky tamaño lapilli, son comunes los cristaloclastos muy gruesos de cuarzo y feldespato euhedral, en ocasiones parcial o totalmente disueltos. Presenta escasos litoclastos volcánicos rojos indiferenciados de diverso tamaño. Se observan abundantes fisuras y venillas rellenas por sílice. 
Otras zonas presentan alto grado de soldamiento $(\mathrm{mLs})$ y aspecto fluidal (Figura 4.17b), de color rosado característico dado por el contenido de óxidos de hierro en la pasta. Se identifican sectores más cristalinos con abundantes cristaloclastos de cuarzo ehuedrales a subhedrales y escasa plagioclasa tamaño ceniza, inmersos en una pasta vítrea afanítica, otorgándole una textura porfírica. Es frecuente la presencia de litoclastos rojos de ignimbrita (Lv). Contiene abundantes vitroclastos como fragmentos pumíceos elongados (Tvf) y trizas vítreas tipo blocky, monocuspidales, bicuspidales y tricuspidales (Figura 4.16).

Interpretación: depósitos de flujos piroclásticos a partir actividad volcánica explosiva, las cuales se enfriaron lentamente después de su depositación. (McPhie, 1993; Llambías, 2003; Branney y Kokelaar, 2002).

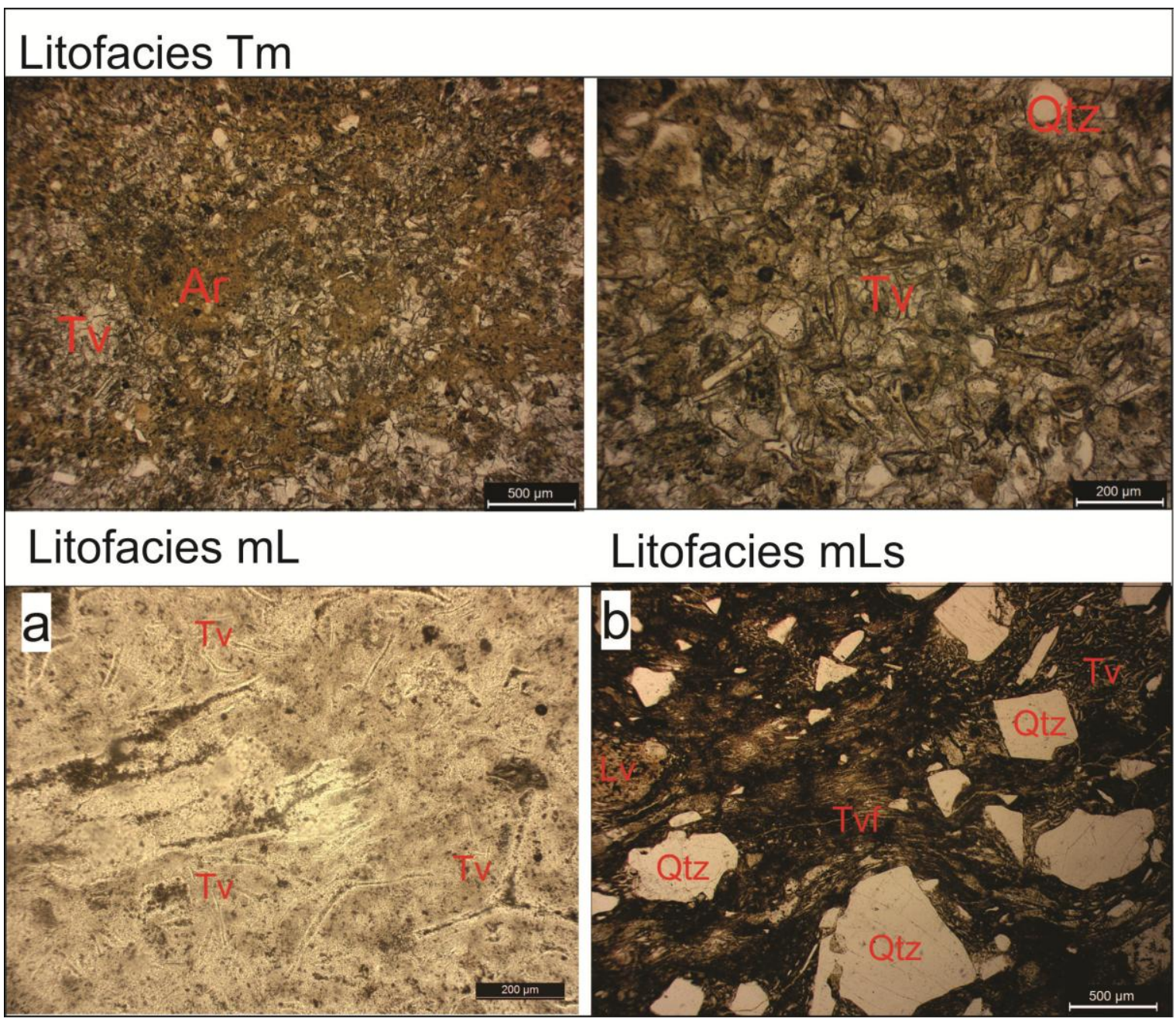

Figura 4.16. Petrografía de litofacies de rocas piroclásticas. 


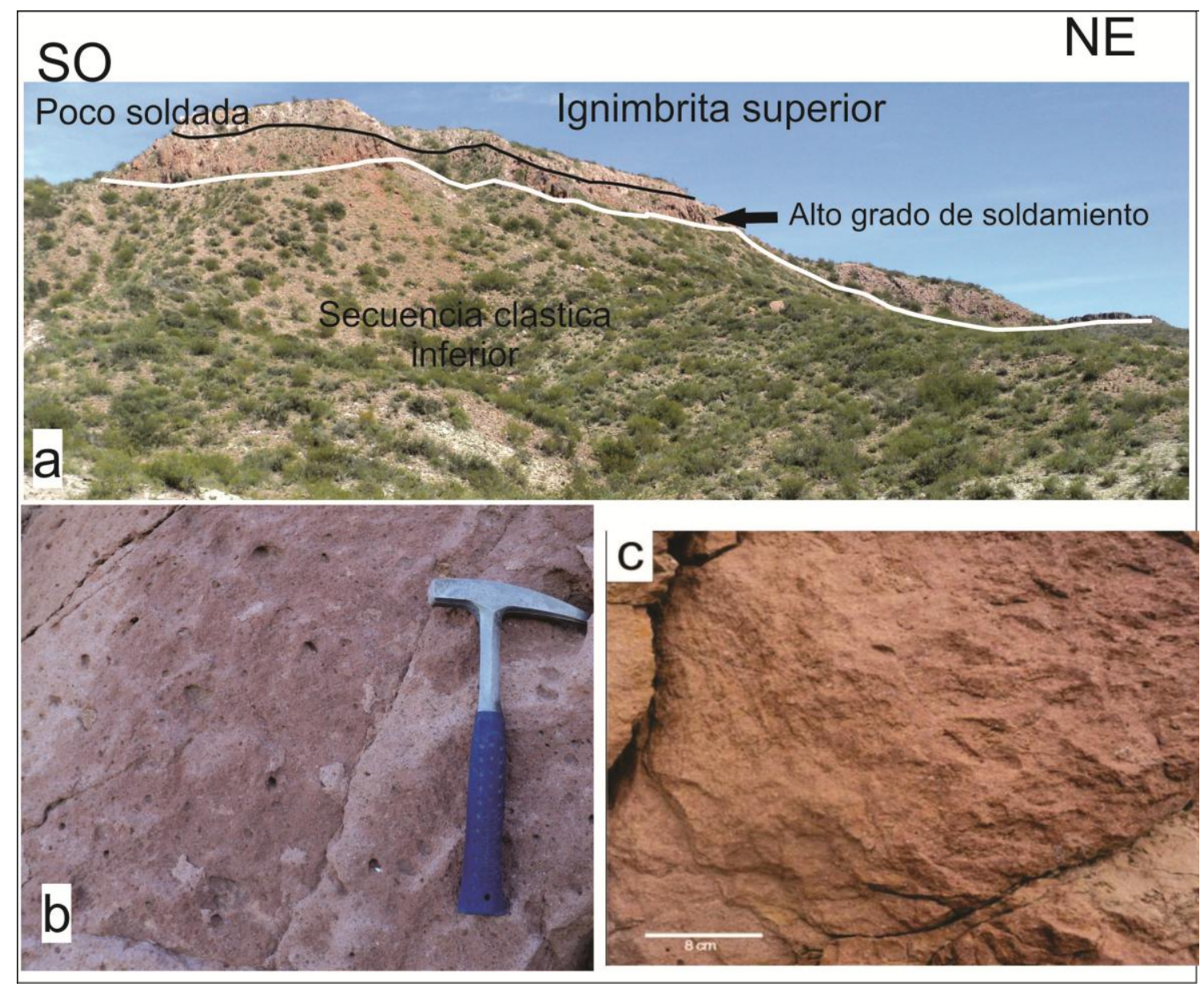

Figura 4.17. a) Afloramientos de los flujos ignimbríticos superiores en la denominada Pequeña Quebrada (Figura 4.1). b) detalle de ignimbrita poco soldada. c) detalle de ignimbrita soldada.

\section{Litofacies volcánicas}

Consisten en rocas básicas de composición yesita basáltica y yesítica, representadas por lavas (coladas fluidales) y cuerpos hipabisales (criptodomos y filones capa).

Intrusivos $(\mathrm{Bi})$

Se presentan como cuerpos de dimensiones y espesores variados constituidos por yesitas y yesitas basálticas afaníticas con colores homogéneos entre gris oscuro y gris azulado (Figura 4.18a). Su aspecto general es masivo, muy vesiculado y con amígdalas rellenas por carbonatos, sílice, cloritas y 
calcedonia. A escala microscópica se describe una textura porfírica con fenocristales de plagioclasa y pasta intergranular, holocristalina, muy fina (Figura 4.18b).

Interpretación: cuerpos formados por la solidificación de magma en condiciones subvolcánicas con un período de enfriamiento que permitió la nucleación y crecimiento de cristales (Llambías, 2003).

\section{Lavas (LAB)}

Conforman mantos de lavas andesíticas afíricas, de color gris y tonalidad oscura con abundantes vesículas elongadas (Figura 4.18a). A escala microscópica se describe una pasta pilotáxica, compuesta por microlitos de plagioclasa y minerales de hierro intersticial (Figura 4.18b). Presenta escasos fenocristales de yesina y minerales accesorios. Las cavidades se encuentran en ocasiones rellenas por illita, cuarzo y sílice microcristalina, ceolitas y carbonatos muy finos.

Intepretación: cuerpos formados por la solidificación de lava de composición yesítica, con un corto período de crecimiento de cristales, seguido por un rápido enfriamiento en un ambiente subaéreo (Best y Christiansen, 2001).

Peperitas (Pp)

Conforman cuerpos irregulares de brechas constituidos por clastos angulosos de basaltos con matriz sedimentaria de arena gruesa. En ocasiones consiste en una matriz pelítica color morada y verde con estructura laminar a ondulítica (Figura 4.18a), en la que se han identificado restos de equisetales y marcas de raíces. El impacto térmico se ve reflejado en la materia orgánica quemada. $A$ escala microscópica se observan los clastos de líticos basálticos en una matriz pelítica (Figura 4.18b).

Interpretación: facies formadas por el contacto entre un intrusivo y sedimento inconsolidado (McP hie et al.1993). 

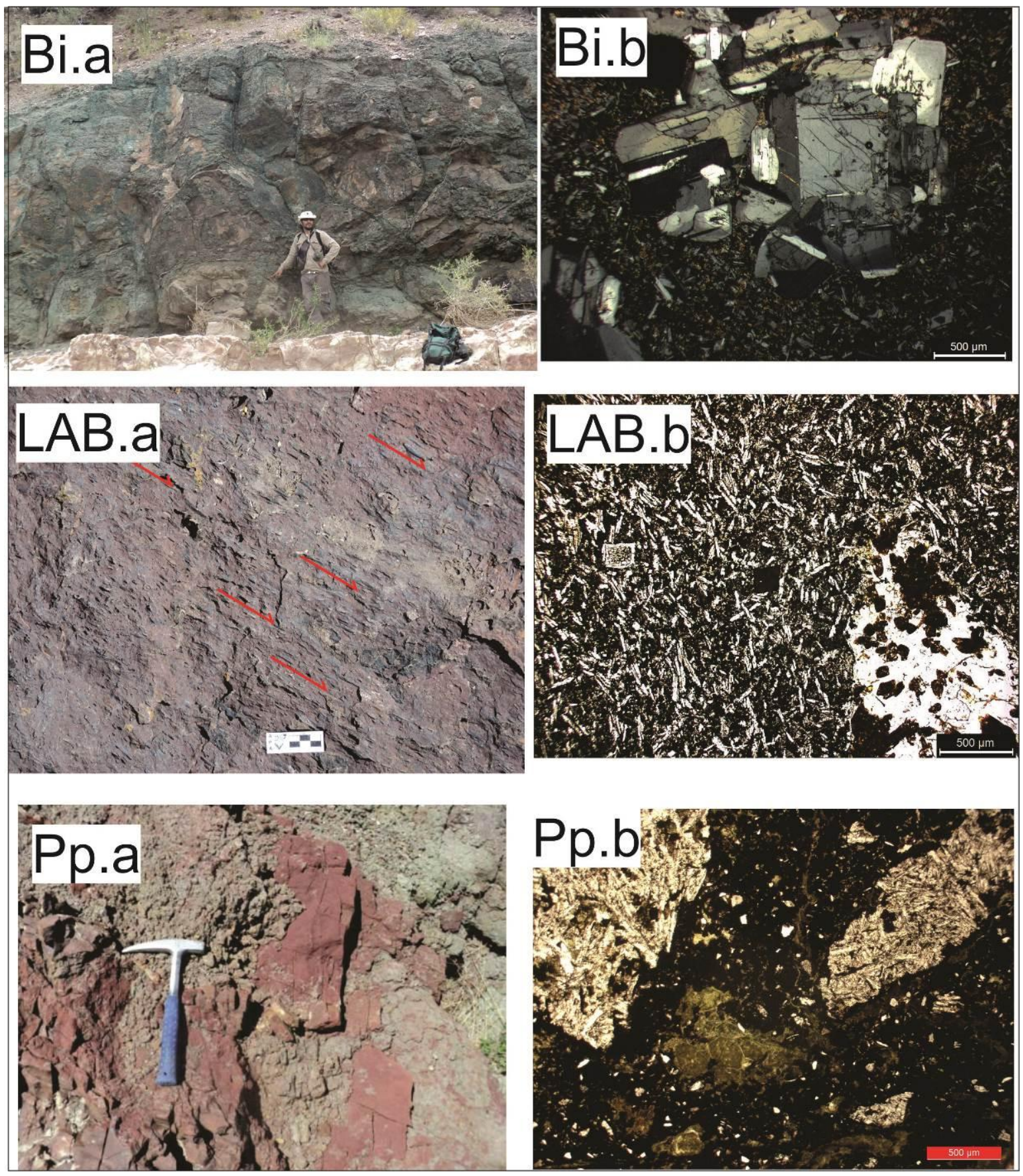

Figura 4.18. Litofacies volcánicas.

\subsection{B.2. Análisis litogeoquímico}

Con el objeto de caracterizar a las rocas volcánicas y piroclásticas del Grupo

Puesto Viejo a partir de su composición geoquímica, la fuente magmática que le dio origen y el tipo de asociación petrotectónica, se realizó un muestreo de las unidades más representativas del Grupo Puesto Viejo (Tabla 2). Se 
recolectaron 10 muestras en diferentes localidades de la zona de estudio, de rocas previamente clasificadas como yesitas, basaltos e ignimbritas riolíticas (véase Anexo 3. Mapa de ubicación) y se enviaron al Laboratorio Actlabs $®$ de Canadá (Capítulo 2.2.2.) para determinar valores de elementos mayoritarios, minoritarios y trazas. A los resultados de las muestras analizadas (véase Anexo 3) se le han incorporado los resultados de análisis geoquímicos realizados en el mismo laboratorio y publicados (Kleiman y Salvarredi, 2001) sobre seis muestras de rocas volcánicas y piroclásticas provenientes de áreas aledañas a la zona de estudio con la finalidad de comparar y aumentar el grado de confianza de los resultados obtenidos.

\begin{tabular}{|c|c|c|c|c|}
\hline $\begin{array}{l}\text { Ubicación } \\
\text { Estratigráfica }\end{array}$ & Litología & Muestra & \multicolumn{2}{|c|}{ Coordenadas Geográficas } \\
\hline \multirow{7}{*}{$\begin{array}{l}\text { Formación } \\
\text { Río Seco de } \\
\text { la Quebrada }\end{array}$} & \multirow{2}{*}{ Lava } & $3-10-10-10$ & $\mathrm{~S} 34^{\circ} 53,64^{\prime}$ & W68 $24,42^{\prime}$ \\
\hline & & $53 / 88^{*}$ & $\mathrm{~S} 34^{\circ} 43,00^{\prime}$ & $W 68^{\circ} 33,91^{\prime}$ \\
\hline & \multirow{4}{*}{ Criptodomo } & $1-5-10-10$ & S34 $53,88^{\prime}$ & $W 68^{\circ} 23,24^{\prime}$ \\
\hline & & $\mathrm{BI} 2$ & $\mathrm{~S}^{\prime} 4^{\circ} 55,39^{\prime}$ & $W 68^{\circ} 25,02^{\prime}$ \\
\hline & & $\mathrm{BI} 3$ & $\mathrm{~S}^{\prime} 4^{\circ} 54,32^{\prime}$ & $\mathrm{W}^{\prime} 8^{\circ} 23,23^{\prime}$ \\
\hline & & $146 / 92$ * & $\mathrm{S}^{\prime} 4^{\circ} 53,29^{\prime}$ & $\mathrm{W}^{\prime} 8^{\circ} 32,80^{\prime}$ \\
\hline & Filón capa & $3-7-10-10$ & $\mathrm{~S}^{\prime} 4^{\circ} 54,63^{\prime}$ & $W 68^{\circ} 23,45^{\prime}$ \\
\hline \multirow{9}{*}{$\begin{array}{l}\text { Formación } \\
\text { Quebrada de } \\
\text { los Fósiles }\end{array}$} & \multirow{7}{*}{$\begin{array}{l}\text { Ignimbrita } \\
\text { superior }\end{array}$} & $1-10-10-10$ & S $34^{\circ} 53,60^{\prime}$ & W68 $25,36^{\prime}$ \\
\hline & & $2-5-10-10$ & $\mathrm{~S}^{\prime} 4^{\circ} 54,01^{\prime}$ & $\mathrm{W}^{\prime} 68^{\circ} 23,75^{\prime}$ \\
\hline & & Is. 3 & $\mathrm{~S} 34^{\circ} 55,49^{\prime}$ & W68 $24,86^{\prime}$ \\
\hline & & $52 / 88$ * & \multirow{3}{*}{$\mathrm{S} 34^{\circ} 43,00^{\prime}$} & \multirow{3}{*}{ W68 $33,91^{\prime}$} \\
\hline & & $142 / 91 *$ & & \\
\hline & & $104 / 93$ * & & \\
\hline & & $61 / 88$ * & $\mathrm{S} 34^{\circ} 53,29^{\prime}$ & $W 68^{\circ} 32,80^{\prime}$ \\
\hline & \multirow{2}{*}{$\begin{array}{l}\text { Ignimbrita } \\
\text { inferior }\end{array}$} & $1-7-10-10$ & $\mathrm{~S} 34^{\circ} 54,71^{\prime}$ & W68 $23,46^{\prime}$ \\
\hline & & lb 1 & S $34^{\circ} 55,32^{\prime}$ & $W 68^{\circ} 24,97^{\prime}$ \\
\hline
\end{tabular}

Tabla 2. Rocas muestreadas en la zona de estudio para análisis geoquímico. Se incorporaron las muestras $\left({ }^{*}\right)$ publicadas por Kleiman y Salvarredi, 2001).

Se realizaron los diagramas de clasificación álcalis total versus sílice (TAS) (Middelemost, 1994) y el diagrama de elementos inmóviles de Winchester y Floyd (1977) con el objetivo de especificar la composición de las muestras analizadas. Con el diagrama TAS se obtuvo una primera clasificación en base 
al porcentaje de elementos mayoritarios móviles (Figura 4.19): la escasa dispersión que presentan permite apreciar dos agrupamientos. Las rocas piroclásticas se ubican en el campo de las riolitas con muy alto porcentaje de sílice. Las rocas volcánicas se distribuyen en los campos de traqui-yesitas a dacitas. Se ha agregado el diagrama de discriminación de series subalcalinas de Irvine y Baragar (1971) en el cual, salvo las muestras de rocas volcánicas PV 3.10.10.10 y PV 3.7.10.10 que se ubican en el campo de rocas subalcalinas, el resto de las muestras de rocas volcánicas y piroclásticas lo hacen en el campo de rocas alcalinas (Figura 4.19). Al observar el diagrama de elementos inmóviles (Figura 4.20) se reconocen dos grupos bien separados de rocas: uno para los rocas piroclásticas de composición riolítica y otro para rocas volcánicas de composición yesítica (muestra PV 3.10.10.10 de lavas) a yesita/basáltica (muestras de intrusivos), lo cual confirma desde un punto de vista composicional que se trata de una secuencia bimodal, como ha sido propuesto por otros autores (Kleiman y Salvarredi, 2001) para el Grupo Puesto Viejo en particular. 


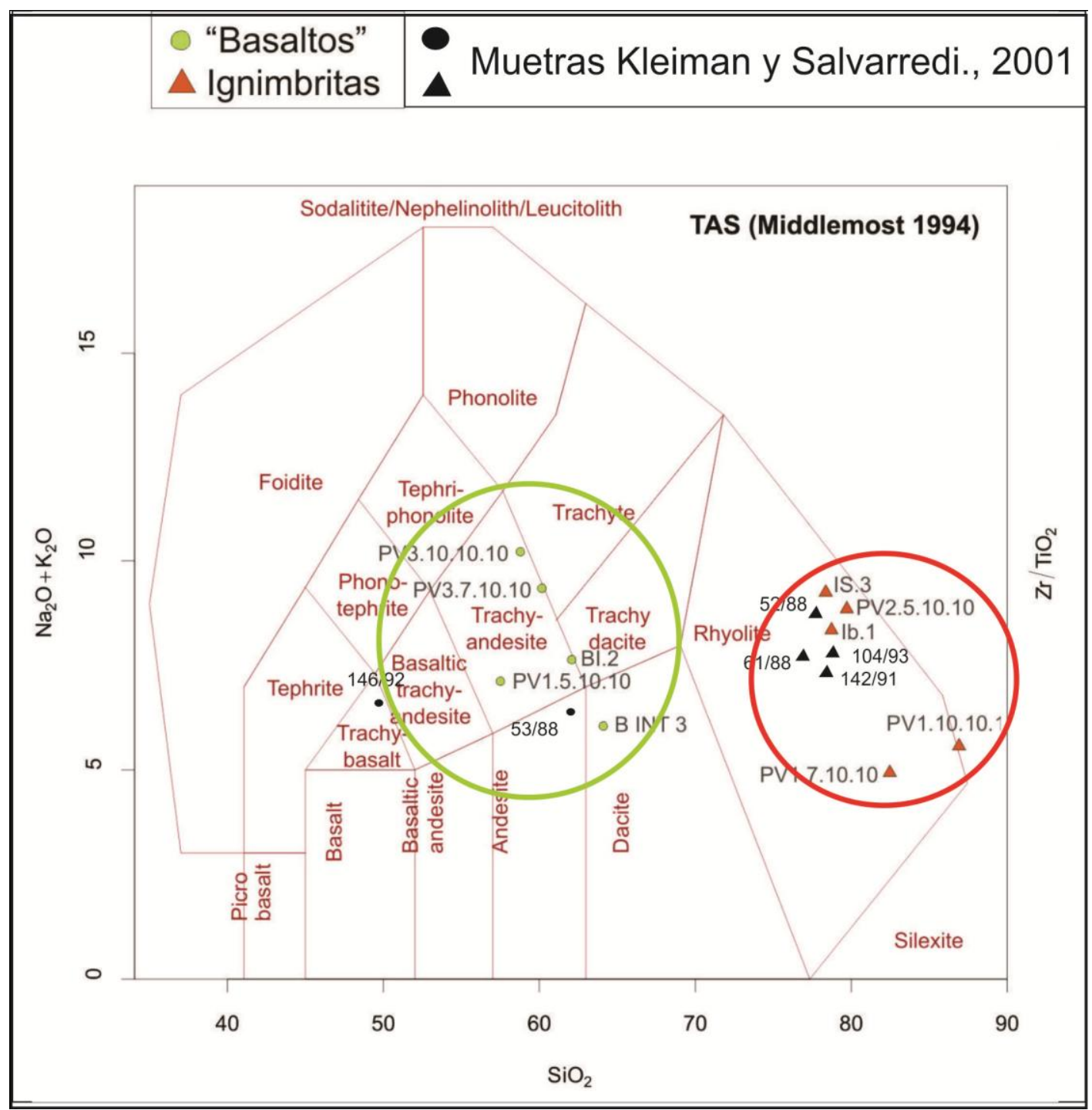

Figura 4.19. Diagrama de clasificación de rocas de álcalis totales versus sílice (TAS, Winchester y Floyd, 1977). Se incorporó la subdivisión entre rocas alcalinas y subalcalinas de Irvine y Baragar (1971). 


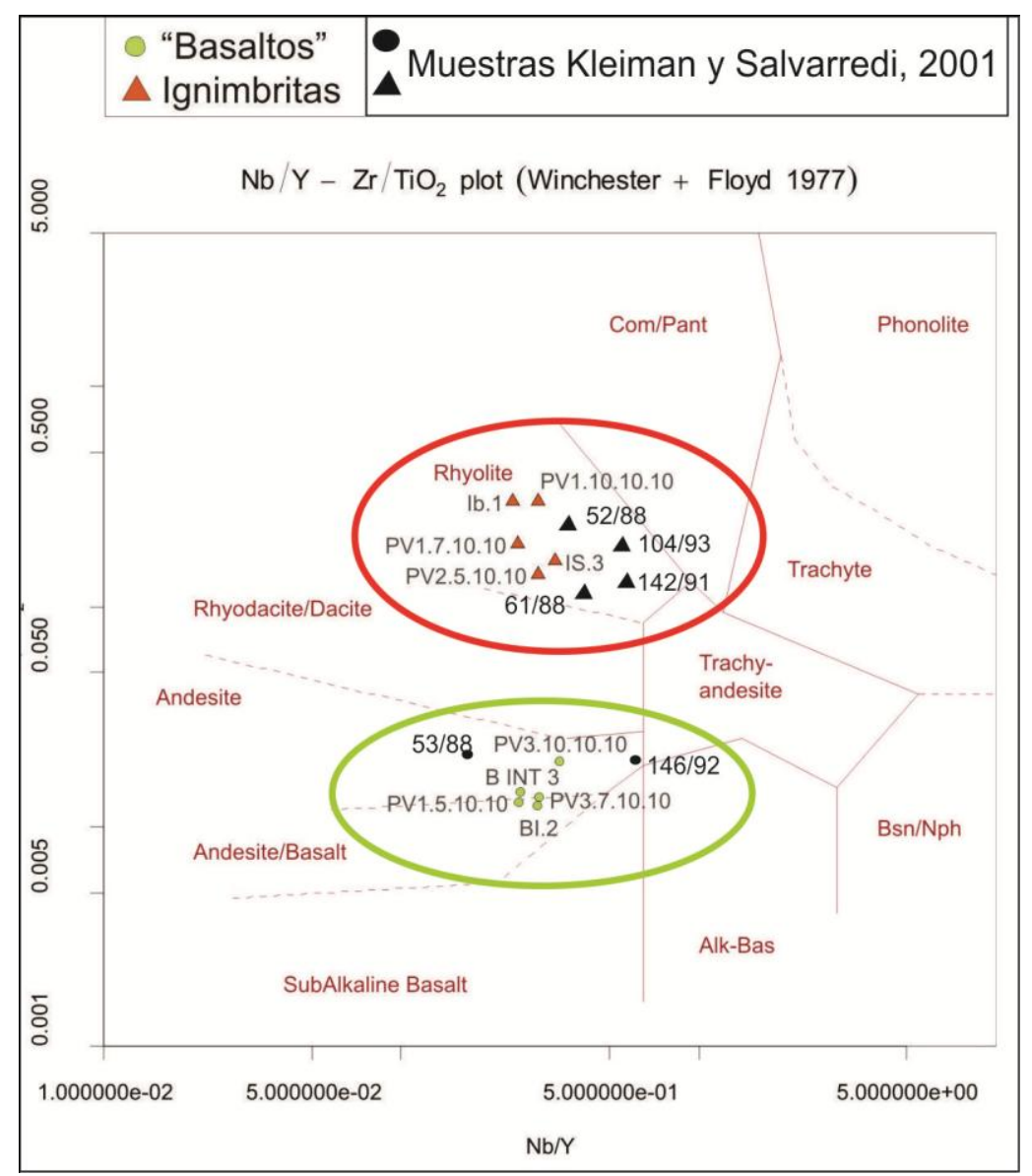

Figura 4.20. Diagrama de clasificación de rocas de elementos inmóviles (Middlemost, 1994) para las muestras volcánicas y piroclásticas del Grupo Puesto Viejo.

Los bajos contenidos de LOI (Loss on Ignition) (véase Anexo 3) que presentan estas muestras, inferiores a $2 \mathrm{w} \%$ para rocas piroclásticas (excepto la muestra PV 1.7.10.10 con LOI: $5,25 \mathrm{w} \%$ ) e inferiores a $4 \mathrm{w} \%$, para rocas volcánicas (excepto las muestras BINT 3 con LOI 5,4 w\%) son indicativos de que dichas rocas no habrían sufrido una alteración considerable, conservyo contenidos de sílice primarios (Gifkins et al., 2005). El diagrama de K/Na versus SiO2 no muestra una gran dispersión de los elementos mayores (Figura 4.19), confirmyo que estos no sufrieron movilidad considerable.

Los diagramas de discriminación de asociaciones petrotectónicas de Syl y Gardon (2002) basados en la relación de elementos traza (Ta,Hf) y tierras raras (REE; Yb), fueron utilizados para caracterizar a las muestras en el marco tectónico en el que se originaron y permitieron identificar dos tendencias 
(Figura 4.21). Las rocas volcánicas se distribuyen en el campo de zonas volcánicas de intraplaca y las rocas piroclásticas se distribuyen en el campo de margen continental activo.

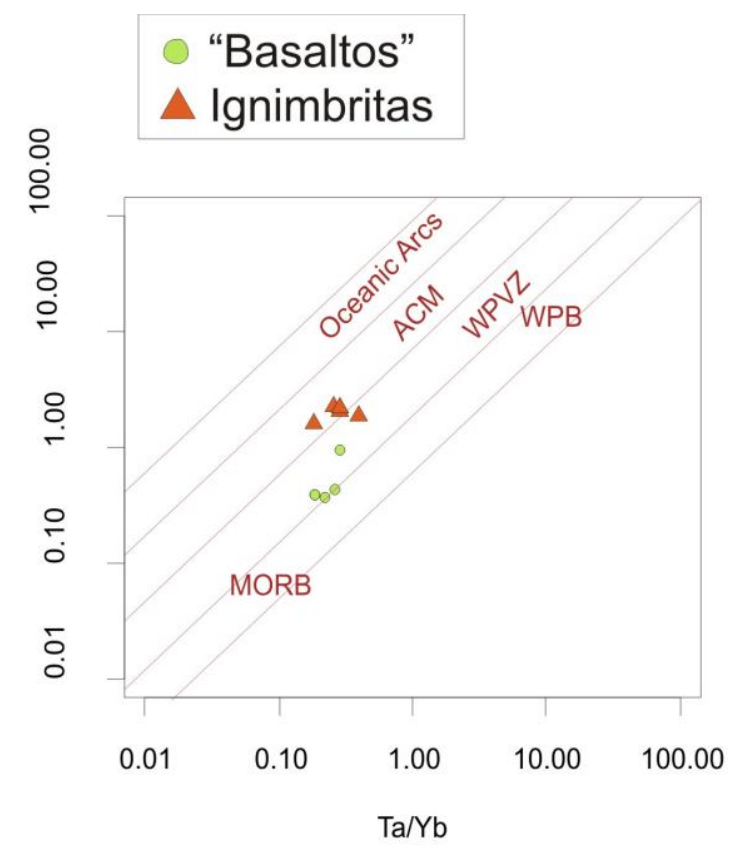

Shandl y Gordon (2002)
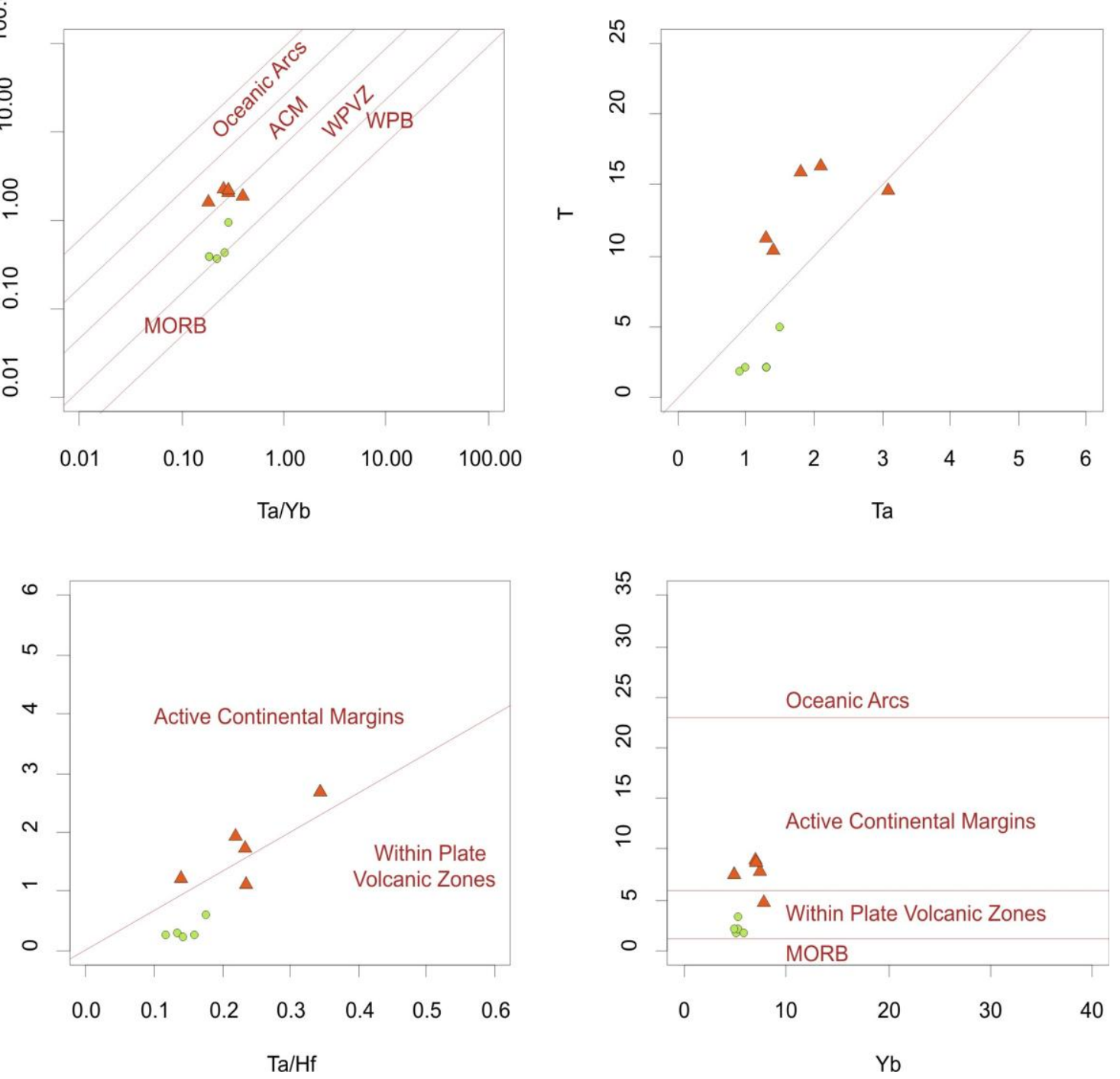

Figura 4.21. Diagramas de discriminación de asociaciones petrotectónicas de Syl y Gardon (2002) para las muestras de rocas volcánicas y piroclásticas del Grupo Puesto Viejo de la zona estudiada.

Se realizaron dos diagramas araña multielemento normalizado a basalto OIB para las rocas volcánicas (Figura 4.23) y normalizado a la corteza superior para las rocas piroclásticas (Figura 4.24) que permiten estimar el origen de los magmas que formaron a las rocas volcánicas del Grupo Puesto Viejo a partir 
de una fuente enriquecida y a las piroclásticas con fuertes depresiones en Sr. Los diagramas multielemento muestran un enriquecimiento en elementos LIL con respecto a los elementos HFS, mientras que el diagrama de elementos de REE muestra un leve enriquecimiento en tierras raras livianas (LREE) con respecto a las tierras raras pesadas (HREE).

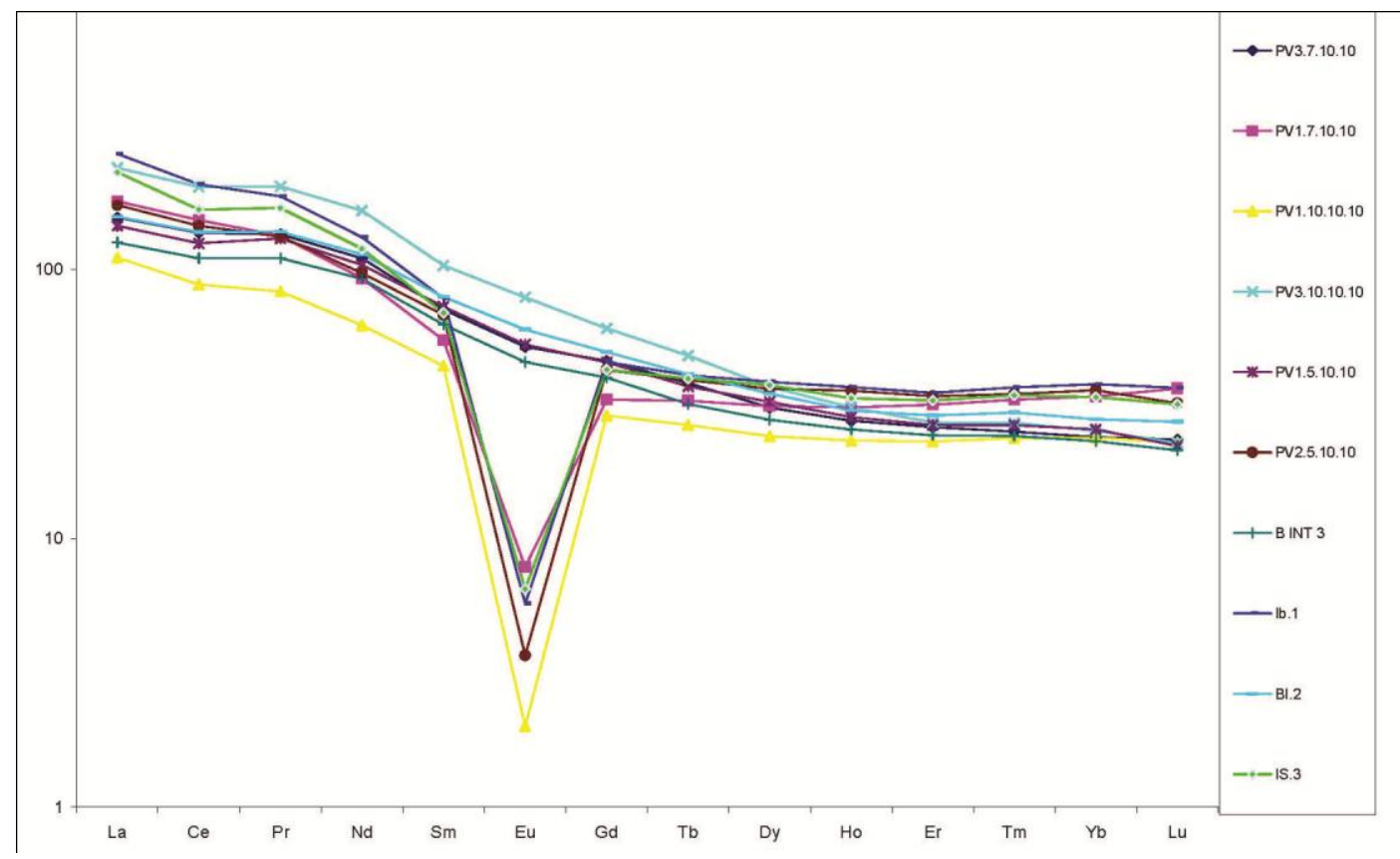

Figura 4.22. Diagrama multielemento para las rocas volcánicas y piroclásticas del Grupo Puesto Viejo en la zona de estudio.

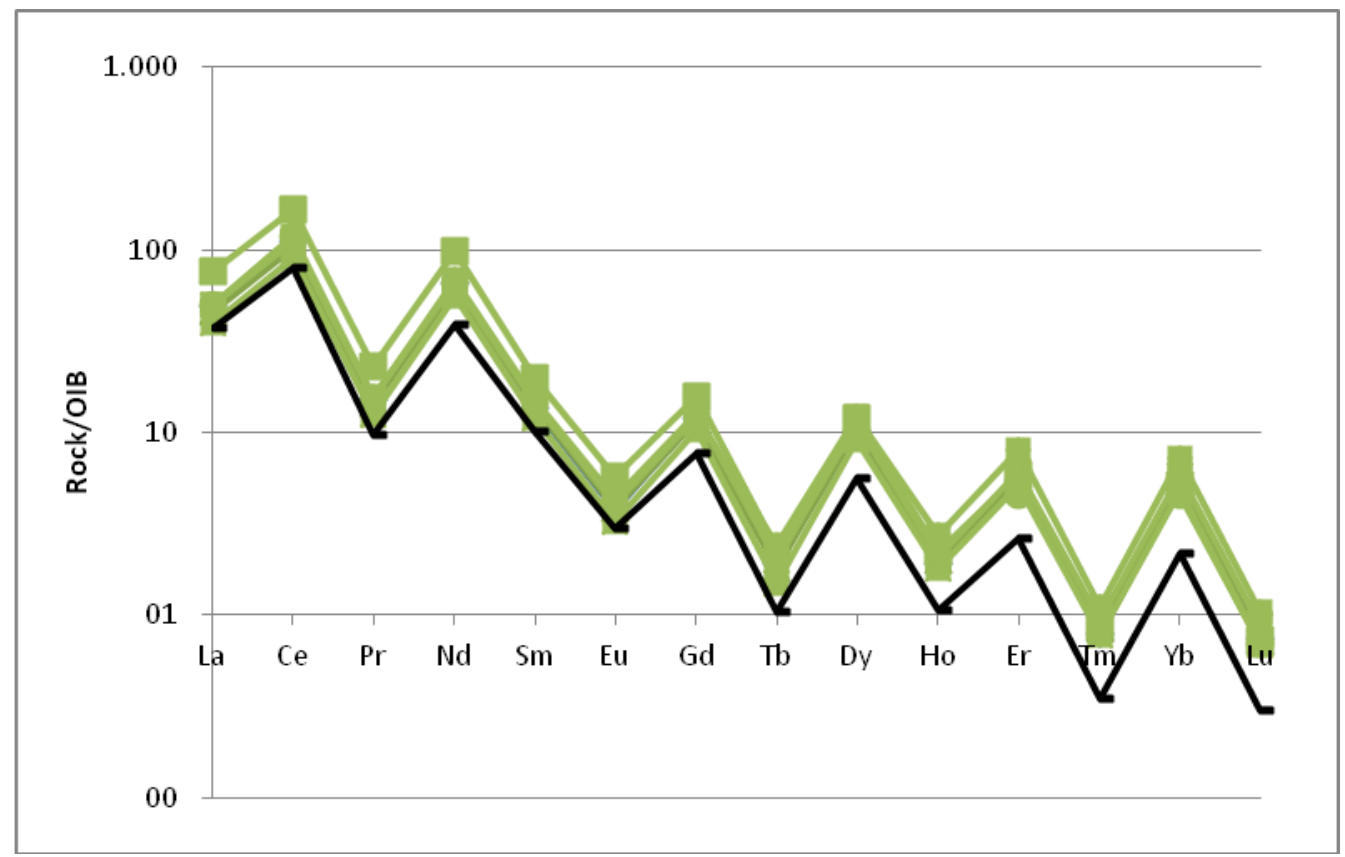


Figura 4.23. Diagrama multielemento para rocas volcánicas normalizado a OIB (Sun y McDonough, 1989).

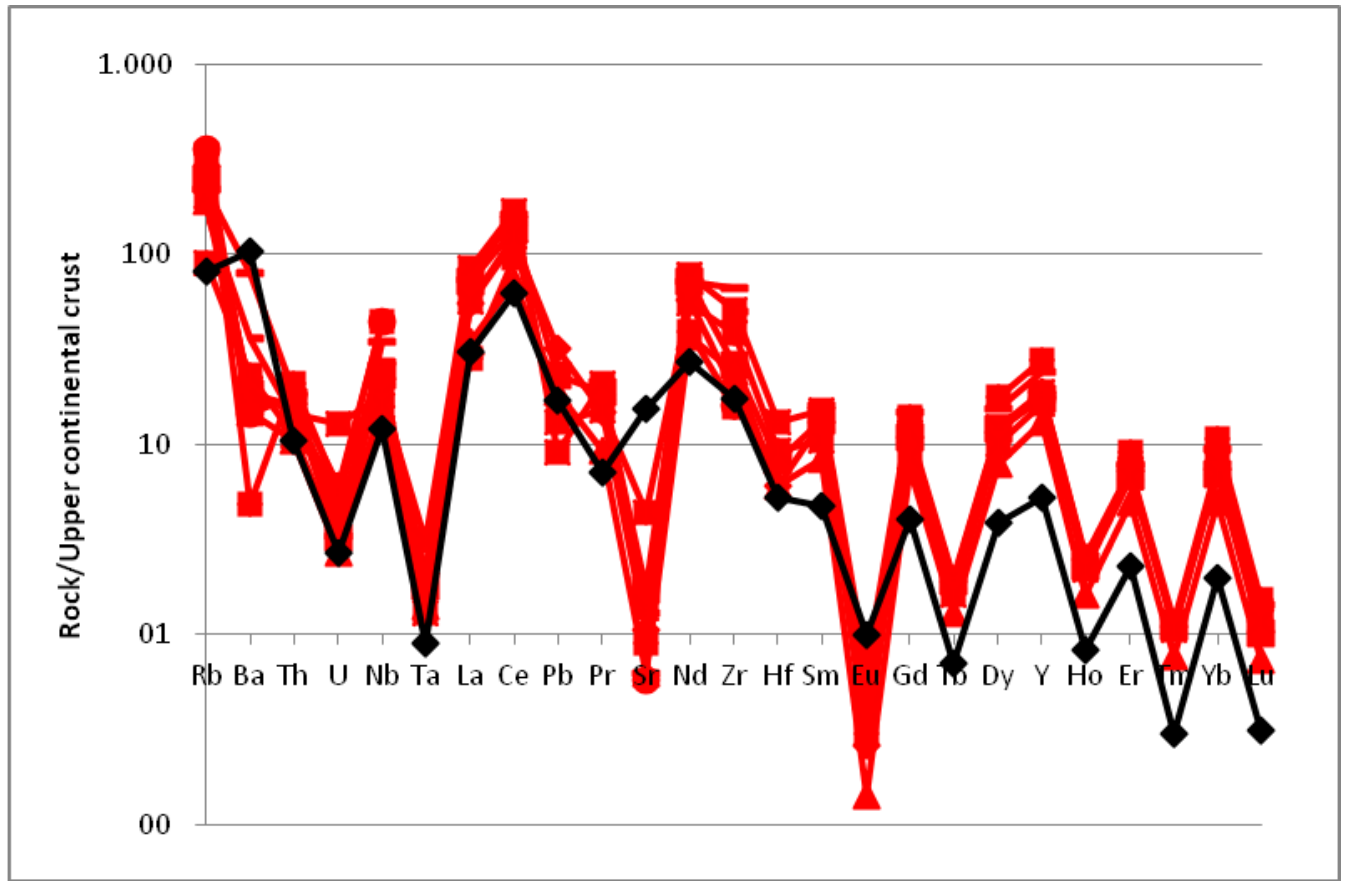

Figura 4.24. Diagrama multielemento para rocas piroclásticas normalizado a la corteza superior (Rudnick y Gao, 2003).

A continuación se presenta las siguientes tablas (Tablas 3 y 4 ) donde se resumen las características litogeoquímicas de las muestras analizadas para el Grupo Puesto Viejo. 


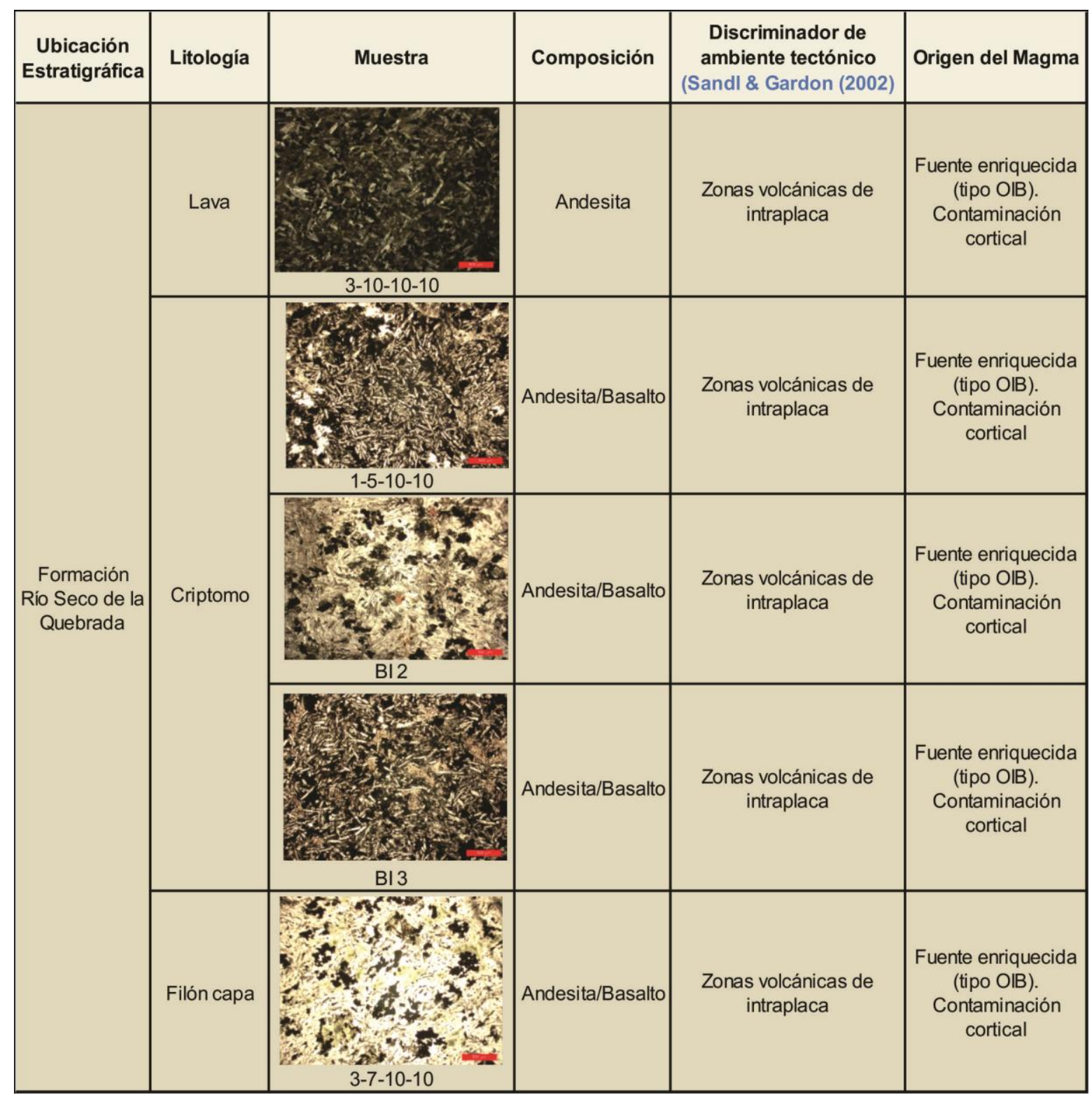

Tabla 3. Muestras de rocas volcánicas del Grupo Puesto Viejo. 


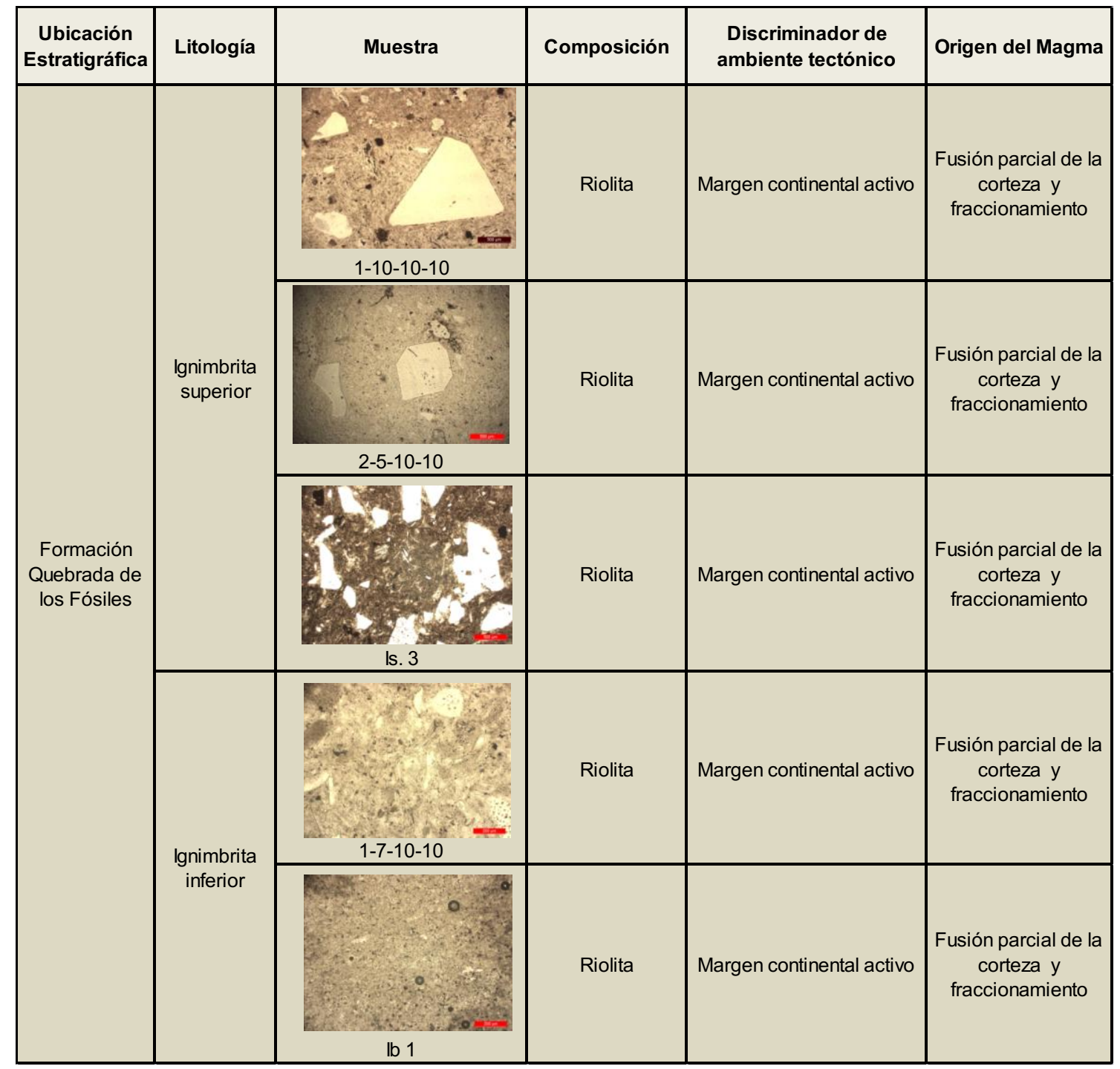

Tabla 4. Muestras de rocas piroclásticas del Grupo Puesto Viejo.

\subsection{Asociación de litofacies}

A continuación se avanza en el análisis de las litofacies definidas en el inciso 4.1 (Tabla 1). Sobre la base de las relaciones genéticas, la geometría general de los depósitos, su continuidad y forma así como los tipos de rocas y estructuras sedimentarias reconocidas (Reading, 1978), se establecieron 38 asociaciones de litofacies (Tabla 5) para el Grupo Puesto Viejo. La distribución espacial de las diferentes litofacies observadas y representadas en los perfiles sedimentológicos (véase Anexo 2) sumado a la identificación de los principales procesos sedimentarios, piroclásticos y volcánicos involucrados en la generación de las litofacies, permitió agrupar a las asociaciones de facies en 14 
tipos de cuerpos bien diferenciados (Tabla 5) a partir de los cuales fueron interpretados los diferentes subambientes depositacionales desarrollados durante la acumulación del Grupo Puesto Viejo.

Dadas las característica particulares que presenta el depocentro analizado en el área de estudio y con el objetivo de realizar un análisis integrado de la historia depositacional, las asociaciones de facies establecidas en esta sección luego serán analizadas en el marco de "unidades de acumulación”.

Las diferentes combinaciones de litofacies que constituyen las sucesiones pertenecientes al Grupo Puesto Viejo pueden dividirse básicamente en cuatro gryes grupos: aquellas formadas por procesos aluviales, las que se originaron por procesos fluviales, las formadas a partir de procesos piroclásticos y las originadas por procesos volcánicos. A continuación se describen los procesos involucrados que dieron origen a las asociaciones de facies establecidas para los diferente subambientes.

\subsubsection{Análisis de las asociaciones de rocas sedimentarias}

\section{Sistemas aluviales dominados por flujos de detritos (SG)}

Flujos hiperconcentrados: se presentan como cuerpo tabulares, no canalizados. Pueden desarrollarse en sucesiones puramente formadas por flujos o sino aparecen aislados en las porciones más distales en los sistemas aluviales. Son el producto de flujos densos de detritos en condiciones de alto régimen de flujo (véase Tabla 5; Smith y Lowe 1991; Miall, 1996).

Flujos de detritos diluidos: constituyen cuerpos principalmente tabulares siempre asociados depósitos de flujos de detritos. Formados por flujos de detritos pseudoplásticos con baja resistencia, viscosos, formados en condiciones de alto régimen de flujo (véase Tabla 5; Miall, 1996; Leeder, 1999; Bridge, 2003).

\section{Sistemas fluviales dominados por carga traccional}


Canales, $\mathrm{CH}$ : constituyen cuerpos de forma lenticular con base erosiva y techo plano, constituido a partir de la migración de megaóndulas 3D. Formados a partir se interpreta como depósitos traccionales de canal bajo un régimen de flujo intermedio (Miall, 1996; Leeder, 1999, Bridge, 2003). Pueden constituir canales angostos y profundos o bien canales anchos y someros asociados a depósitos más finos de planicies. También es común la presencia de depósitos aluviales asociados. Los canales son por lo general fuertemente erosivos, con formas de migración lateral y a veces desarrollan barras internas. Pueden darse de manera aislada o amalgamados (véase Tabla 5).

Barras gruesas, GB: constituyen cuerpos de lenticular a tabular con base erosiva e internamente conformada por capas planas producto de la migración de megaóndulas "2D" en condiciones de bajo régimen de flujo (véase Tabla 5; Miall, 1996; Leeder, 1999; Bridge, 2003).

Barras arenosas, DA/LA: consisten en cuerpos de forma lenticular con base erosiva y techo plano, constituido a partir de la migración de megaóndulas "3D" y "2D" formadas en condiciones de bajo régimen de flujo (véase Tabla 5; Leeder, 1999; Bridge, 2003). Se encuentran siempre asociadas a canales.

Capas planas, LA: consisten en cuerpos arenosos de forma tabular con base y techo netos. Internamente presentan estructura laminar generada en condiciones de alto régimen de flujo (Miall, 1996; Leeder, 1999). Se encuentran asociados siempre al tope de barras (véase Tabla 5).

Canales de crevasse y crevasse splay, SB: consisten en cuerpos arenosos de forma tabular con base y techo plano que se presentan de manera aislada dentro de planicies de inundación. Son producidos a partir de episodios de desbordamiento de canal o descarga. Internamente son masivos o se encuentran estratificados a partir de la migración de crestas planas (véase Tabla 5; Miall, 1996; Leeder, 1999).

Sistemas fluviales dominados por decantación 
Relleno de canal, OF: consisten en delgados cuerpos tabulares finos formados por decantación a partir de suspensiones ácueas en canales abandonados, (Miall, 1996; Blair y McPherson, 2008). Se encuentran siempre asociados al tope de barras y canales (véase Tabla 5).

Planicies de inundación, FF: forman extensos cuerpos tabulares pelíticos internamente laminados o masivos. Se formaron por decantación a partir de suspensiones ácueas en pantanos o canales abandonados (Blair y McPherson, 2008). Constituyen planicies de inundación con importante acción biogénica y marcas de raíces (véase Tabla 5).

Cuerpos de agua someros, FF: constituyen delgados cuerpos tabulares pelíticos de poca extensión. Caracterizados por un alto grado de bioturbación, abundantes marcas de raíces, ricos en restos vegetales y materia orgánica. Son depósitos formados por decantación en llanura de inundación o canales abandonados (Plint y Brown, 1994). Presentan una marcada intercalación de niveles asociados al desarrollo incipiente de paleosuelos (Retallack, 2001) con niveles carbonáticos producto del crecimiento algas fijadoras de carbonatos de calcio desarrolladas en cuerpos de agua someros (Tucker, 2001; véase Tabla $5)$.

\subsubsection{Análisis de las asociaciones de rocas piroclásticas}

Depósitos de caída: Constituyen cuerpos muy delgados y aislados de la Litofacies Tm (véase Tabla 5).

Depósitos de corrientes piroclásticas: se trata de cuerpos aislados 0 superpuestos de las Litofacies $\mathrm{mL} / \mathrm{mLs}$ (véase Tabla 5).

\subsubsection{Análisis de las asociaciones de rocas volcánicas}


Intrusivos subvolcánicos: consisten en cuerpos de variadas dimensiones con formas dómicas, formados por la solidificación de magma básico en condiciones subvolcánicas con un período de enfriamiento que permitió la nucleación y crecimiento de cristales (Llambías, 2003). Los intrusivos están asociados a depósitos autoclásticos (peperitas) localizados en el techo de los intrusivos como producto del contacto entre un intrusivo y el sedimento inconsolidado (McP hie et al., 1993; véase Tabla 5).

Efusiones superficiales: constituyen extensos cuerpos de forma tabular formados a partir de la solidificación de lava de composición yesítica, con un corto período de crecimiento de cristales, seguido por un rápido enfriamiento en un ambiente subaéreo (Best y Christiansen, 2001; véase Tabla 5). 


\begin{tabular}{|c|c|c|c|c|}
\hline $\begin{array}{l}\text { Tipo de } \\
\text { roca }\end{array}$ & Asociación de Litofacies & $\begin{array}{c}\text { Código } \\
\text { ar qui tectur al }\end{array}$ & origen & Sub-ambiente \\
\hline \multirow{32}{*}{ Ep iclasticas } & Gcm & \multirow{3}{*}{ SG } & $\begin{array}{l}\text { Depósitos de flujos } \\
\text { hiperconcentrados }\end{array}$ & \multirow{3}{*}{$\begin{array}{l}\text { Depósitos aluviales } \\
\text { proximal- med io-distal. }\end{array}$} \\
\hline & Gm/Gmg, Gmp, Gh, /Sm & & \multirow{2}{*}{$\begin{array}{l}\text { Depósitos de flujos de } \\
\text { detritos diluidos no } \\
\text { canalizados }\end{array}$} & \\
\hline & Gt/Gmg, Gh,SGt,Sm/Sl & & & \\
\hline & $S G t / G t$ & \multirow{10}{*}{$\mathrm{CH}$} & \multirow{4}{*}{$\begin{array}{l}\text { Depósitos de canales } \\
\text { ama lgamados. Do min io de } \\
\text { carga traccional }\end{array}$} & \multirow{10}{*}{$\begin{array}{l}\text { Miembro grueso de sistem } \\
\text { meandroso. Canales } \\
\text { principales. }\end{array}$} \\
\hline & Gt/Gmg-Sh & & & \\
\hline & $\mathrm{Gt} / \mathrm{Sp}$ & & & \\
\hline & St & & & \\
\hline & $\mathrm{Gt} / \mathrm{SGt}$ & & \multirow{6}{*}{$\begin{array}{l}\text { Depósitos de canales } \\
\text { aislados. Dominio de carga } \\
\text { traccional }\end{array}$} & \\
\hline & $\mathrm{Gp} / \mathrm{St} / \mathrm{Sm}$ & & & \\
\hline & SGp/SGt & & & \\
\hline & $\mathrm{St}$ & & & \\
\hline & $\mathrm{Gt} / \mathrm{Gmg}$ & & & \\
\hline & Gp & & & \\
\hline & $\mathrm{Gh} / \mathrm{Gmg}$ & \multirow{2}{*}{ GB } & \multirow{2}{*}{$\begin{array}{c}\text { Barras gruesas } \\
\text { longitudinales y } \\
\text { transversales }\end{array}$} & \multirow{2}{*}{$\begin{array}{l}\text { Miembro grueso de sistema } \\
\text { meandroso (canal-barras). }\end{array}$} \\
\hline & SGp , Gp & & & \\
\hline & $\mathrm{Sp}$ & DA/LA & $\begin{array}{l}\text { Barras arenosas } \\
\text { agradacionales }\end{array}$ & \multirow{2}{*}{ Barras arenosas } \\
\hline & $\mathrm{Sp} / \mathrm{Sl} / \mathrm{Sh}$ & LA & $\begin{array}{c}\text { Depósitos de acreción } \\
\text { lateral. }\end{array}$ & \\
\hline & $\mathrm{Sm} / \mathrm{Sh} / \mathrm{STm}$ & LS & $\begin{array}{c}\text { Capas planas. Tamb ién de } \\
\text { banco acrecionario o tope de } \\
\text { barra. }\end{array}$ & $\begin{array}{c}\text { Depósitos de } \\
\text { desbordamiento poco } \\
\text { canalizado. }\end{array}$ \\
\hline & $\mathrm{Sm} / \mathrm{F} 1$ & $\mathrm{OF}$ & Depositos de decantación & $\begin{array}{c}\text { Relleno de canales } \\
\text { abandonados. Depósitos } \\
\text { de estiaje }\end{array}$ \\
\hline & $\mathrm{S} 1 / \mathrm{Sh} / \mathrm{Sp}$ & \multirow{7}{*}{ SB } & \multirow{5}{*}{$\begin{array}{l}\text { Depósitos de canales de } \\
\text { crevasse, también canales } \\
\text { pequeños de descarga o } \\
\text { chutes de sistema fluvial }\end{array}$} & \multirow{7}{*}{$\begin{array}{l}\text { Planicie de inundación con } \\
\text { canales de descarga y } \\
\text { lóbulos de desbordamiento }\end{array}$} \\
\hline & $\mathrm{Sl} / \mathrm{St} / \mathrm{Sp}$ & & & \\
\hline & STp & & & \\
\hline & St & & & \\
\hline & $\mathrm{STm}$ & & & \\
\hline & $\mathrm{Gp} / \mathrm{Sm}$ & & \multirow{2}{*}{$\begin{array}{l}\text { Depósitos de canales de } \\
\text { crevasse splay }\end{array}$} & \\
\hline & $\mathrm{Gh} / \mathrm{S} 1$ & & & \\
\hline & $\mathrm{Sm} / \mathrm{F} 1 / \mathrm{Fs} \mathrm{m}$ & \multirow{6}{*}{$\mathrm{FF}$} & \multirow{6}{*}{$\begin{array}{l}\text { Depositos de decantación, } \\
\text { subácueos y subaéreos de } \\
\text { planicie de inundación }\end{array}$} & \multirow{6}{*}{$\begin{array}{l}\text { Miembro fino en sistema } \\
\text { meandroso. Planicie de } \\
\text { inundación con depósitos } \\
\text { de decantación }\end{array}$} \\
\hline & Fs $1 /$ Fsm/ Sm & & & \\
\hline & FTm & & & \\
\hline & $\mathrm{Fl} / \mathrm{Fr}$ & & & \\
\hline & Fsm/F1 & & & \\
\hline & Fsm/F1/FTm & & & \\
\hline
\end{tabular}




\begin{tabular}{|c|c|c|c|}
\hline \multirow{3}{*}{$\begin{array}{c}\text { Ep iclasticas } \\
\text { Carbonáticas } \\
\text { Pirocásticas } \\
\text { de caída }\end{array}$} & $\mathrm{Cl} / \mathrm{Fr} / \mathrm{FTrf} / \mathrm{Fsm} / \mathrm{Fl} / \mathrm{Tm}$ & \multirow{3}{*}{$\begin{array}{c}\text { Depositos de decantación, } \\
\text { subácueos y subaéreos } \\
\text { (loéssicos) }\end{array}$} & \multirow{3}{*}{$\begin{array}{c}\text { Depósitos de planicie } \\
\text { lacustres y desarrollo } \\
\text { incipiente de paleosuelos } \\
\text { en planicie de inundación. }\end{array}$} \\
\hline & Fl/Fr/ FTrf/FTm & & \\
\hline & FTl/FTm & & \\
\hline \multirow{2}{*}{$\begin{array}{l}\text { Piroclasticas } \\
\text { de flujo }\end{array}$} & $\mathrm{mL}$ & \multirow{2}{*}{$\begin{array}{l}\text { Depósitos de corrientes } \\
\text { piroclásticas }\end{array}$} & \multirow{2}{*}{$\begin{array}{l}\text { Planic ie con depósitos de } \\
\text { flu jo piroc lástico }\end{array}$} \\
\hline & $\mathrm{mLs} / \mathrm{mL}$ & & \\
\hline \multirow[t]{2}{*}{ Vo lcánicas } & $\mathrm{Bi} / \mathrm{Pp}$ & $\begin{array}{l}\text { Intrusivos subvolcánicos y } \\
\text { rocas derivadas de la } \\
\text { intrusión en rocas de caja } \\
\text { inconsolidadas }\end{array}$ & $\begin{array}{l}\text { Cuerpos hipoabisales en } \\
\text { planicies de inundación }\end{array}$ \\
\hline & LAB & Efusiones superficiales & $\begin{array}{l}\text { Lavas andesíticas sobre } \\
\text { depósitos fluviales }\end{array}$ \\
\hline
\end{tabular}

Tabla 5. Asociación de litofacies.

\subsection{Análisis de las unidades de acumulación}

En esta sección se presentan las distintas unidades de acumulación que hacen al relleno de la Cuenca de San Rafael en la zona de estudio. El término "unidad" se utiliza para poder dividir al relleno del depocentro como agrupamientos naturales de roca. Cada unidad de acumulación se compone de rocas formadas por procesos similares, que comparten una composición muy parecida y cuyos límites son comunes y se encuentran bien definidos. Este método permite abordar el análisis del registro estratigráfico que presenta el Grupo Puesto Viejo integrado por rocas de origen volcánico efusivo y extrusivo en asociación íntima con depósitos de origen epiclástico en el marco de un régimen extensional. La definición de cada unidad de acumulación implica la integración de las asociaciones litofaciales descriptas en el inciso anterior que presenten relación genética y se repiten a lo largo de la secuencia. En ese sentido se han definido unidades de acumulación como una herramienta para comenzar a conocer y entender las diferentes etapas de relleno de la cuenca, como entidades con un sentido tectonoestratigráfico tratados en el próximo Capítulo .

Del análisis de los sub-ambientes sedimentarios en conjunto con los procesos de depositación, la distribución, geometría y la relación con las estructuras originales del depocentro, se determinaron cinco unidades de acumulación: 1) Abanicos aluviales, 2) Sistema meandroso de baja sinuosidad, 3) Sistema 
meandroso de alta sinuosidad, 4) Flujos piroclásticos y 5) Rocas volcánicas. A continuación se describirá cada una de ellas.

\subsubsection{Abanicos aluviales}

Esta unidad de acumulación se caracteriza por un notable predominio de depósitos de grano grueso, que se presentan como cuerpos tabulares superpuestos (Figura 4.25c). Aunque no es posible establecer la geomorfología de estos depósitos dada su mala preservación, las asociaciones de facies descriptas para esta unidad (véase Tablas 5 y 6 ) localizadas en los márgenes del depocentro y los procesos que le dieron origen permite reunirlas dentro un sistema de abanicos aluviales (Blair y McPherson, 1994).

\begin{tabular}{|c|c|c|c|c|}
\hline $\begin{array}{l}\text { Asociación de } \\
\text { Litofacies }\end{array}$ & $\begin{array}{c}\text { Código } \\
\text { ar qui tectur al }\end{array}$ & origen & Sub-ambientes & $\begin{array}{c}\text { Unidad de } \\
\text { acumulación }\end{array}$ \\
\hline $\mathrm{Gcm}$ & \multirow{3}{*}{ SG } & $\begin{array}{l}\text { Depósitos de flujos } \\
\text { hiperconcentrados }\end{array}$ & \multirow{3}{*}{$\begin{array}{c}\text { Depósitos } \\
\text { aluviales } \\
\text { proximal a } \\
\text { med io }\end{array}$} & \multirow{7}{*}{$\begin{array}{l}\text { Abanicos } \\
\text { aluviales }\end{array}$} \\
\hline $\begin{array}{l}\mathrm{Gm} / \mathrm{Gmg}, \mathrm{Gmp}, \mathrm{Gh}, \\
/ \mathrm{Sm}\end{array}$ & & Depósitos de flujos de & & \\
\hline Gt/Gmg, Gh, SGt ,Sm/Sl & & canalizados distales. & & \\
\hline St & \multirow{2}{*}{ SB } & \multirow{2}{*}{$\begin{array}{c}\text { Depósitos de canales de } \\
\text { crevasse }\end{array}$} & \multirow{4}{*}{$\begin{array}{l}\text { Depósitos } \\
\text { aluviales } \\
\text { distales. } \\
\text { Planicie aluvial } \\
\text { con canales de } \\
\text { descarga }\end{array}$} & \\
\hline $\mathrm{STm}$ & & & & \\
\hline $\mathrm{Fs} 1 / \mathrm{Fsm} / \mathrm{Sm}$ & \multirow{2}{*}{$\mathrm{FF}$} & \multirow{2}{*}{$\begin{array}{c}\text { Depositos de decantación, } \\
\text { subácueos y subaéreos de } \\
\text { planicie }\end{array}$} & & \\
\hline FTm & & & & \\
\hline
\end{tabular}

Tabla 6. Asociaciones de facies definidas para esta unidad de acumulación.

Al analizar las litofacies que componen estos cuerpos se observa una predominancia de litofacies conglomerádicas Gcm, Gmg, Gh, Gt, SGt (véase Tabla 1) y en menor proporción facies arenosas Sm, SI (véase Tablas 5 y 6). Los niveles proximales de esta unidad de acumulación abanicos aluviales se encuentran esencialmente compuestos por dos asociaciones de facies (véase 
Tablas 5 y 6): una corresponde a los flujos hiperconcentrados y la otra a los flujos diluidos no canalizados formados en condiciones de flujo relativamente altos y descarga de sedimento. Ocasionalmente, entre estos paquetes de conglomerados con estratificación horizontal y masivos, intercalan pequeños cuerpos lenticulares aislados de arenisca con estratificación entrecruzada en artesa (St, véase Tabla 5 y Figura $4.25 \mathrm{~b}$ ) en respuesta a una rápida disminución de la descarga de sedimento y del régimen de flujo. Además, los cuerpos conglomerádicos se encuentran separados por delgadas particiones pelíticas (Fsm, véase Tabla 1) lo cual sugiere que en determinadas áreas (posiblemente inter-abanicos) se produjeron acumulaciones suspensivas (Figura 4.25d). Estas asociaciones de facies responden a las condiciones que se generan cuyo se crea un cambio brusco de pendiente (que podría generarse como producto del fallamiento normal), donde el canal de alimentación antecedente fluye por gravedad hacia el piedemonte alcanzando una alta capacidad, alta competencia y alto régimen de flujo, resultyo en depósitos de sheetfloods (Erikson et al. 1993; Blair y McPherson, 1994). 


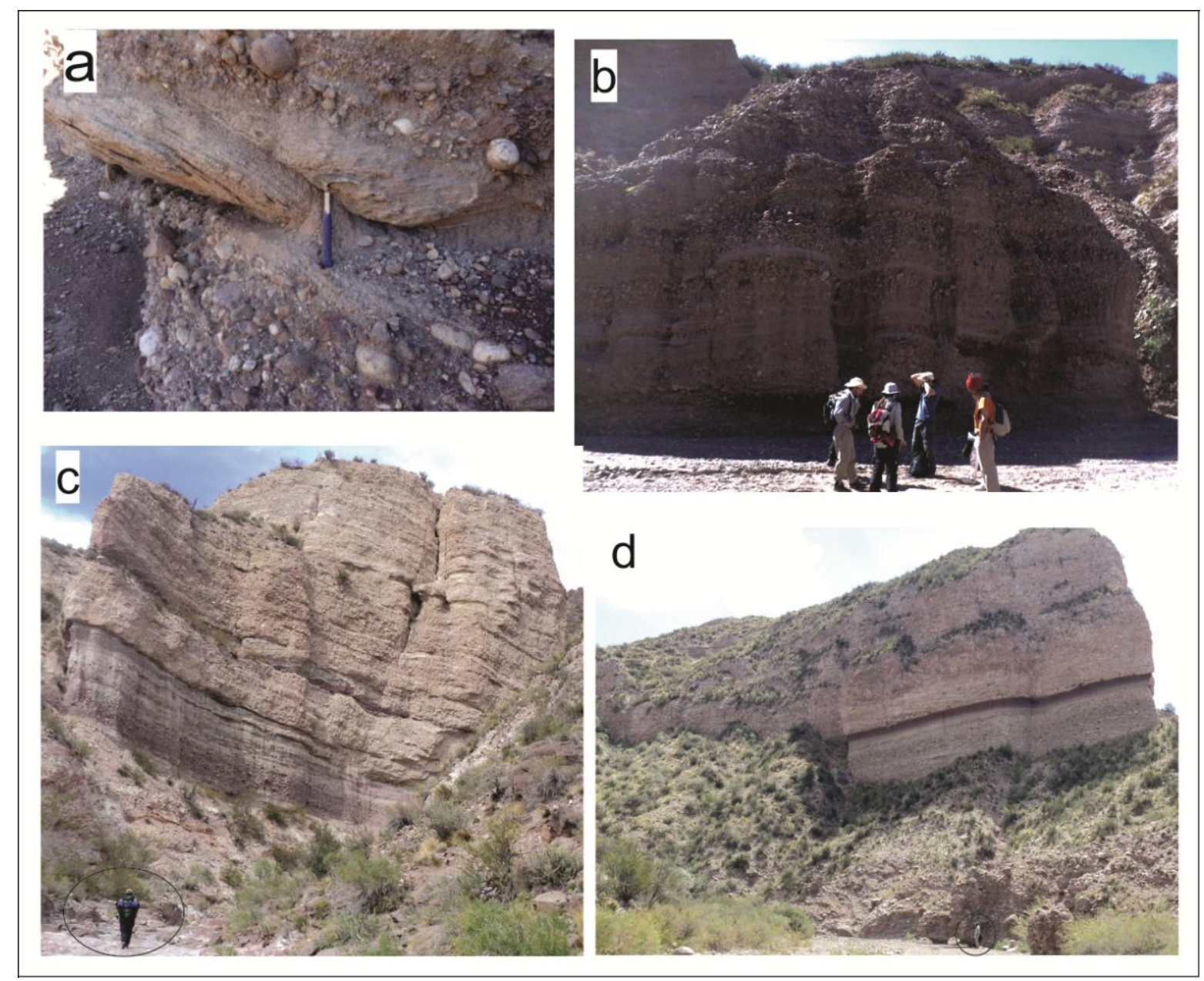

Figura 4.25. Afloramientos de abanicos aluviales en la localidad del Río Seco de la Quebrada (Figura 4.1 para ubicación). a) Detalle de pequeños canales de areniscas con estratificación entrecruzada. b) Afloramientos en el borde oriental. c) y d) afloramientos en el borde occidental.

Las litofacies que representan las partes más distales de esta unidad de acumulación se caracterizan por la superposición de delgados depósitos tabulares no canalizados, con amplia continuidad lateral y un marcado arreglo granocreciente. Se observa un importante predominio de litofacies finas formyo potentes bancos de cuerpos tabulares laminados caracterizados por la intercalación de litofacies Fsl/Fsm/Sm y FTm (véase Tabla 6). Consisten principalmente en limolitas arcillosas y pelitas rojas laminadas o masivas, posiblemente como producto de actividad biogénica. En los niveles pelíticos intercalan delgados cuerpos tabulares de arenisca fina a media, de composición tobácea y color blanquecino (Figuras 4.26a y c) de las asociaciones de litofacies St y STm (véase Tabla 4). El miembro fino de esta 
unidad de acumulación se asigna a procesos de decantación en planicies de inundación (Véase Tablas 5 y 6) con flujos eventuales de descarga conformyo canales de crevasse (véase Tabla 6). Es común el desarrollo local de flujos de detritos y flujos hiperconcentrados formyo cuerpos tabulares con base y techo neto de hasta 5 metros de espesor (Figuras $4.26 a$ y b). La homogeneidad de estos depósitos, las asociaciones de facies que presentan y los procesos que les dieron origen, indican la existencia de suaves paleopendientes del terreno que dieron lugar a la depositación de la posición más distal de un sistema aluvial que durante su evolución generó ciclos grano y estratocrecientes.

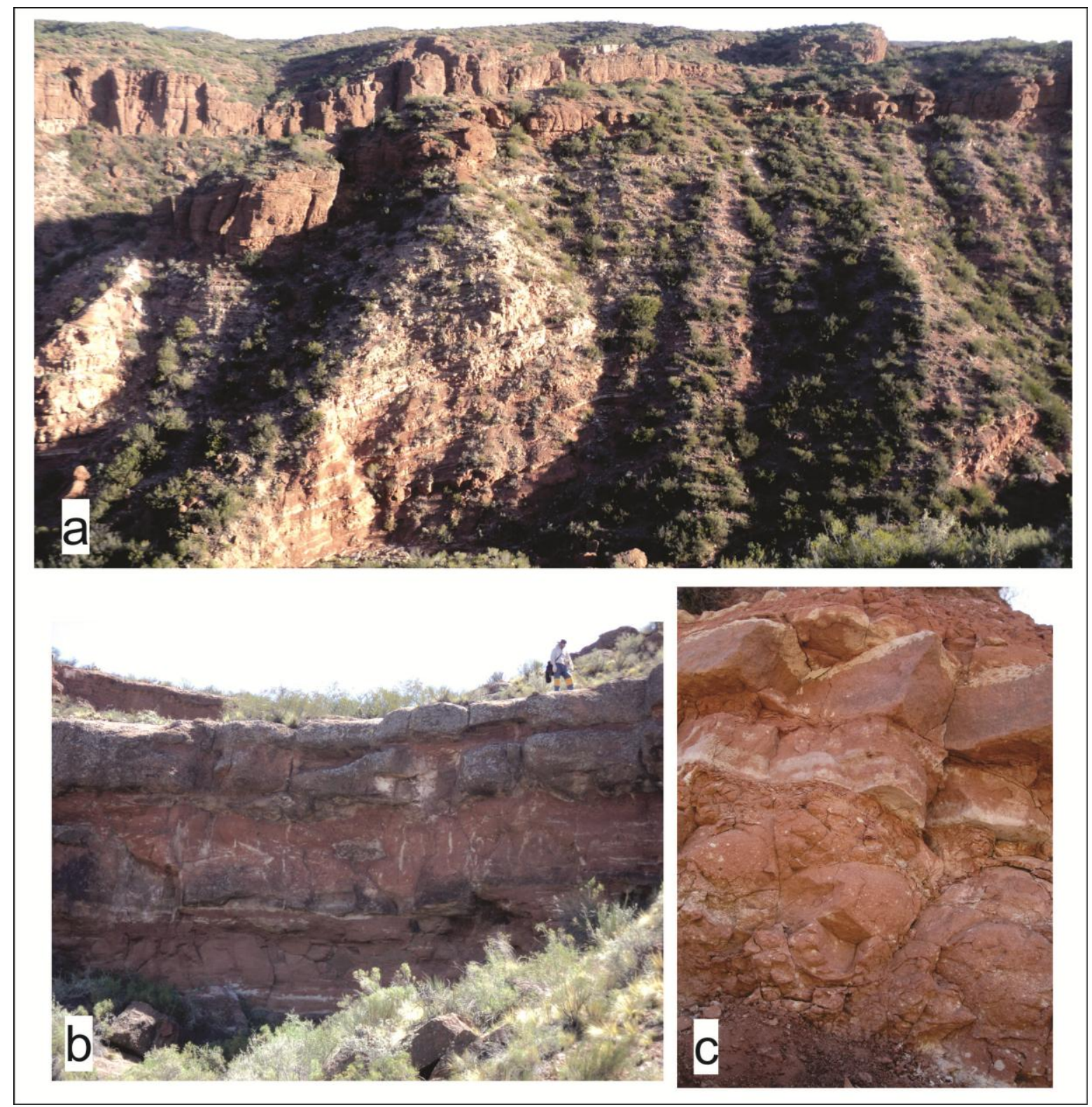

Figura 4.26. Afloramientos al norte de la localidad El Durazno (Figura 4.1 para ubicación). a) Sistema aluvial con dominio de facies finas y gruesas. b) detalle 
de flujo de detritos no canalizados. c) detalle de canales de crevasse en planicie aluvial.

\subsubsection{Sistema fluvial meandroso de baja sinuosidad}

Esta unidad de acumulación se describe como un sistema compuesto por una importante proporción de conglomerados con textura matriz-sostén, con litofacies arenosas y sabulíticas subordinadas.

Se caracteriza por el desarrollo de cuerpos lenticulares con base erosiva a neta, arreglo interno granodecreciente y techo erosionado a neto conformyo múltiples canales amalgamados (véase Tabla 5) y en ocasiones como canales aislados (véase Tabla 5) compuestos por conglomerados, sabulitas y areniscas medias a gruesas (véase Tabla 7).

\begin{tabular}{|c|c|c|c|c|}
\hline $\begin{array}{l}\text { Asociación de } \\
\text { Litofacies }\end{array}$ & $\begin{array}{c}\text { Código } \\
\text { ar qui tectur al }\end{array}$ & origen & Sub-ambientes & $\begin{array}{c}\text { Uni dad de } \\
\text { acumulación }\end{array}$ \\
\hline $\mathrm{SGt} / \mathrm{Gt}$ & \multirow{8}{*}{$\mathrm{CH}$} & \multirow{4}{*}{$\begin{array}{c}\text { Depósitos de canales } \\
\text { malgamados. Do minio de } \\
\text { carga traccional }\end{array}$} & \multirow{8}{*}{$\begin{array}{l}\text { Miembro grueso de } \\
\text { sistema meandroso. } \\
\text { Canales principales. }\end{array}$} & \multirow{16}{*}{$\begin{array}{c}\text { Sistema } \\
\text { meandroso } \\
\text { de baja } \\
\text { sinuosidad } \\
\text { (Braided) }\end{array}$} \\
\hline Gt/Gmg-Sh & & & & \\
\hline $\mathrm{Gt} / \mathrm{Sp}$ & & & & \\
\hline St & & & & \\
\hline $\mathrm{Gt} / \mathrm{SGt}$ & & \multirow{4}{*}{$\begin{array}{l}\text { Depósitos de canales } \\
\text { aislados. Do min io de carga } \\
\text { traccional }\end{array}$} & & \\
\hline $\mathrm{Gp} / \mathrm{St} / \mathrm{Sm}$ & & & & \\
\hline $\mathrm{SGp} / \mathrm{SGt}$ & & & & \\
\hline $\mathrm{St}$ & & & & \\
\hline $\mathrm{Gh} / \mathrm{Gmg}$ & \multirow{2}{*}{ GB } & \multirow{2}{*}{$\begin{array}{c}\text { Barras gruesas } \\
\text { longitudinales y } \\
\text { trans versales } \\
\end{array}$} & \multirow{3}{*}{$\begin{array}{l}\text { Miembro grueso de } \\
\text { sistema meandroso } \\
\text { (canal-barras). }\end{array}$} & \\
\hline $\mathrm{SGp}, \mathrm{Gp}$ & & & & \\
\hline $\mathrm{Sp}$ & $\mathrm{DA} / \mathrm{LA}$ & $\begin{array}{c}\text { Barras arenosas } \\
\text { agradacionales }\end{array}$ & & \\
\hline $\mathrm{Sm} / \mathrm{Sh} / \mathrm{STm}$ & LS & $\begin{array}{c}\text { Capas planas. También de } \\
\text { banco acrecionario o tope } \\
\text { de barra. }\end{array}$ & $\begin{array}{c}\text { Depósitos de } \\
\text { desbordamiento poco } \\
\text { canalizado. }\end{array}$ & \\
\hline $\mathrm{Sl} / \mathrm{Sh} / \mathrm{Sp}$ & \multirow{3}{*}{ SB } & \multirow{3}{*}{$\begin{array}{l}\text { Depósitos de canales de } \\
\text { crevasse, también canales } \\
\text { pequeños de descarga o } \\
\text { chutes de sistema fluvial }\end{array}$} & \multirow{3}{*}{$\begin{array}{l}\text { Planic ie de inundación } \\
\text { con crevasse. }\end{array}$} & \\
\hline $\mathrm{Sl} / \mathrm{St} / \mathrm{Sp}$ & & & & \\
\hline STp & & & & \\
\hline $\mathrm{Sm} / \mathrm{Fl} / \mathrm{Fs} \mathrm{m}$ & $\mathrm{FF}$ & $\begin{array}{c}\text { Depositos de decantación } \\
\text { subácuea }\end{array}$ & $\begin{array}{l}\text { Miembro fino en sistema } \\
\text { meandroso. Plan icie de } \\
\text { inundación con depósitos } \\
\text { de decantación }\end{array}$ & \\
\hline
\end{tabular}


Tabla 7. Asociaciones de facies definidas para esta unidad de acumulación.

Los términos más gruesos contienen clastos subangulosos a subredondeados de líticos de muy variada composición: riolita pérmica, basaltos e ignimbritas triásicas, areniscas verdes cementados por sílice, pelitas y cristales de cuarzo. En la mayoría de los casos presentan una matriz de arena gruesa a media con clastos subredondeados de la misma composición. El conjunto de litofacies descriptas (véase Tablas 5 y 7 ) representa un sistema de depositación por tracción a partir de múltiples canales y con carga de lecho predominante (Bridge, 2003), con paleocorrientes medidas hacia el noroeste.

Acompañan a los canales, cuerpos tabulares a lenticulares con base neta a erosiva (Figura 4.27a) constituidos por las asociaciones de litofacies $\mathrm{Gh} / \mathrm{Gmg}$, SGp, Gp y Sp (véase Tablas 5 y 7 ). Se atribuyen a una progradación de los canales con el desarrollo de barras longitudinales y transversales en un sistema fluvial con carga de lecho predominante (véase Tabla 5). Asociados al tope de las barras se describen cuerpos de forma tabular con base y techo netos, internamente laminados (véase Tabla 5), conformados por areniscas finas a medias con moderada a buena selección. La asociación de litofacies definida como Sm/Sh/STm (véase Tabla 5) permite interpretarlo como depósito de desbordamiento próximos al canal principal (Miall, 1996; Leeder, 1999).

Las planicies de inundación se encuentran poco desarrolladas dentro de este sistema fluvial con canales recurrentes de alta energía (Figura 4.27c), caracterizadas por depósitos fango-limosos color rojo y verdoso, laminados en asociación de litofacies Sm/F/Fsm (véase Tabla 1 para su descripción individual) interrumpidos por pequeños canales arenosos con típicas asociaciones de litofacies SI/Sh/Sp; SI/St/Sp y STp. Estos depósitos constituyen canales crevasse o canales pequeños de descarga del sistema fluvial (véase Tabla 5) posiblemente asociados a eventos de crecidas (Miall, 1996; Bridge, 2003). 


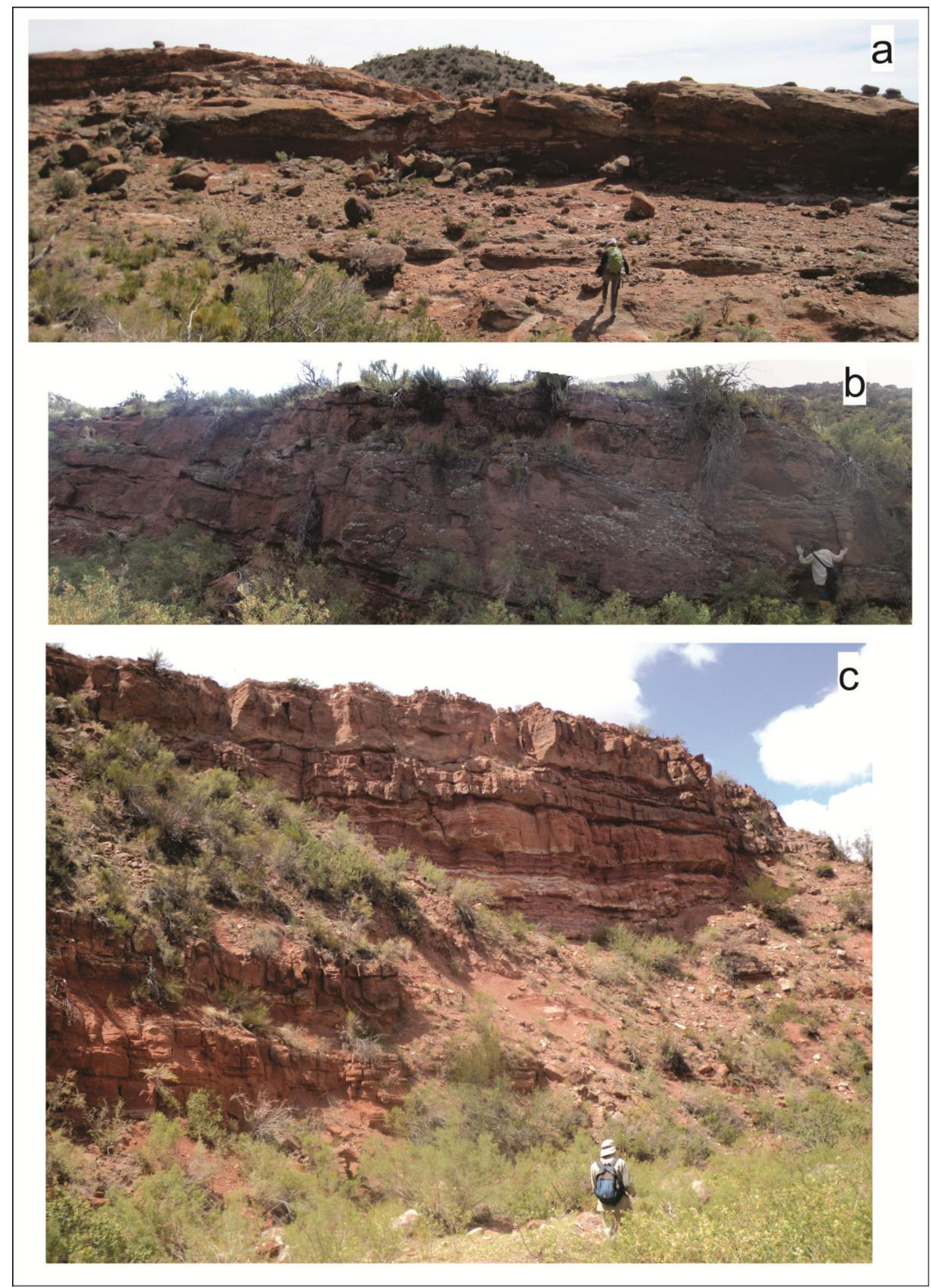

Figura 4.27. a) Migración de barras en canal principal; b) canales amalgamados; c) delgadas planicies de inundación con canales de crevasse. 


\subsubsection{Sistema fluvial meandroso de alta sinuosidad}

Esta unidad de acumulación se caracteriza por un notable predominio de depósitos de grano fino cuyo desarrollo supera al de los términos de grano más grueso asociados.

\begin{tabular}{|c|c|c|c|c|}
\hline $\begin{array}{l}\text { Asociación de } \\
\text { Litofacies }\end{array}$ & $\begin{array}{c}\text { Código } \\
\text { ar qui tectur al }\end{array}$ & origen & Sub-ambientes & $\begin{array}{l}\text { Unidad de } \\
\text { acumulación }\end{array}$ \\
\hline $\mathrm{Gt} / \mathrm{Gmg}$ & \multirow[t]{2}{*}{$\mathrm{CH}$} & \multirow{2}{*}{$\begin{array}{l}\text { Depósitos de canal. } \\
\text { Do min io de carga } \\
\text { traccional }\end{array}$} & \multirow{2}{*}{$\begin{array}{l}\text { Miembro grueso de sistema } \\
\text { meandroso. Canal principal }\end{array}$} & \multirow{15}{*}{$\begin{array}{l}\text { Sistema } \\
\text { meandroso } \\
\text { de alta } \\
\text { sinuosidad }\end{array}$} \\
\hline Gp & & & & \\
\hline $\mathrm{Sp}$ & \multirow{2}{*}{ LA } & \multirow{2}{*}{$\begin{array}{c}\text { Depósitos de acreción } \\
\text { lateral. }\end{array}$} & \multirow{2}{*}{$\begin{array}{c}\text { Barras arenosas } \\
\text { agradacionales }\end{array}$} & \\
\hline $\mathrm{Sp} / \mathrm{Sl} / \mathrm{Sh}$ & & & & \\
\hline $\mathrm{Sm} / \mathrm{F} 1$ & OF & $\begin{array}{l}\text { Depositos de } \\
\text { decantación }\end{array}$ & $\begin{array}{c}\text { Relleno de canales } \\
\text { abandonados. Depósitos de } \\
\text { estiaje }\end{array}$ & \\
\hline $\mathrm{STm}$ & \multirow{4}{*}{ SB } & \multirow{4}{*}{$\begin{array}{c}\text { Depósitos de canales } \\
\text { de crevasse aislados y } \\
\text { crevasse splay }\end{array}$} & \multirow{4}{*}{$\begin{array}{l}\text { Planicie de inundación con } \\
\text { canales de descarga y lóbulos } \\
\text { de desbordamiento }\end{array}$} & \\
\hline St & & & & \\
\hline $\mathrm{Gp} / \mathrm{Sm}$ & & & & \\
\hline $\mathrm{Gh} / \mathrm{S} 1$ & & & & \\
\hline Fl/ Fr & \multirow{6}{*}{$\mathrm{FF}$} & \multirow{3}{*}{$\begin{array}{c}\text { Depositos de } \\
\text { decantación, } \\
\text { subácueos de planicie } \\
\text { de inundación }\end{array}$} & \multirow{3}{*}{$\begin{array}{l}\text { Miembro fino de sistema } \\
\text { meandroso. Depísitos de } \\
\text { planicie de inundación }\end{array}$} & \\
\hline $\mathrm{Fsm} / \mathrm{F} 1$ & & & & \\
\hline $\mathrm{Fsm} / \mathrm{F} 1 / \mathrm{FTm}$ & & & & \\
\hline $\begin{array}{c}\mathrm{Cl} / \mathrm{Fr} / \mathrm{FTrf} / \mathrm{Fsm} / \\
\text { Fl/Tm }\end{array}$ & & \multirow{3}{*}{$\begin{array}{c}\text { Depositos de } \\
\text { decantación, } \\
\text { subácueos y subaéreos } \\
\text { (loessicos) }\end{array}$} & \multirow{3}{*}{$\begin{array}{l}\text { Depósitos de planicie } \\
\text { lacustres y desarrollo } \\
\text { incipiente de paleosuelos en } \\
\text { planicie de Inundación. }\end{array}$} & \\
\hline $\mathrm{Fl} / \mathrm{Fr} / \mathrm{FTrf} / \mathrm{FTm}$ & & & & \\
\hline $\mathrm{FTl} / \mathrm{FTm}$ & & & & \\
\hline
\end{tabular}

Tabla 8. Asociaciones de facies definidas para esta unidad de acumulación.

Los depósitos que constituyen el miembro grueso de este sistema están compuestos por litofacies conglomerádicas Gt, Gmg, Gp (véase Tabla 1) y arenosas Sp, SI, Sh, Sm (véase Tabla 1) agrupadas en cuerpos lenticulares bien definidos. Internamente se identifican sets de aproximadamente 1 metro de espesor y arreglo granodecreciente. Esta unidad de acumulación incluye a depósitos de fondo de canal meandroso (véase Tabla 5) con asociaciones de 
litofacies $\mathrm{Gt} / \mathrm{Gmg}$ y $\mathrm{Gp}$ y de barras arenosas (véase Tablas 5 y 8 ) en asociación de litofacies $\mathrm{Sp} / \mathrm{SI} / \mathrm{Sh}$ que culminan con asociaciones de litofacies $\mathrm{Sm} / \mathrm{FI}$ como relleno de canal en períodos de estiaje (véase Tablas 5 y 8). En conjunto representan los canales principales del sistema fluvial de alta sinuosidad con un típico arreglo granodecreciente (Figura 4.28; Collinson, 1986; Clemente y Pérez-Arlucea, 1993; Spalletti, 1994; Veiga et al., 2002; Bridge, 2006).

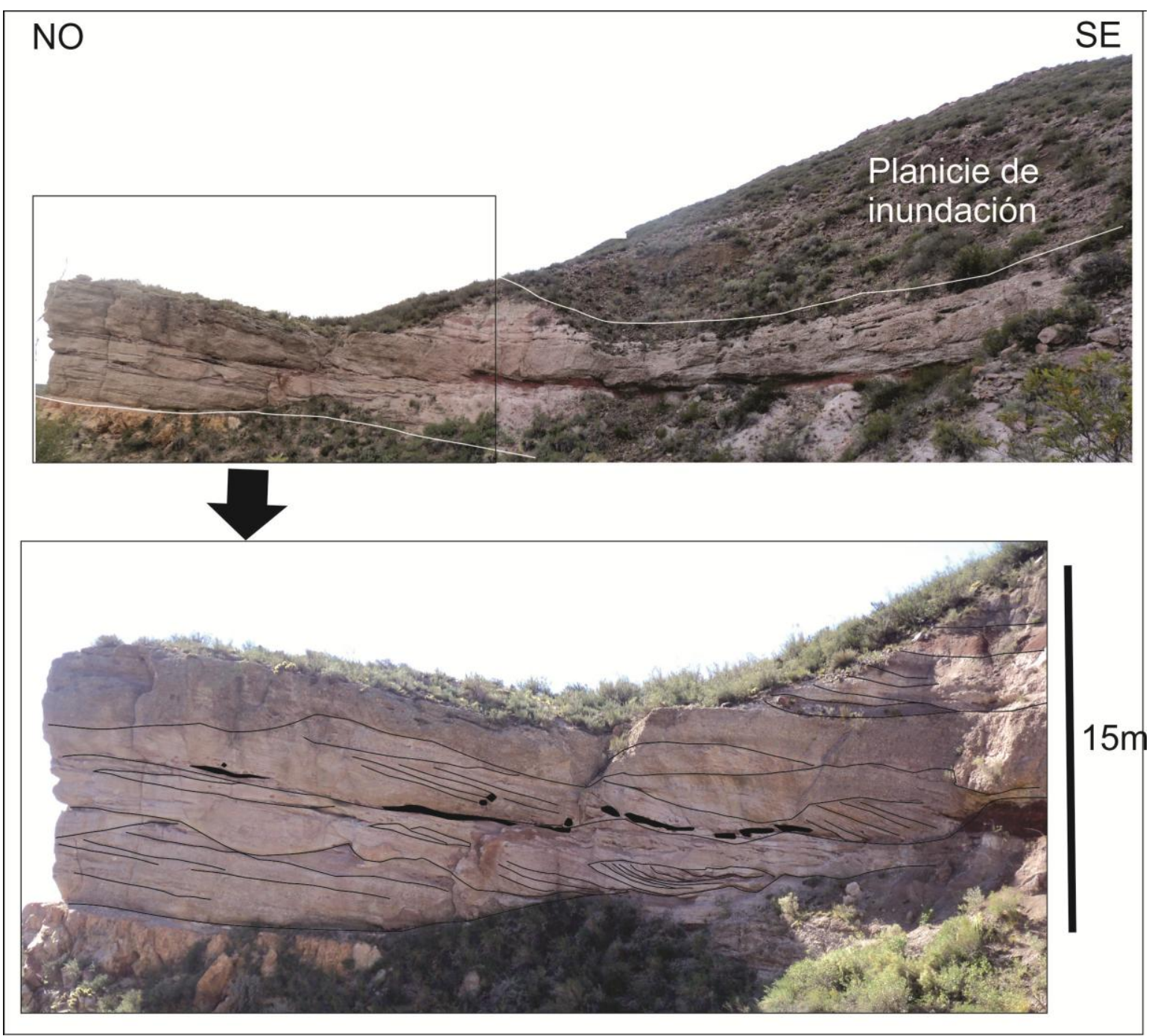

Figura 4.28. Depósitos de canal que afloran en el extremo suroeste de la zona de estudio.

El miembro fino consiste en potentes depósitos tabulares (Tablas 5 y 8 ) de pelitas y pelitas tobáceas de las litofacies FI, Fsm, Fr, FTm, FTI, FTrf (véase Tabla 1) generados por decantación en medios subácueos, como pantanos y lagos de abyono. Comprende a las acumulaciones de la planicie de inundación 
en asociaciones de litofacies Fl/Fr, Fsm/FI y Fsm/FI/FTm (Tablas 5 y 8) cuyo espesor supera al de los términos de grano más grueso (Figuras 4.29a y d).

Dentro de los niveles pelíticos intercalan dos tipos principales de cuerpos relativamente delgados y formados durante las crecidas del sistema fluvial. Uno posee base abrupta a erosiva, techo gradacional o neto y geometría le nticular. Se encuentra conformado por areniscas finas a gruesas de la asociación de litofacies STm y St (Tablas 5 y 8) que se atribuye a canales de descarga o crevasse. El otro tipo, de geometría más tabular con base y techo netos y arreglo interno granocreciente, está constituido por conglomerados con clastos menores a $3 \mathrm{~cm}$ y areniscas medias en asociación de litofacies Gh/SI y Gp/Sm (véase Tablas 5 y 8). Es asignado a depósitos de crevasse splay (Ghosh, 1987; Clemente y Pérez, 1993; Spalletti et al., 1996; Figuras 4.29c y e).

Como parte del sistema depositacional de áreas de bajo gradiente se desarrollaron localmente cuerpos tabulares pelíticos potentes (véase Tablas 5 y 8), sin una vinculación lateral con facies arenosas de canal. A partir de las litofacies descriptas (véase Tabla 1) se establecieron las siguientes asociaciones de facies para estos cuerpos: Cl/ Fr/ FTrf/ Fsm/ Fl/T; Fl/Fr/ FTrf/FTm y FTI/FTm (véase Tablas 5 y 8). El desarrollo de niveles carbonáticos laminados (estromatolíticos) junto a la gradación de facies macizas a laminadas permite asignar un origen subacuático para estos depósitos (Plint y Browne, 1994), asociado con el desarrollo de cuerpos de agua no permanentes y de poca profundidad (Figura 4.29b). Es común que estas sedimentitas, al igual que las facies de planicie de inundación, presenten abundante bioturbación y cutanes arcillosos asociadas al desarrollo de paleosuelos arcillosos bajo condiciones de clima subhúmedo a subárido (Retallack, 2001). Todas estas constituyen evidencias características de cuerpos lacustres desarrollados localmente.

Esta unidad de acumulación representa la depositación por decantación en una planicie de inundación a partir de eventos de desbordamiento del canal principal, con el desarrollo de lóbulos de desbordamiento y canales de descarga. 


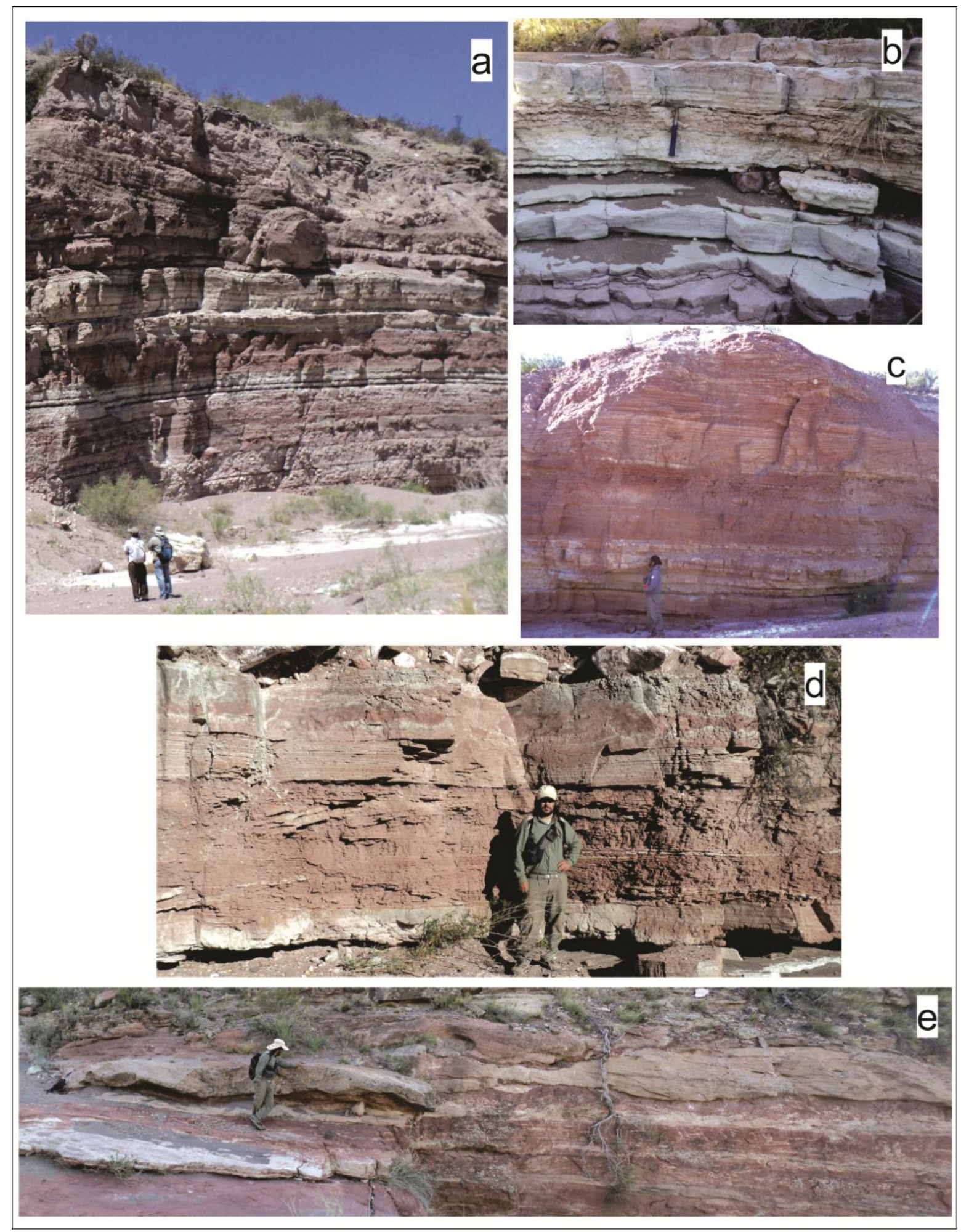

Figura 4.29. Afloramientos en la localidad Río seco de la Quebrada (Figura 4.1 para ubicación). a) Depósitos de planicie de inundación. b) Niveles lacustres. c) Depósitos de crevasse splay en planicie de inundación. d) Depósitos pelíticos laminados. e) Depósitos de crevasse en planicie de inundación. 


\subsubsection{Rocas piroclásticos}

En esta unidad de acumulación se agrupan todos los depósitos primarios de rocas piroclásticas ácidas identificados en la estratigrafía del Grupo Puesto Viejo. Como ya se mencionó, se reconocen dos litofacies principales: una producto de la depositación a partir de plumas piroclásticas constituyendo depósitos primarios de caída de la litofacies Tm (Tablas 1 y 5) y la otra consiste en depósitos primarios de flujos piroclásticas de la litofacies $\mathrm{mLs}$ y $\mathrm{mL}$ (Tablas 1 у 5$)$.

Los depósitos de caída se encuentran muy subordinados. Se han preservado como delgados depósitos asociados a niveles lacustres de planicies de inundación desarrollados en los sistemas meandrosos de alta sinuosidad y conformyo asociaciones de litofacies Cl/ Fr/ FTrf/ Fsm/ Fl/Tm (Tablas 1 y 5 ).

En contraposición, los depósitos de flujos piroclásticos se encuentran bien desarrollados en toda la zona de estudio como mantos que cubren a las unidades de acumulación epiclástica. En términos generales consisten en depósitos masivos de flujos ignimbríticos ácidos de composición riolítica (Figuras 4.19 y 4.20 del inciso 4.1.B) con marcado diaclasamiento como producto de su enfriamiento. Posiblemente se trate de unidades de flujos superpuestos, pero la homogeneidad que presentan estos depósitos dificultan su identificación, solo es posible identificar una grosera estratificación vertical dada por alto grado de soldamiento (litofacies $\mathrm{mLs}$; Tabla 5 ) en posición basal (Figura 4.30c), que pasan a sectores con bajo grado de soldamiento (litofacies $\mathrm{mL}$; Tabla 5) formada por debajo de la temperatura de transición del vídrio (Figura 4.30b).

Por las características de estos depósitos de flujos piroclásticos con alto grado de fragmentación, se puede inferir que se formaron a partir del colapso de columnas eruptivas asociadas a actividad volcánica explosiva aledaña (McPhie, 1993; Branney y Kokelaar, 2002; Llambías, 2003). 


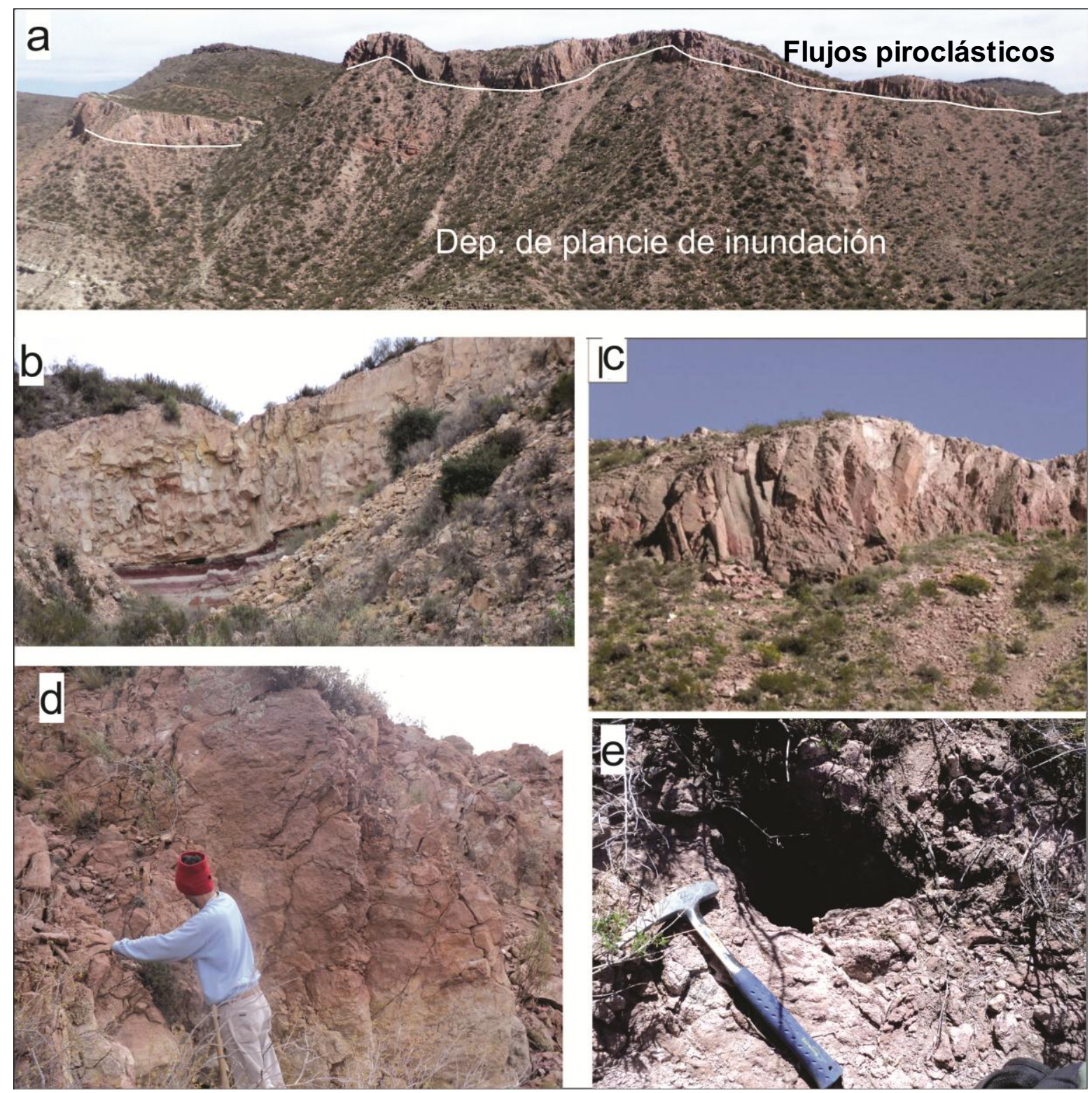

Figura 4.30. a) Depósitos de flujos piroclásticos sobre planicies de inundación del sistema meandroso de alta sinuosidad, localidad Quebrada de los Fósiles (Figura 4.1 para ubicación). b) lgnimbritas poco soldadas (surge) que afloran en el extremo suroeste de la zona de estudio. c) Ignimbritas soldadas que afloran en la localidad de la Pequeña quebrada (Figura 4.1 para ubicación). d) Detalle de ignimbrita soldada con base brechada. e) Pipe en el techo de ignimbrita. 


\subsubsection{Rocas volcánicas}

En esta unidad de acumulación se agrupan las rocas volcánicas básicas (ver análisis de litofacies) del Grupo Puesto Viejo. Consisten en lavas y cuerpos hipoabisales (como criptodomos y filones capa) de colores homogéneos entre gris oscuro y gris azulado, de composición yesitas/basálticas y yesitas (véase Tablas 3 y 5 ).

Los cuerpos hipoabisales intruyen a las unidades de acumulación epiclástica. Consisten en intrusivos (litofacies Bi; Tabla 5) de composición yesita/basalto con formas dómicas (Figura 4.31a). Internamente se identifican líneas de flujo paralelas a las paredes del cuerpo. En el techo de los cuerpos es común la formación de peperitas (Litofacies Pp; Véase Tabla 5) formadas al ponerse en contacto con sedimentos inconsolidados y húmedos (McPhie et al., 1993) (Figura 4.31c). Un rasgo común en los afloramientos es la generación de fracturación perlítica (Figura 4.31b) producto del contraste de temperatura y el rápido enfriamiento. En ocasiones se observaron líneas de flujo con dirección NNO-SSE y venas con textura de relleno en los niveles sedimentarios que conforman la roca de caja. 

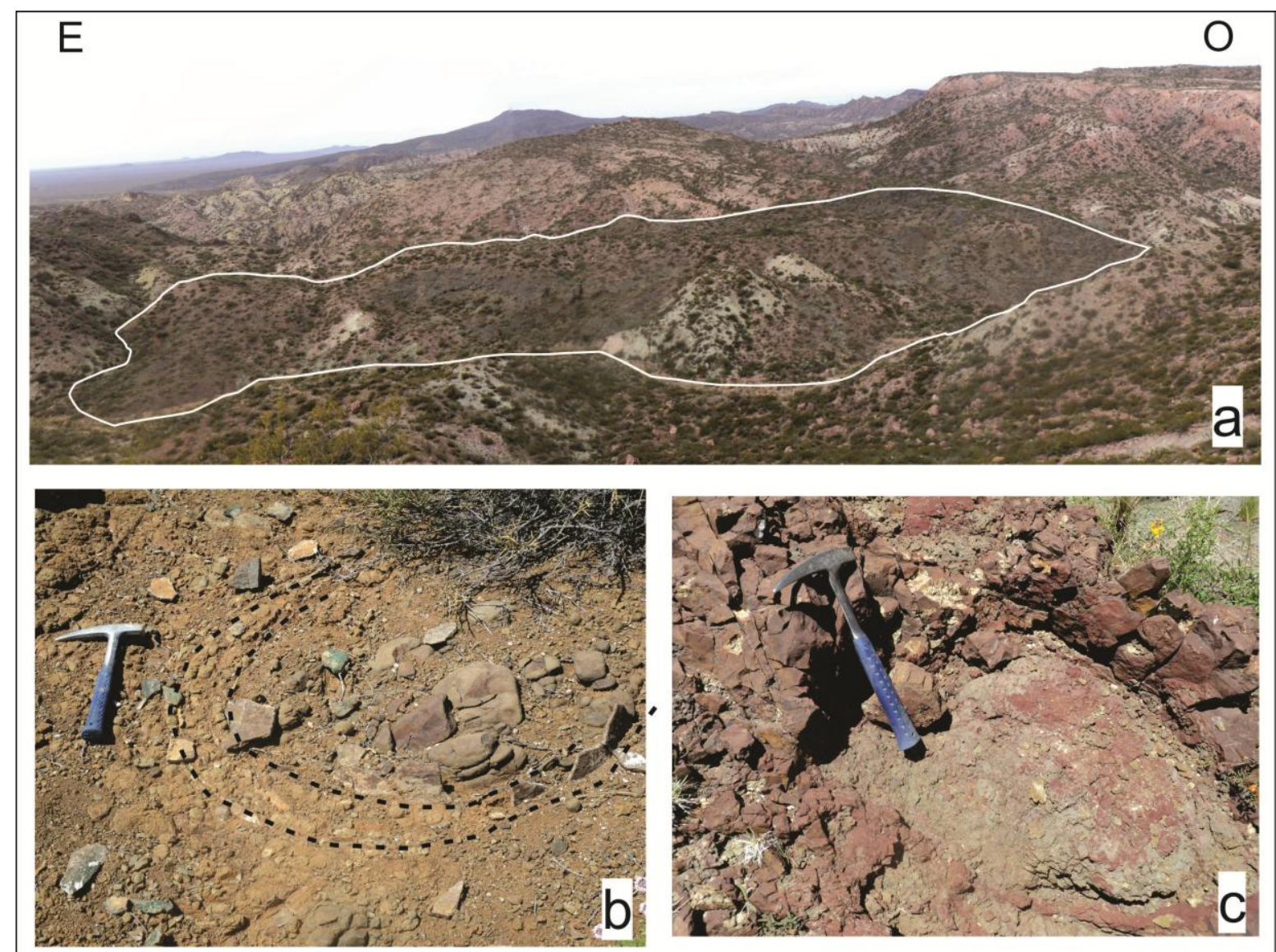

Figura 4.31. a) Cuerpo intrusivo en la localidad Agua de los Burros y Quebrada de los Fósiles ("Anfiteatro"; Figura 4.1 para ubicación). b) Fracturación perlíticas en depósitos de planicie de inundación del techo del intrusivo. c) Peperitas formadas en depósitos pelíticos de planicie de inundación.

De los cuerpos subvolcánicos se desprenden otros dos cuerpos de la misma composición como filones capa (Figura 4.32) de hasta 11 metros de espesor, concordantes con la estratificación de la Formación Quebrada de los Fósiles. Internamente se observan fracturas perlíticas en el techo producto de enfriamiento. También se pueden observar algunos diques pequeños que cortan la estratificación generando autobrechas en sus bordes. 


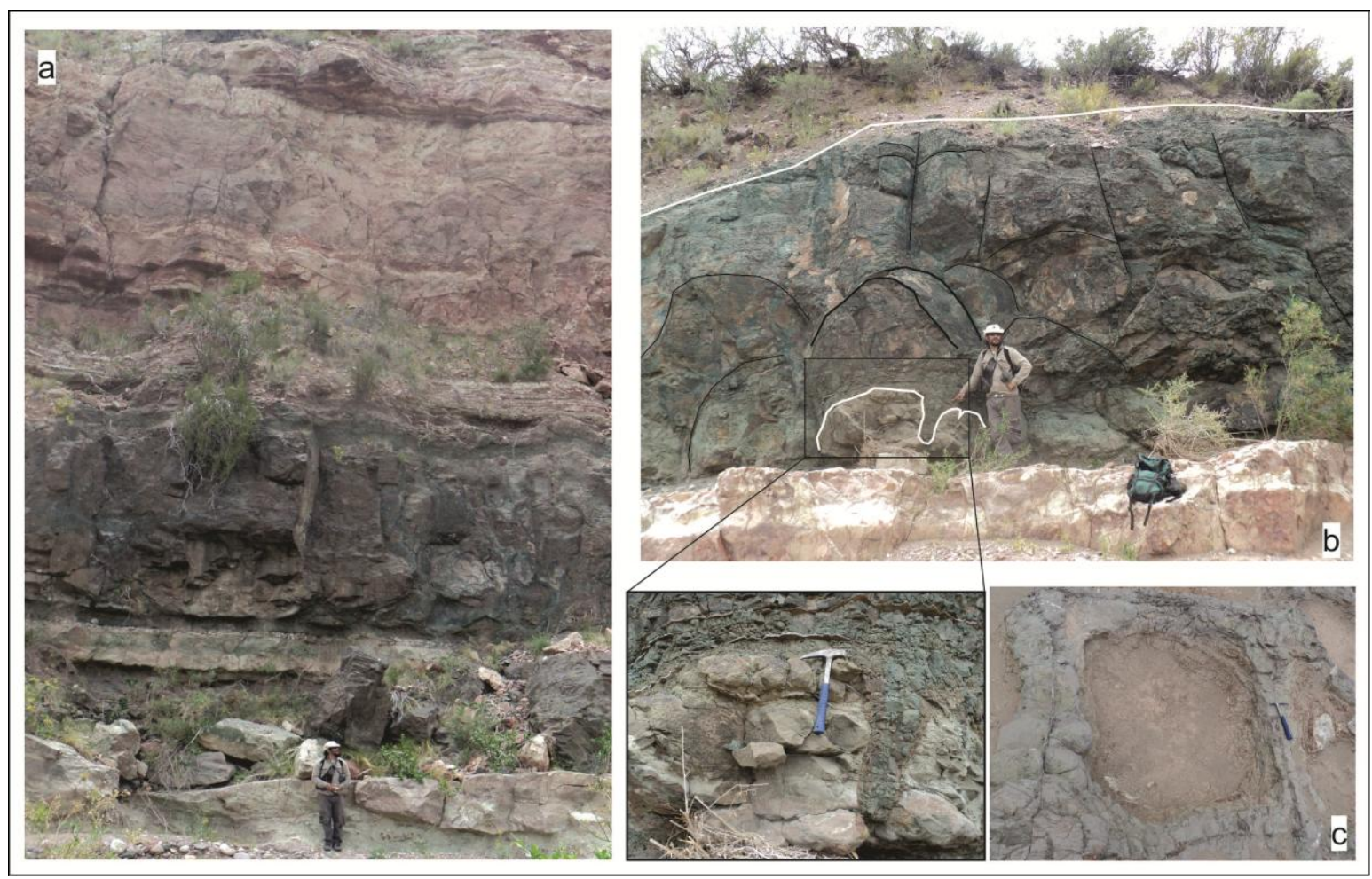

Figura 4.32. a) Filón capa concordante a la estratificación de la planicie de inundación. b) Detalle de filón capa con fracturación perlítica. c) Vista en planta del filón capa.

Las lavas se encuentran como efusiones sucesivas y homogéneas cubriendo las unidades de acumulación epiclásticas (Figura 4.33a y b). Conforman coladas masivas de composición yesítica/basáltica (litofacies LAB. Tabla 3) con abundantes vesículas alagadas en la dirección de flujo (Figura 4.33c). En el techo de las lavas, es común observar fracturas paralelas como producto de su enfriamiento (Figura 4.33d).

Las asociaciones de rocas básicas que conforman esa unidad de acumulación se produjeron por ascenso de magma a partir de cámaras magmáticas emplazadas en niveles someros de la corteza y en ocasiones alcanzando la superficie como erupciones magmáticas no explosivas (McPhie et al, 1993, Llambías 2003). 

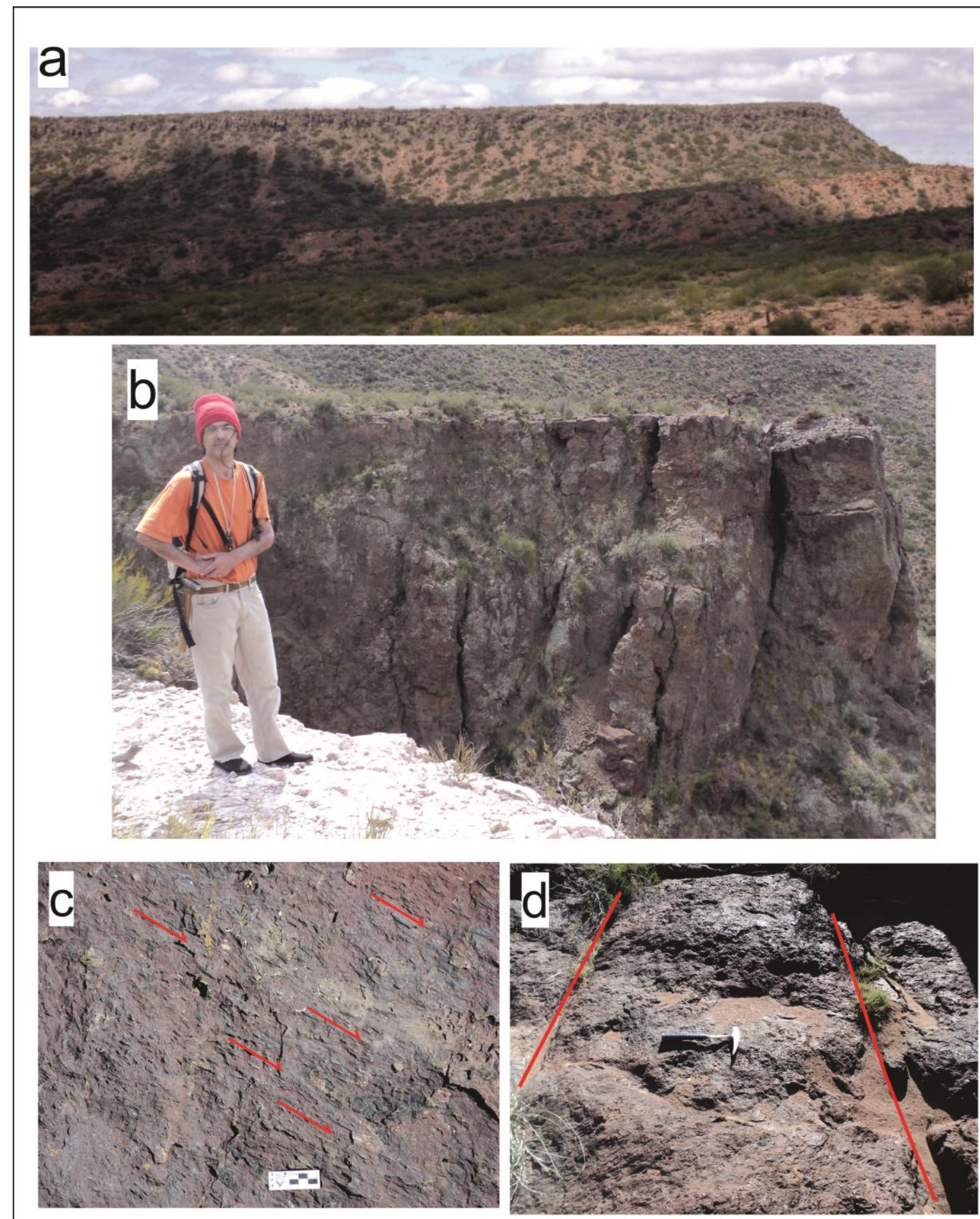

Figura 4.33. a y b) Lavas andesíticas cubriendo depósitos fluviales en la localidad El Durazno (Figura 4.1 para ubicación). c) Detalle de vesículas elongadas que marcan el sentido de flujo de las lavas hacia el NE. d) Fracturas paralelas con sentido E-W. 


\title{
CAPÍTULO 5
}

\author{
ANÁLISIS DEL RELLENO \\ DEL DEPOCENTRO DEL \\ GRUPO PUESTO VIEJO
}




\section{Capítulo 5. Análisis del relleno del depocentro del Grupo Puesto Viejo}

\subsection{Introducción}

La configuración de los depocentros dentro de las cuencas extensionales deriva de la actividad del fallamiento normal como factor principal en la generación de relieve y del espacio de acomodación (Schlische, 1991; Leeder, 1995 y 1999; Allen y Allen, 2005, entre otros). Se trata de un proceso dinámico que determina cambios en la geometría de los depocentros a partir de la generación y el crecimiento de estructuras e interconexión entre estructuras de borde y estructuras internas. Las estructuras poseen una influencia fundamental sobre el desarrollo de los sistemas sedimentarios, piroclásticos y volcánicos establecidos en el Capítulo 4. No sólo controlan la creación de espacio para su acumulación, también la procedencia y dirección del material de relleno, la geometría de los cuerpos y la posición de las unidades de acumulación en el depocentro. Es por esto que conocer la geometría de los depocentros y su evolución es primordial a la hora de evaluar el control de las estructuras sobre el relleno de los mismos.

Este contexto tectonoestratigráfico demuestra que las diferentes unidades de acumulación definidas no se encuentran depositadas en continuidad vertical, sino que lo hacen en depresiones estructurales con una continuidad lateral entre las mismas. Por esta razón la estratigrafía nunca se ve completa y los $440 \mathrm{~m}$ de espesor vertical señalados por estudios previos es parcial.

La caracterización de las estructuras desarrolladas en el Capítulo 3 permitió dividir la evolución de las mismas en 4 etapas de actividad tectónica (Figura 5.1) que condicionaron un relleno sedimentario depositado en diferentes etapas separados por períodos de quietud que culminan con eventos de actividad volcánica. En este Capítulo se presentan los procesos que actuaron en la acumulación de las unidades dentro de este esquema estructural. 


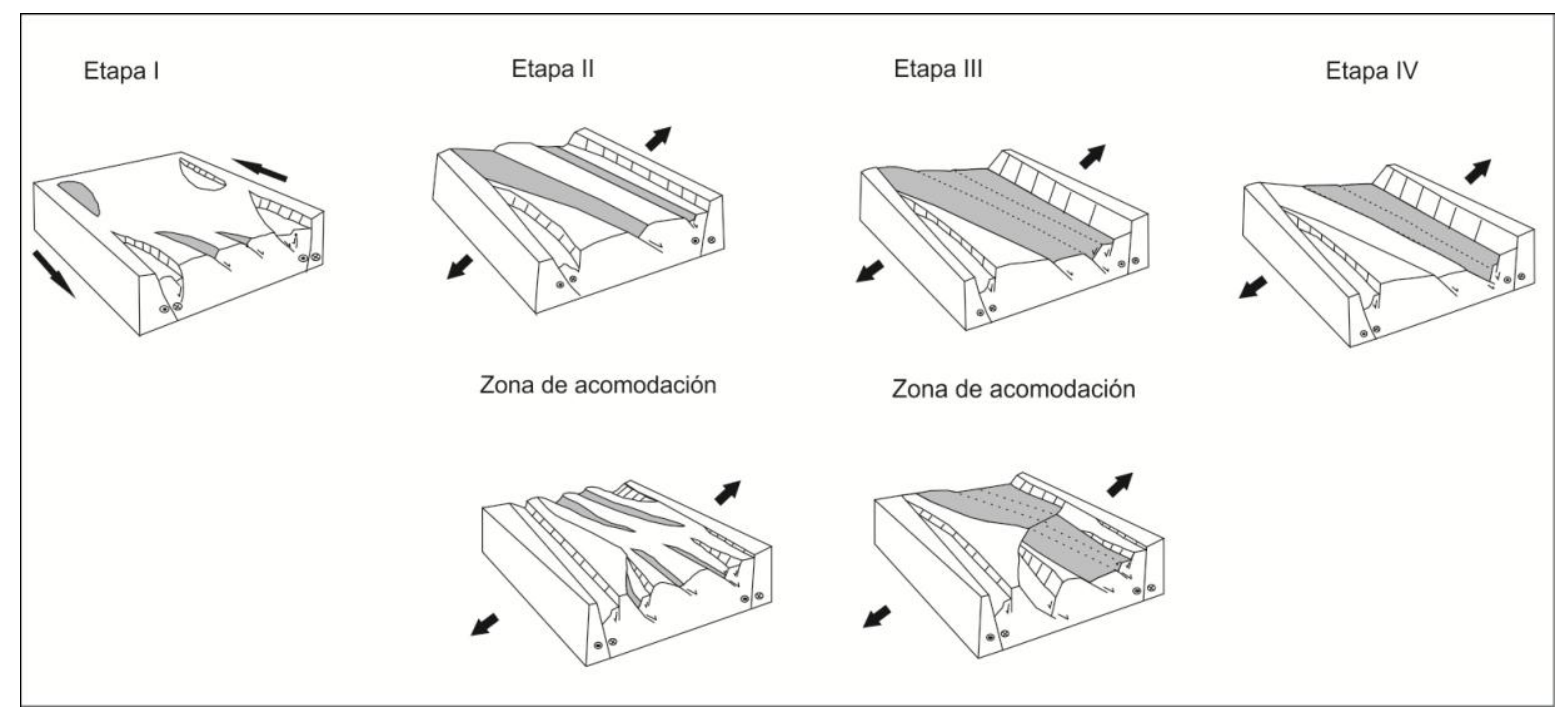

Figura 5.1. Etapas de estructuración definidas para la evolución del depocentro triásico de San Rafael en el Capítulo 3.

\subsection{Relleno de la etapa I: Generación del espacio de acumulación inicial. Niveles basales del Grupo Puesto Viejo (Formación Quebrada de los Fósiles)}

Los primeros desplazamientos de las fallas de bordes con carácter transcurrente / transtensional (Capítulo 3) generaron un espacio de acumulación incipiente con bajo contraste de relieve, que permitió el desarrollo de depósitos gruesos anexados a las fallas, con escasa extensión areal. Estas fallas se observan en el mapa (Figura 5.2) con orientación principal NO-SE como líneas rectas y continuas que, en ocasiones, se cortan en segmentos conformyo fallas en echelón. 


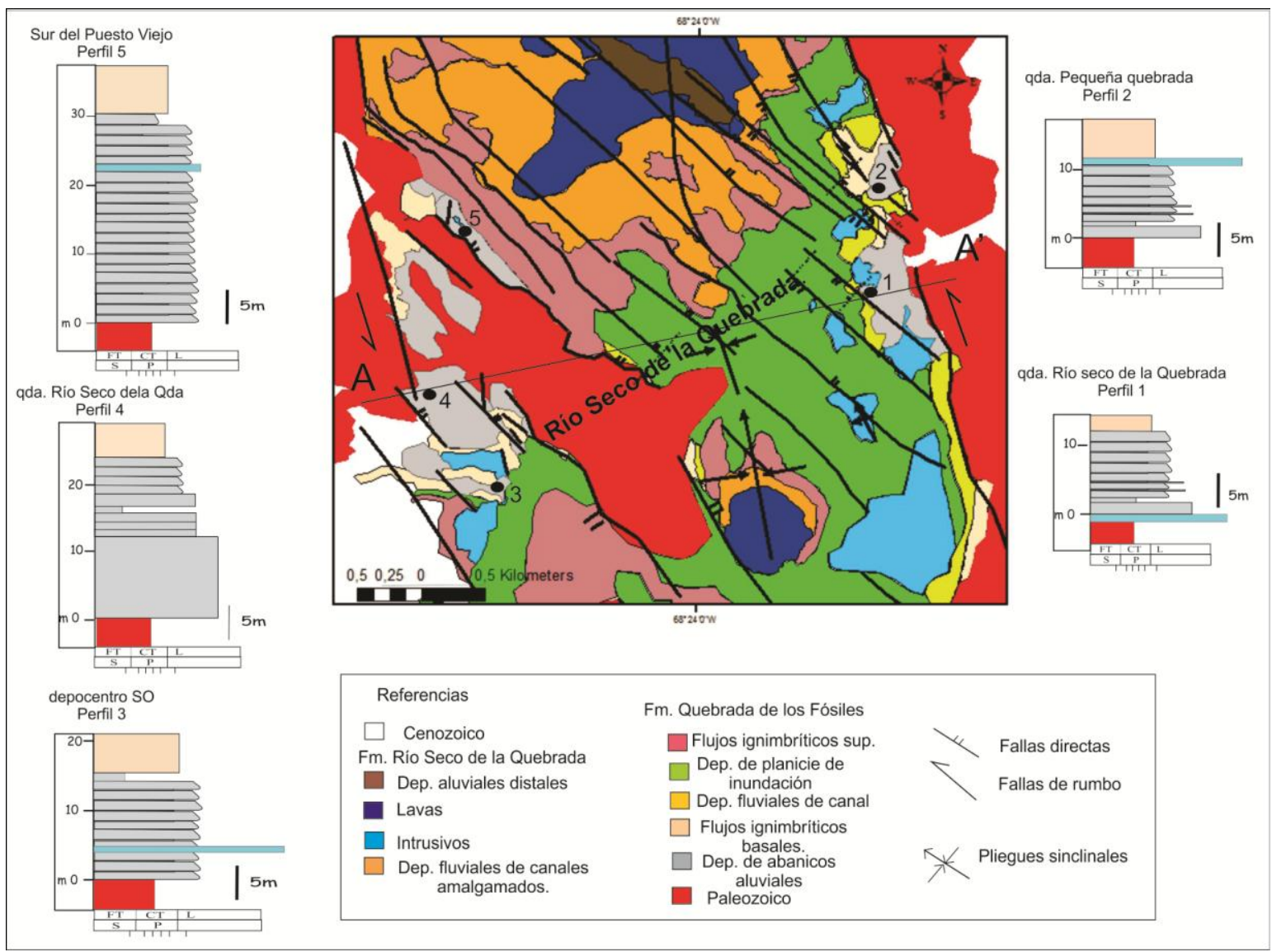

Figura 5.2. Mapa geológico de detalle y distribución de perfiles sedimentológicos para la Etapa I. Ubicación de corte geológico A-A’.

\subsubsection{Unidades de acumulación que definen la etapa I}

El relleno de esta etapa puede ser descripto por la acumulación de dos principales unidades de acumulación: Abanicos Aluviales y Flujos Piroclásticos (Capítulo 4.3). Los abanicos aluviales se reconocen en los borde de cuenca con una distribución transversal a las fallas principales. Sus afloramientos se localizan de manera reducida y aislada en el sector sur de la zona de estudio (Figura 5.2), coincidiendo en gran medida con la zona de acomodación descripta en el Capítulo 3. Desde el punto de vista estratigráfico se depositaron por encima del basamento pérmico y fueron cubiertos por depósitos de la unidad de acumulación de flujos Piroclásticos. Los flujos piroclásticos acompañan a los abanicos aluviales en los bordes de cuenca, cubriéndolos como un delgado pero extenso manto y marcyo la culminación de 
esta etapa de relleno. Los flujos piroclásticos de la etapa I causaron el cese abrupto del desarrollo de los sistemas aluviales.

\section{a) Los abanicos aluviales de la etapa I}

Esta unidad de acumulación constituye los niveles basales de la Formación Quebrada de los Fósiles y representa los términos conglomerádicos más gruesos del Grupo Puesto Viejo formados a partir de flujos de detritos diluidos e hiperconcentrados no canalizados (Capítulo 4.3. Figura 4.19) constituidos en su totalidad por clastos provenientes de la erosión de los bloques elevados del basamento pérmico. En la región estudiada se preservan con una extensión reducida. En el extremo suroeste del borde oriental de la cuenca (Figura 5.3) afloran de forma discontinua, separados por altos de basamento pérmico, con extensiones máximas de 600 metros a lo largo de la falla de borde y entre 100 y 500 metros hacia el interior de cuenca. Los espesores medidos aumentan desde el sureste (10 metros) hacia el noroeste (30 metros). En el borde occidental (Figura 5.4) afloran por 300 metros a lo largo de la falla de borde al sur de la quebrada Agua de los Burros y se infiere que afloran hasta 500 metros al sur de la localidad Río Seco de la Quebrada (Figura 5.2). Su desarrollo hacia el interior de cuenca varía de 125 a 375 metros. Los espesores medidos en este sector son inferiores a los 10 metros. En todos los casos su consistencia es muy friable, posiblemente como producto de la cercanía a áreas de la falla de borde con varias etapas de actividad tectónica posterior a su acumulación.

A partir del análisis de los perfiles estratigráficos y sedimentológicos (véase Anexo 2) se aprecia un arreglo granodecreciente y un aspecto homogéneo que dificulta identificar más de un nivel de desarrollo del abanico. Solamente en el perfil 4 (Figura 5.2) se observan al menos dos niveles de abanicos superpuestos, caracterizados por asociaciones de litofacies gruesas (Capítulo 4.3; Figura 4.19) de flujos gavitacionales en la base que pasan a flujos hiperconcentrados de grano más fino hacia el techo y culminan con cuerpos tabulares pelíticos de hasta un metro de espesor lo cual sugiere condiciones más diluidas. La recurrencia de estas asociaciones en sentido vertical y el patrón general granodecreciente podrían representar una contracción gradual 
de las facies hacia el margen activo del depocentro seguido de una etapa de progradación del sistema sedimentario hacia el depocentro tal como ha sido descripto en otros depocentros extensionales por otros autores (por ejemplo, Spalletti, 1994; Franzese et al., 2006; López et al., 2013; Muravchick et al., 2014).

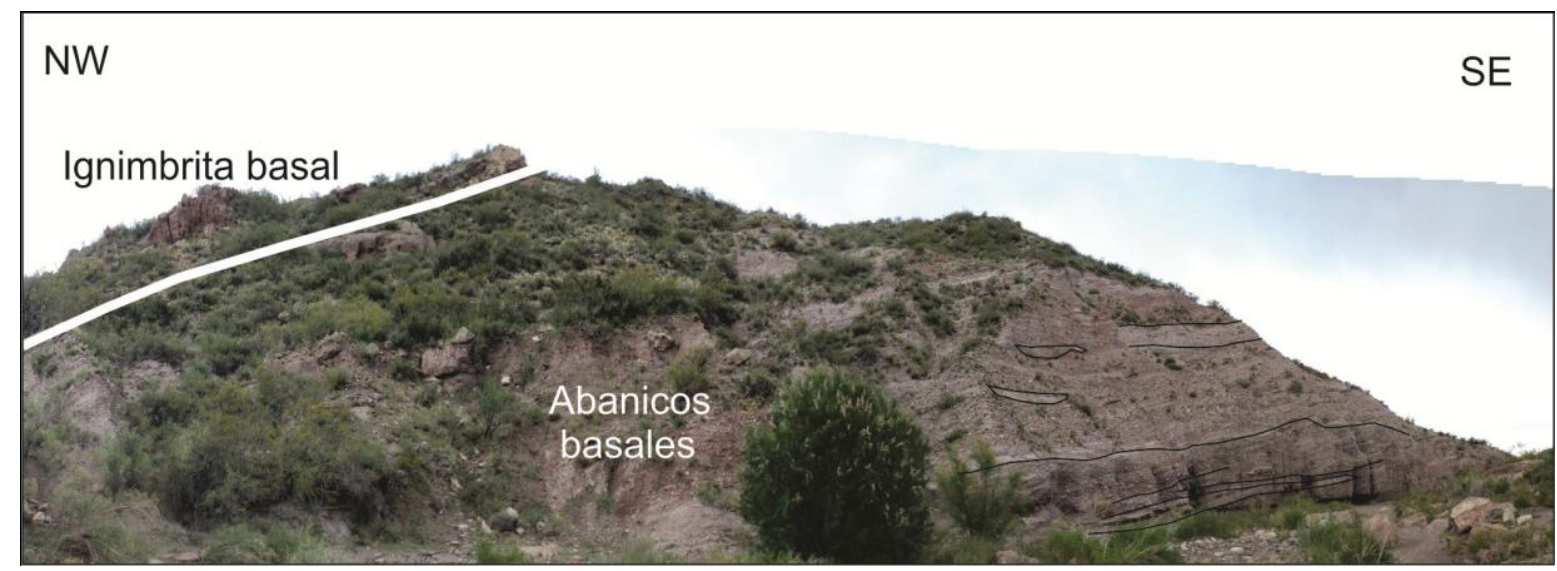

Figura 5.3. Abanicos aluviales en la margen este de la quebrada Río Seco de la Quebrada (ubicación en Figura 5.2).

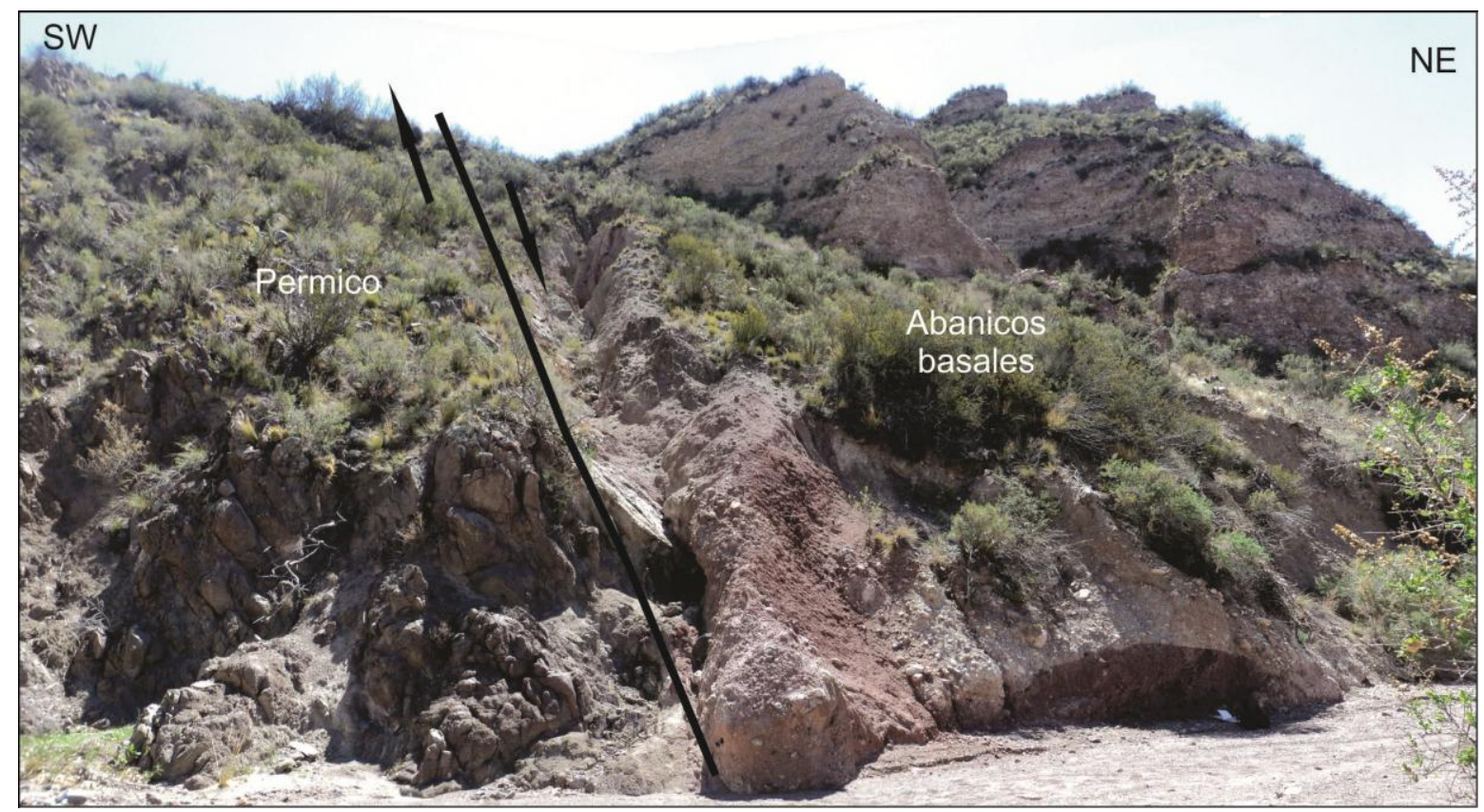

Figura 5.4. Abanicos aluviales en la margen oeste de la quebrada Río Seco de la Quebrada (ubicación en Figura 5.2). 


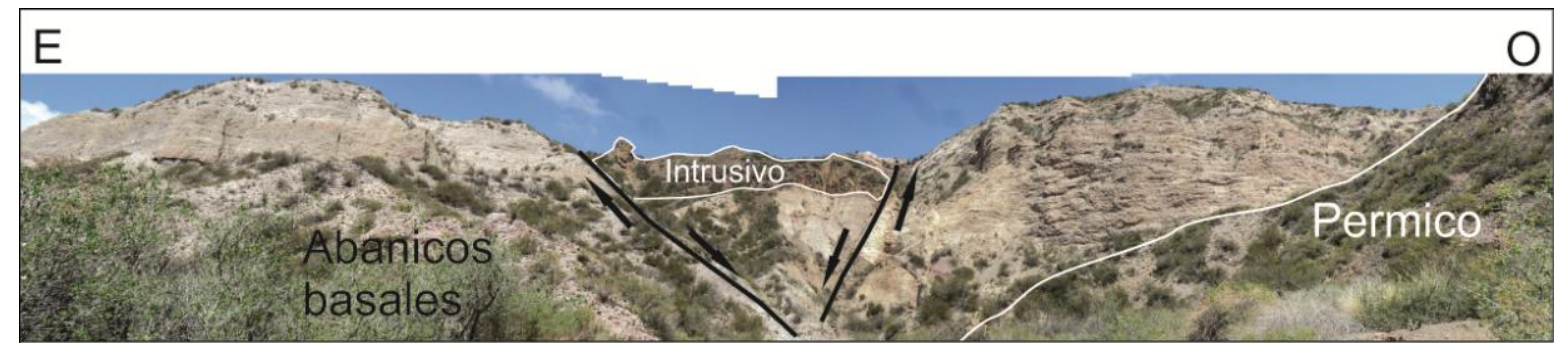

Figura 5.5. Abanicos aluviales afectados por fallas directas activas durante el Triásico en la margen oeste de la quebrada Río Seco de la Quebrada (ubicación en Figura 5.2.

\section{b) Los flujos piroclásticos de la etapa I}

Consisten en flujos ignimbríticos ácidos, definidos a partir del análisis petrográfico y geoquímico, de composición riolítica (Capítulo 4.1.B). En la zona de estudio, sus afloramientos son reducidos y se registran en forma aislada en los alrededores de los bordes de cuenca y altos pérmicos del sector sur (Figura 5.2). Yace como delgados mantos que cubren parcialmente a los abanicos aluviales (Figura 5.3 y 5.6). En el borde occidental se registran los mayores espesores que alcanzan 10 metros y en el borde oriental sus espesores son menores (entre 3 y 8 metros).

El aspecto masivo de esta unidad de acumulación (Capítulo 4.2; Figura 4.19), sus reducidos afloramientos y su escaso espesor, sumado a que se encuentra afectada por fallas inversas cenozoicas (Capítulo . 3), son características que no permiten establecer si se trata de una única unidad de flujo o si son varias superpuestas. Solo es posible inferir, a partir de sus escasas variaciones de espesor y su aspecto poco soldado, que constituyen las partes distales de corrientes de flujos piroclásticos (McPhie, 1993; Llambías, 2003) provenientes desde el sector SO. 


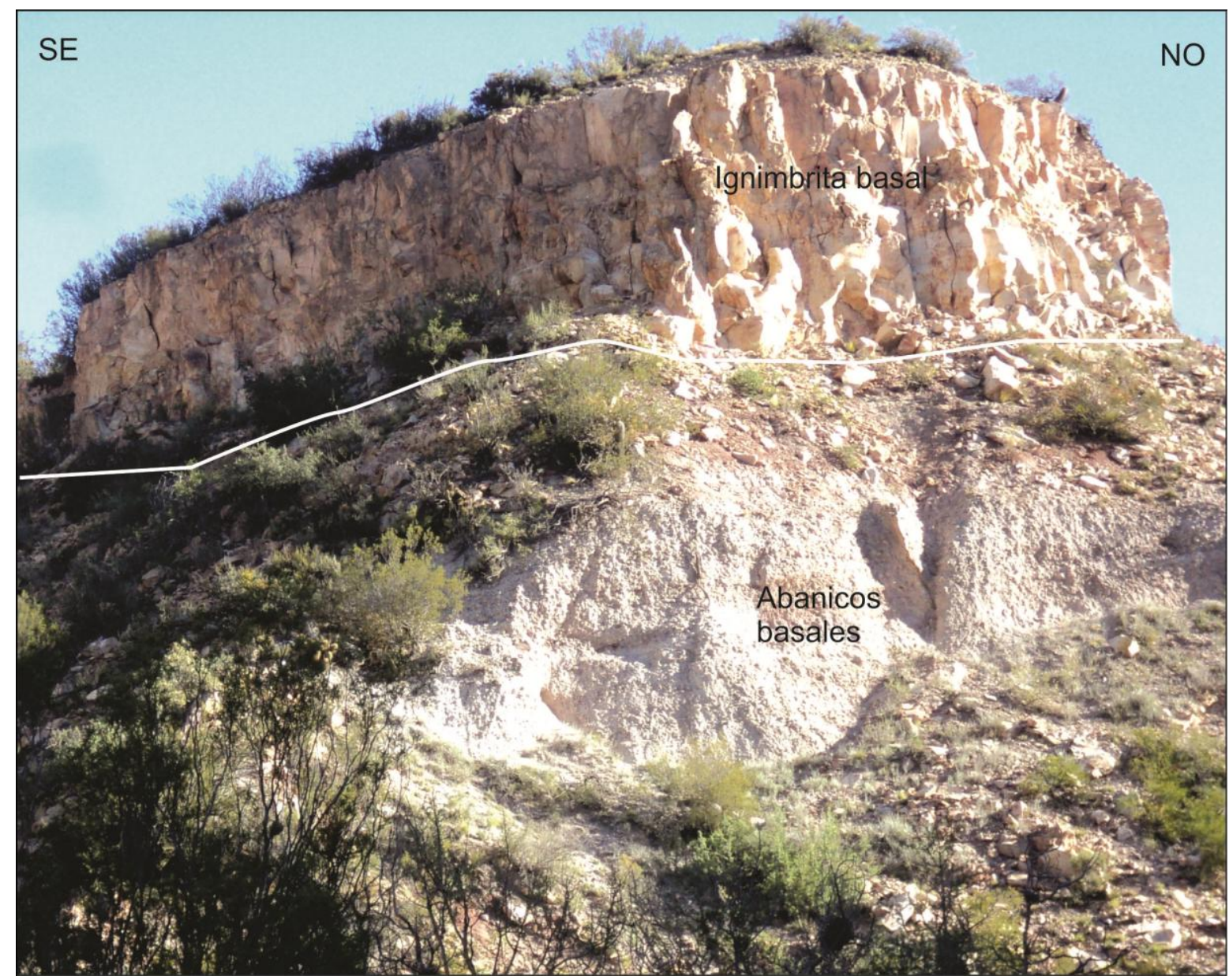

Figura 5.6. Ignimbrita basal cubre a los abanicos aluviales en la margen suroeste de la quebrada Río Seco de la Quebrada (ubicación en Figura 5.2).

Síntesis de la etapa I

El desarrollo de esta unidad de acumulación refleja las condiciones iniciales de la evolución de la cuenca como pequeños depocentros adyacentes a los bordes de cuenca separados por altos de basamento pérmico (Figura 5.7). Se caracteriza por el predominio de depósitos aluviales proximales gruesos formados en condiciones de alta energía dinámica. El arreglo que presenta esta unidad de acumulación refleja variaciones locales en el comportamiento del sistema depositacional vinculadas con oscilaciones en la descarga de material e inestabilidad de las pendientes en el área de aporte producto de la elevación relativa del bloque de basamento pérmico, tal como otros autores citan para el desarrollo de abanicos aluviales en ambientes extensionales (Spalletti, 1994; Leeder et al., 1995 y 1999). Por otra parte la participación 
piroclástica se encuentra sujeta a la morfología de los depocentros generando un rápida agradación del relieve que modifica el equilibrio hidrológico y las pendientes del sistema tal como lo han sintetizado otros autores (Smith, 1991; Haughton, 1993).

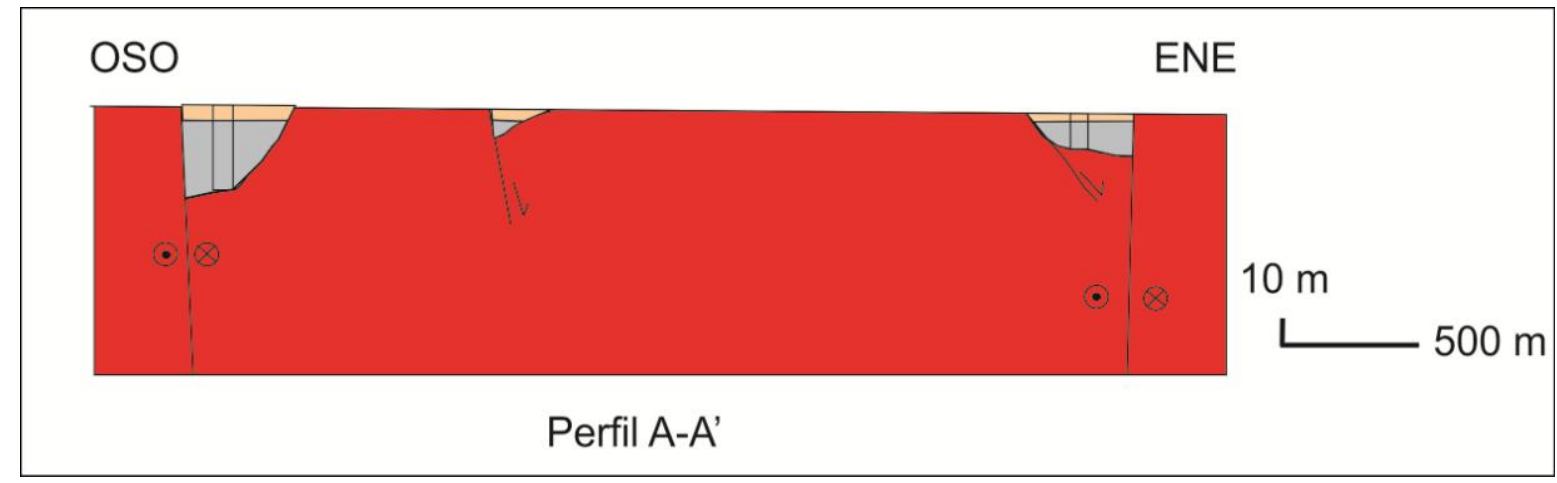

Figura 5.7. Corte geológico A-A’ para la etapa I y distribución de las unidades de acumulación. Ubicación en Figura 5.2.

\subsection{Relleno de etapa II. Desarrollo de espacios de acumulación internos. Niveles inferiores del Grupo Puesto Viejo (Formación Quebrada de los Fósiles)}

Durante esta etapa se desarrolló un conjunto de nuevas fallas directas con orientaciones preferenciales (NO-SE, paralelas al borde de cuenca y ONOESE, oblicuas a al borde) muy marcadas en el interior de la cuenca (Figura 5.8; Capítulo 3). La generación de estas fallas se prolonga durante toda la etapa II de estructuración de la cuenca definida en el Capítulo 3.2, generando espacios internos menores como grábenes y hemigrábenes y controlyo la sedimentación triásica de esta etapa de relleno a diferentes escalas. Fallas menores con orientación NE-SW coinciden con un cambio de polaridad de los espacios de acomodación, definido en el Capítulo 3 como una zona de acomodación (Figura 5.8). El registro de la actividad extensional generalizada (Capítulo 3) desarrollada durante esta etapa, se ve reflejado en las fallas menores NO-SE y ONO-ESE, dispuestas en el sector sureste del área de estudio (Capítulo 3.1) donde se puede observar la distribución de los sedimentos asociados y limitados por estas fallas directas, tema que se ampliará en el presente véase Capítulo . 


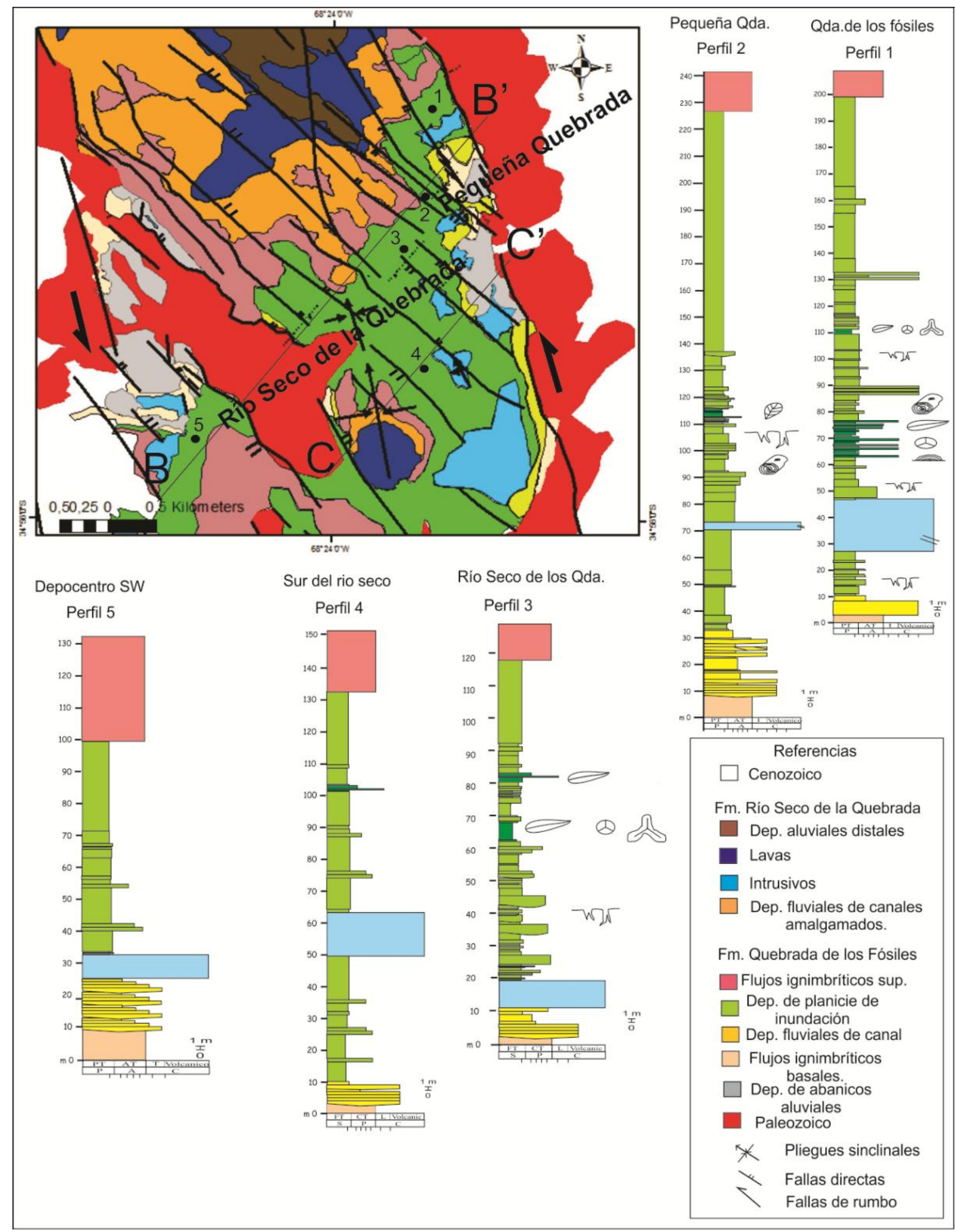

Figura 5.8. Mapa geológico de detalle y distribución de perfiles sedimentológicos para la etapa II. Ubicación de los cortes geológicos B-B' y C-C'. 


\subsubsection{Unidades de acumulación que definen la etapa II}

En los nuevos espacios generados durante la etapa II se acumuló un relleno caracterizado por el predominio de dos unidades de acumulación: Sistema meandrosos de alta sinuosidad y flujos piroclásticos (Figura 5.8; Capítulo 4.3.3). El sistema meandroso de alta sinuosidad presenta una distribución axial en estrecha relación con el crecimiento de las fallas establecidas para esta etapa. En las inmediaciones de los márgenes de la cuenca, se desarrollaron los canales principales del sistema fluvial (Capítulo 4.3. Figura 4.24) controlados por la geometría heredada del fallamiento inicial (Capítulo 3). Sus afloramientos se encuentran restringidos a lo largo de los bordes de cuenca y en estrecha relación con la unidad de acumulación basal, depositándose por encima de los flujos ignimbríticos basales e incorporyo parte los mismos como clastos (Figura 5.9). Una extensa parte de esta etapa de relleno de cuenca queda representada por el desarrollo de extensas planicies de inundación que cubren toda el área de estudio y en la que se registran eventos de desbordamiento con generación de canales de crevasses y crevasses-splay (Capítulo 4.3; Figura 4.24) encauzados en pequeños grábenes. El desarrollo local de cuerpos de agua poco profundos (Capítulo 4.3; Figura 4.24) se encuentra estrechamente localizado en las proximidades de bordes de fallas internas normales activas, dando lugar a depositación subácuea. La segunda unidad de acumulación definida en el Capítulo 4.3 como depósitos de flujos piroclásticos se extiende ampliamente en la cuenca cubriendo a las planicies de inundación como mantos continuos (Figura 5.8). Este evento coincide con la culminación de esta etapa de relleno y marca un cese abrupto del desarrollo de los sistemas fluviales. 


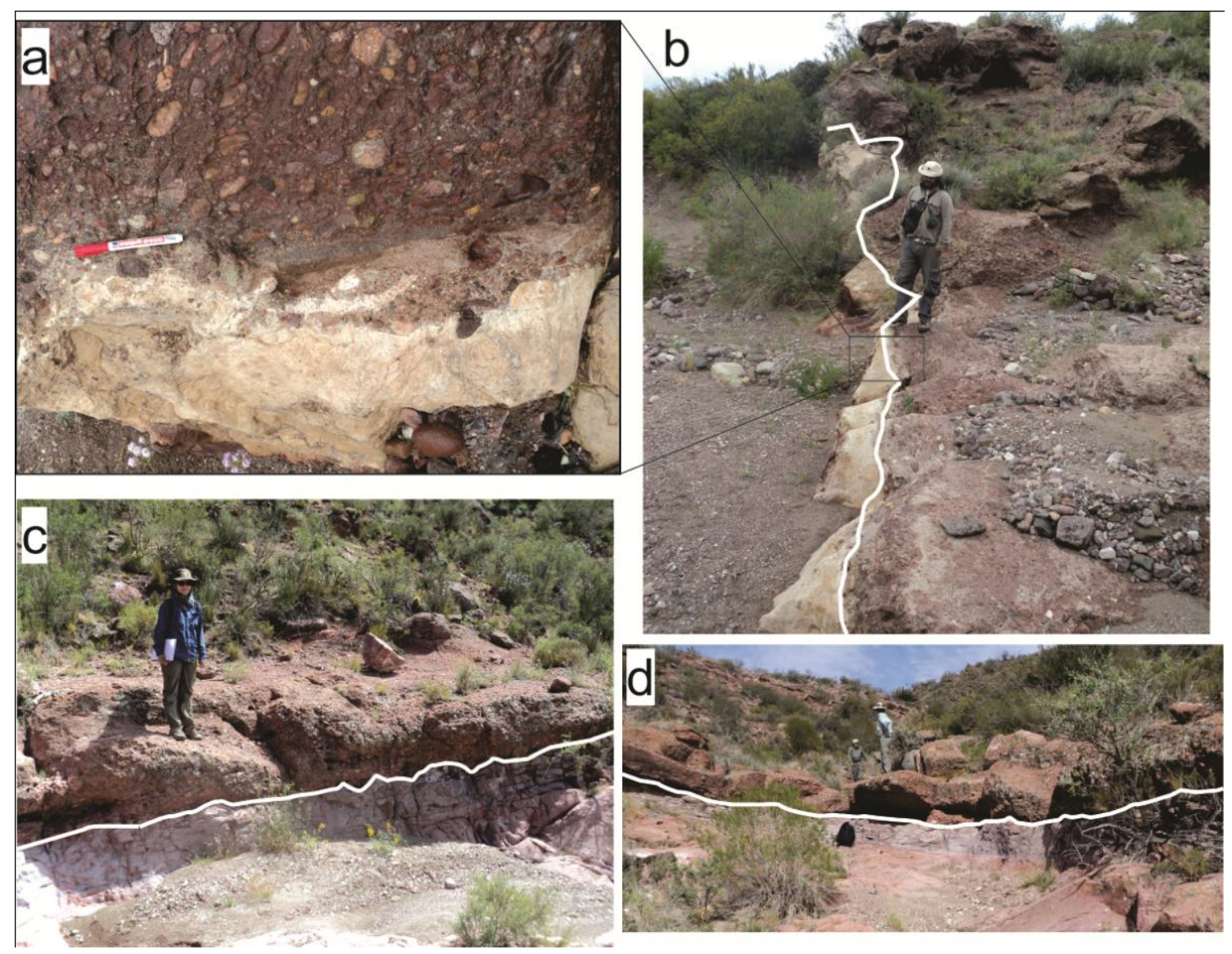

Figura 5.9. Canales principales del sistema fluvial depositados encima de los flujos ignimbríticos basales. a) clastos de la ignimbrita basal incorporados en depósitos del sistema fluvial. Fotos tomadas en la quebrada Río Seco de la Quebrada ( $\mathrm{a}$ y b) y en la quebrada Pequeña (c y d; Figura 5.8 para la localización de las quebradas).

\section{a) Los sistemas meandrosos de alta sinuosidad de la etapa II}

Los afloramientos de esta unidad de acumulación son extensos y continuos pero sus espesores varían sustancialmente. En el extremo noreste del borde occidental se registran los mayores espesores, 200 y 230 metros (perfiles 1 y 2 de la Figura 5.8). En cambio, hacia el borde oriental, los espesores disminuyen a 130 metros (perfiles 3 y 4 de la Figura 5.8), registrándose espesores mínimos de 100 metros en el depocentro suroeste (perfil 5 de la Figura 5.8). Este sistema depositado de forma coetánea con el desarrollo de fallas normales internas, con orientación preferencial ONO-ESE (Capítulo 3 ) en espacios de 
acumulación asimétricos condicionó las distribución de las asociaciones de litofacies que lo componen.

El miembro grueso, representado por las asociaciones de facies de canal principal (Capítulo 4.3; Figura 4.24), y está constituido por cuerpos individuales de geometría lenticular con base erosiva que alcanzan hasta 4 metros de espesor y extensión lateral variable hasta 10 metros (inversamente proporcional a su espesor). Esta asociación de litofacies con posición basal en esta unidad de acumulación, presenta sus mayores espesores en el borde oriental donde superan los 20 metros (perfil 2 de la Figura 5.8) con paleocorrientes hacia el norte y noroeste medidas en artesas frontales (Capítulo 4.1), y en el borde occidental con 15 metros de espesor (perfil 5 de la Figura 5.8) donde la migración de las barras indican paleocorrientes que se orientan hacia el suroeste y sureste (Figura 5.9). Ambos sectores coinciden con los principales espacios de acumulación asimétricos (hemigrábenes) y registran una importante agradación vertical. Lateralmente no superan 10 metros de espesor (perfiles 1, 3 y 4 de la Figura 5.8) registrados en las zonas más elevadas.

Hacia el sector suroeste, donde disminuye la profundidad de la cuenca y se registran los menores espesores para esta unidad de acumulación, la distribución vertical de los miembros gruesos (traccional dominante) y finos (suspensivo dominante) mantienen una relación gradual y granodecreciente relativamente constante (perfiles 3 y 4 de la Figura 5.8). Este hecho permite inferir una migración lateral del canal principal hacia el oeste acompañado por el crecimiento de las fallas del borde occidental, siguiendo los modelos de evolución de rift propuestos por Leeder et al. (1995 y 1999); Morley (1999); Gawthorpe y Leeder (2000), entre otros.

El miembro fino comprende a las acumulaciones de la planicie de inundación (Figura 4.24 del Capítulo 4.3.). Se extiende con una distribución continua en todo el depocentro del área de estudio. Consiste en potentes depósitos pelíticos formados por cuerpos tabulares de hasta 8 metros de espesor, entre los que intercalan delgados cuerpos arenosos de geometría lenticular y tabular con espesores menores a 1,5 metros y escasa continuidad lateral, a los que se 
atribuyen las asociaciones de facies canales crevasse y crevasse splay (Figura 4.24 del Capítulo 4.3.). Localmente se desarrollan cuerpos de agua someros de hasta 3 metros de espesor (Figura 4.24 del Capítulo 4.3) en la planicie de inundación. Estos cuerpos se observan principalmente en el sector noreste (perfiles 1 y 2 de la Figura 5.8), donde se identifican al menos dos eventos lacustres desarrollados en esta etapa de relleno, separados por eventos de desbordamientos producto de la continua migración lateral del canal principal. El primero posee un importante desarrollo vertical (hasta 15 metros) y se encuentra constituido por 5 niveles carbonáticos seguidos por el desarrollo incipiente de paleosuelos y niveles ricos en materia orgánica (perfil 1 de la Figura 5.8). Esta disposición estaría indicando una variabilidad periódica del nivel de agua. La extensión lateral de estos cuerpos se encuentra condicionada por el espaciado del fallamiento normal y la asimetría de los espacios de acumulación, lo que dificulta establecer su extensión real. Hacia el suroeste se observa una marcada disminución del espesor de estos cuerpos (perfiles 2 y 3 de la Figura 5.8). Hacia el tope de esta etapa de relleno se registra el segundo evento lacustre con escaso desarrollo vertical que muestra una extensa continuidad lateral hacia el sector suroeste (perfiles 3 y 4 de la Figura 5.8). Cabe destacar que estos depósitos constituyen los principales niveles portadores de restos fósiles paleobotánicos y palinológicos identificados para el Triásico del Grupo Puesto Viejo y de forma subordinada contienen restos fósiles de vertebrados, otorgándole una connotación bioestratigráfica importante.

El control que ejerce el sistema de fallas normales en la distribución de las facies sedimentarias desarrolladas durante esta unidad de acumulación se evidencia en los paneles que se muestran a continuación (Figura 5.8 para la ubicación de las localidades citadas). 


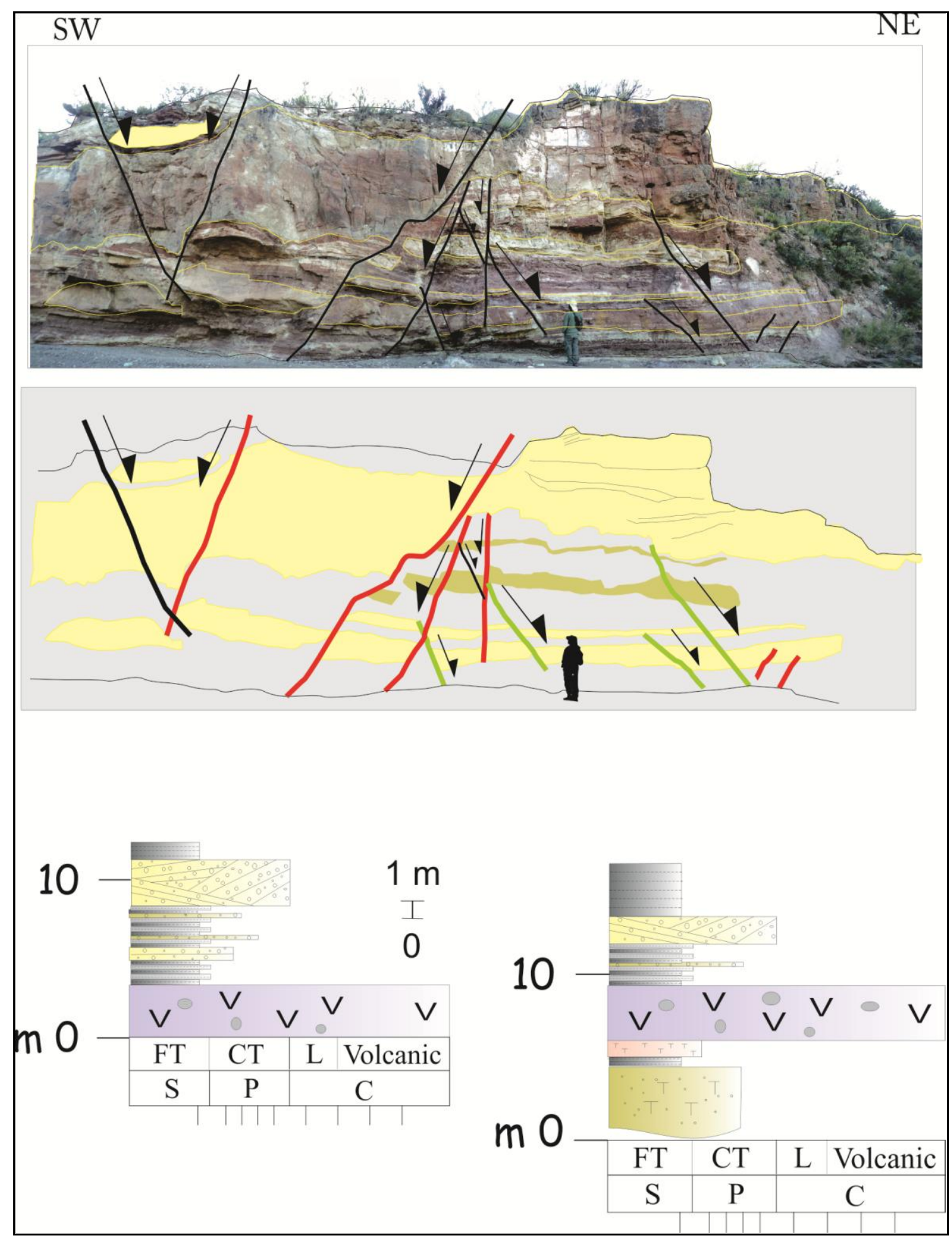

Figura 5.10. Fallas normales sinsedimentarias en los niveles inferiores de la Fm Quebrada de los Fósiles. Foto tomada en la localidad Río Seco de la Quebrada. 


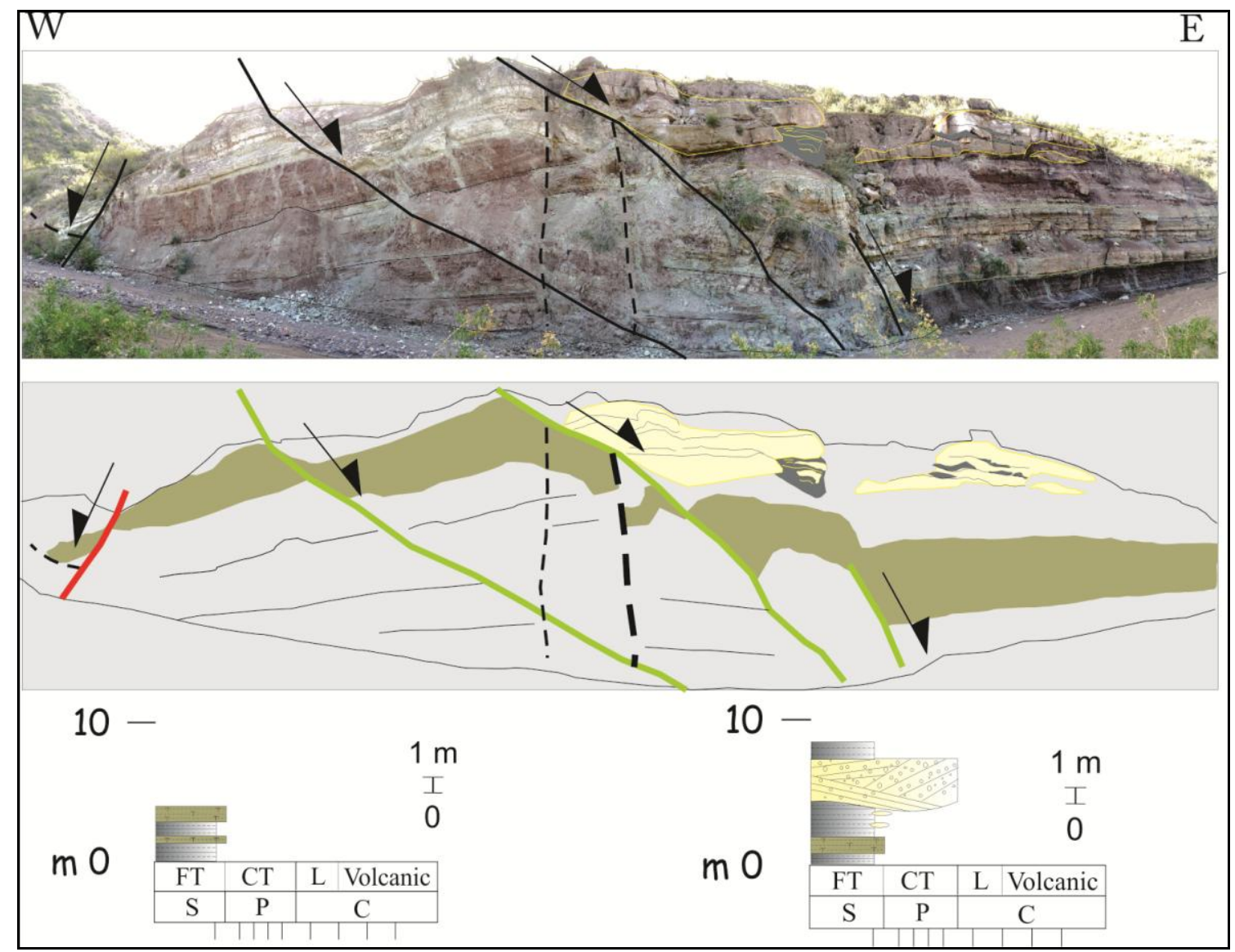

Figura 5.11. Plegamiento por arrastre producido por fallas normales. Foto tomada en la localidad Río Seco de la Quebrada. 


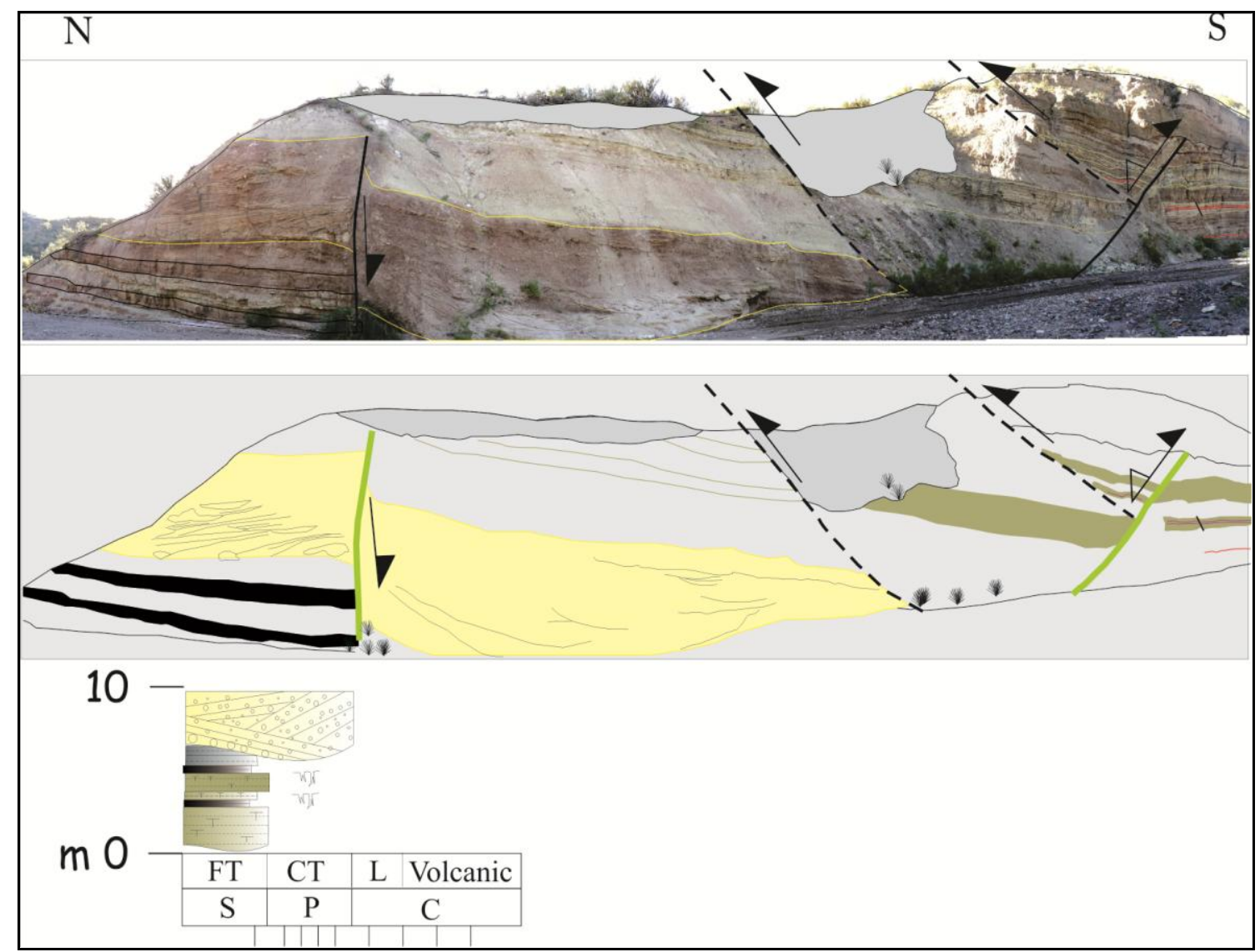

Figura 5.12. Fallas normales cortan la planicie de inundación y a los canales desarrollados. Foto tomada en la localidad Río Seco de la Quebrada. 


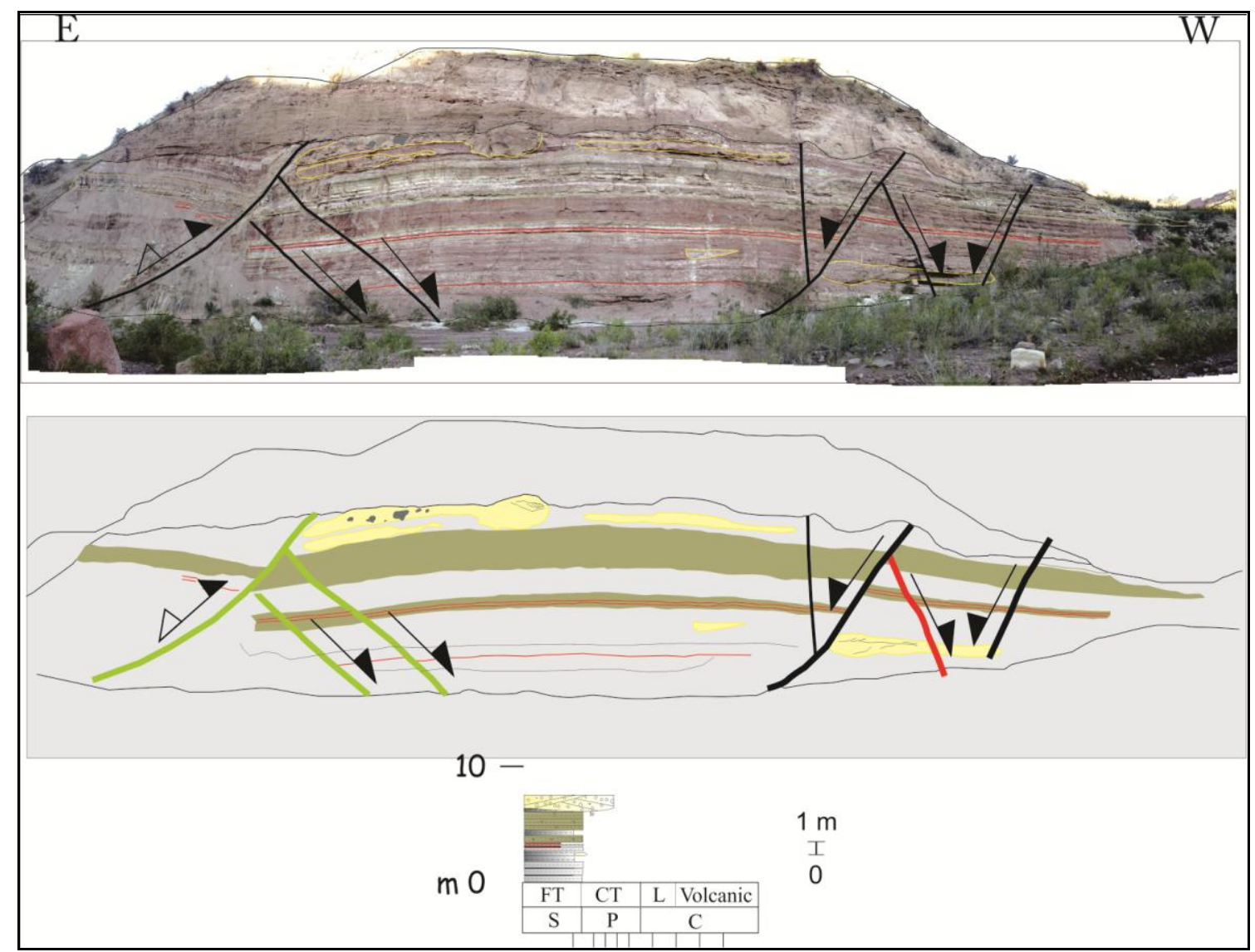

Figura 5.13. Depositación sinsedimentaria de canales en depresiones estructurales dentro planicie de inundación. Foto tomada en la localidad Río Seco de la Quebrada. 


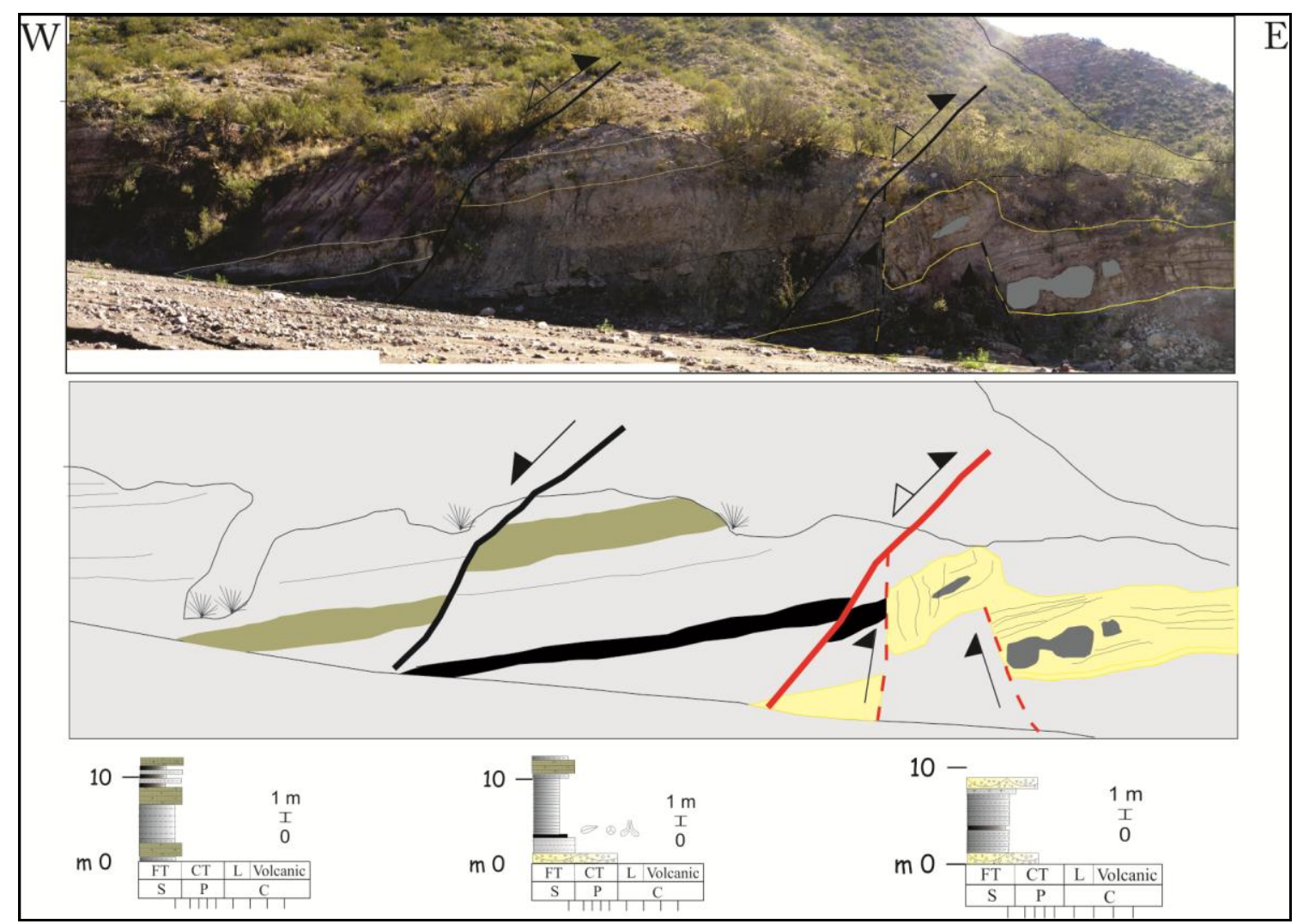

Figura 5.14. Niveles lacustres en planicie de inundación desarrolladas en zonas más deprimidas, vinculados al borde fallas normales. Foto tomada en la localidad Río Seco de la Quebrada.

\section{b) Los flujos piroclásticos de la etapa II}

Integrando esta etapa del relleno se observan niveles constituidos por la unidad de acumulación de flujos ignimbríticos ácidos (Capítulo 4.3) de composición riolítica (Capítulo . 4.1.B). Esta unidad se presenta como depósitos masivos y sus afloramientos se observan discontinuos en el área de estudio y cubriendo como mantos a las planicies de inundación previamente descriptas (Figura 5.8). Sus espesores son pequeños en relación a la unidad de acumulación subyacente. En el extremo sur del borde oriental de la cuenca se registran espesores máximos de 30 metros (perfiles 5 y 4 de la Figura 5.8), ocupa y colmata bajos estructurales, que disminuyen gradualmente a 10 metros hacia el norte del borde occidental (perfiles 1 y 2 de la Figura 5.8). Estos depósitos se caracterizan por presentar un alto grado de soldamiento que en los sectores de mayor espesor pasan a niveles poco soldados, mostryo una estratificación 
grosera producto de su depositación con asociación de litofacies $\mathrm{mL} / \mathrm{mL}$ (Figura 4.19 del Capítulo 4.2). A partir de ello es posible inferir que se trata de varias unidades de flujo superpuestas. Las variaciones de espesor que muestra esta unidad de acumulación distribuida en la zona de estudio, sumadas a los diferentes grados de soldamiento vinculados a los mayores espesores, permiten inferir que constituyen las partes medias a distales de corrientes de flujos piroclásticos provenientes desde el sector sur- suroeste.

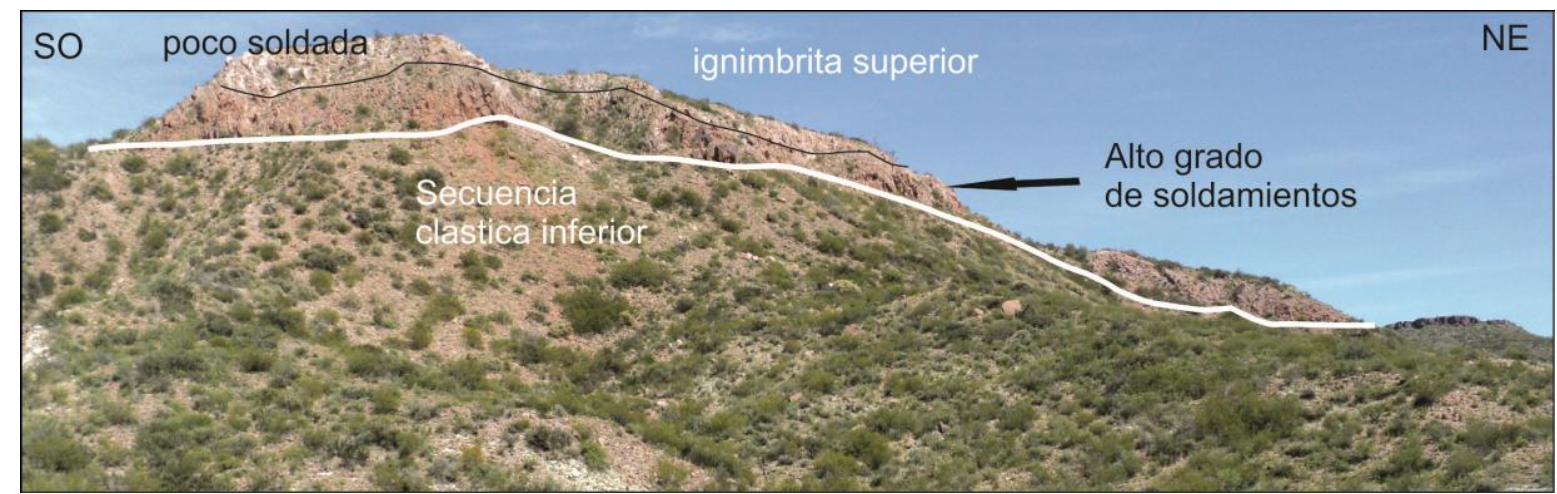

Figura 5.15. Afloramientos de los flujos ignimbríticos con diferente grado de soldamiento, cubren a la planicie de inundación. Foto tomada en la denominada Pequeña Quebrada. (Figura 5.8 para la localización de la quebrada).

Sintesis de la etapa II

Del análisis litológico (Capítulo 4), sumado a los observaciones de campo, es posible afirmar que la Formación Quebrada de los Fósiles está constituida principalmente a partir de la erosión, transporte y redepositación de rocas de basamento pérmico, conformadas principalmente por rocas volcaniclásticas de la Formación Agua de los Burros, tal como plantean otros autores (González Díaz, 1972; Spalletti et al., 1996; Stipanicic et al., 2007). Esta unidad aflora en el margen este del borde oriental de la zona de estudio (Capítulo 1). Las rocas sedimentarias representan más del $80 \%$ de la totalidad del relleno de la etapa II. Los sistemas fluviales constituyen el principal agente proveedor de material clástico proveniente del bloque piso elevado. Por otra parte, las rocas piroclásticas representan menos del $15 \%$ del volumen total de esta etapa de 
relleno. Las observaciones de campo y las características composicionales definidas en el análisis litológico (Capítulo 1) evidencian que los flujos piroclásticos son, en ocasiones, retrabajados e incorporados como parte de los mismos depósitos fluviales pero no constituyen un control sobre la evolución y morfología de la cuenca en esta etapa. Esta situación ya fue descripta detalladamente por Smith (1991) en su clásico estudio sobre la interacción de procesos sedimentarios y volcánicos. Por todo lo dicho, es posible afirmar que durante esta etapa de relleno II el espacio de acomodación fue aumentyo y los sistemas fluviales se desarrollaron hacia el interior de la cuenca constituyendo depósitos formados en condiciones inter-eruptivas (Smith, 1991).

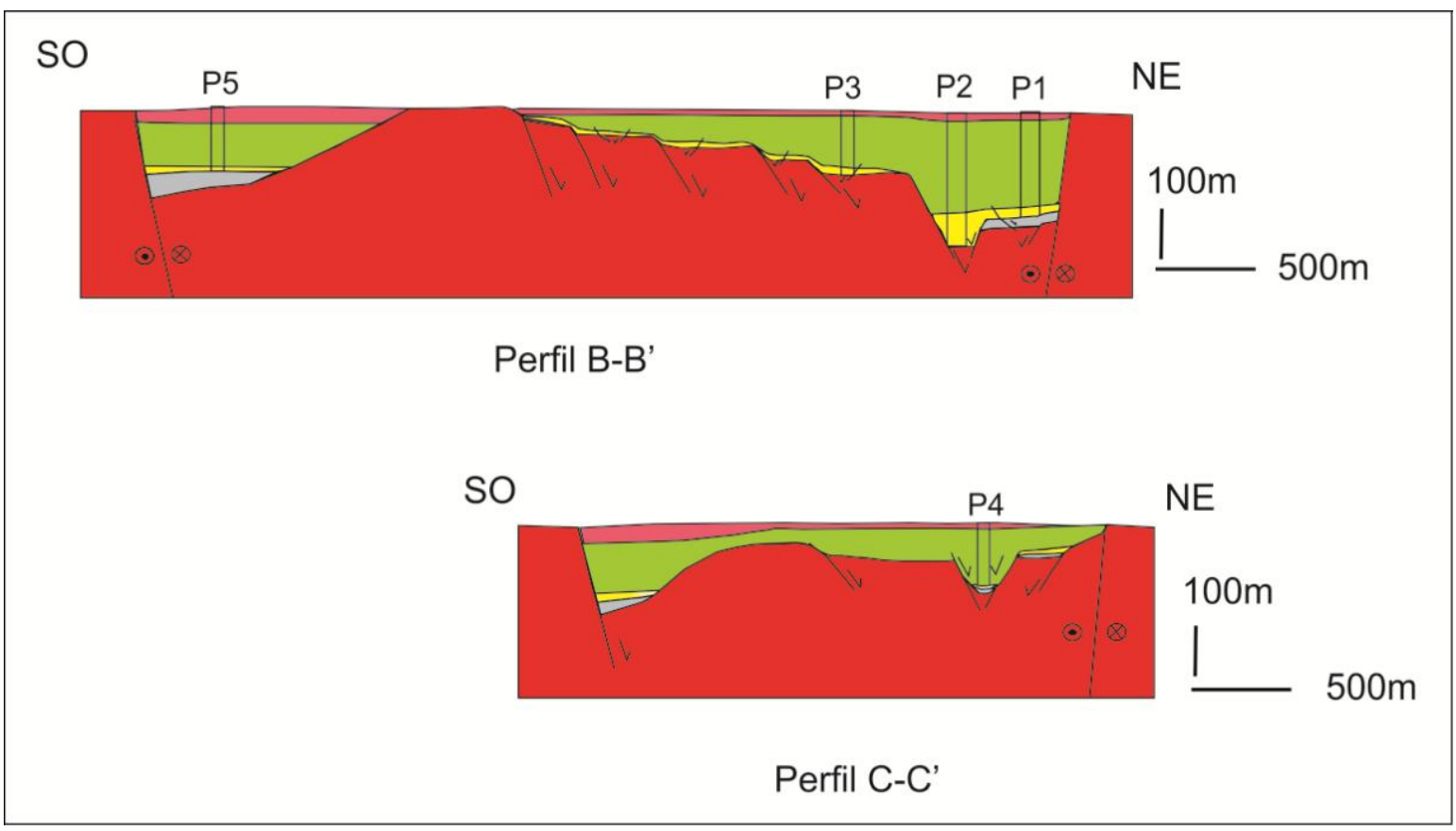

Figura 5.16. Cortes geológicos para la etapa II y distribución de las unidades de acumulación. Ubicación en Figura 5.8.

\subsection{Relleno de la etapa III. Reactivación y crecimiento de las estructuras internas. Nivel medio del Grupo Puesto Viejo (Fm Río Seco de la Quebrada)}

Durante esta etapa de relleno, la extensión continuó con el desarrollo de un conjunto de fallas internas directas sintéticas entre sí, con orientación preferencial ONO-ESE, oblicuas al borde de cuenca (Capítulo 3.1.2). El patrón 
de crecimiento de estas fallas fue variyo a medida que los segmentos de falla se propagaron y conectaron entre sí. Constituyen fallas directas o flexuras monoclinales (como se ve en los niveles de flujos piroclásticos superiores de la Formación Quebrada de los Fósiles; Capítulo 3.1.4).

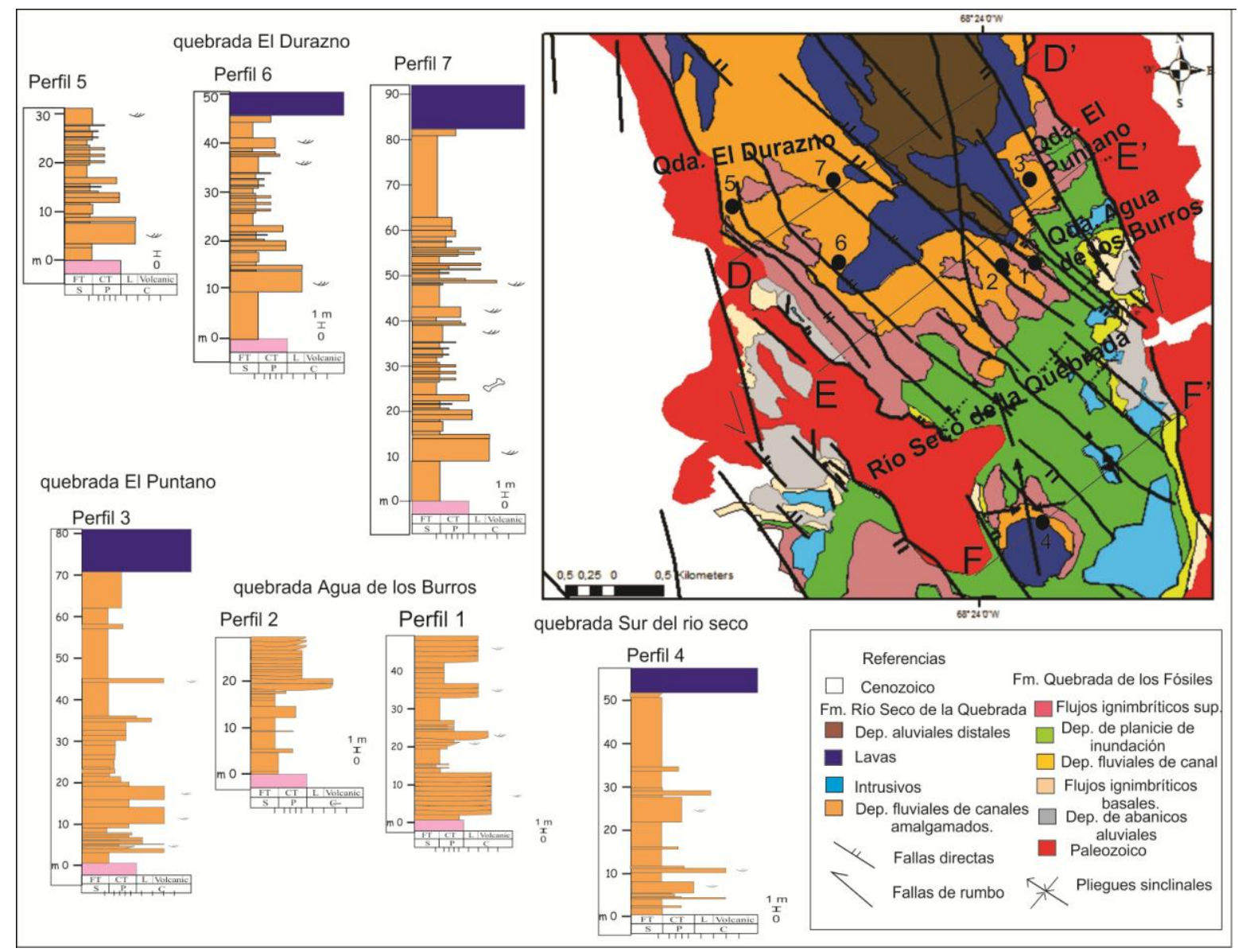

Figura 5.17. Mapa geológico de detalle y distribución de perfiles sedimentológicos para la etapa III. Ubicación de los cortes geológicos D-D', EE' y F-F A-A'.

\subsubsection{Unidades de acumulación que definen esta etapa}

Durante esta etapa se desarrollaron sistemas fluviales que se depositaron a los largo de los hemigrábenes generados principalmente hacia el sector noroeste de la zona de estudio (Figura 5.17). Hacia el sector sur y suroeste se produce un cambio de polaridad de los espacios de acumulación producto de una zona de acomodación desarrollada con sentido NE-SW (Capítulo 3), dando lugar a 
la depositación aislada de estos sistemas fluviales. Acompañyo a los sistemas fluviales, en esta etapa se registra el volcanismo basáltico del Grupo Puesto Viejo.

Para esta tercera etapa de relleno se reconocen, por lo tanto, dos unidades de acumulación: los sistemas fluviales meandrosos de baja sinuosidad y las rocas volcánicas (Capítulo 4.3).

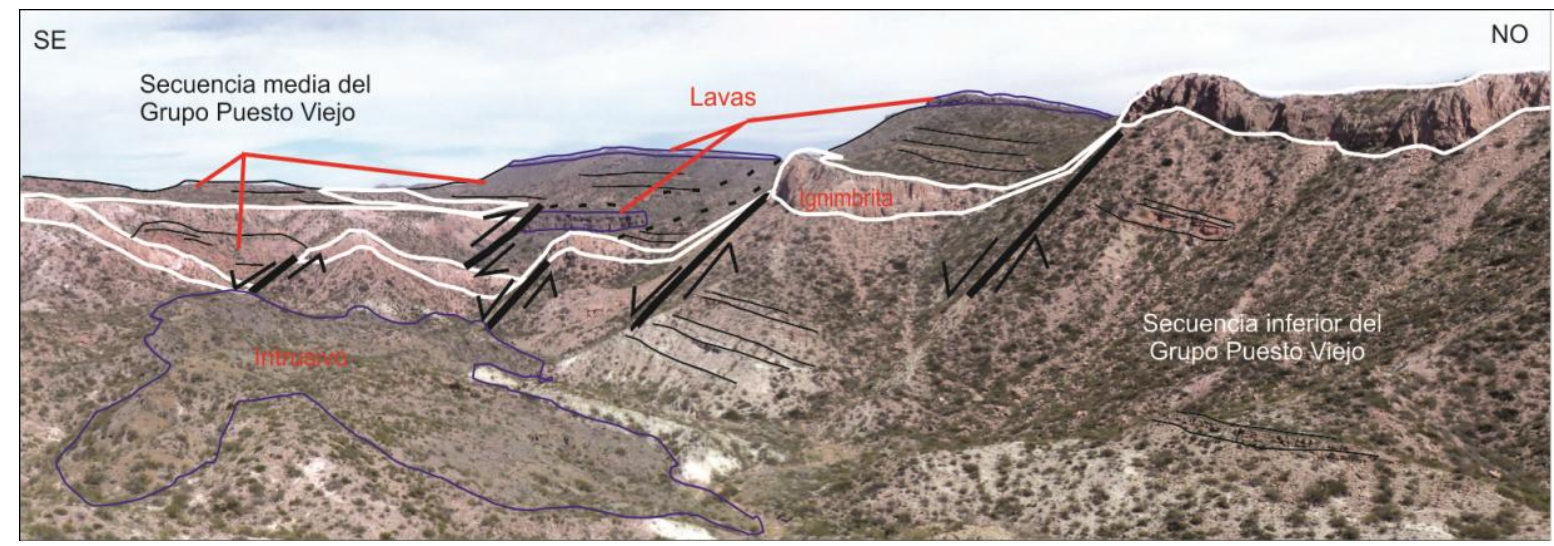

Figura 5.18. Flexuras monoclinales en la ignimbrita superior por fallas directas con orientación ONO-ESE y reactivación de las mismas, cortyo las coladas basálticas. Foto tomada en la Quebrada de los Fósiles (vista al SO). Ubicación en la Figura 5.17.

\section{a) Los sistemas meandrosos de baja sinuosidad de la etapa III}

Esta unidad se acumuló en los nuevos espacios generados en esta etapa ocupando una amplia extensión de la cuenca (Figura 5.17). Sus afloramientos son continuos hacia el noroeste, cubriendo los flujos ignimbríticos subyacentes $y$, en forma aislada, se registran en el extremo suroeste. Su distribución axial en la cuenca está estrechamente ligada a la dirección ONO-ESE de las fallas directas y a la ligera asimetría de los espacios de acomodación generados por el fallamiento. A partir del análisis de los perfiles sedimentarios y su distribución en el área de estudio se puede apreciar cambios en el espesor. Los máximos espesores entre 70 y 80 metros se registran en la región central y noreste (perfiles 3 y 7 de la Figura 5.17), disminuyendo a 50 y 30 metros hacia el borde occidental y el extremo sur del área de estudio (perfiles 1, 2, 4, 5 y 6 de la Figura 5.17) 
En los términos basales de esta unidad de acumulación predominan las facies gruesas formyo múltiples canales amalgamados de hasta 10 metros de espesor integrados por las asociaciones de facies canal (Figura 4.22 del Capítulo 4.3) y barras arenosas (Figura 4.22 de Capítulo 4.3), de hasta 8 metros de espesor en ocasiones acompañadas por 2 a 4 metros de capas arenosas planas integradas por las asociaciones de facies barras arenosas (Figura 4.22 del Capítulo 4.3). Estos cuerpos presentan importante agradación de los miembros gruesos en los bajos estructurales y un fuerte arreglo granodecreciente. La acreción lateral que presentan estos cuerpos, sumado a la presencia de depósitos hiperconcentrados (Figura 4.22. Capítulo 4.3), dificulta identificar los límites de los canales principales (perfiles 1, 2, 3 y 4 de la Figura 5.17). Estas características responden a sistemas meandrosos de baja sinuosidad en concordancia a interpretaciones efectuadas por diferentes autores para otras áreas de trabajo (Veiga et al., 2002, Bridge, 2003, entre otros).

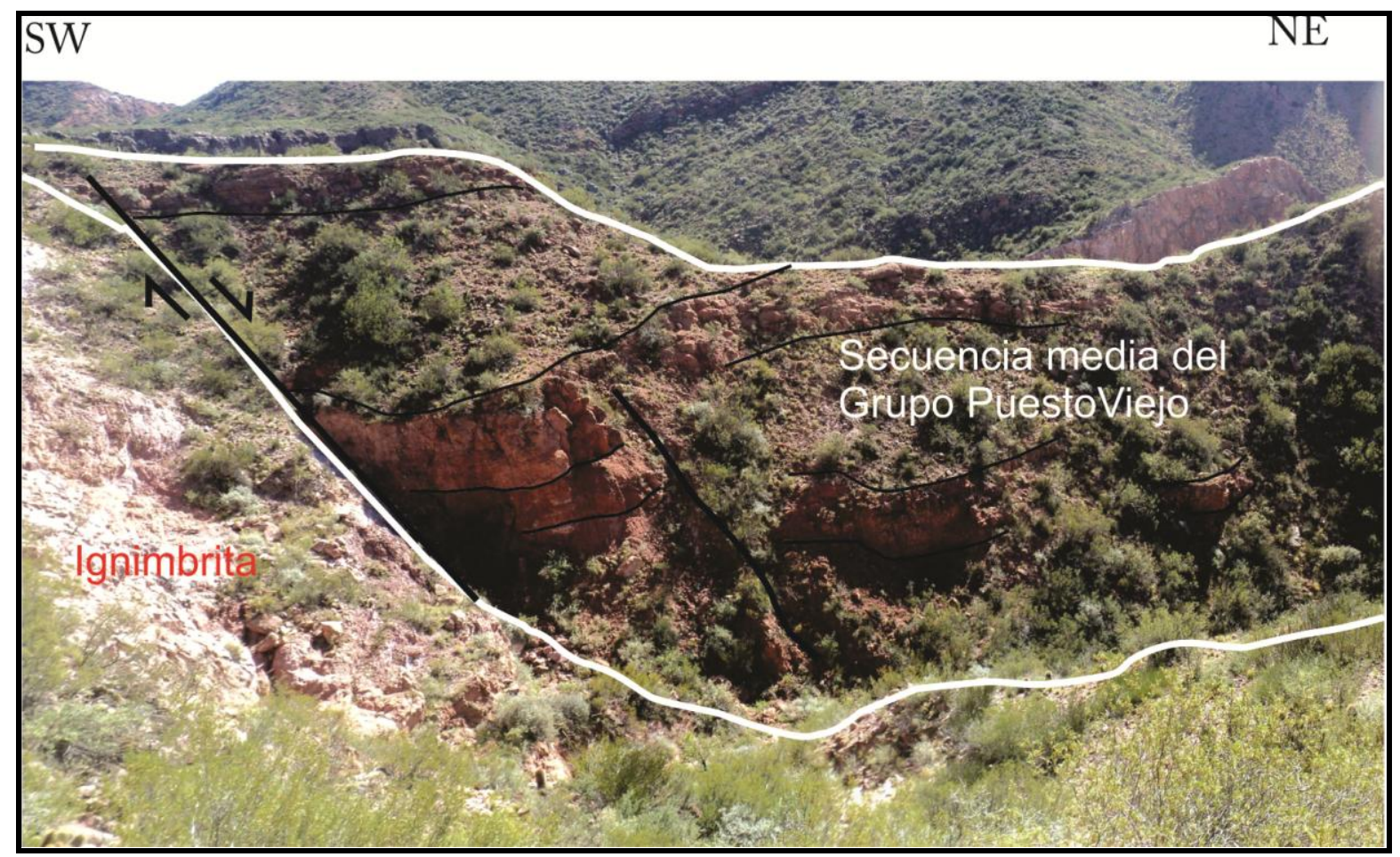

Figura 5.19. Sistemas meandrosos de baja sinuosidad depositados en hemigraben generado por fallamiento directo en la ignimbrita superior. Foto 
tomada en la localidad Agua de los Burros (ubicación en la Figura 5.16; vista al nororeste).

Hacia el noroeste, donde las pendientes son más suaves, el miembro grueso se distribuye como cuerpos aislados bien definidos en canales y barras (Figura 4.22 del Capítulo 4.3) de hasta 5 metros de espesor y extensión lateral superior a 10 metros, que pasan en forma gradual y granodecreciente a miembros más finos (perfiles 5, 6 y 7). En esta unidad de acumulación los miembros finos presentan distribución lateral y vertical discontinua. El desarrollo de planicies de inundación se reduce a depósitos fango-limosos (Figura 4.22; Capítulo 4.3) que no superan los 6 metros de espesor. Se encuentran frecuentemente interrumpidas por eventos de desbordamiento (perfiles de 2 al 7 de la Figura 5.17) representados por canales de crevasse o canales de descarga (Figura 4.22; Capítulo 4.3) y espesores menores a los 2 metros pero con amplia extensión lateral. Estas planicies constituyen los depósitos que propiciaron la preservación de restos fósiles de vertebrados en la Formación Río Seco de la Quebrada, con importante connotación para el registro paleontológico del Triásico (Figura 5.20).

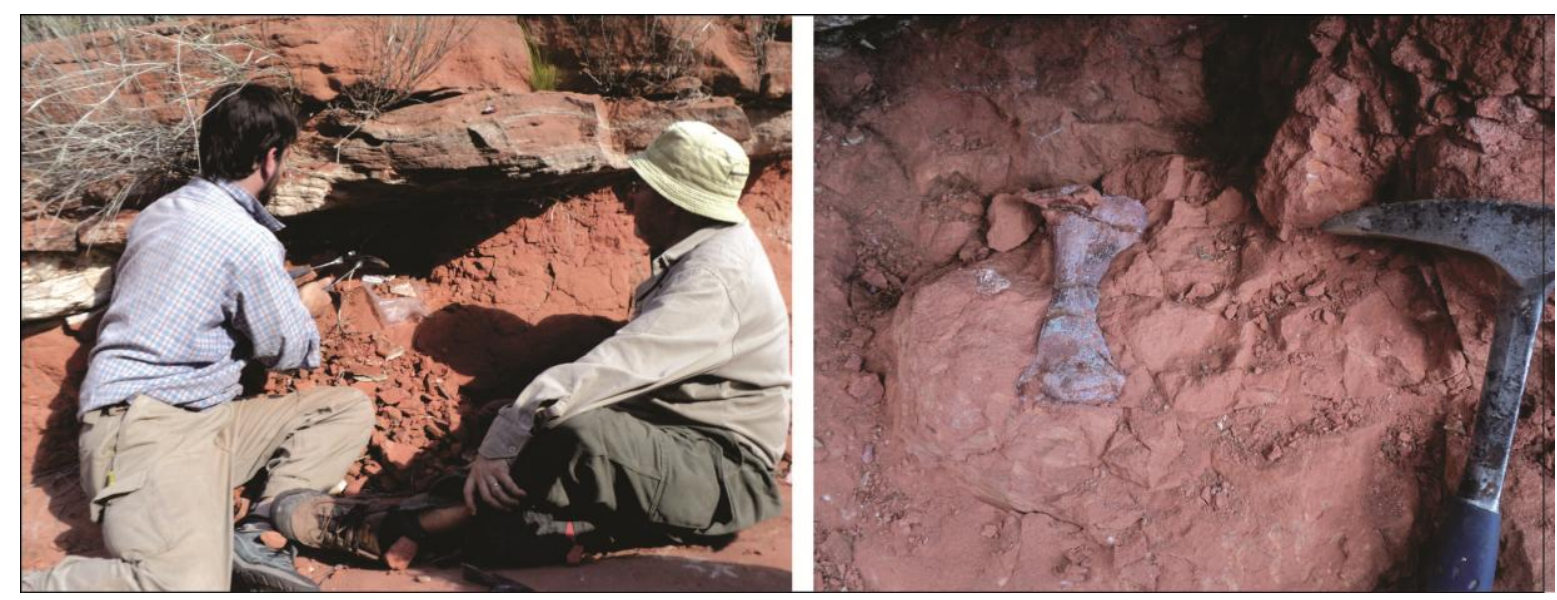

Figura 5.20. Miembros finos de planicies de inundación portadoras de restos fósiles vertebrados (indeterminado).

\section{b) Las rocas volcánicas de la etapa III}


El sistema fluvial se ve interrumpido por la segunda unidad de acumulación constituida por rocas volcánicas, definidas en el Capítulo 4.3 como lavas y cuerpos hipabisales. En esta unidad de acumulación se agrupan las rocas producidas por erupciones magmáticas superficiales, no explosivas e intrusivas someras, clasificadas a partir de análisis petrográficos y geoquímicos, como rocas andesíticas y yesitas basálticas (Capítulo 4.1B). Este evento volcánico marca la finalización de esta etapa de relleno, produciendo un cese en el desarrollo de los sistemas fluviales. El control que ejerce el fallamiento durante esta etapa de relleno se ve reflejado en la distribución de esta unidad de acumulación. En el extremo sureste del área de estudio afloran una serie de cuerpos subvolcánicos emplazados en la zona de acomodación (ver Capitulo 3) a lo largo la falla de borde oriental (Figura 5.17). La localización de este magmatismo implica que las fallas directas oblicuas al borde de cuenca facilitaron el ascenso de magma, alcanzando la superficie como efusiones fisurales de lavas que cubren a los sistemas fluviales hacia el noreste del área de estudio. Los cuerpos subvolcánicos definidos por las asociaciones de facies Bi (Figura 4.19 del Capítulo 4.2), constituyen criptodomos de composición yesítica/basáltica (Capítulo 4.1B) de variada extensión. En esta localidad se midieron cuerpos pequeños de $0,5 \mathrm{~km}$ de largo por $0,25 \mathrm{~km}$ de ancho y cuerpos mayores de 1,5 km de largo por 0,8 km de ancho, que intruyen y deforman las planicies de inundación de la unidad de acumulación de sistema meandroso de alta sinuosidad perteneciente a la Formación Quebrada de los Fósiles (Figura 5.21) generando un suave plegamiento de los estratos, que acompañan la forma de los cuerpos dómicos. Otros rasgos del impacto térmico que generó lo intrusión de estos cuerpos en la roca de caja fueron descriptos en el Capítulo 4.3 como líneas de flujo, texturas de relleno, fracturación perlítica y peperitas.

Como cuerpos menores que se desprenden de los cuerpos subvolcánicos se describieron también filones capa y diques que acompañan o cortan respectivamente la estratificación de la Formación Quebrada de los Fósiles. 


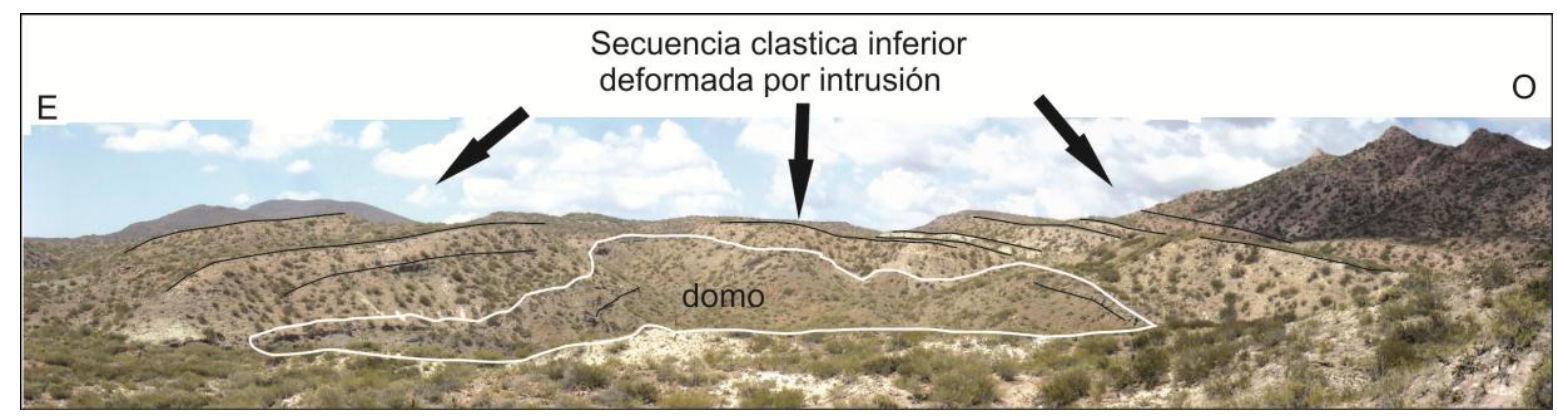

Figura 5.21. Domo deformyo los niveles inferiores de la Fm Quebrada de los Fósiles. Foto tomada al sur de la localidad Río Seco de la Quebrada. Ubicación en la Figura 5.17.

Las Lavas, definidas como asociaciones de facies LAB (Figura 4.19 del Capítulo 4.2), constituyen efusiones sucesivas en forma de manto que cubren las unidades fluviales previas, colmatyo los niveles estructurales más bajos (Figura 5.22). Sus afloramientos son continuos y se concentran en la parte central del área de estudio, con sentido SO-NE, extendiéndose por $7 \mathrm{~km}$ de largo y $2 \mathrm{~km}$ de ancho (Figura 5.17). Las lavas andesíticas (Capítulo 4.1B) presentan una marcada fluidalidad hacia el NNE (Figura 5.23 a) que responde principalmente a la topografía del terreno al momento de su depositación. En ese sentido, el espesor medido de las lavas aumenta desde sus partes proximales en el extremo suroeste con sólo 5 metros hasta alcanzar 15 metros de espesor hacia las partes distales en el noreste, donde se ha producido su acumulación. El aspecto general de estas coladas es homogéneo y masivo. Sólo se destaca la generación de fracturas verticales con dirección E-O (Figura 5.23 b) posiblemente generadas durante su enfriamiento.

La disposición de las lavas hacia el noreste y en el extremo suroeste, así como sus variaciones de espesor evidencia su estrecha relación con la estructuración de la cuenca durante esta etapa de relleno, depositándose y colmatyo espacios de acumulación asimétricos (hemigrábenes). 


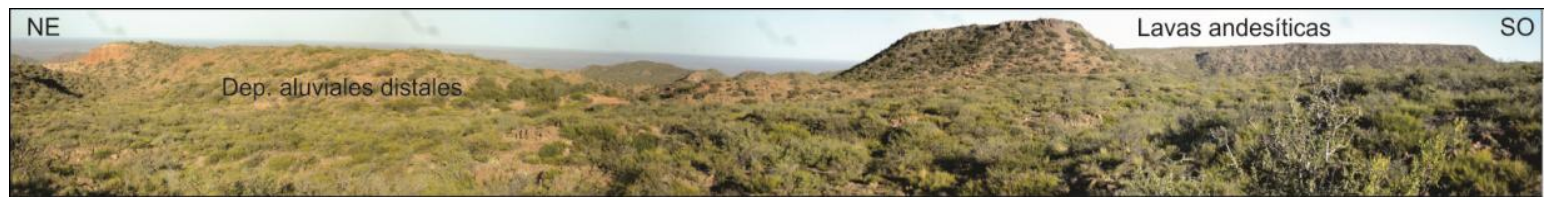

Figura 5.22. Afloramientos de lavas andesíticas en la localidad del Durazno.

Figura 5.17 para su localización.
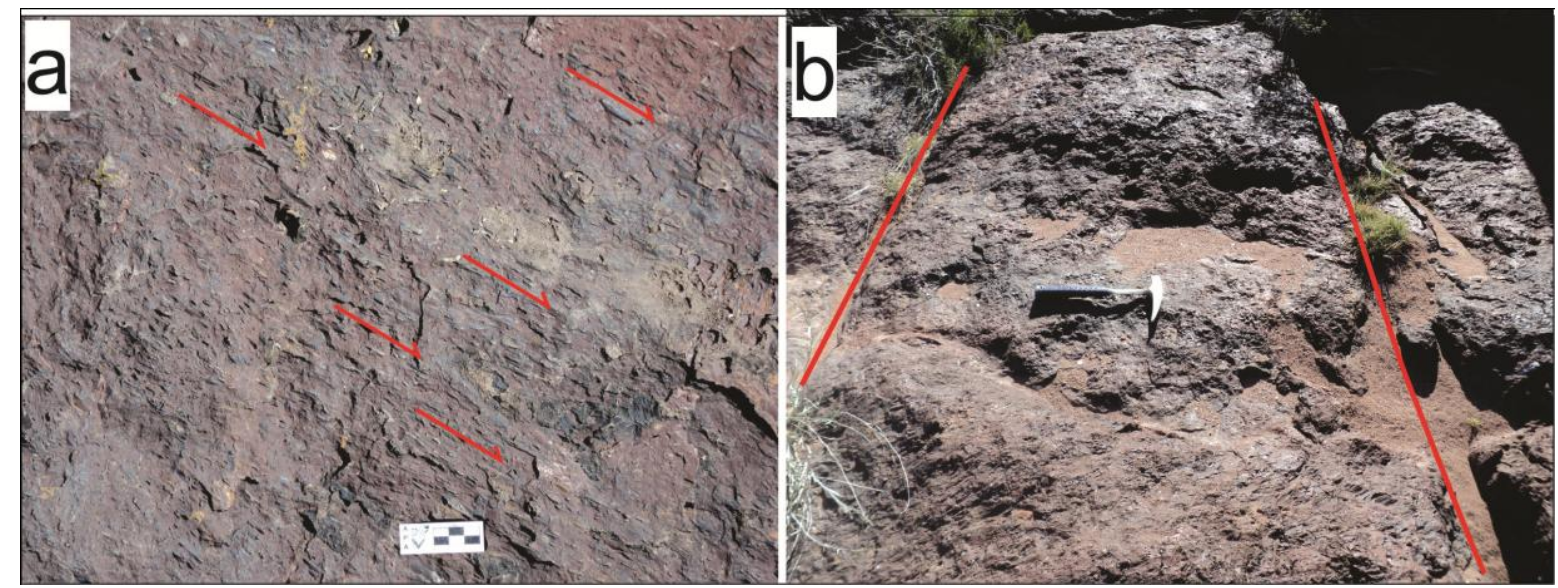

Figura 5.23. Detalle de la colada basáltica. a) Dirección del flujo. b) Fracturas.

Síntesis de la etapa III

A partir del análisis litológico (Capítulo 4) surge que la unidad de acumulación epiclástica de la Formación Río Seco de la Quebrada, descripta para esta etapa de relleno, se compone de material clástico proveniente del bloque piso elevado constituido por el pórfido riolítico pérmico (Formación Cerro Carrizalito), rasgo ya mencionado por González Díaz (1964) y Stipanicic et al. (2007) (Capítulo 1; Figura 1.3), pero con una importante participación de material clástico sedimentario producto de la erosión y redepositación de la propia sucesión triásica (Fm Quebrada de los Fósiles). Esta modificación en el área de aporte se acentúa por la presencia de una zona de acomodación de alto relieve en sentido NE-SO desarrollada en el sector sureste del área de estudio (Capítulo 3) que generó un cambio de polaridad en los espacios de acomodación con elevación parcial de los bloques piso y como consecuencia la desviación y el desarrollo de sistemas fluviales (véase: Morley, 1995, 1999) en condiciones de moderada a alta energía sobre la unidad de acumulación de flujos ignimbríticos de la etapa II. 
Las rocas volcánicas representan solo el $11 \%$ del volumen total de rocas que conforman esta etapa de relleno y los sistemas fluviales constituyen el principal agente proveedor de material, pero su desarrollo ha sido condicionado por la actividad volcánica. En ese sentido es posible considerar esta etapa de relleno como un período sin-volcánico (Smith, 1991; Haughton, 1993; Erikson et al. 1993).

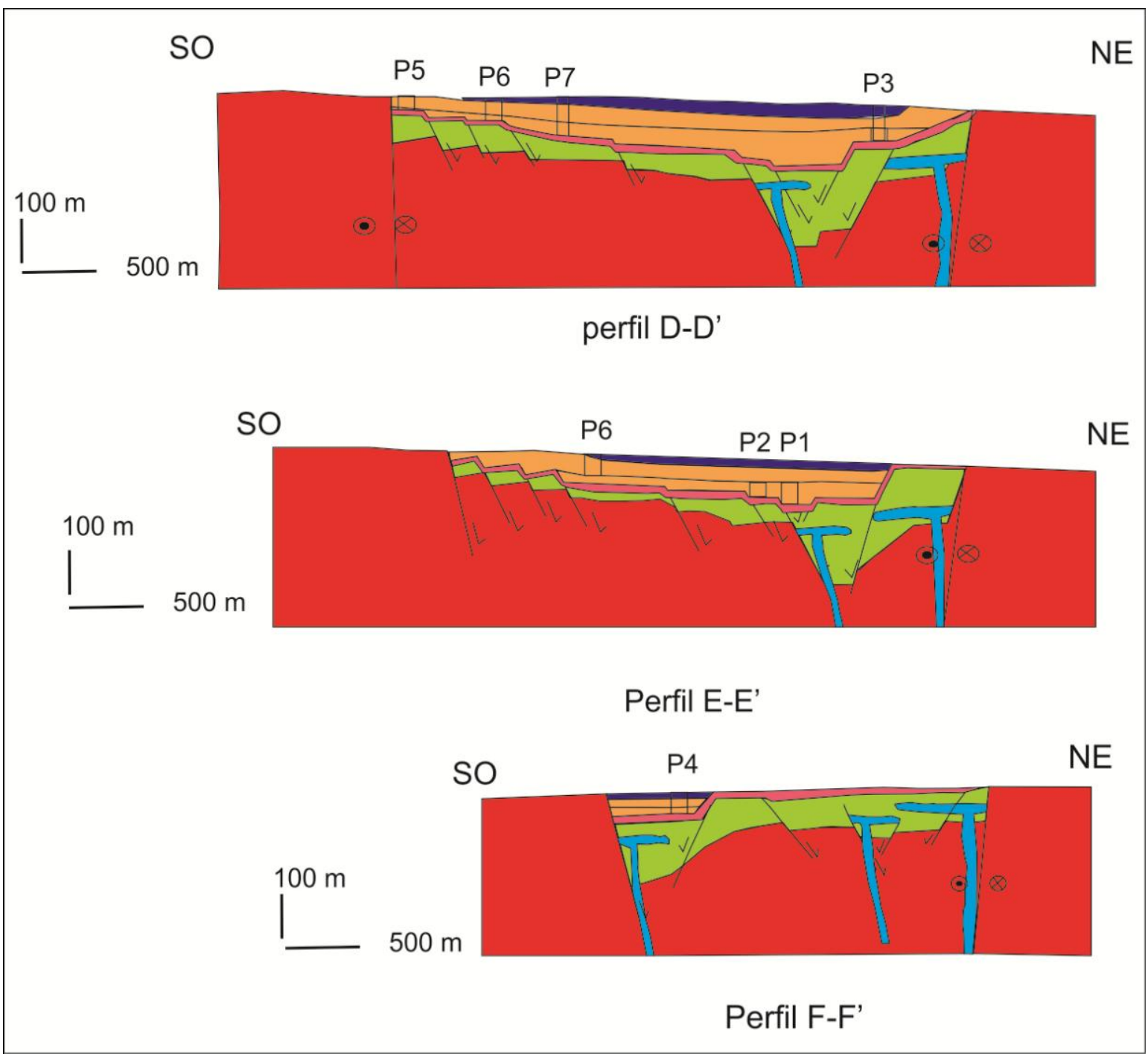

Figura 5.24. Cortes geológicos para la etapa III y distribución de las unidades de acumulación. Ubicación en Figura 5.17. 


\subsection{Relleno de la etapa IV. Generación y colmatación de los espacios de acumulación finales. Nivel superior del Grupo Puesto Viejo (Fm Río Seco de la Quebrada)}

En el marco de la extensión generalizada en este depocentro, el crecimiento de algunas fallas internas ONO-ESE, oblicuas al borde de cuenca, continuó propagándose hacia la superficie (Capítulo 3 ) y cortyo las lavas andesíticas depositadas en la etapa de relleno previa, en el extremo noroeste de la zona de estudio (Figura 5.25). Los nuevos espacios de acumulación tuvieron la forma de hemigrábenes con marcada asimetría en los cuales se depositaron sistemas aluviales que constituyen los términos finales del Grupo Puesto Viejo. 


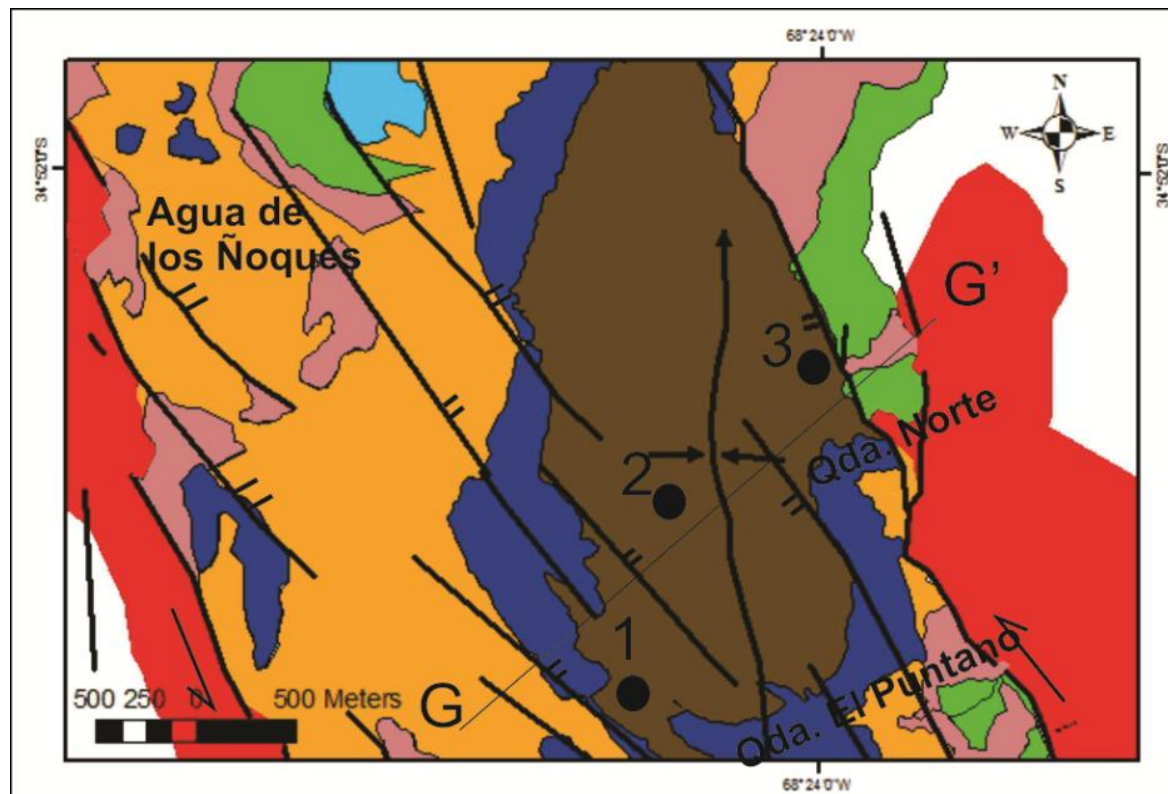

Quebrada Norte Perfil 3

Quebrada EI Durazno Perfil 1

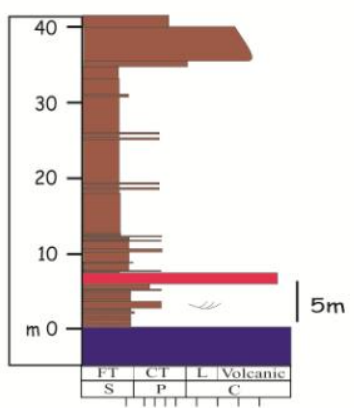

\section{Referencias}

Cenozoico
Perfil 2

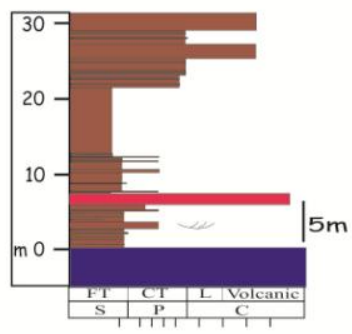

Fm. Río Seco de la Quebrada

$\square$ Dep. aluviales distales

- Lavas

$\square$ Intrusivos

$\square$ Dep. fluviales de canales amalgamados.

Fallas directas

Fallas de rumbo
Fm. Quebrada de los Fósiles

$\square \quad$ Flujos ignimbríticos sup.

Dep. de planicie de inundación

- Paleozoico

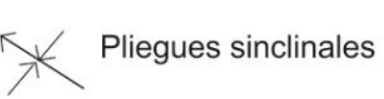

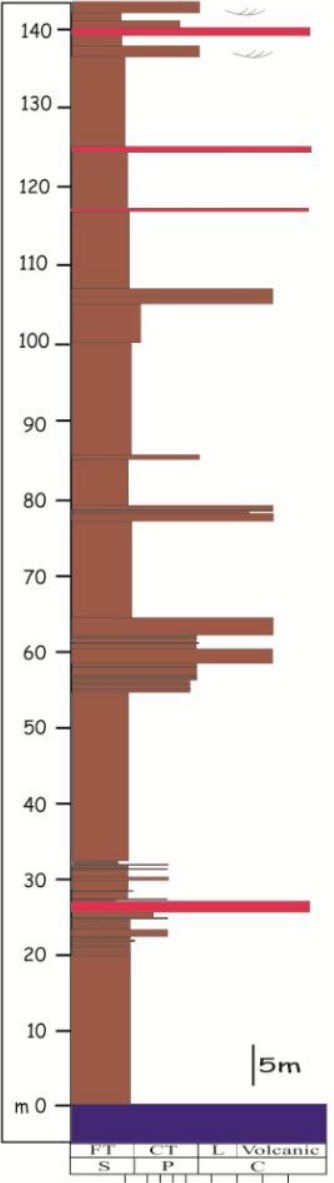

Figura 5.25. Mapa geológico de detalle y distribución de perfiles sedimentológicos para la Etapa I. Ubicación de corte geológico G-G’. Etapa IV 


\subsubsection{Unidades de acumulación que definen esta etapa}

Durante esta etapa de relleno se reconocen dos unidades de acumulación que intercalan en su depositación: los abanicos aluviales y los flujos piroclásticos (Capítulo 4.3). La primera (abanico aluvial) es la unidad de acumulación más desarrollada durante esta etapa. Sus depósitos se localizan únicamente en el sector central de la zona de estudio extendiéndose hacia el borde oriental de la cuenca (Figura 5.26), donde se acumulan a partir de abanicos aluviales transversales al depocentro. De manera subordinada se desarrolla la segunda unidad de acumulación (flujos piroclásticos) que intercala en toda la unidad sedimentaria como niveles delgados, lo cual indica la existencia de actividad volcánica explosiva en los alrededores de la cuenca, coetánea con el desarrollo del sistema aluvial.

\section{a) Abanicos aluviales de la etapa IV}

Esta unidad de acumulación representa los niveles triásicos más modernos del Grupo Puesto Viejo que fueron depositados a partir de abanicos aluviales (Capítulo 4.3) cubriendo a las lavas andesíticas de la etapa III con una disposición actual casi horizontal (Figura 5.26). Sus afloramientos son continuos y se concentran en la parte central del área de estudio, con sentido SO-NE extendiéndose por $6 \mathrm{~km}$ de largo y 1,5 km de ancho hacia el borde oriental de la cuenca. Sus espesores varían sustancialmente en el área de estudio, con espesores máximos de 144 metros en el borde occidental (perfil 3 de la Figura 5.25) y disminuyen abruptamente a 30 metros de espesor hacia el suroeste (perfiles 1 y 2 de la Figura 5.25).

A partir del análisis de los perfiles sedimentológicos (véase Anexo 2) se aprecia un arreglo general granocreciente (Figura 5.27) definido por el desarrollo de una extensa planicie aluvial distal (Figura 4.27 Capítulo 4.3) que conforma cuerpos tabulares de variado espesor (entre 2 y 10 metros) interdigitados por delgados canales de crevasse (Figura 4.27; Capítulo 4.3) y espesores menores a 1 metro. Hacia los niveles superiores de esta unidad de acumulación (perfil 3 de la Figura 5.25) el desarrollo de las planicies aluviales se ve interrumpido temporalmente por la depositación de al menos tres eventos 
de flujos de detritos diluidos y flujos hiperconcentrados no canalizados (Figura 4.27 del Capítulo 4.3). Conforman cuerpos tabulares de hasta 5 metros de espesor que se desarrollan principalmente en el borde oriental, adyacentes a las fallas aunque también se registran hacia el interior de la cuenca (perfiles $1 \mathrm{y}$ 2).

Al tratarse de abanicos aluviales se infiere que en la base de esta unidad de acumulación se habrían desarrollado facies proximales con flujos de detritos gruesos equivalentes a los niveles gruesos superiores. Pero no se hallan representados en los perfiles sedimentológicos realizados (véase Anexo 2) posiblemente debido a su erosión o bien porque la preservación de estos niveles se encuentra reducida a otras áreas.

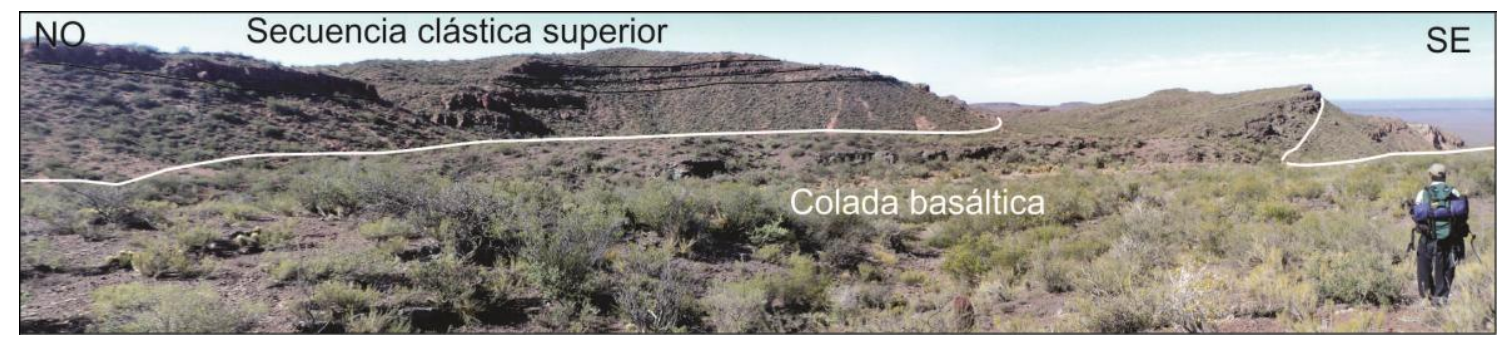

Figura 5.26. Disposición casi horizontal de la secuencia superior por encima de las coladas basálticas. Quebrada El Puntano (a) extremo oeste (b) extremo este. Ubicación en la Figura 5.25.

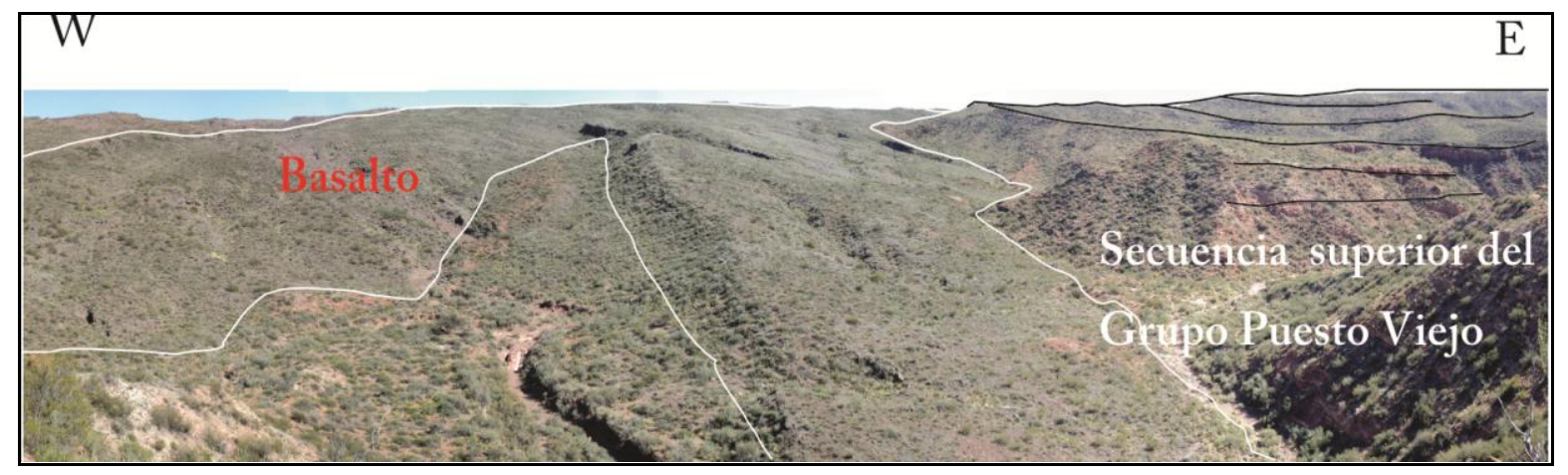

Figura 5.27. Depósitos aluviales distales depositada sobre lavas andesíticas. Foto tomada al norte de la quebrada EI Puntano. Ubicación en la Figura 5.25. 


\section{b) Los flujos piroclásticos de la etapa IV}

Esta unidad de acumulación, como se puede apreciar en los perfiles sedimentológicos (Figura 5.19) tiene una participación subordinada en el desarrollo de esta etapa de relleno. Consiste en flujos ignimbríticos ácidos (Capítulo 4.3) de composición riolítica (Capítulo 4.1.B). Se presenta como depósitos masivos y poco soldados, definidos como facies $\mathrm{mL}$ (Figura 4.19 del Capítulo 4.2), que intercalan como delgados cuerpos tabulares de 1,5 metros de espesor máximo entre las planicies aluviales basales de la unidad de acumulación (sistema aluvial) y disminuyen a 0,5 metros de espesor hacia el tope (Perfil 3 de la Figura 5.25).

Su aspecto masivo no soldado, sus escasos espesores y su disposición entre niveles epiclásticos son características que permiten inferir que se trata de facies distales de corrientes piroclásticas (McPhie, 1993) provenientes de los alrededores de la cuenca, posiblemente desde el sector suroeste.

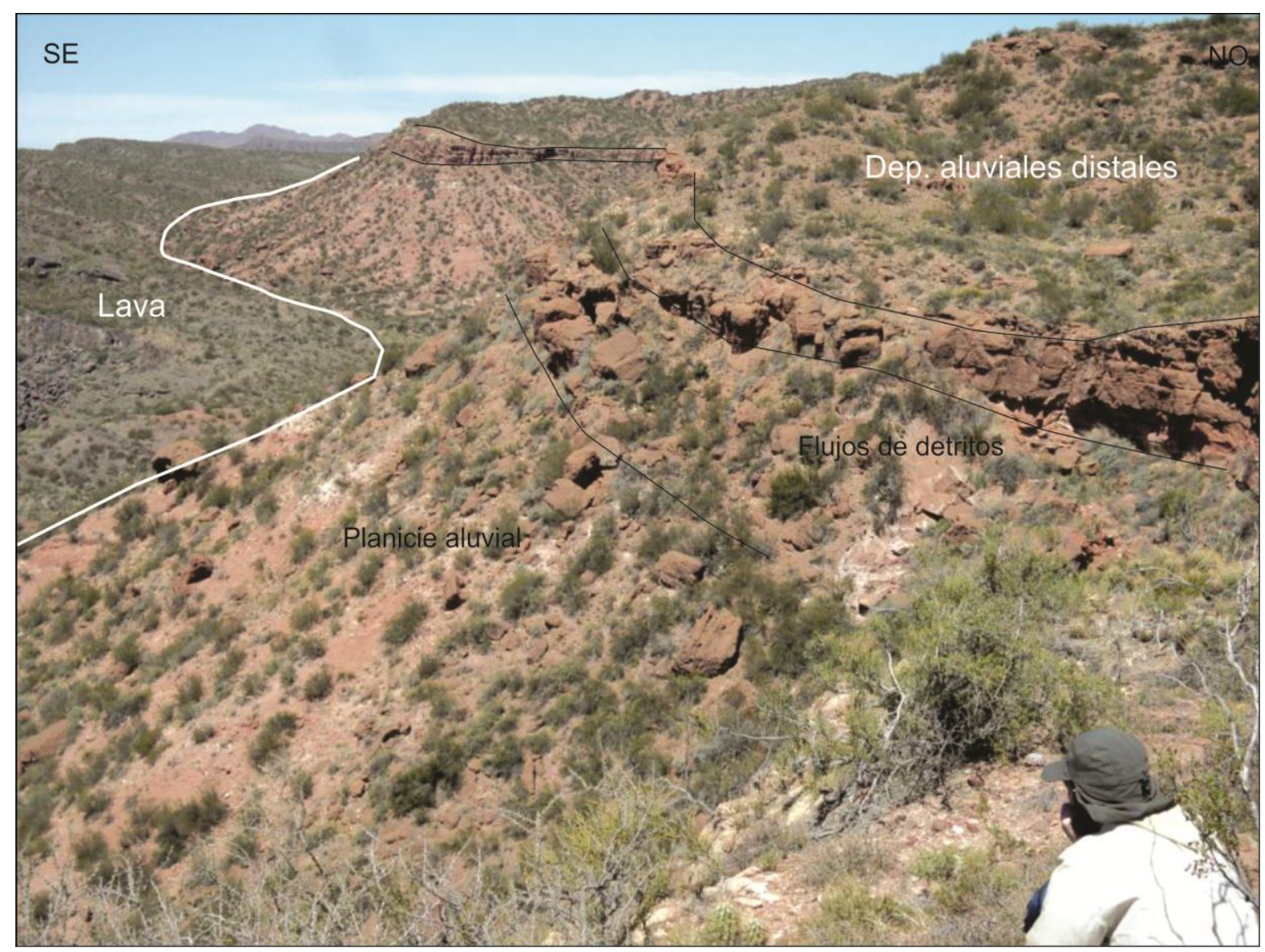

Figura 5.28. Nivel de Flujos ignimbríticos intercalados en planicie aluvial. Perfil 3. Ubicación en Figura 5.25. 
Síntesis de la etapa IV

El análisis litológico (Capítulo 4) correspondiente a los términos finales de la Formación Río Seco de la Quebrada muestra que esta etapa de relleno se compone principalmente de material volcaniclástico (limolitas tobáceas y arenitas tobáceas ricas en cuarzo y líticos basálticos) producto del retrabajamiento (McPhie, 1993) de las unidades de acumulación triásicas subyacentes y de la incorporación de depósitos piroclásticas primarios proveniente de actividad volcánica explosiva coexiste nte en los alrededores de la cuenca, evidenciado por la presencia de depósitos primarios de flujos piroclásticos.

Los depósitos relevados para de la etapa de relleno $\mathrm{N}$ constituyen abanicos aluviales desarrollados únicamente sobre las lavas de la etapa de relleno III, con una disposición transversal posiblemente provenientes del bloque techo, atribuidos al levantamiento parcial del mismo como producto de la reactivación y crecimiento de las fallas directas oblicuas a los bordes de cuenca con desequilibro de las pendientes (Capítulo 3). Aunque los sistemas aluviales constituyen el principal agente proveedor de material, éste se encuentra fuertemente condicionado por la actividad volcánica constituyendo una etapa de relleno sin-volcánica (Smith, 1991; Haughton, 1993).

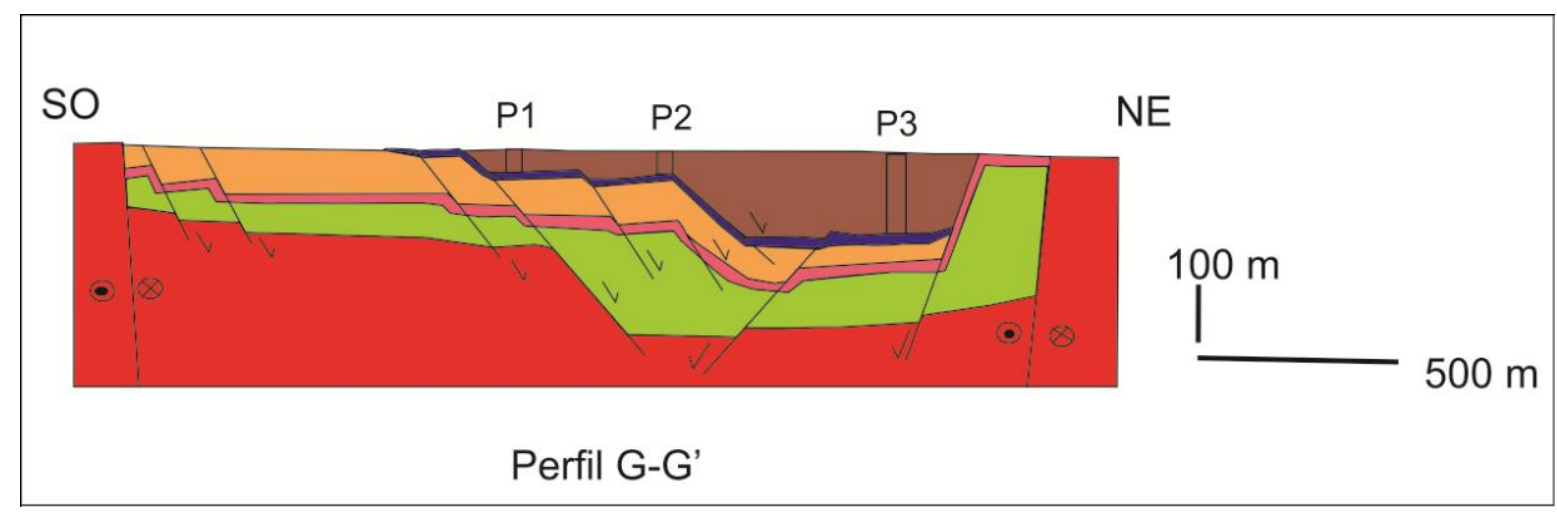

Figura 5.29. Corte geológico para la etapa IV y distribución de las unidades de acumulación. Ubicación en Figura 5.25 
CAPÍTULO 6

\section{DISCUSIÓN DE LOS RESULTADOS}




\section{Capítulo 6. Discusión de los resultados}

\subsection{El depocentro del Grupo Puesto viejo en el contexto de la extensión triásica}

Spalletti (1999) define a las cuencas triásicas de Argentina como un conjunto de depresiones angostas y elongadas en sentido NO-SE, dispuestas en forma subparalea, con diseños en échelon (Charrier, 1979) y oblicuas al margen pacífico del megacontinente de Gondwana. En este contexto se desarrollan las cuencas triásicas conocidas (Ischigualasto-Villa Unión; Cuyana; San Rafael; Malargüe, entre otras) siguiendo la disposición estructural del orógeno de San Rafael (Criado Roque, 1972). El origen y evolución de las cuencas triásicas del oeste argentino estarían ligados al marco geotectónico regional. Así, los eventos extensionales acaecidos entre el Triásico Inferior y el Medio estarían controlados por el régimen extensional vinculado al adelgazamiento cortical y el colapso del orógeno de San Rafael, vinculado con la posición relativamente estacionaria del megacontinente de Gondwana (Spalletti, 1999). En cambio, los del Triásico Tardío aparecen principalmente asociados con un marco tectónico en el que se combinan transcurrencia con subducción (Rapela y Alonso, 1991; Rapela et al., 1991; 1992; Pankhurst et al., 1992).

El depocentro estudiado, que alberga al Grupo Puesto Viejo de la cuenca triásica de San Rafael, se localiza en un contexto tectónico muy particular dentro de ese conjunto, como parte integral del bloque, entre las latitudes $34^{\circ} \mathrm{y}$ $36^{\circ} \mathrm{S}$ de la provincia de Mendoza, (Figura 6.1). La disposición del depocentro, como una franja angosta con rumbo general noroeste, copia la disposición estructural del bloque de San Rafael. Esta disposición no es casual, ya que se superpone de forma neta sobre la sutura de la anexión continental del terreno alóctono Chilenia contra el margen suroeste de Gondwana en el Devónico Superior (Ramos, 1984). En la Figura 6.1 se puede observar que el bloque de San Rafael, junto a Precordillera, constituye el borde occidental del terreno Cuyania, otro bloque exótico que había sido anexado a Gondwana en el Paleozoico inferior (Ramos 2004). La geometría de la sutura entre los terrenos anexados durante el Paleozoico, habría controlado la ubicación y las etapas 
iniciales de todos los procesos termotectónicos subsiguientes en el bloque de San Rafael y áreas adyacentes (Ramos 2004).

El Triásico del bloque de San Rafael, por lo tanto, se desarrolla sobre un basamento heterogéneo con estructuras previas que condicionaron los patrones normales del fallamiento extensional. Los análisis realizados sobre la localización de los principales sistemas de rift en otras regiones sugieren que las estructuras preexistentes de la litósfera son un parámetro clave en el proceso de rifting. La localización de cinturones móviles constituyen zonas débiles que controlan tanto el desarrollo como la arquitectura del rift (Tommasi y Vauchez, 2001; Keranen y Klemperer 2008; Corti et al., 2011). El depocentro estudiado se habría desarrollado bajo un fuerte control estructural, tal como el observado en otras áreas extensionales ampliamente estudiadas (Rift de Etiopía, Corti, 2008; Rift del Lago Baikal, Corti et al., 2011). 


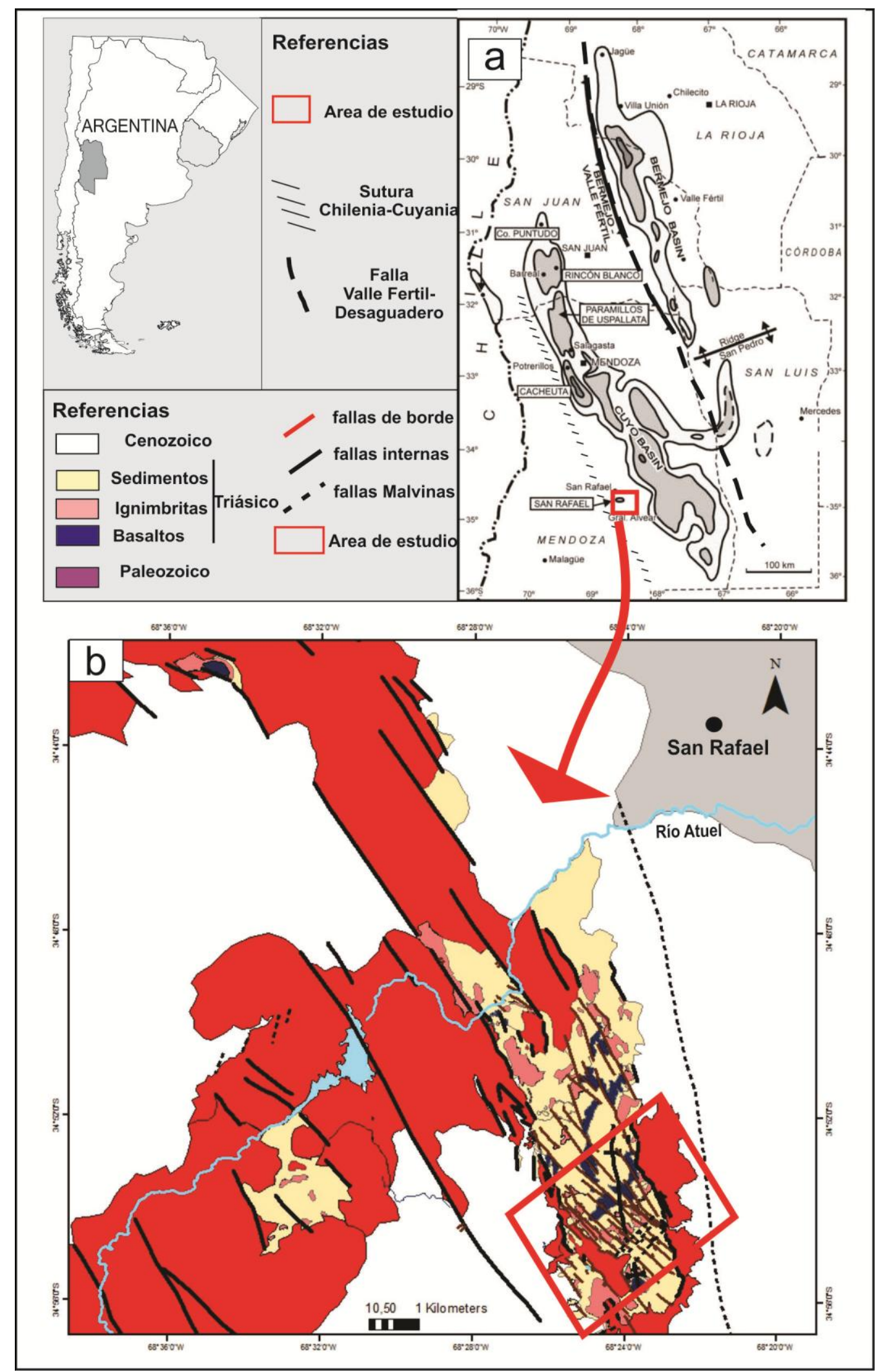

Figura 6.1. Mapa de ubicación del Bloque de San Rafael en su contexto tectónico y localización del área de estudio. 
Sobre ese basamento heterogéneo, el depocentro del área de estudio se desarrolló a través de procesos de fracturación cortical con un estilo particular. El análisis de la geometría y los patrones de las fallas estudiados en este trabajo revela una disposición sistemática de las fallas que generaron el espacio de acumulación de la secuencia del Grupo Puesto Viejo. En el Capítulo 3 se señaló que las principales estructuras activas durante el Triásico consistieron en fallas que fueron subdivididas en fallas de borde y fallas internas. Existe una relación de baja oblicuidad angular entre ambos sistemas. Las fallas de borde (ver Capitulo 3) copian la orientación de la sutura y enmarcan el área deposicional del Grupo Puesto Viejo. Las fallas internas, que controlan la acumulación del relleno durante su desarrollo, poseen un grado sistemático de oblicuidad (entre $10^{\circ}$ y $15^{\circ}$ ) con respecto a las de borde (Capítulo 3). Esta configuración es común en grandes estructuras extensionales del mundo, especialmente en el rift africano oriental (Chorowicz, 2005; Corti et al., 2007) y señalan, mayormente, la oblicuidad de la dirección de extensión con las estructuras de debilidad cortical previas que controlan la localización del rift. Trabajos de modelado tanto analógico como numérico (McClay et al., 2002; Agostini et al., 2011; Corti, 2012) han mostrado que la geometría de las fallas internas de los depocentros se encuentra controlada por el ángulo de oblicuidad de la extensión. En términos generales, las fallas internas se desarrollan perpendicularmente a la dirección de máxima extensión horizontal, mientras que las de borde son paralelas a la heterogeneidad previa. La caracterización de las fallas internas de rumbo ONO-ESE como fallas normales con componentes de desplazamiento en la inclinación casi puros (Capítulo 3), y responsables principales de la generación de los hemigrábenes y grábenes donde se acumuló el relleno permite interpretar que el proceso que dio origen a la acumulación del Grupo Puesto Viejo en el área de estudio consistió en una extensión continental de dirección ENE, perpendicular a los sistemas de fallas internos y oblicua a la zona de debilidad de la sutura paleozoica y a las fallas de borde. Esta configuración resulta típica de un sistema de rift oblicuo, y se encuentra en numerosas zonas extendidas del mundo, donde la dirección de mayor elongación posee una relación angular no ortogonal con la debilidad litosférica que nuclea el rifting (Morley et al., 2004; Agostini et al., 2009; Corti, 2012). En este modelo, las fallas de borde copian la 
dirección de la heterogeneidad del basamento y generan el espacio de depositación general. Estas fallas de borde pueden actuar como fallas de rumbo en el marco de la extensión oblicua si la deformación está altamente particionada (Figura 6.2). Esto permite explicar el movimiento de rumbo detectado en las fallas de borde en el área de estudio. Modelos recientes han comprobado que en muchas localidades del rift africano, las estructuras mayores que bordean las áreas depocentrales pueden ser activas como fallas de rumbo, mientras que el sistema interno, oblicuo, actúa con una componente de extensión ortogonal pura como ocurre en los rifts de Etiopía y Tanganica (Tommasi y Vauchez, 2001; Chorowicz, 2005; Corti et al., 2007; Corti et al., 2013).

Algunos autores han señalado un origen transtensional para las acumulaciones triásicas de San Rafael, lo cual traería implicada la instalación de un régimen transcurrente para este período. Los resultados de este trabajo muestran la existencia de desplazamientos de rumbo de las estructuras de borde pero los enmarcan fuera de un ambiente transcurrente. Los modelos más conocidos de la evolución de cuencas de pull-apart transtensionales y transcurrentes puras, muestran que las fallas transcurrentes que dan origen a estas cuencas se mantienen activas durante todo su desarrollo, limitando los mayores espesores de las acumulaciones volcanosedimentarias y con un bajo grado de oblicuidad respecto a la dirección del movimiento. A su vez, las fallas extensionales / transtensionales internas se desarrollan con una relación angular variable a lo largo de la historia, apuntando a una disposición cada vez más perpendicular con respecto a las fallas de borde (Basile et al., 1999; Morley et al. 2004; Waldron, 2005; Wu et al., 2009). Ninguna de estas características fue observada en el depocentro estudiado, Todas las evidencias recogidas en el área de estudio indican la existencia de un rift oblicuo con una dirección de máxima extensión horizontal dispuesta ENE. 


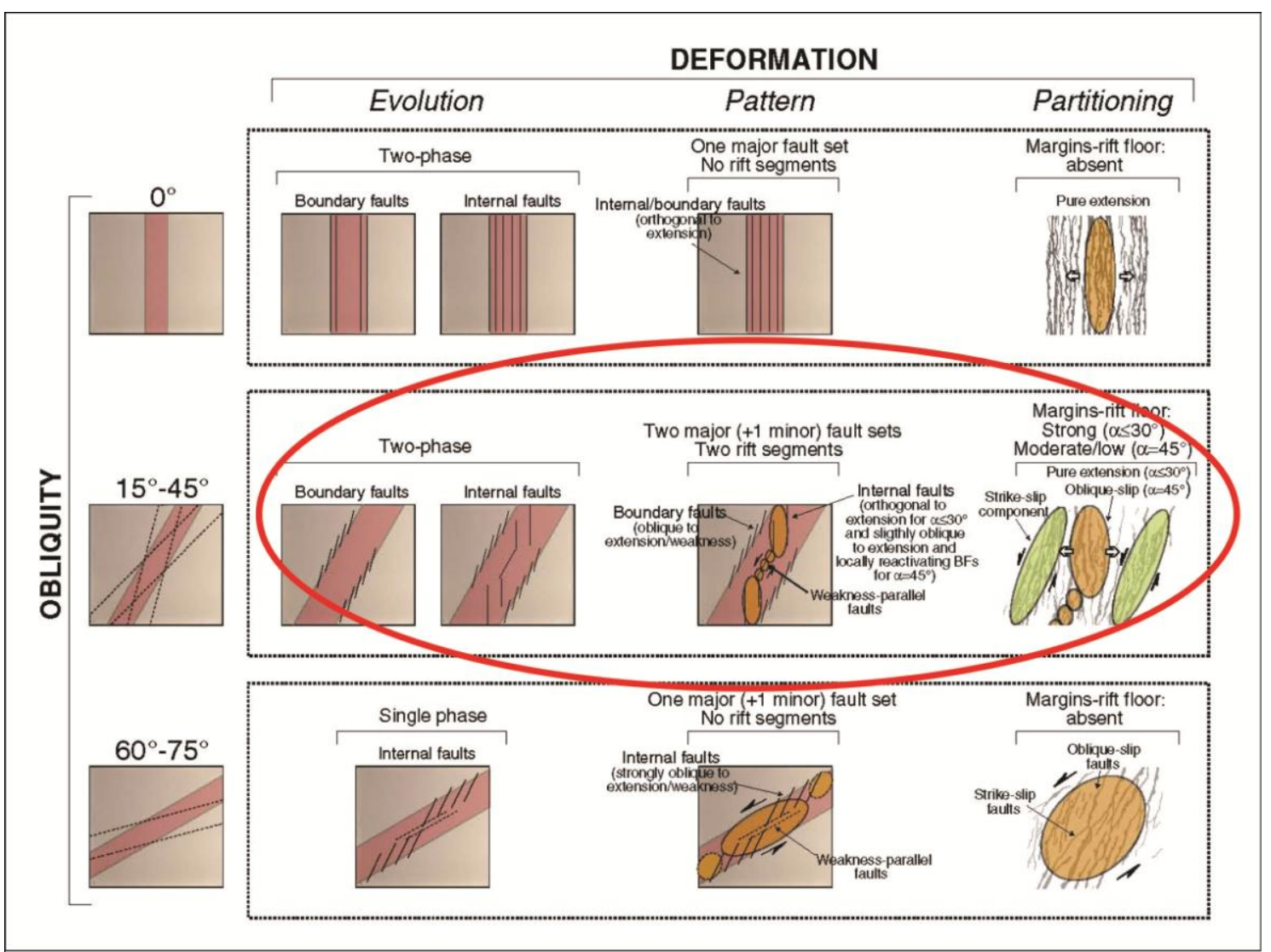

Figura 6.2. Modelo de rift oblicuo que muestra la partición de la deformación. Según Agosti, 2009.

\subsection{Características tecto-sedimentarias del depocentro del Grupo Puesto Viejo}

\subsubsection{Estructura y estilo de fallamiento}

La caracterización del área depositacional como parte del relleno de una cuenca extensional se ha realizado sobre la base del levantamiento geológico en la porción sur de la cuenca triásica de San Rafael. En el área de estudio, con excelentes exposiciones de las estructuras que afectan a rocas triásicas aflorantes al sur del Río Atuel, se obtuvieron datos que permitieron realizar un análisis de la evolución tectosedimentaria de la cuenca. Los estudios realizados definieron que la cuenca constituye un graben asimétrico alargado en sentido NO-SE localizado sobre una zona de debilidad cortical. Su estrecho desarrollo areal estuvo condicionado por las fallas de borde y el reducido espacio para la 
acumulación del Grupo Puesto Viejo fue delimitado por las fallas internas. Todas estas características permiten establecer que la fábrica del basamento no solo condicionó la ubicación del rift, también su geometría, la longitud y el desplazamiento de las fallas dentro del mismo, el espaciado entre ellas y la ubicación de zonas acomodación. La configuración geométrica del depocentro está dada por dos sistemas de fallas bien definidas generadas bajo un régimen extensional con dirección ENE. En una primera etapa, un sistema de fallas principales dio origen a la cuenca con orientación principal NO-SE, con ángulo de oblicuidad ente $55^{\circ}$ y $60^{\circ}$ con respecto al régimen extensional. Estas fallas de borde actuaron como fallas verticales de rumbo vinculadas con una componente transtensional sinestral y conformyo un sistema de fallas con un patrón complejo que muestra segmentación, con fallas dispuestas en echelón y generando un trazo en zig-zag (Figura 6.3). Los desplazamientos se habrían acomodado a lo largo de múltiples segmentos y probablemente no fueron de gran magnitud para cada uno de los tramos individuales que componen la estructura de borde. La generación de subsidencia mecánica ligada a la actividad de estas fallas de borde las condiciona como fallas normales con componente de rumbo que pudieron haber tenido diferentes estadíos de actividad a lo largo de la historia del depocentro, pero que, sin dudas, fueron las primeras estructuras que condicionaron la localización y magnitud del mismo. Aunque no es posible establecer con certeza si la disposición de los planos de falla medidos en superficie presenta continuidad en profundidad o si varía su angularidad, puede inferirse que continuarían con alto ángulo de inclinación en profundidad, posibilityo su desplazamiento lateral tal como lo describen Corti (2009) y Agostini et al. (2011) para el rift principal de Etiopía. Inmediatamente, en el interior del depocentro se desarrolló un sistema de fallas internas normales, de geometría plana y alto ángulo de inclinación, que dio lugar al desarrollo de grábenes y hemigrábenes estrechos con dirección general NO-SE. Estas fallas muestran dos patrones de orientación: uno paralelo a las fallas principales de borde y otro oblicuo con una orientación principal ONO-ESE, perpendiculares a la dirección de máxima elongación horizontal, que responden a un régimen extensional puro (Figura 6.3). Todas estas características, junto a un cambio de orientación del tramo sur de la cuenca a una dirección NNO, responden a los modelos de rift oblicuo 
conocidos en diversas partes del mundo, especialmente en el rift africano oriental (Chorowicz, 2005; Corti et al., 2007). En el área de estudio, las variaciones estructurales están fuertemente influenciadas por la presencia de anisotropías oblicuas pérmicas, derivadas de la historia paleozoica que culminó con el desarrollo del orógeno de San Rafael. En un ambiente de rift oblicuo, el modelo dinámico asume que el campo de esfuerzos está localizado entre las fallas y las regiones próximas a ellas, y en el modelo cinemático, la deformación se puede encontrar fuertemente particionada. Un rift oblicuo se caracteriza por desarrollarse en campos de deformación complejos, con significativas variaciones en la orientación de la dirección de extensión en distancias cortas (Agostinini et al., 2011; Corti, 2012; Corti et al., 2013). Existe un control fuerte por parte de las debilidades preexistentes oblicuas a la dirección de extensión principal, capaces de causar una rotación local de la extensión. Durante la deformación inicial, cuya actividad está localizada esencialmente en las fallas de borde de carácter transtensivo, las trayectorias de desplazamiento se desvían de las impuestas por la extensión regional, resultyo en una cinemática general oblicua. Por el contrario, fallas internas, formadas con posterioridad, afectan a una litósfera más débil y responden directamente a la dirección de extensión regional resultyo en un desplazamiento perpendicular a la extensión. Las fallas internas subparalelas a las de borde se localizan en las cercanías de éstas, por lo cual es probable que su orientación haya sido influida por la heterogeneidad estructural previa, tal como se pudo comprobar en modelos analógicos (Clifton et al., 2000; McClay et al., 2002; Corti, 2012).

Modelos experimentales realizados por Corti et al. (2001) muestran los rasgos de deformación principales que caracterizan al rifting oblicuo: (1) un patrón de fallas en échelon, (2) tendencias de las fallas principales a ser oblicuas al vector de extensión, (3) partición de la deformación entre diferentes conjuntos de fallas, y (4) en general las fallas tienen inclinaciones más pronunciadas que en fallas normales puras. La deformación comienza con el desarrollo de fallas en échelon que normalmente se unen dando lugar a gryes grábenes o hemigrábenes en la zona central de los modelos. Las fallas que limitan estos grábenes generalmente muestran trazas de fallas tortuosas, característica de sistemas de fallas segmentadas. Esta geometría de las fallas de borde puede 
ser observada en el depocentro del área de estudio (Capítulo 3). Los resultados experimentales indicaron que dos parámetros importantes controlan el patrón de fallas de la superficie: (1) el ángulo de oblicuidad, y (2) la presencia de subplacado magmático en la base de la corteza, rasgo que puede ser indirectamente confirmado en el volcanismo basáltico registrado en la estratigrafía del Grupo Puesto Viejo.

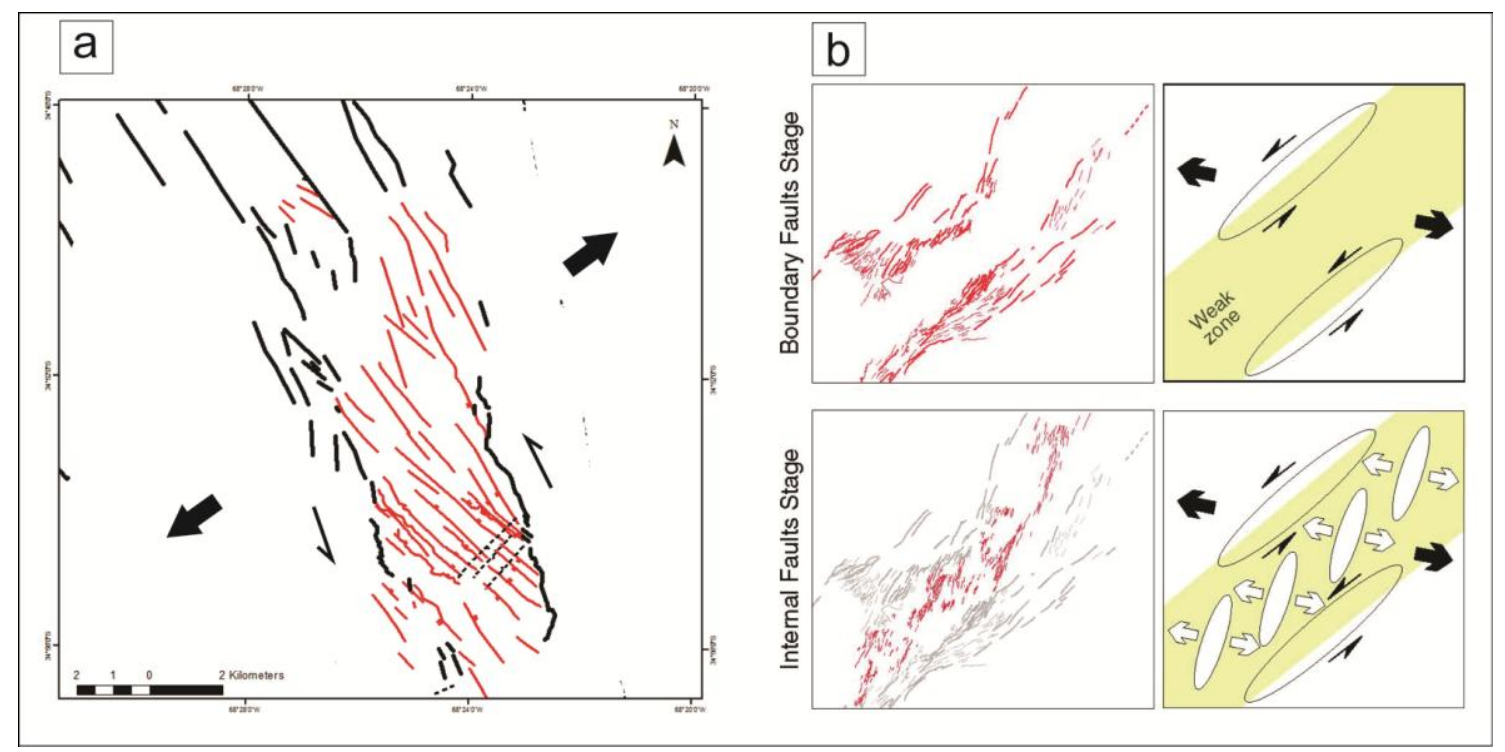

Figura 6.3. a) Distribución de fallas principales (negro) y fallas internas (rojo) en el depocentro que alberga al Grupo Puesto Viejo. b) Modelos de que muestran la evolución del patrón de fallamiento para rift del Este de Africa (Corti, 2012).

La zona de acomodación que se define cerca del extremo sur del depocentro se desarrolló a partir de fallas directas dextrales con orientación NE-SO formyo un ángulo alto (mayor a $60^{\circ}$ ) con las estructuras principales del rift. Esta zona de acomodación de alto relieve (Faulds y Varga, 1988; Morley, 1999) no sólo marca un cambio de polaridad en los espacios de acumulación por la presencia de altos estructurales que modifican las áreas de aporte de sedimentos, sino que, además, puede centralizar el emplazamiento de magma (Figura 6.4) tal como lo sugieren diversos autores (Acocella et al., 1999; Chorowicz, 2005; Hernyo et al., 2014). Este sistema de fallas identificadas por Japas y Kleiman (2004) como estructuras del Paleozoico temprano, reutilizadas durante la Orogenia Sanrafaelica (Kleiman y Japas, 2009) posiblemente fueron 
reactivadas durante la extensión triásica como fallas directas dextrales, antitéticas al sistema principal. La Figura 6.4 muestra un detalle de la zona acomodación donde se observa el desplazamiento que producen estas fallas NE-SO en los niveles basales del Grupo Puesto Viejo. Siguiendo a Corti et al. (2007) la intersección de estas estructuras con las fallas principales tuvo un papel importante a principios de la historia del rift condicionyo la ubicación de las zonas de acomodación y el ascenso de magma. 


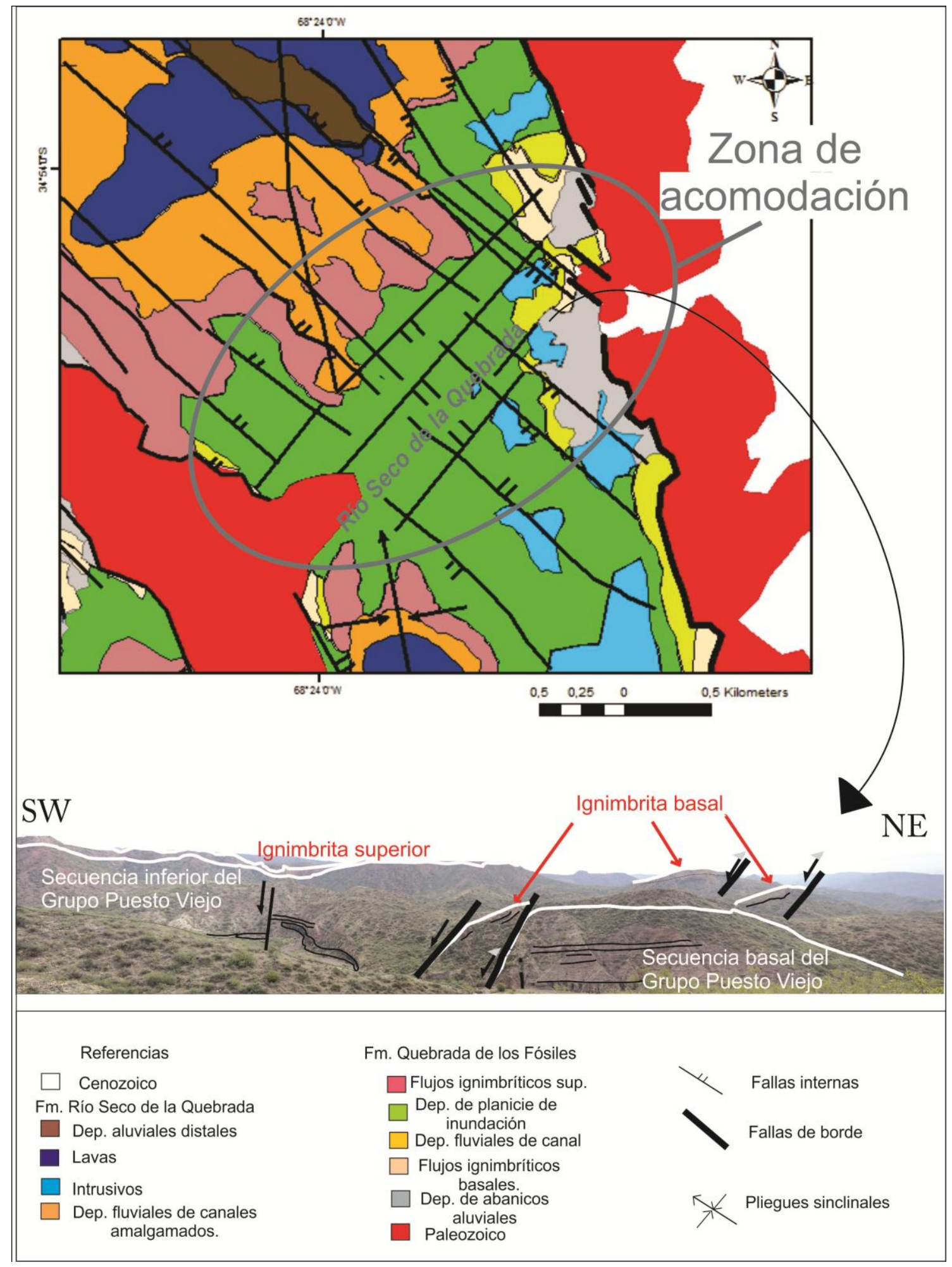

Figura 6.4. Detalle de la zona de acomodación donde se observa el desplazamiento de las unidades basales y la ubicación de los intrusivos. Abajo foto en la localidad Río Seco de la Quebrada.

La mayoría de los pliegues formados en ambientes extensionales están asociados con sistemas de fallas (Schlische, 1995) y los descriptos en la zona 
de estudio para el Grupo Puesto Viejo (Capítulo 3) no son la excepción. El crecimiento de las fallas internas normales ha producido pliegues longitudinales a diferentes escalas. El depocentro que alberga al Grupo Puesto Viejo fue descripto clásicamente como un amplio sinforme (González Díaz, 1964), cuyas características lo definen como un pliegue suave, de forma simétrica con ángulo interflanco cercano a los $180^{\circ}$, con sus flancos tendidos y cercanos a la horizontal. Descripciones similares se realizaron para otras áreas de trabajo (Khalil y McClay, 2002). El fuerte control estructural que se ejerce sobre el plegamiento queda evidenciado por la presencia de dos sinformes con ejes NNO-SSE separados por la zona de acomodación (Figura 6.5). Los flancos orientales de ambos sinformes muestran inclinaciones opuestas limitadas por las fallas NE-SO de la zona de acomodación, lo que sugiere la presencia de un antiforme transversal con eje NE-SO. Estas características responden a los modelos realizados por Faulds et al. (2002) para otras áreas de trabajo. A escala de afloramiento se describieron flexuras monoclinales como producto de la propagación de fallas normales, además de pliegues de arrastre y flexión de fallas producto del desplazamiento a lo largo de planos de falla con distinta inclinación. 


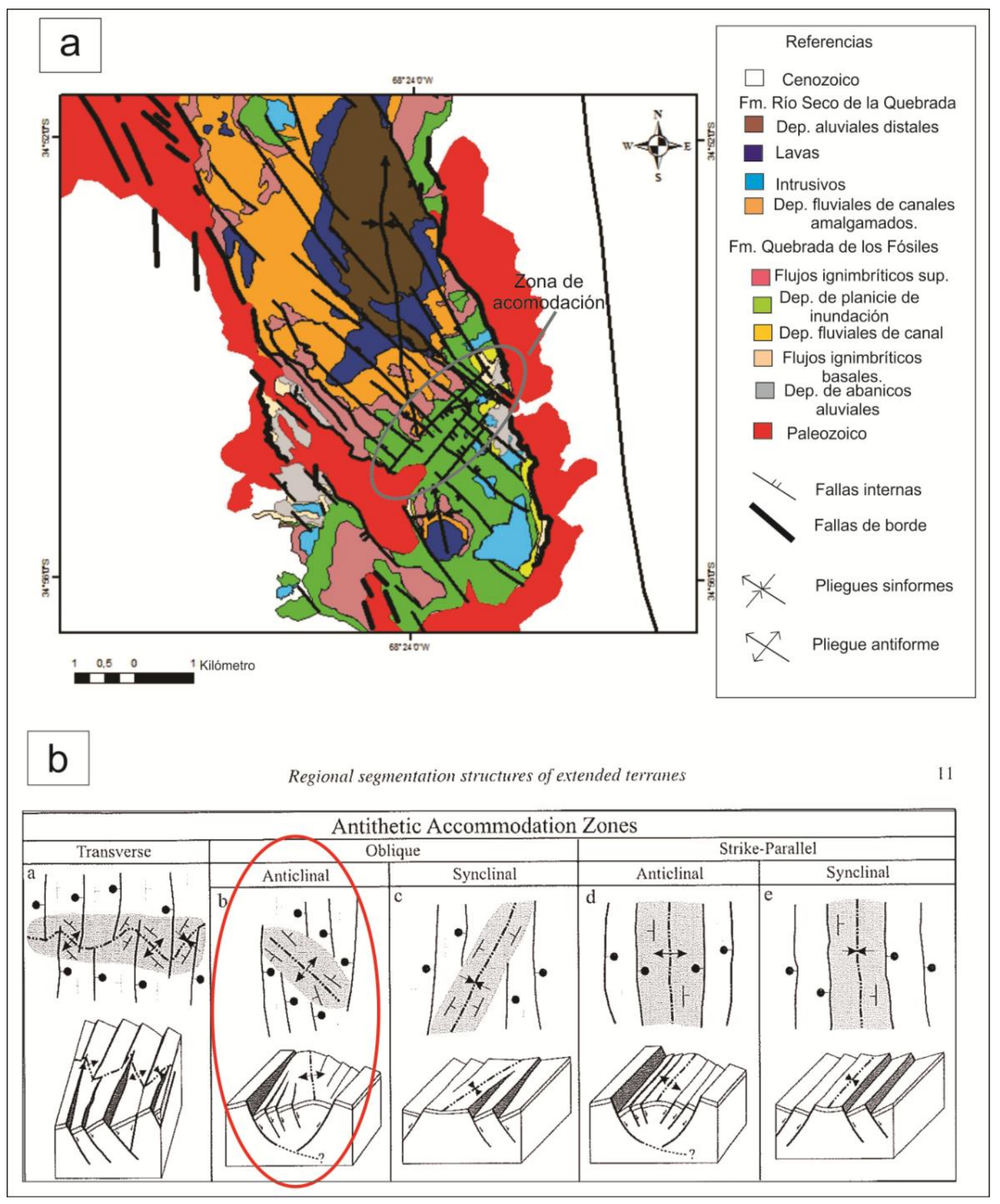

Figura 6.5. a) Mapa de la zona de estudio donde se observa la disposición de los pliegues. b) Modelos de Faulds et al. (2002), para pliegues asociados a diferentes zonas de acomodación.

\subsubsection{Síntesis del relleno}

El análisis realizado sobre los depósitos que conforman al Grupo Puesto Viejo (Capítulo $s 4$ y 5 ) permite afirmar que el depocentro del área de estudio 
constituye una cuenca de rift continental cuyo relleno presenta un arreglo general aluvial con desarrollo de sistemas meandrosos de baja y de alta sinuosidad que evolucionó de forma local con poco transporte del material sedimentario, controlada por sus estructuras y la actividad volcánicapiroclástica existente. La actividad volcánica se mantiene activa durante casi todo el desarrollo del depocentro, estableciendo una notable participación en la composición de los ambientes sedimentarios. Lo picos de actividad registrados como flujos piroclásticos ácidos, intrusivos y efusiones basálticas son coincidentes con un cese en la acumulación de sedimentos; y seguidos por una reactivación de las estructuras (Capítulos; $3 ; 4 ; 5)$. El carácter tectoestatigráfico que presenta el Grupo Puesto Viejo en el área de estudio implica que las secuencias de relleno fueron ocupando nuevos espacios ante cada reestructuración, y por lo tanto, unidades sucesivas en el tiempo están dispuestas en lugares diferentes y se continúan lateralmente a través de fallas (Figura 6.6). Esta circunstancia dificulta analizar el relleno desde una perspectiva puramente litoestratigráfica ya que la secuencia triásica no se halla apilada sucesivamente en una sola sección tipo. En este contexto, es posible afirmar que el espesor medido para el Grupo Puesto Viejo de 440 metros (Ottone et al., 2014 a y b) es parcial. Si se considera la suma de perfiles sedimentológicos parciales para cada unidad de acumulación (véase Anexo 2), el Grupo Puesto viejo podría alcanzar hasta 1000 metros de espesor total. En esta sección se procede a describir el relleno utilizyo la clásica modalidad de formaciones para el Grupo Puesto Viejo con la finalidad de facilitar su discusión. 


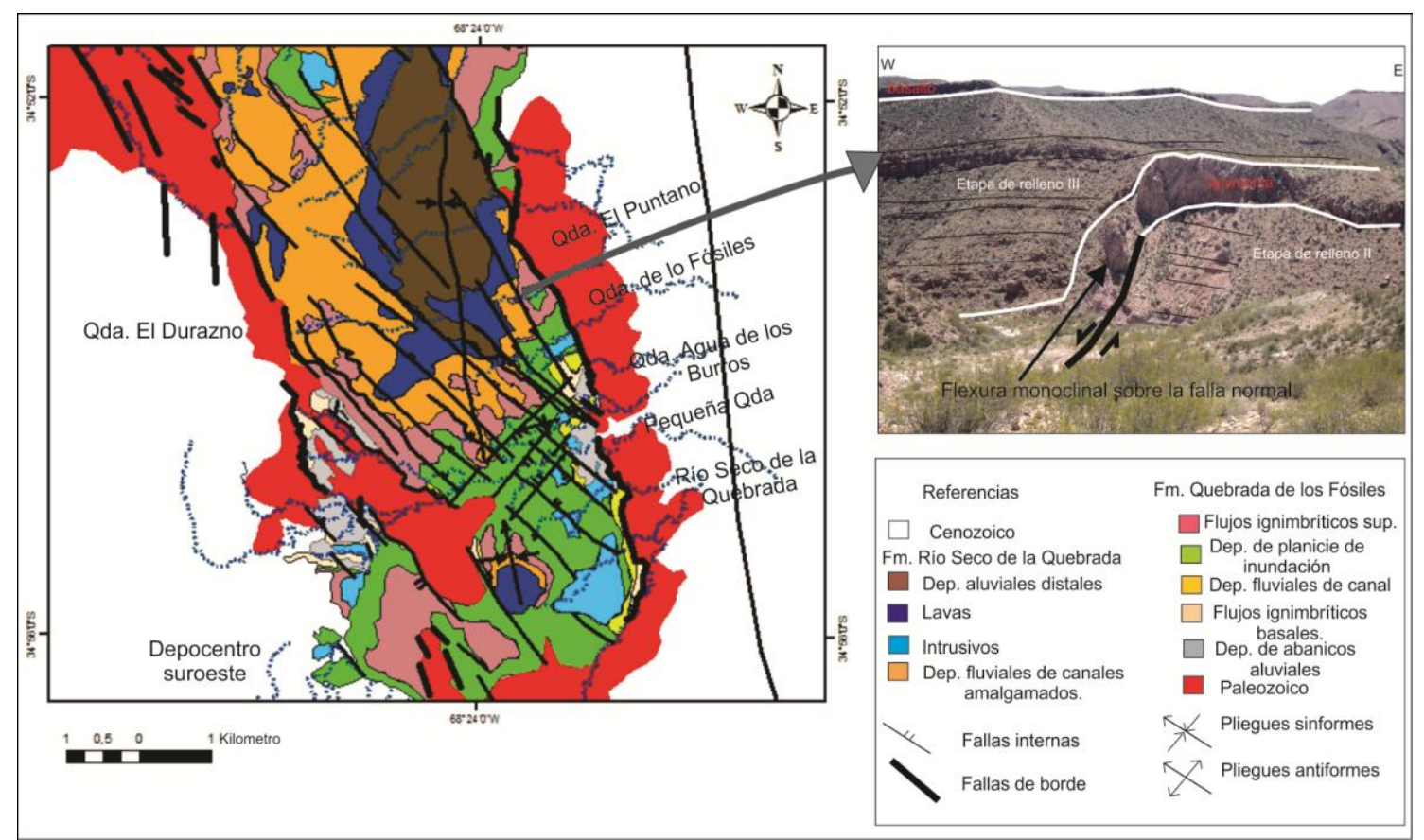

Figura 6.6. Hemigraben que pone en contacto lateral la etapa de relleno II (Formación Quebrada de los Fósiles) con la etapa de relleno III (Formación Río Seco de la Quebrada) en la localidad de EI Puntano.

La Formación Quebrada de los Fósiles, unidad inferior del Grupo Puesto Viejo, está constituida en su base por sistemas de abanicos aluviales vinculados a los estadíos iniciales de apertura de la cuenca y, por consiguiente, compuesto en su totalidad de material clástico proveniente de la erosión de los bloques de basamento pérmico elevados. Su escaso desarrollo, restringido a los márgenes del depocentro, se vincula al incipiente espacio de acumulación inicial producido por las fallas de borde, de carácter transtensional, y a la depositación suprayacente de flujos piroclásticos de composición riolítica que interrumpen su desarrollo producto de una temprana actividad volcánica desarrollada en áreas cercanas al depocentro (Capítulo 5). A estos estadíos iniciales le sigue otra etapa caracterizada por el desarrollo de un sistema fluvial meandroso de alta sinuosidad, típico de la unidad litoestratigráfica, que se extiende ampliamente hacia el interior del rift ocupando los espacios de acumulación que generaron las fallas internas inicialmente segmentadas. El sistema fluvial incide en los depocentros con una disposición axial a los hemigrábenes, evidenciada por la presencia de canales paralelos a los bordes activos. El desarrollo sinsedimentario de amplias planicies de inundación con 
eventos frecuentes de desbordamiento y desarrollo local de cuerpos de agua someros en estrecha relación con el fallamiento interno son indicios de actividad tectónica prevaleciente (Capítulo 5; Figura 6.7). Niveles fosiliferos identificados, ricos en restos vegetales (Capítulo 1) permiten inferir un clima cálido y húmedo que se mantuvo relativamente estable durante el desarrollo del sistema fluvial (Spalletti, 1994; Tassi et al., 2013). Del análisis litológico (Capítulo 4) surge que la composición volcaniclástica de la Formación Quebrada de los Fósiles es producto del retrabajamiento de rocas del basamento pérmico, provenientes principalmente de la Formación Agua de los Burros y que la participación de depósitos piroclásticos primarios ha sido muy subordinada lo que implica una disminución de actividad volcánica durante la depositación. Hacia el tope de la Formación Quebrada de los Fósiles se registra un cambio abrupto en las condiciones establecidas en el depocentro con la reanudación de actividad volcánica. Flujos ignimbríticos ácidos de composición riolítica ocuparon los espacios de acumulación cubriendo las planicies fluviales y extendiéndose en forma de amplios mantos en todo el depocentro. Este evento volcánico habría generado un desequilibro hidrológico que coincide con modificaciones locales en el clima hacia condiciones más áridas. Todas estas características coinciden con las descripciones e interpretaciones realizadas en trabajos previos por González Díaz (1964) y Sapalletti $(1994 ; 1996)$ para secciones parciales del Grupo Puesto Viejo. 


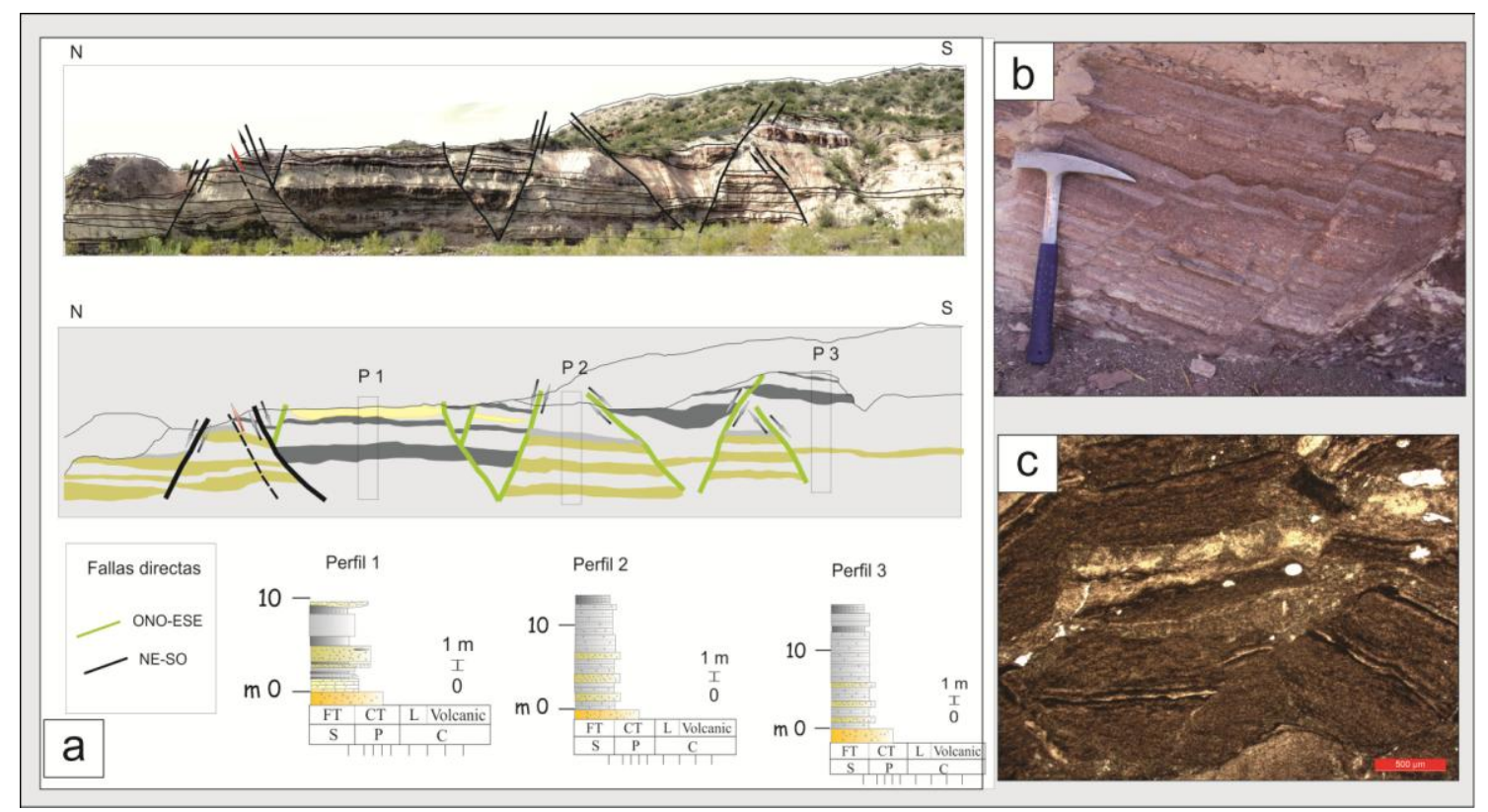

Figura 6.7. Muestra la actividad tectónica prevaleciente durante la depositación de la etapa de relleno II (Formación Quebrada de los Fósiles) a diferentes escalas: a) Depósitos de planicie de inundación que afloran en la localidad Río Seco de la Quebrada (Figura 6.6 para su localización). b) Detalle de canales inferiores afloramientos en la misma localidad. c) Corte petrográfico de niveles carbonáticos lacustres aflorantes en la misma localidad.

La actividad tectónica continuó con la reactivación de fallas internas que generó nuevos grábenes y hemigrábenes donde comenzó a acumularse la Formación Río Seco de la Quebrada como depósitos de sistemas fluviales meandrosos de baja sinuosidad (Capítulo s 4 y 5). Los niveles basales desarrollados sobre los flujos ignimbríticos subyacentes consisten en canales amalgamados que ocupan los espacios de acumulación en dirección axial (Capítulo 4). El escaso desarrollo de planicies de inundación y la presencia de flujos de detritos no canalizados, que intercalan esporádicamente, reflejan las condiciones de moderada a alta energía de flujo en el que se desarrollo el sistema inicialmente, con un elevado y continuo aporte de material clástico que indica inestabilidad de las pendientes circundantes (Bridge, 2003). Luego, el sistema tiende a estabilizarse, los canales inciden de forma aislada permitiendo el desarrollo de planicies fluviales algo más extensas, tal como lo muestran los perfiles sedimentológicos (véase Anexo 2; Figura 6.8) en el sector noroeste del área de 
estudio. Estas nuevas condiciones permitieron la preservación de los restos fósiles vertebrados conocidos clásicamente en el Grupo Puesto Viejo (Capítulo 1). El análisis litológico permitió corroborar un cambio en la composición de la Formación Río Seco de la Quebrada con respecto a la unidad infrayacente. Esta última unidad está conformada principalmente por material clástico proveniente del bloque de basamento elevado constituido por el pórfido riolítico pérmico (Formación Cerro Carrizalito) y con una importante participación de material clástico sedimentario producto del retrabajamiento del propio Triásico, de la Formación Quebrada de los Fósiles (Capítulo 4). Esta modificación en el área de aporte se atribuye al cambio de polaridad en los espacios de acumulación que generan las fallas con orientación NE-SO con el levantamiento parcial de bloques internos al depocentro que dejan expuestos niveles triásicos más antiguos en la zona de acomodación en continuo desarrollo (Capítulo 3). Trabajos previos han propuesto que el límite entre las formaciones Quebrada de los Fósiles y Río Seco de la Quebrada es discordante (Stipanicic et al., 2007), lo que sugiere la presencia de un hiato temporal de carácter regional entre las dos unidades. En este trabajo se ha comprobado que el contacto entre ambas formaciones está asociado con un episodio de fallamiento normal relacionado con la tectónica extensional que controló la evolución sinsedimentaria del Triásico, condicionyo la dirección y el desarrollo de los sistemas fluviales y como consecuencia las áreas de aporte.

El sistema sedimentario de la Formación Río Seco de la Quebrada se ve interrumpido por el desarrollo de una actividad volcánica básica que marca un cambio sustancial en la evolución magmática del depocentro. Este evento está representado por una serie de cuerpos subvolcánicos de composición andesîtco/basáltica que intruyen a la Formación Quebrada de los Fósiles, y que alcanzan la superficie a través de las fallas internas como efusiones de lavas andesíticas que cubren parcialmente a los depósitos fluviales (Capítulo 4). Hacia el tope de la Formación Río Seco de la Quebrada se reanuda localmente la actividad tectónica con la reactivación de algunas fallas internas que, junto al enfriamiento y contracción termal del volcanismo efusivo, crean el espacio para la acumulación de los sistemas de abanicos aluviales que constituyen los términos finales del Grupo Puesto Viejo (Capítulos 4 y 5; Figura 6.9). Del análisis litológico surge que las condiciones de alta energía de flujo en 
las que se desarrolló este sistema produjeron la erosión, transporte y redepositación de los depósitos triásicos subyacentes parcialmente elevados por fallamiento, mientras que en las cercanías del depocentro continuaba la actividad volcánica ácida.

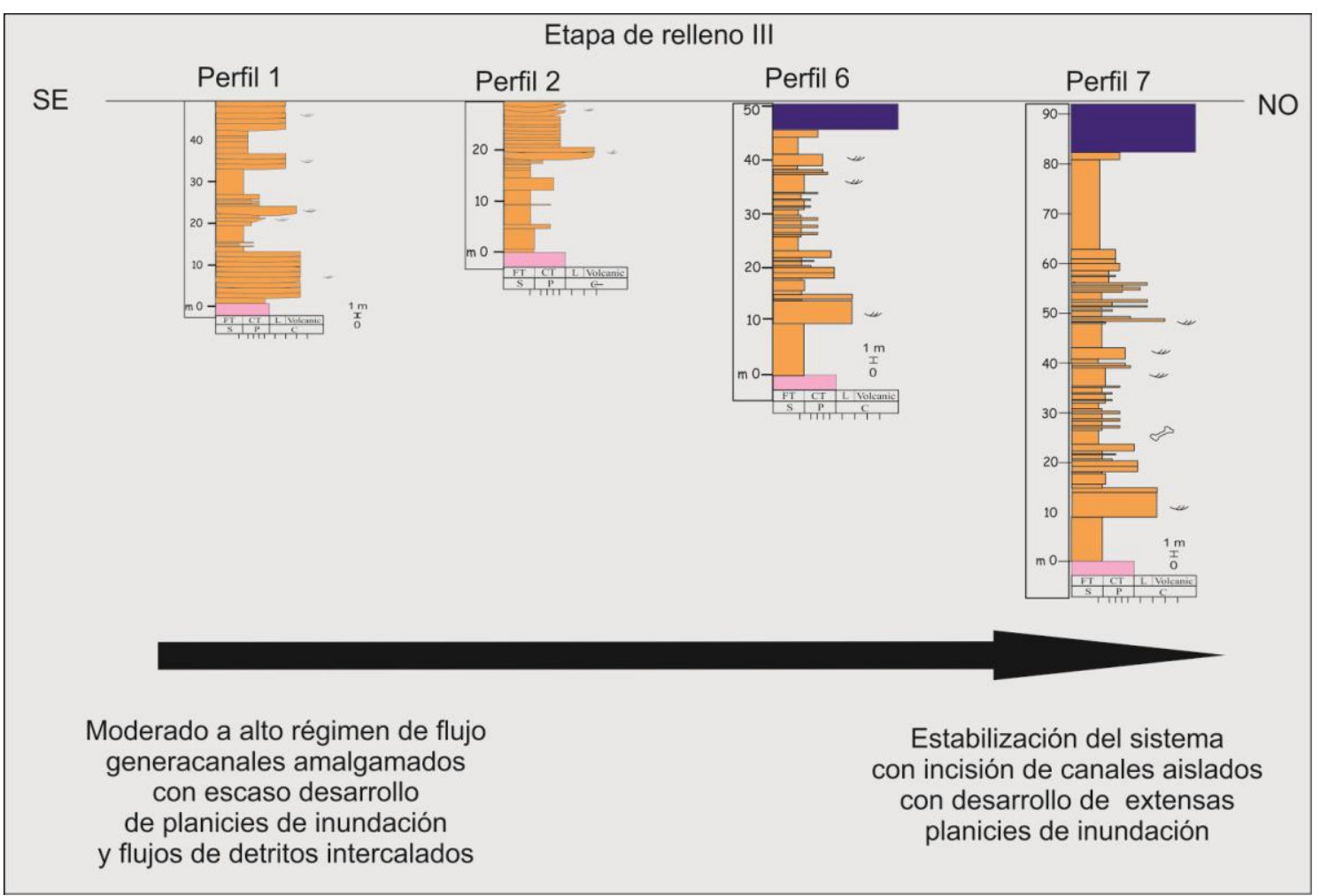

Figura 6.8. Perfiles estratigráficos de la etapa de relleno III (Formación Río Seco de la Quebrada) muestran el cambio de facies hacia el noroeste. Ubicación de los perfiles en Figura 5.17 (Capitulo 5). 


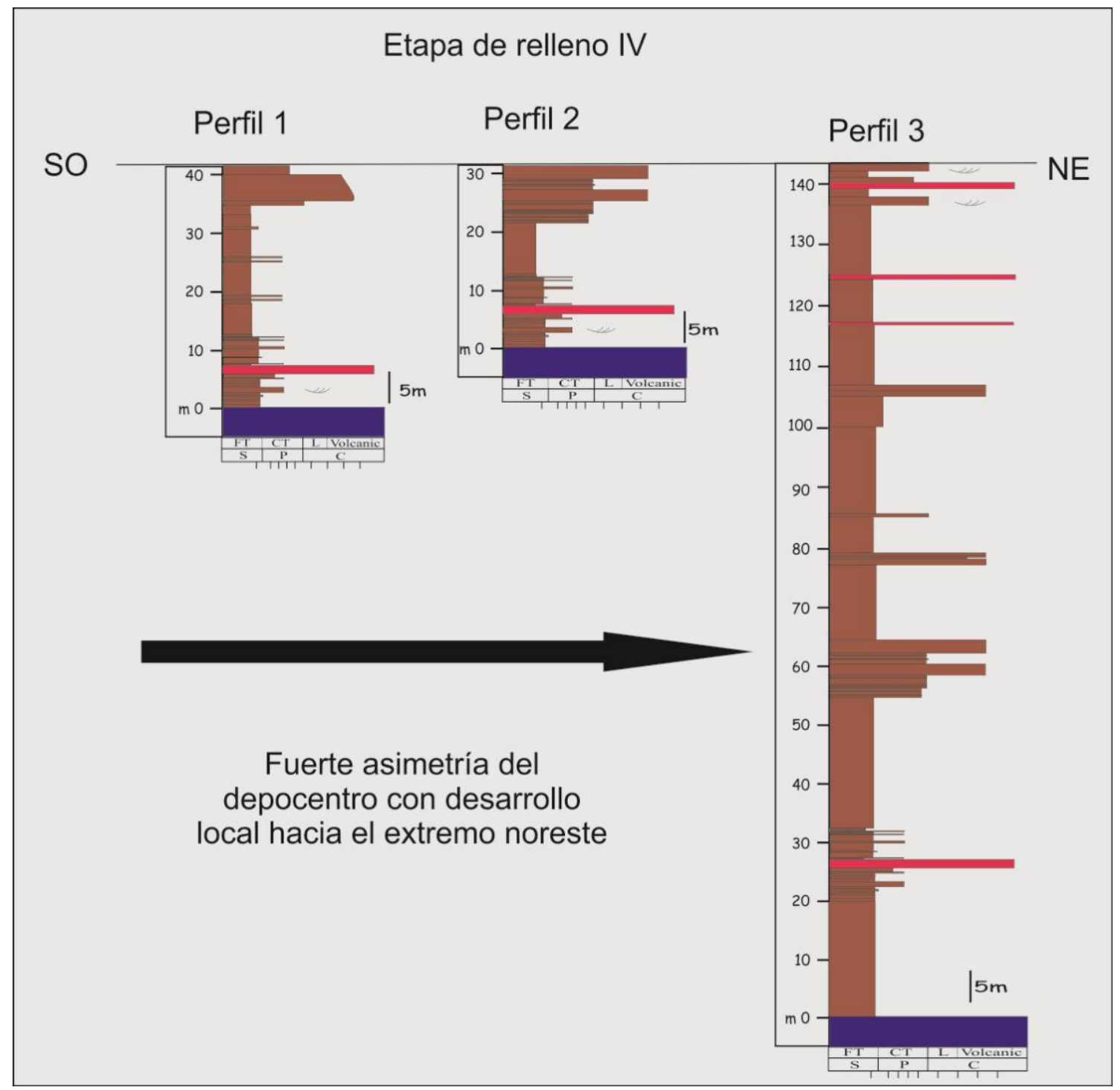

Figura 6.9. Perfiles estratigráficos de la etapa de relleno $\mathrm{N}$ (Formación Río Seco de la Quebrada) muestran la asimetría hacia el noreste.

\section{El volcanismo del Grupo Puesto Viejo}

El análisis geoquímico realizado sobre muestras de rocas volcánicas y piroclásticas del Grupo Puesto Viejo (Capítulo 4; véase Anexo 2) permitió determinar, a partir de diagramas de clasificación álcalis total versus sílice (TAS) (Middlemost, 1994) y el diagrama de elementos inmóviles de Winchester y Floyd (1977), una composición riolítica para las rocas piroclásticas y una composición andesítica y andesítico/basáltica para las rocas volcánicas que se incluyen en su estratigrafía, lo que muestra claras características bimodales. A partir de discriminadores de ambientes tectónicos (Shyl y Gordon, 2002) se obtuvo que las rocas volcánicas se distribuyen en el campo de zonas 
volcánicas de intraplaca y las rocas piroclásticas lo hacen en el campo de margen continental activo. Los resultados obtenidos a partir de diagramas araña multielemento normalizado a basalto OIB (Sun y McDonough, 1989) para las rocas volcánicas otorgan un origen a partir de una fuente enriquecida para estos magmas. En cambio, para las rocas piroclásticas, los diagramas araña multielemento normalizado a la corteza superior (Rudnick y Gao, 2003) muestran una importante asimilación cortical. Para comprender e interpretar estos resultados es necesario contextualizar el régimen extensional en el que se desarrolló el Grupo Puesto Viejo, posterior al desarrollo del Orógeno de San Rafael, evento que trae asociado engrosamiento litosférico y es el responsable de la asimilación cortical que posiblemente sufrieron estos magmas. Los resultados de estos análisis coinciden con los datos publicados por Kleiman y Salvarredi (2001), donde se postula como origen de esta secuencia bimodal, a un subplacado basáltico en un régimen extensional, asociado a un alto gradiente geotérmico, estacionamiento del magma con fusión parcial de la corteza y fraccionamiento.

El carácter bimodal que presenta el volcanismo del Grupo Puesto Viejo es típico de los rift continentales, donde las tasas de deformación son altas y la corteza lo suficientemente gruesa como para permitir que el magma sea emplazado y pueda diferenciarse sucesivamente para generar productos evolucionados. A su vez, las fallas de borde con importante componente de rumbo y disposición mayormente vertical, combinadas a sistemas de fallas casi perpendiculares que conducen a una zona de acomodación, pueden ser responsables de la emisión de productos más primitivos. Como se puede observar en la Figura 6.4 los cuerpos subvolcánicos básicos se concentran en el extremo sureste de la zona estudiada dentro de la zona de acomodación y su distribución presenta un fuerte control estructural. Estas características responden a los modelos presentados por Acocella et al., 1999; Mazzarini, 2004; Corti et al., 2007) para otras cuencas de rift continentales.

Ramos and Kay (1991), proponen que el rift de la cuenca de Cuyo se desarrolló durante las últimas etapas del magmatismo Choiyoi a lo largo de zonas de sutura de terrenos acrecionados durante el Paleozoico. Este ciclo magmático habría ejercido una fuerte influencia durante las primeras etapas de desenvolvimiento de la cuenca de Cuyo, donde abundan rocas piroclásticas de 
caída, laharitas y depósitos de flujos piroclásticos, en concordancia con lo descripto para el Grupo Puesto Viejo. Para la sucesión clástica descripta en la zona de Paramillos de Uspallata (Formación Las Cabras) se describen filones capa basálticos, asignados al Triásico Medio (?235 Ma), emplazados durante la fase de sinrift a través de fallas activas. Las características geoquímicas proporcionadas por los autores sugieren un bajo grado de fusión para estos basaltos, confirmando un carácter bimodal similar al descripto en esta Tesis.

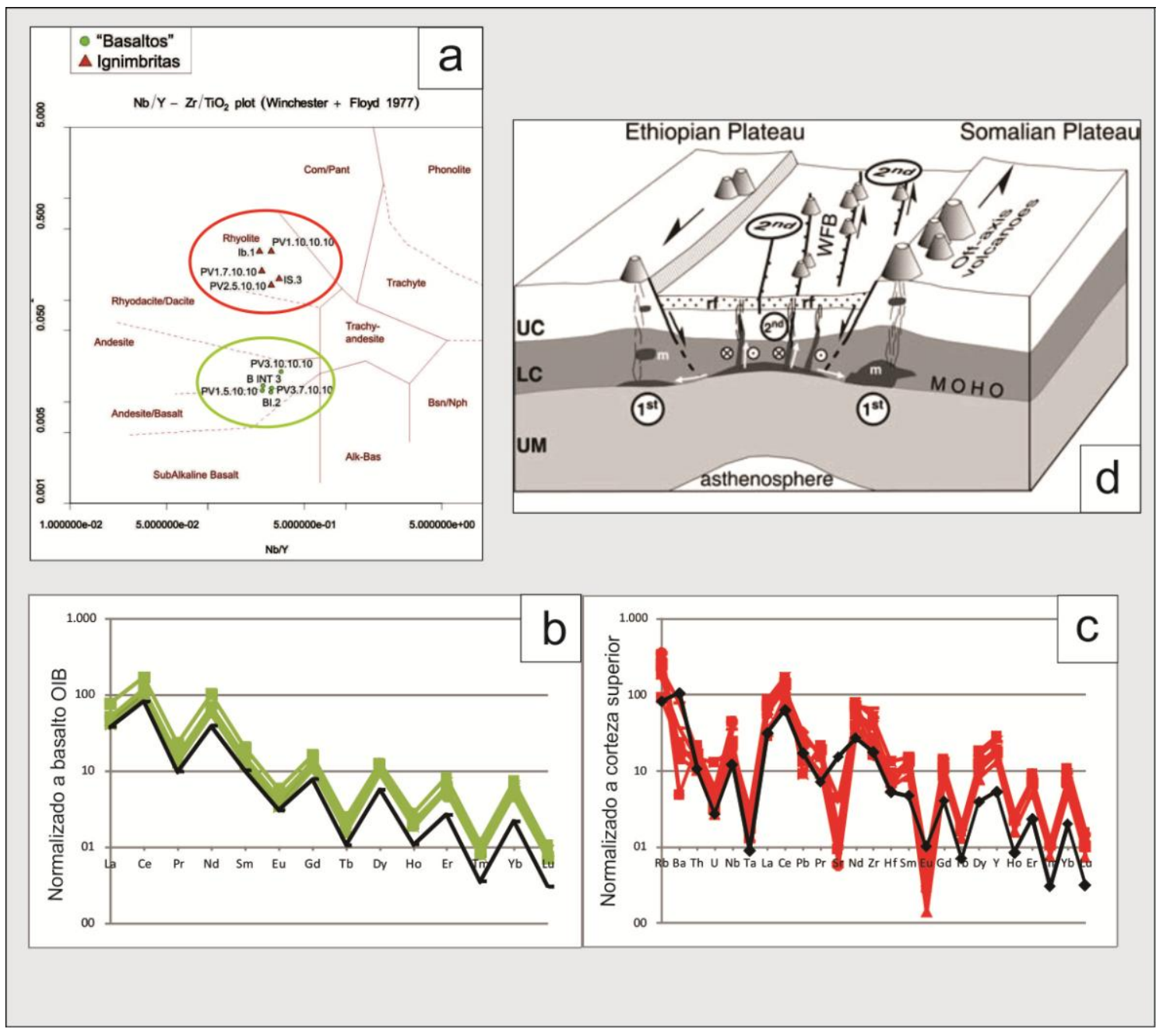

Figura 6.10. a) El diagrama de elementos inmóviles de Winchester y Floyd (1977), muestra una composición bimodal para el volcanismo del grupo Puesto Viejo. b) Diagrama spider Sun y McDonough, (1989) para las rocas volcánicas otorgan un origen a partir de una fuente enriquecida. c) Diagrama spider multielemento Rudnick y Gao, (2003) muestran una importante asimilación cortical para las rocas piroclásticas. d) Modelo según Corti et al., 2009, que muestra la distribución y migración del magmatismo asociado a fallamiento. 


\subsubsection{Evolución de las etapas de relleno}

La cuenca de rift oblicuo que alberga al Grupo Puesto Viejo en el área de estudio muestra diversos estadíos de relleno vinculados con la actividad de los sistemas de fallas, al grado de subsidencia mecánica, los aportes sedimentarios y la intensidad de los fenómenos volcánicos sincrónicos con la acumulación (Capítulo 5). El análisis del relleno de esta cuenca extensional muestra una fuerte subsidencia mecánica por fallamiento normal y tanto el estado evolutivo como el registro sedimentario son propios de un período de sin-rift. La definición de las etapas de relleno está condicionada por tres aspectos esenciales: a) la escala regional, b) el nivel del detalle estratigráfico al que se hacen las observaciones, y c) la escala temporal involucrada en el estudio. Por el escaso desarrollo areal que presenta el depocentro estudiado se pudo tratar a la evolución del registro de un modo localizado. En cuanto a la estratigrafía, la escala de observación tiene alta precisión, al tratarse de un único depocentro. Respecto a la escala temporal hay un buen nivel de detalle por tratarse de un período corto de tiempo dentro del Triásico.

La etapa I de relleno representa el estado inicial de generación de la cuenca, a partir de las fallas principales de borde. Los rellenos sedimentarios están concentrados en depocentros aislados, mientras que los bloques de basamento pérmico aparecen sobreelevados y sujetos a procesos erosivos dando lugar a la generación de los abanicos aluviales con una distribución transversal a las fallas de borde (Figura 6.11a). Esta configuración inicial refleja condiciones de alta energía dinámica con inestabilidad de las pendientes en el área de aporte producto de la elevación relativa del basamento y oscilaciones en la descarga de material que determinan un comportamiento progradacional-regresivo del sistema depositacional. Estas características responden a los modelos planteados para etapas iniciales de rifting por Allen y Allen (1990; 2005); Gawthorpe y Leeder (2000); Posamentier y Walker (2006).

El desarrollo de los flujos piroclásticos que cubren a estas secuencias iniciales se encuentra sujeto a la morfología de los depocentros, generando un rápida agradación del relieve que colmata los espacios de acumulación, modificyo el equilibrio hidrológico y las pendientes del sistema (Figura 6.11b). 
La etapa II de relleno se caracteriza por una fuerte subsidencia mecánica con desarrollo de un sistema de fallas internas que dieron lugar a la generación de espacios internos de acumulación y a la propagación de la cuenca con una geometría marcadamente asimétrica con un patrón de fallamiento variado, especialmente en el borde activo de los hemigrábenes, donde se dispone de un amplio espacio de acomodación. En un principio, los segmentos de falla se habrían encontrado aislados entre sí por diversos altos intracuencales y a medida que la extensión progresó los segmentos se habrían interconectado, tal como se ha comprobado en otras cuencas extensionales (Schlische, 1995; Morley, 1999; Young et al., 2001; Peacock, 2002; Corti, 2004; Chorowicz, 2005, entre otros). El espesor sedimentario se hizo cada vez más homogéneo a lo largo del conjunto de fallas ya conectadas. Las facies sedimentarias experimentan rápidas variaciones, principalmente paralelas al eje mayor de las depresiones, a medida que los sistemas fluviales avanzaron hacia el interior de la cuenca como sistemas meandrosos de alta sinuosidad (Figura 6.11c). Durante esta etapa de relleno se desarrolla el sistema de depositación más distal que responde al clásico modelo de sedimentación de Allen y Allen (2005) y refleja condiciones de moderada energía y gradiente relativamente bajo. Representa el período de menor energía dinámica en la evolución del depocentro de San Rafael, dando lugar a la mayor acumulación sinsedimentaria, con típicos arreglos granodecrecientes y constituyendo depósitos formados en condiciones inter-eruptivas (en el sentido de Smith1991).

Hacia el final de esta etapa se reanuda la actividad volcánica explosiva que interrumpe el desarrollo del sistema fluvial con la depositación de amplios mantos de flujos ignimbríticos que se extienden en todo el depocentro cubriendo a las planicies de inundación (Figura 6.11d). Este evento piroclástico colmata los espacios de acomodación produciendo una rápida agradación del terreno y marca la finalización de esta etapa de relleno.

Es de destacar que la secuencia del Grupo Puesto Viejo estudiada por Spalletti, (1994), equivale al relleno de esta etapa y, por lo tanto, no registra el relleno completo de la unidad. Se señala nuevamente aquí que, debido a la 
evolución segmentada del depocentro, no existe una sucesión completa apilada verticalmente.

Durante la etapa III de relleno continuó el desarrollo de las fallas internas con orientación ONO-ESE oblicuas al borde de cuenca. Los depocentros aislados tendieron a unificarse otorgyo una geometría deposicional con carácter simétrico. En la zona de acomodación del Río Seco de la Quebrada (Capítulo 3), desarrollada en el sector sureste del área de estudio, las fallas con orientación NE-SO, generaron un cambio de polaridad en los espacios de acumulación por elevación parcial de los bloques piso. Como consecuencia se produjo una modificación en el área de aporte con la desviación de los sistemas fluviales. Los flujos ignimbríticos depositados durante la etapa de relleno II habrían producido una especie de capa impermeable que destruyó la vegetación existente y no permitió la incisión inicial de los sistemas fluviales luego del período de actividad volcánica explosiva (Smith, 1991). Por consiguiente, en los nuevos espacios de acumulación se desarrolló un sistema fluvial meandroso de baja sinuosidad, en condiciones de moderada a alta energía (Capítulo s 4 y 5; Figura 6.11e). Los depósitos basales de la etapa constituyen una depositación proximal a media del sistema fluvial, atribuidos al desequilibro hidrológico y de las pendientes, que produjo la actividad piroclástica previa, sumado a la reactivación y crecimiento de las fallas directas oblicuas a los bordes de cuenca. Todas estas características permiten asignar a esta etapa de relleno como un período sin-volcánico siguiendo los modelos de Smith (1991), Haughton (1993) y Erikson et al. (1993).

La extensión generalizada habría alcanzado durante esta etapa un adelgazamiento sustancial de la corteza, rasgo que fue acompañado por ascenso de magma a través de las fallas de borde, tal como se ha reconocido en otras cuencas de rift continental (Purtika et al. 2012). Allí y, especialmente en la zona de acomodación del área sureste (Capítulo s 3 y 4 ) se alojó formyo cuerpos subvolcánicos de composición andesítco/basáltica (Capítulo 4). La llegada a la superficie de estos magmas se habría producido a través de fallas internas y dio lugar a las efusiones de lavas que cubren a los sistemas fluviales (Figura 6.11f) y marcan la finalización de esta etapa de relleno. 
Se reconoce aquí que las secuencias del estadío III coinciden con las analizadas previamente como constitutivas de toda la secuencia triásica por González Díaz (1964).

Durante la etapa IV de relleno continuó el crecimiento y la propagación hacia la superficie de algunas de las fallas ONO-ESE oblicuas al borde de cuenca generando espacios de acumulación asimétricos (hemigrábenes) localizados hacia el borde oriental. En los nuevos espacios de acumulación se desarrolló un sistema de abanicos aluviales en condiciones de baja a moderada energía (Capítulo s 4 y 5 ; Figura $6.11 \mathrm{~g}$ ). Las lavas andesíticas depositadas durante la etapa de relleno III produjeron una rápida agradación de los espacios de acomodación, modificyo la distribución de los sistemas fluviales luego del período de actividad volcánica tal como lo plantean Haughton (1993) y Erikson (1993) para otras áreas de trabajo. La composición principal volcaniclástica de estos depósitos sumado a la presencia de depósitos piroclásticos primarios provenientes de la actividad volcánica explosiva coexistente en los alrededores de la cuenca, permiten afirmar que esta etapa de relleno se encuentra fuertemente condicionada por la actividad volcánica constituyendo una etapa de relleno sin-volcánica (ver Smith, 1991; Haughton, 1993). 


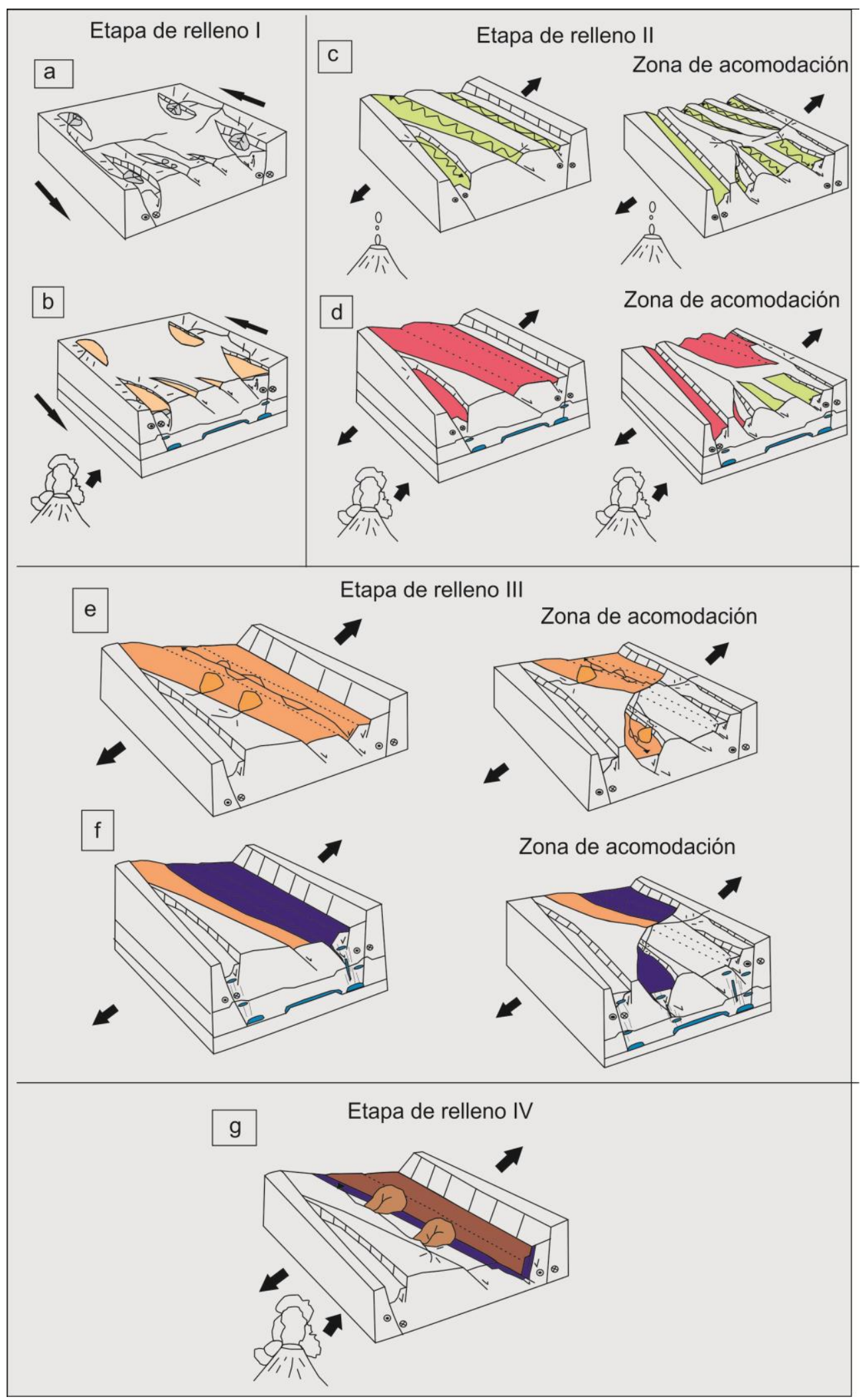

Figura 6.11. Modelos 3D que muestran la evolución de las etapas de relleno que conforman al Grupo Puesto Viejo. 
A modo de síntesis, cada una de las etapas de relleno evoluciona según una sucesiva alternancia de episodios: $1^{\circ}$ ) subsidencia mecánica; $2^{\circ}$ ) quietud tectónica con desarrollo de sistemas aluviales y fluviales; $3^{\circ}$ ) actividad volcánica. Lo más destacado en este ambiente de sedimentación es la alternancia de períodos sin-eruptivos e inter-eruptivos. El desarrollo de períodos inter-eruptivos se encuentra sujeto principalmente a una alta tasa de subsidencia mecánica en las etapas iniciales de rifting, en contraposición a los períodos sin-eruptivos subsiguientes donde la tasa subsidencia es baja. El análisis de las distintas etapas de relleno permite identificar secuencias volcaniclásticas depositadas en forma coetánea con el volcanismo, donde se reconoce una periodicidad de las erupciones y las fluctuaciones resultantes en el tamaño de grano, composición, volumen de los sedimentos y los procesos que transportan esos sedimentos que se diferencian de los períodos intereruptivos iniciales. Estas fluctuaciones se producen en una frecuencia demasiado alta para ser adscritos a tectonismo, y las modificaciones en el clima no son propensas a alterar bruscamente los paisajes lo suficiente como para explicar estos cambios en la sedimentación, concluyendo que se producen en respuesta a la actividad volcánica, tal como plantean Smith (1991) y Eriksson y Simpson (1993).

Tal como se ha expresado al principio de esta discusión, la ubicación del rift ha sido controlada por la reactivación de una zona de debilidad de la litosfera preexistente, de orientación NO-SE, donde se ha demostrado que las estructuras transversales NE-SO identificadas por la zona de acomodación del Río Seco de la Quebrada, ejercen un control significativo sobre la distribución de la actividad volcánica. Las diferentes etapas descriptas permiten establecer que el rifting está marcado inicialmente por la actividad ignimbrítica generalizada y la activación fallas de bordes, seguidas por el desarrollo de fallas internas asociadas a un volcanismo bimodal. Esta migración de la actividad volcano-tectónica hacia el interior del rift documenta una transición de un proceso de extensión dominado por fallas en las primeras etapas de rifting, que pasa a una extensión asistida por magma. Esto demuestra un aumento en el acoplamiento entre los procesos tectónicos y magmáticos durante la evolución del rift acorde a los modelos planteados por Corti (2009) para los rifts del este de África. 


\subsection{Evolución tectónica del depocentro que alberga al Grupo Puesto Viejo en el marco de las cuencas triásicas vecinas}

El depocentro estudiado forma parte de un grupo de depocentros triásicos que forma parte del sistema de acumulación del Triásico continental del oeste argentino, en un contexto de cuencas extensionales con orientación NO-SE (Spalletti, 1999). Dentro de esta conjunto de cuencas, el Grupo Puesto Viejo se transformó en una secuencia muy incómoda de ubicar y correlacionar dentro de la evolución triásica y fue considerado, en muchos trabajos, como un depocentro ajeno al resto de las cuencas (Spalletti, 1999; Ramos y Kay, 1991; Ramos 2004; Barredo, 2012) debido, principalmente, a su escaso desarrollo y a que su edad fue considerada significativamente más antigua que la de los demás depocentros. Esta edad, del Triásico Inferior, fue acotada bioestratigráficamente por la presencia de restos fósiles de vertebrados mencionados en el Capítulo 1 (Abdala et al., 2008; Martinelli, 2010), restos fósiles vegetales (Morel et al., 2003; Coturel et al., 2012) y estudios microfloristicos (Ottone y García, 1991; Zavattieri et al., 2003). Las edades de 245 Ma y 235,8 Ma obtenidas en los últimos años (Domeier et al., 2011; Ottone et al., 2014a y b), esta última obtenida para el nivel ignimbrítico superior de la Formación Quebrada de los Fósiles (tope de la etapa de relleno II) respaldan la edad obtenida por Valencio et al. (1975) y permiten reubicar al Grupo Puesto Viejo en el Triásico Medio (Anisiano- Ladiniano, hasta el límite con el Carniano). Así, las acumulaciones estudiadas pueden incluirse dentro de la escala cronológica de los episodios típicos de la Cuenca Cuyana (Figura 6.12), quizá el conjunto de depocentros más desarrollado y estudiado del Triásico del oeste argentino, consideración que acompaña la de otros autores (Japas et al. 2008a; Ottone et al., 2014a y b). De acuerdo a la nueva edad, el depocentro que alberga al Grupo Puesto Viejo se habría originado en momentos en los que el resto de los depocentros del rift de la Cuenca Cuyana de posición más oriental alcanzan su máxima expansión y espesor (Ramos, 1993; Spalletti, 1999; Jenchen y Rosenfeld, 2002), coincidente con el eje de la extensión (Allen y Allen, 2005). La posición que ocupa el depocentro que alberga al Grupo Puesto Viejo sobre la sutura paleozoica, alejada del eje principal de extensión triásica, habría condicionado sus características y su expansión. La corta historia que se 
registra en el depocentro, con espesores máximos acotados y su escasa extensión areal son características coherentes con una rápida velocidad de los procesos extensionales que originaron el sin-rift (Allen y Allen, 2005). Aunque no se sabe con certeza en qué momento se abrió la cuenca en la que se albergó el Grupo Puesto Viejo, las edades recientes obtenidas por Domeier et al. (2011) podrían circunscribir su origen en alrededor de los 245-250 Ma. Teniendo en cuenta las edades de $264 \mathrm{Ma}$ establecidas para el tope del Pérmico (Rocha-Campos et al., 2010; Domeier et al., 2011), debería haber existido un hiatus mayor a 10 Ma entre las últimas unidades pérmicas y el inicio de la sedimentación triásica.

El relleno de las primeras etapas del Grupo Puesto Viejo es muy acotado en el tiempo pero las características litoestratigráficas y ambientales son coherentes con las primeras etapas de sin-rift descriptas para la Cuenca Cuyana, representada por las formaciones Río Mendoza y Cerro de las Cabras, cuyo desarrollo se vincula con sistemas de fallas activas marginales y acumulación de depósitos volcaniclásticos de abanicos aluviales que hacia el tope registra un incremento de la actividad volcánica explosiva (Kokogián et al., 1989; Kokogián y Mancilla, 1989). Las etapas de relleno subsiguientes muestran cierta relación genética. Mientras que en el Grupo Puesto Viejo se desarrollaban sistemas fluviales meandrosos con desarrollo local de cuerpos de agua someros, en la Cuenca Cuyana, durante el Carniano se desarrollaban las formaciones Potrerillos y Cacheuta, caracterizadas por sistemas fluviales entrelazados a meyriformes con desarrollo de barreales y lagunas (Kokogián y Boggetti, 1986; Kokogián et al., 1989; 1993; Kokogián y Mancilla, 1989), con neto dominio de estos últimos al final del ciclo. Los fenómenos volcánicos explosivos son comunes durante la depositación de sin-rift tanto en el resto de los depocentros de la Cuenca Cuyana como en el Grupo Puesto Viejo, y hay evidencias de fenómenos explosivos en el noroeste de la Cuenca Cuyana (Formación El Alcázar, San Juan; Barredo, 2012) que sugieren el reinicio de la actividad volcánica en las áreas circundantes, lo que podría asociarse con las primeras etapas de subducción en el margen de Gondwana a comienzos del Triásico Tardío.

A diferencia de la Cuenca Cuyana, el depocentro que alberga al Grupo Puesto Viejo se habría cerrado, tempranamente, en el Triásico Superior bajo. La 
escasa magnitud de la extensión registrada en el depocentro que alberga al Grupo Puesto Viejo, reflejada por el menor espesor acumulado respecto de las otras localidades en el eje de la extensión (por ejemplo, Cuenca Cuyana) y por la corta historia depositacional, posiblemente condicionada por su posición sobre la zona de sutura, periférica al eje de extensión triásica, son factores que habrían derivado en la ausencia de un período de post-rift definido. Acorde a Allen y Allen (2005) la subsidencia de sin-rift y post-rift depende esencialmente de la cantidad de extensión. Una rápida extensión de la litosfera continental produce una subsidencia mecánica de sin-rift seguida de una importante disminución de la subsidencia de post-rift debido a la relajación térmica. En cambio, otras áreas donde los procesos extensionales continuaron hasta fines del Triásico, produciendo el máximo desarrollo de las cuencas, pasaron por fases con subsidencia termotectónica, que dieron lugar a un incremento en las dimensiones de los depocentros a partir de su integración y al desarrollo de etapas de post-rift (Spalletti, 1999).

La tectónica cenozoica (fase Andina) es la responsable de la configuración actual del Bloque de San Rafael con el desmembramiento de los depocentros del Grupo puesto Viejo. En el depocentro estudiado, la inversión cenozoica de las estructuras triásicas es baja. Internamente las fallas se encuentran selectivamente modificadas por la inversión y no afecta la distribución general de los hemigrábenes triásicos, sólo se identifica hacia los bordes de cuenca, a partir de indicadores cinemáticos que muestran un desplazamiento de tipo inverso y la presencia de fallas inversas que producen la superposición de los niveles triásicos. Algunas estructuras menores también muestran rasgos de inversión como atajos con muy bajo ángulo. 


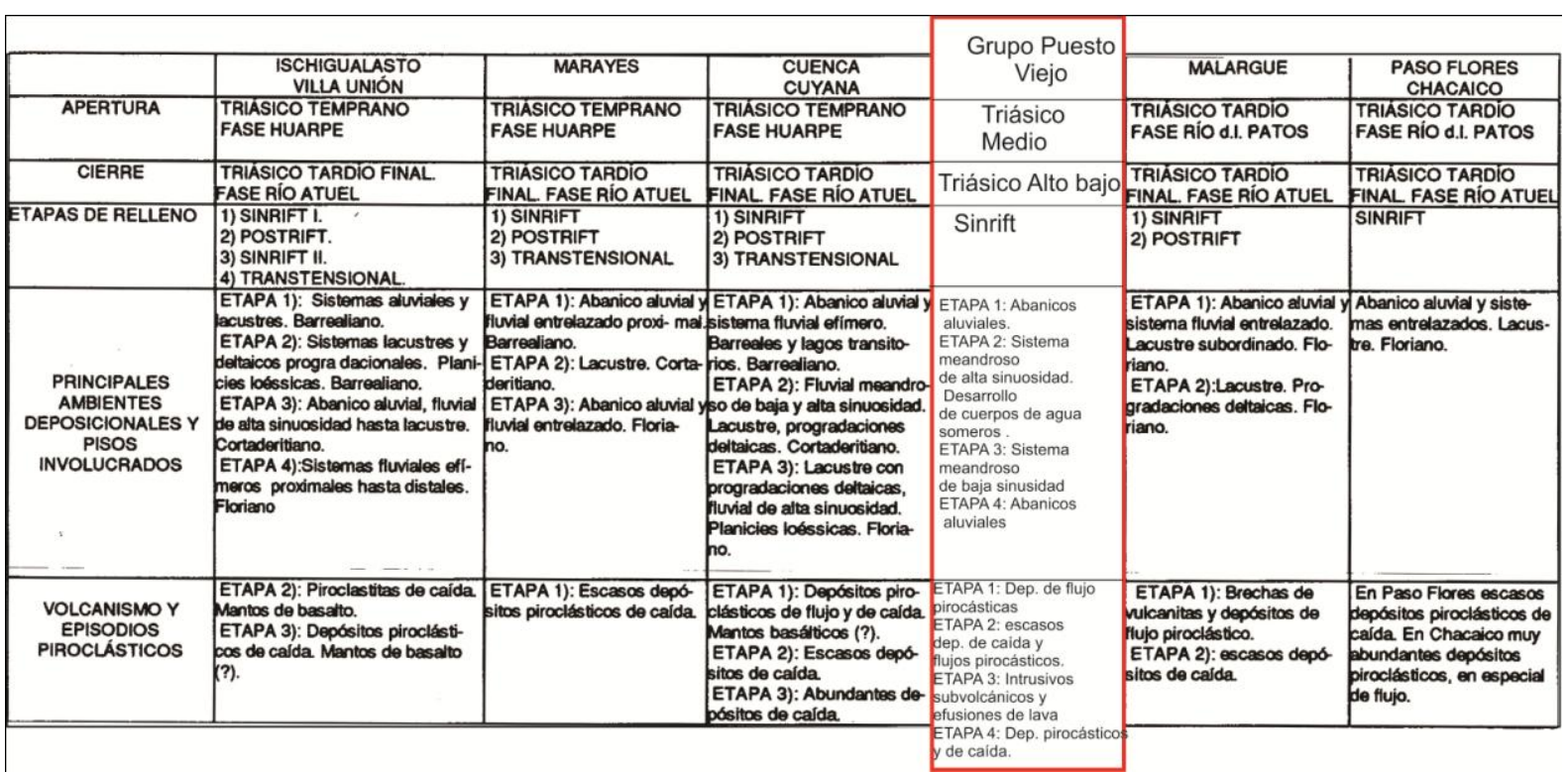

Figura 6.12. Cuadro comparativo del Grupo Puesto Viejo con cuencas Triásicas de Argentina (modificado de Spalletti, 1999).

\subsection{Discusión sobre la edad del Grupo Puesto Viejo y sus connotaciones bioestratigráficas}

El régimen extensional en el que se desarrolló la cuenca que alberga al Grupo Puesto Viejo habría durado algunos millones de años entre el Anisiano y el límite Ladiniano-Carniano (ver edades radimétricas; Domeier et al., 2011; Ottone et al., 2014a y b). Estos procesos habrían sucedido luego de los eventos tectotérmicos del Pérmico (264,8 \pm 2,3 Ma, Formación Agua de los Burros; 251,9 \pm 2,7 Ma, Formación Cerro Carrizalito; Rocha-Campos et al., 2010). La finalización de los eventos pérmicos, la poste rior exhumación cortical y la instauración de un proceso de extensión continental debieron tomar un período considerable de tiempo, eliminando desde una perspectiva geológica, la posibilidad de una continuidad estratigráfica entre el Pérmico y el Triásico en la zona estudiada. Ese período no habría sido menor a $10 \mathrm{Ma}$, tal como ha sido señalado anteriormente. Estas consideraciones hacen imprescindible la discusión sobre las connotaciones bioestratigráficas para el registro fósil del Grupo Puesto Viejo, que incluye restos vegetales, palinológicos y vertebrados pertenecientes a biozonas correlacionadas a nivel intercontinental que apuntaron por mucho tiempo a considerar esa continuidad y ubicyo al Grupo 
Puesto Viejo en el Triásico Inferior a Medio e incluso al Triásico temprano o cercana al límite permo-triásico. A su vez, las características tectoestratigráficas en las que se depositó el Grupo puesto Viejo no se adaptan a consideraciones meramente litoestratigráficas, ya que unidades temporalmente sucesivas se hallan en continuidad lateral mediante depresiones estructurales. Por lo tanto, como ya ha sido expresado, no existe en el área una columna estratigráfica que represente verticalmente al Grupo Puesto Viejo. Estas características pueden haber creado confusión en la ubicación de algunos niveles fosilíferos del Grupo Puesto Viejo, en especial aquellos niveles con fósiles de vertebrados (Abdala et al., 2008; Martinelli et al., 2009, Martinelli, 2010). Esos niveles se encuentran en la etapa de relleno III, por encima de los niveles datados y por lo tanto no pueden ser más viejos que esa edad $(235,8$ $\mathrm{Ma}$ ) ya que los depósitos de esta etapa, debido al estilo tectonoestratigráfico, suelen encontrarse en niveles estructurales más bajos que los de la secuencia II.

Con la nueva posición cronoestatigráfica del Grupo Puesto Viejo, siguiendo a Ottone et al. (2014a y b), se plantean incongruencias al comparar las faunas del Grupo Puesto Viejo con otras faunas coetáneas del Triásico de Argentina, ya que se modifican los esquemas de las biozonas de vertebrados de Argentina y Gondwana. Los restos vertebrados de dicinodontes conocidos hasta el momento en el la cuenca que alberga al Grupo Puesto Viejo son: Rechinisaurus sp. y dicinodonte indet. y un arcosauriforme basal (probable proterosuquio) indet. (Bonaparte, 2002) ubicados en la Formación Quebrada de los Fósiles, que fueron asignados al Triásico Temprano y correlacionados con la Zona de Lystrosaurus (AZ) de Sudáfrica; y kannemeyéridos, Kannemeyeria argentinensis y Vinceria sp. y los cinodontes Pascualgnathus polanskii, Cynognathus crateronotus y Diademodon tetragonus (Bonaparte, 1966 a, b, 1969; Abdala, 1996; Martinelli y De la Fuente, 2008; Abdala et al., 2008; Martinelli et al., 2009) ubicados en la Formación Río Seco de la Quebrada, asignados al Anisiano o Anisiano Tardío y correlacionados con la Zona de Cynognathus (AZ) de Sudáfrica. Respecto a las unidades equivalentes de la Cuenca Cuyana, se dificulta encontrar una correspondencia en las composiciones de los distintos grupos fósiles. La edad de la Formación Río Mendoza, en la secuencia triásica de la Cuenca Cuyana, fue atribuida al 
Triásico Inferior por las características de su fauna de vertebrados (tetrápodos). Esta asignación ha sido motivo de controversia entre diferentes autores y en la actualidad esta unidad se asigna al Triásico Medio (Ávila et al., 2006; Spalletti et al., 2008; Abdala et al., 2008). Los restos de dicinodontes kannemeyeriidos y eucinodontes indeterminados hallados en niveles estratigráficos de la Formación Cerro de Las Cabras permitieron considerar que la edad de los amniotas más antiguos hasta ahora exhumados en la Cuenca Cuyana, no podría ser más antigua que Triásico Medio Alto, dada la edad asignada a la Formación Cerro de Las Cabras en base a la asociación microflorística que contiene (Zavattieri y Arcucci, 2007). La fauna hallada en la Formación Chañares (Cuenca de Ischigualasto-Villa Unión), incluye el cinodonte traversodonte Massetognathus pascuali (el taxón más abundante), Probainognathus jenseni y Chiniquodon theotonicus que fueron asignados al Ladiniano - Noriano (Abdala y Riveiro, 2010).

Los fósiles vegetales descriptos para el Grupo Puesto Viejo se ubican, en su totalidad, en la etapa de relleno II y, aunque no se generan dudas sobre su ubicación estratigráfica, la edad que le asignan a la Formación Quebrada de los Fósiles es variada y controversial. Los restos de megaflora correspondientes a la "Flora de Pleuromeia" (Stipanicic, 1969; Morel y Artabe, 1993; 1994), referida a la Biozona CSD aparecen a partir del Triásico Temprano, aunque son comunes en el Triásico Medio y alcanzan el Triásico Tardío (Retallack, 1977). Los registros palinológicos referidos a la Zona de Protohaploxypinus samoilovichii de Australia (Ottone y García, 1991; Zavattieri et al., 2003) son ubicados en el Triásico Inferior temprano pero se han hallado elementos de la Zona de Triplexysporites playfordii de Australia (Ottone y García, 1991) referidas al Eo - Mesotríasico. La Formación Quebrada de los Fósiles presenta un gran desarrollo de facies con licófitas de tipo Pleuromeia, un segundo tipo de licófita, herbácea, y equisetáceas, siendo el primero el taxón dominante en la asociación (Zamuner et al., 2001; Arce y Lutz, 2010). En depósitos más restringidos se preservaron troncos de gimnosperma de gran tamaño (por su preservación, indeterminable) y se hallaron hojas de pteridospermas (Gallego et al., 2009). Si bien no se hallaron elementos en posición de vida, se interpreta que la tafocenosis de licófitas y equisetales podría ser autóctona, y la de 
gimnospermas podría ser para-autóctona. Respecto de la edad de la megaflora, la mayor abundancia de pleuromeiáceas se registra en sedimentos del Triásico Inferior (Morel et al., 2003; Coturel et al., 2012), sin embargo, ésta puede estar producida por una similitud ambiental. Las otras licófitas herbáceas son similares a un taxón reconocido para el Anisiano de Italia. La presencia de gimnospermas puede indicar que hubo una mayor recuperación del ambiente respecto de las floras puras de Pleuromeia del Triásico Inferior y la asociación puede referirse a una edad anisiana.

Las secuencias continentales triásicas superiores de la Cuenca Cuyana, contienen diversas asociaciones de megaflora y microflorísticas en las formaciones Potrerillos y Cacheuta atribuidas al Triásico Superior temprano en base a las distribuciones cronoestratigráficas de especies seleccionadas y a los elementos cosmopolitas triásicos asociados (Zavattieri y Rojo, 2005; Spalletti et al., 2005). En términos de la palinoestratigrafía del Gondwana, las microfloras de las secciones de Cacheuta fueron correlacionadas por Zavattieri y Rojo (2005) con la Microflora Ipswich (Carniano).

En síntesis, los datos paleontológicos en parte contradicen la edad de la evolución del Grupo Puesto Viejo en el marco de la extensión triásica, principalmente al referirnos a los restos fósiles de vertebrados ubicados en la Formación Río Seco de la Quebrada (etapa de relleno III). La diversidad de asociaciones de megaflora y microflorísticas podría apoyar la nueva posición cronoestratigráfica dado que se hallan en su totalidad en la Formación Quebrada de los Fósiles (etapa de relleno II), por debajo del límite LadinianoCarniano. Consideryo que el Grupo Puesto Viejo comenzó a depositarse durante el Anisiano su edad no puede ser inferior al Triásico Medio. 


\section{CAPÍTULO 7}

\section{CONCLUSIONES}




\section{Capítulo 7. Conclusiones}

$>$ El depocentro estudiado, que alberga al Grupo Puesto Viejo de la cuenca triásica de San Rafael, forma parte del Bloque de San Rafael siguiendo su disposición estructural con rumbo general noroestesudeste.

$>$ El depocentro Triásico se desarrolla sobre la sutura de la anexión continental del terreno alóctono Chilenia contra el margen suroeste de Gondwana, constituyendo un basamento heterogéneo con estructuras previas que condicionaron los patrones normales del fallamiento extensional.

> Su localización sobre una zona de debilidad cortical condicionó el desarrollo de un rift oblicuo con una dirección de máxima extensión horizontal dispuesta ENE oblicua a la zona de debilidad de la sutura paleozoica y a las fallas de borde

> El depocentro constituye un graben asimétrico alargado en sentido NOSE cuyas principales estructuras activas durante el Triásico consistieron en fallas principales o de borde y fallas internas con una relación de baja oblicuidad angular entre ambos sistemas.

Las fallas principales fueron las primeras estructuras que condicionaron la localización y magnitud del depocentro mediante subsidencia mecánica. Con orientación principal NO-SE y ángulo de oblicuidad ente $55^{\circ}$ y $60^{\circ}$ con respecto al régimen extensional. Actuaron como fallas de rumbo vinculadas con una componente transtensional sinestral y deformación altamente particionada.

Las fallas internas normales dieron lugar al desarrollo de grábenes y hemigrábenes y controlaron la acumulación del relleno durante su desarrollo. Muestran dos patrones de orientación: uno paralelo a las 
fallas principales de borde y otro oblicuo, con una orientación principal ONO-ESE. Actuaron como fallas normales de geometría plana, perpendiculares a la dirección de máxima de extensión horizontal y responden a un régimen extensional puro.

Dentro del área de estudio se desarrolló una zona de acomodación de alto relieve a partir de fallas directas dextrales con orientación NE-SO formyo un ángulo alto con las estructuras principales del rift. Constituye un control fundamental sobre las áreas de aporte de sedimentos, el emplazamiento de magma y la generación de plegamiento.

$>$ El crecimiento de las fallas internas normales produjo pliegues longitudinales a diferentes escalas. Dos sinformes suaves con ejes NNO-SSE distribuidos a lo largo del depocentro y separados por la zona de acomodación. Un antiforme transversal con eje NE-SO. A escala de afloramiento se describieron flexuras monoclinales como producto de la propagación de fallas normales, además de pliegues de arrastre y flexión de fallas en la zona de acomodación.

> El depocentro de San Rafael constituye una cuenca de rift continental cuyo relleno presenta un arreglo general aluvial con desarrollo de sistemas meandrosos de baja y de alta sinuosidad que evolucionó de forma local con poco transporte del material sedimentario, controlada por sus estructuras y la actividad volcánica-piroclástica coetánea.

Las características tectonoestratigráficas en las que se depositó el Grupo Puesto Viejo no permiten analizar el relleno desde una perspectiva puramente litoestratigráfica ya que unidades temporalmente sucesivas se hallan en continuidad lateral mediante depresiones estructurales. Por lo tanto se recomienda volver a la antigua denominación "Formación Puesto Viejo". El Grupo Puesto Viejo podría alcanzar hasta 1000 metros de espesor total. 
> Se definieron cuatro etapas de relleno que evolucionaron siguiendo una alternancia sucesiva de episodios: $1^{\circ}$ ) subsidencia mecánica; $2^{\circ}$ ) quietud tectónica con desarrollo de sistemas aluviales y fluviales; $3^{\circ}$ ) actividad volcánica. Este arreglo condiciona el desarrollo de períodos intereruptivos con alta tasa de subsidencia mecánica en las etapas iniciales de rifting y períodos sin-eruptivos subsiguientes con baja tasa de subsidencia. La Formación Quebrada de los Fósiles incluye a las etapas I y II, mientras que la Formación Río Seco de la Quebrada equivale a las etapas III y IV.

> El carácter bimodal que presenta el volcanismo del Grupo Puesto Viejo, con composición riolítica para las rocas piroclásticas y composición yesítica y andesítco/basáltica para las rocas volcánicas, es típico de los rift continentales, donde las tasas de deformación son altas y la corteza lo suficientemente gruesa como para permitir que el magma sea emplazado y pueda diferenciarse sucesivamente para generar productos evolucionados

$>$ Las diferentes etapas de relleno permiten establecer un fuerte control de las estructuras sobre el volcanismo. Inicialmente el rifting está caracterizado por actividad ignimbrítica generalizada vinculada a las fallas de bordes activas, seguido por el desarrollo de fallas internas asociadas a un volcanismo bimodal. A su vez los cuerpos subvolcánicos básicos se concentran dentro de la zona de acomodación distribuidos a lo largo de las fallas de borde.

$>$ El análisis del relleno del depocentro del Grupo Puesto Viejo muestra una fuerte subsidencia mecánica por fallamiento normal y tanto el estado evolutivo como el registro sedimentario son propios de un período de sin-rift. La corta historia registrada en el Grupo Puesto Viejo y la escasa magnitud de la extensión reflejada por espesores máximos acotados, son rasgos coherentes con una rápida velocidad de los procesos extensionales que originaron el sin-rift. Estas características habrían derivado en la ausencia de un período de post-rift definido y el temprano 
cierre de la cuenca en el Triásico Superior bajo. Estas características pudieron estar condicionadas por su ubicación, periférica al eje de extensión triásica, sobre la zona de sutura.

Las últimas edades obtenidas (245 Ma, Domeier et al., 2011; 235,8 Ma, Ottone et al., 2014a y b) ubican al Grupo Puesto Viejo en el Triásico Medio (Anisiano- Ladiniano, hasta el límite con el Carniano). Esta edad permite ubicar al depocentro del Grupo Puesto Viejo dentro de la escala cronológica de los episodios típicos de la cuenca Cuyana. El depocentro que alberga al Grupo Puesto Viejo se habría originado en momentos en los que el resto de los depocentros del rift de la cuenca Cuyana de posición más oriental alcanzan su máxima expansión y espesor.

> Entre la finalización de los eventos pérmicos, la posterior exhumación cortical y la instauración de un proceso de extensión continental debería haber existido un hiatus mayor a $10 \mathrm{Ma}$, eliminando, desde una perspectiva geológica, la posibilidad de una continuidad estratigráfica entre el Pérmico y el Triásico en la zona estudiada.

> Dado el contexto tectonoestratigráfico en el que se depositó el Grupo Puesto Viejo, no existe en el área una columna estratigráfica que lo represente verticalmente. Esto dificulta la ubicación de algunos niveles con fósiles de vertebrados adjudicados a la etapa de relleno III que, de acuerdo a las nuevas dataciones, se encontraría por encima del límite Ladiniano-Carniano.

La diversidad de asociaciones de megaflora y microflorísticas podrían apoyar la nueva posición cronoestratigráfica dado que se hallan en su totalidad en la Formación Quebrada de los fósiles (etapa de relleno II), la cual comenzó a depositarse durante el Anisiano, pero su edad no puede ser inferior al Triásico Medio.

La fase tectónica Andina es la responsable de la configuración actual del Bloque de San Rafael con el desmembramiento de los depocentros del Grupo puesto Viejo. Pero en el depocentro estudiado del Grupo Puesto 
Viejo, la inversión cenozoica de las estructuras triásicas es baja y no afecta la distribución general de los hemigrábenes triásicos. 


\section{BIBLIOGRAFÍA}




\section{BIBLIOGRAFÍA}

Abdala, F. 1996. Redescripción del cráneo y reconsideración de la validez de Cynognathus minor (Eucynodontia-Cynognathidae) del Triásico Inferior de Mendoza. Ameghiniana 33 (2): 115-126.

Abdala, F., Martinelli, A.G., Bentos Soares, M., De La Fuente, M. y Ribeiro, A.M. 2008. Souht American Midle Triassic continental faunas with amniotes: bioestratigraphy y correlation. 15th Biennial Meeting of the Paleontological Society of Southern Africa 44: 83-87, Matjiesfontein, South Africa.

Abdala, F., Martinelli, A.G., Bentos Soares, M., De La Fuente, M. y Ribeiro, A.M. 2009. South American Midle Triassic continental faunas with amniotes: bioestratigraphy y correlation. Paleontologia Africana 44: 83-87.

Acocella, V., Salvini, F., Funiciello, R. y Faccenna, C. 1999. The role of transfer structures on volcanic activity at Campi Flegrei (Southern Italy). Journal of Volcanology y Geothermal Research 91: 123-139.

Agostini, A., Bonini, M., Corti, G., Sani, F. y Mazzarini, F. 2011. Fault architecture in the Main Ethiopian Rift y comparison with experimental models: Implications for rift evolution y Nubia-Somalia kinematics. Earth y Planetary Science Letters 301 (3): 479-492.

Allen, P.A. y Allen, J.R. 1990. Basin Analysis Principles y Application. Blackwell Scientific Publications, 451 p., Oxford, U.K.

Allen, P.A. y Allen, J.R. 2005. Basin Analysis: Principles y Applications. Blackwell Science, 549 p., Oxford, U.K.

Arce, F.E. y Lutz, A.I. 2010. Fructificaciones de la Formación Los Rastros, Triásico Superior, Provincia de San Juan, Argentina. Revista Mexicana de Ciencias Geológicas 27:32-42.

Artabe, A.E. 1985. Estudio sistemático de la tafoflora triásica de Los Menucos, província de Río Negro, Argentina. Parte 1. Sphenophyta, Filicophita, Pteridospermophyta, Ameghiniana 22 (1-2): 3-22.

Ávila, J.N., Chemale Jr., F., Mallmann, G., Kawashita, K. y Armstrong, R. 2006. Combined stratigraphic y isotopic studies of Triassic strata, Cuyo Basin, Argentine Precordillera. Geological Society of America Bulletin 118: 10881098.

Azcuy, C.L. y Caminos, R. 1987. Diastrofismo En: Archangelsky, S. (Ed.) El Sistema Carbonífero en la República Argentina. Academia Nacional de Ciencias: 239-252, Córdoba, Argentina.

Baez, A., Marsicano, C. y Cione, A. 1993. Vertebrados mesozoicos. En: Ramos, V. (Ed.) $12^{\circ}$ Congreso Exploración de Hidrocarburos. Relatorio de Geología y Recursos Naturales de Mendoza 2 (13): 341-348. 
Barredo, S.P. 2012. Geodynamic y Tectonostratigrafic Study of a Continental Rift: The Triassic Cuyana Basin, Argentina. En: Sharkov, E. (Ed.) Tectonics Recent Advances. Capítulo 5.

Bastías, H., Tello, G.E., Perucca, L.P. y Paredes, J.D. 1993. Peligro sísmico y Neotectónica. En: Ramos, V.A. (Ed.) Geología y Recursos Naturales de Mendoza. $12^{\circ}$ Congreso Geológico Argentino y $2^{\circ}$ Congreso de Exploración de Hidrocarburos, Relatorio: 645-658.

Best, M.G. y Christiansen, E.H. 2001. Igneous Petrology. Blackwell Science, Inc., 460 p., Oxford, U.K.

Blair, T.C. y McPherson, J.G. 1994. Alluvial fans y their natural distinction from rivers based on morphology, hydraulic processes, sedimentary processes, y facies assemblages. Journal of sedimentary research 64 (3): 450-489.

Blair, T.C. y Mcpherson, J.G. 2008. Quaternary sedimentology of the Rose Creek fan delta, Walker Lake, Nevada, USA, y implications to fan-delta facies models. Sedimentology 55 (3): 579-615.

Bonaparte, J.F. 1966a. Sobre nuevos terápsidos triásicos hallados en el centro de la provincia de Mendoza, Argentina (Therapsoda: Dicynodonta y Cynodonta). Acta Geológica Lilloana 8, Museo de Historia Natural.

Bonaparte J.F. 1966b. Una nueva "fauna" Triásica de Argentina (Therapsida: Cynodontiay Dicynodontia). Consideraciones filogenéticas y paleobiogeográficas. Ameghiniana 4 (8): 243-296.

Bonaparte, J.F. 1967. New vertebrate evidence for Southern Transatlantic connection during the Lower or Middle Triassic. Paleontology 10: 554-281.

Bonaparte, J.F. 1969. Cynognathus minor n.sp. (Therapsida-Cynodontia). Nueva evidencia de vinculación faunística Afro-Sudamericana a principios del Triásico. Gondwana Stratigraphy, I.U.G.S., Coloquio Mar del Plata 1967: 273-281.

Bonaparte, J.F. 1981. Notas sobre una nueva fauna del Triásico Inferior del Sur de Mendoza, Argentina, correspondiente a la Zona de Lystrosaurus (DicynodontiaeProterosuchia). $2^{\circ}$ Congresso Latinoamericano de Paleontología, Anales 1: 362-371, Porto Alegre.

Bonaparte, J.F. 1982. Faunal replacement in the Triassic of South America. Journal of Vertebrate Paleontology 2 (3): 362-371.

Bonaparte, J.F. 2000. Comentarios críticos sobre el Triásico Inferior de Puesto Viejo y Potrerillos. Boletín de la Academia Nacional de Ciencias Córdoba 64: 147-152.

Bonaparte, J.F. 2002. Edad/Reptil Puestoviejense. En: Stipanicic, P.N. y Marsicano, C.A. (Eds.) Léxico Estratigráfico de la Argentina. Volumen 8. Triásico. Asociación Geológica Argentina, Serie "B" (Didáctica y Complementaria) 26, 229 p., Buenos Aires. 
Borrello, A.V. 1962. Fanglomerado Río Mendoza, Triásico, Provincia de Mendoza. Notas Comisión de Investigaciones Científicas de la Provincia de Buenos Aires 1 (3): 3-9.

Bracaccini, O. 1945. Acerca de los movimientos intertriásicos en Mendoza norte. I Reunión de Comunicaciones del Instituto Panamericano de Ingeniería de Minas y Geología, IPIMIGEO, Sección Argentina: 26-34, Buenos Aires.

Branney, M.J. y Kokelaar, B.P. 2002. Pyroclastic density currents y the sedimentation of ignimbrites. The Geological Society of London Memoir 27, $143 p$.

Bridge, J.S. 1993. Description y interpretation of fluvial deposits: a critical perspective. Sedimentology 40 (4): 801-810.

Bridge, J.S. 2003. Rivers y Floodplains: Forms, Processes, y Sedimentary Record. Blackwell Science Publishing, 489 p., Oxford, U.K.

Bridge, J.S. 2006. Fluvial facies model: recent developments, En: Posamentier, H.W. y Walker, R.G. (Eds.) Facies model revisted, SEPM Special Publication: 85-170.

Chorowicz, J. 2005. The East African rift system. Journal of African Earth Sciences 43 (1): 379-410.

Clemente, P. y Pérez-Arlucea, M. 1993. Depositional architecture of the Cuerda del Pozo Formation, Lower Cretaceous of the extensional Cameros Basin, north-central Spain. Journal of Sedimentary Research 63 (3): 437-452.

Collinson, J.D. 1986. Alluvial sediments. En: Reading, H.G. (Ed.) Sedimentary Environments y Facies (2nd ed.). Blackwell: 20-62 p., Oxford, U.K.

Cortés, J.M., Gonzalez Bonorino, G., Koukharsky, M.L., Brodkorb A. y Pereyra, F. 1999a. Hoja geológica 3369-09, Uspallata, provincia de Mendoza. Servicio Geológico Minero Argentino Boletín (1999), 281 p., Buenos Aires.

Cortés, J.M., Vinciguerra, P., Yamín, M. y Pasini, M.M. 1999b. Tectónica Cuaternaria de la Región Andina del Nuevo Cuyo $\left(28^{\circ}-38^{\circ}\right.$ LS). En: Caminos, R. (Ed.) Geología Argentina. Subsecretaría de Minería de la Nación, Servicio Geológico Minero Argentino, Anales 29, Cap. 24: 760-778, Bueno Aires.

Corti, G. 2004. Centrifuge modelling of the influence of crustal fabrics on the development of transfer zones: insights into the mechanics of continental rifting architecture. Tectonophysics 384 (1): 191-208.

Corti, G. 2009. Continental rift evolution: from rift initiation to incipient break-up in the Main Ethiopian Rift, East Africa. Earth-Science Reviews 96 (1): 1-53. 
Corti, G., Manetti, P., Abebe, T., Bonini, M. y Mazzarini, F. 2009. The volcanotectonic activity of the mail Ethiopian Rift (East Africa): insight into de evolution of continental rifting. Acta vulcanológica 20.1-2.2008/21.1-2.2009.

Corti, G. 2012. Evolution y characteristics of continental rifting: Analog modeling-inspired view y comparison with examples from the East African Rift System. Tectonophysics 522: 1-33.

Corti, G., Bonini, M., Innocenti, F., Manetti, P. y Mulugeta, G. 2001. Centrifuge models simulating magma emplacement during oblique rifting. Journal of Geodynamics 31: 557-576.

Corti, G., van Wijk, J., Cloetingh, S. y Morley, C.K. 2007. Tectonic inheritance y continental rift architecture: numerical y analogue models of the East African Rift system. Tectonics 26 (6): http://dx.doi.org/10.1029/2006TC002086.

Corti, G., Calignano, E., Petit, C. y Sani, F. 2011. Controls of lithospheric structure y plate kinematics on rift architecture y evolution: an experimental modeling of the Baikal Rift. Tectonics 30 (3): http://dx.doi.org/10.1029/2011TC002871.

Corti, G., Philippon, M., Sani, F., Keir, D. y Kidane, T. 2013. Re-orientation of the extension direction y pure extensional faulting at oblique rift margins: comparison between the Main Ethiopian Rift y laboratory experiments. Terra Nova 25 (5): 396-404.

Costa, C.H., Cisneros, H., Salvarredi, J. y Gallucci, A. 2004. Nuevos datos y reconsideraciones sobre la neotectónica del margen oriental del bloque de San Rafael. $12^{\circ}$ Reunión sobre Microtectónica y Geología Estructural. Resúmenes 7, Cafayate.

Coturel, E.P., Zavattieri, A.M., Cariglino, B. y Morel, E. 2012. Nuevas evidencias de Lycopsidas de la Formación Quebrada de los Fósiles, localidad tipo (Triásico Temprano), Grupo Puesto Viejo, Mendoza. Interpretación paleoambiental. $15^{\circ}$ Simposio Argentino de Paleobotánica y Palinología. Resúmenes: 27.

Criado Roqué, P. 1972. Bloque de San Rafael. En: Leanza, A. (Ed.) Geología Regional Argentina: 72-295, Córdoba.

Criado Roque, P., Mombrú, P. y Ramos, V. 1981. Estructura e interpretación tectónica. En: Irigoyen, M.R. (Ed.) Geología y Recursos Naturales de la provincia de San Luis. $8^{\circ}$ Congreso Geológico Argentino, Relatorio: 155-192.

Dellapé, D. y Hegedus, A. 1995. Structural inversion y oil occurrence in the Cuyo basin of Argentina. En: Tankard, A. Suarez, R.S. y Welsink, H.J. (Eds.) Petroleum Basins of South America. Memoir 62: 359-367.

Dessanti, R.N. 1956. Descripción Geológica de la Hoja Geológica 27c, Cerro Diamante. Servicio Nacional Minero Argentino. Boletín 85: 1-79, Buenos Aires. 
Domeier, M., van der Voo, R., Tomezzoli, R.N., Tohver, E., Hendrinks, B.W., Torsvik, T.H., Vizán, H. y Domínguez, A. 2011. Support for an "A-type" Pangea reconstruction from high-fidelity Late Permian y Early to Middle Triassic paleomagnetic data from Argentina. Journal of Geophysical Research (116) B12114.

Domnanovich, N. y Marsicano, C. 2009. Los dicinodontes (Amniota: Terápsia) de Argentina: Síntesis sobre el conocimiento actual del grupo. $24^{\circ}$ Jornadas Argentinas de Paleontología de Vertebrados, Resúmenes, San Rafael, Mendoza.

Eriksson K.A. y Simpson E.L., 1993. Siliciclastic braided-alluvial sediments intercalated within continental flood basalts in the Early to Middle Proterozoic Mount Isa Inlier, Australlia. En: Marzo, M. y Puigdefabregas, C. (Eds.) Alluvial sedimentation. Special Publication of the International Association of Sedimentologists $17:$ 473-488.

Ezcurra, M.D., Lecuona, A. y Martinelli, A., 2010. A new basal archosauriform diapsid from the Lower Triassic of Argentina. Journal of Vertebrate Paleontology 30: 1433-1450.

Fisher, R.V. y Schmincke, H.U. 1984. Pyroclastic rocks. Springer-Verlag Heidelberg, 472 p., New York.

Folguera, A., Etcheverria, M., Pazos, P., Giambiagi, L., Cortés, J.M., Fauqué, L., Fusari, C. y Rodriguez, M.F. 2004. Descripción de la Hoja Geológica N ${ }^{\circ}$ 3369-15 (Potrerillos). Carta Geológica de la República Argentina Escala: 1:100.000. Subsecretaría de Minería de la Nación, Dirección Nacional del Servicio Geológico, 262 p.

Fossa Mancini, E. 1937. Las investigaciones geológicas de YPF en la Provincia de Mendoza y algunos problemas de estratigrafía regional. Boletín de Informaciones Petroleras 14 (154): 51-118.

Franzese, J.R. y Spalletti, L.A. 2001. Late Triassic-early Jurassic continental extension in southwestern Gondwana: tectonic segmentation y pre-break-up rifting. Journal of South American Earth Sciences 14 (3): 257-270.

Franzese, J.R., Veiga, G.D., Schwarz, E. y Gómez-Pérez, I. 2006. Tectonostratigraphic evolution of a Mesozoic graben border system: the Chachil depocentre, southern Neuquén Basin, Argentina. Journal of the Geological Society 163 (4): 707-721.

Frenguelli, J. 1948. Estratigrafía y edad del llamado 'Rético' en la Argentina. Anales de la Sociedad Argentina de Estudios Geográficos 8: 159-309.

Gallego, O.F., Zavattieri, A.M., Gnaedinger, S.C., Ballent, S., De La Fuente, M.S., Cavaleri, N.G., Lara, M.B., Tassi, L.V. y Monferran, M.D. 2009. Nuevos hallazgos paleontológicos en la Formación Quebrada de los Fósiles (Grupo Puesto Viejo), en el límite Pérmico-Triásico de la Argentina. Revista de la Asociación Paleontológica Argentina. Resúmenes 46, Número 4, Buenos Aires. 
Gawthorpe, R.L. y Leeder, M.R. 2000. Tectono-sedimentary evolution of active extensional basins. Basin Research 12 (3-4): 195-218.

Ghosh, S.K. 1987. Cyclicity y facies characteristic of alluvial sediments in the Monongahela-Dunkard Groups, central West Virginia. En: Recent Developments in Fluvial Sedimentology. Ethridge, F.G., Flores, R.M. y Harvey, M.D. (Eds.). SEPM Special Publication 39: 229-242.

González Díaz, E.F. 1964. Rasgos geológicos y evolución geomorfológica de la Hoja 27d, San Rafael y zona occidental vecina (Provincia de Mendoza). Revista de la Asociación Geológica Argentina 19: 151-188.

González Díaz, E.F. 1967. El hallazgo del Infra?-Mesotriásico continental en el sur del área pedemontana mendocina. Acta Geológica Lilloana 8: 101-134, San Miguel de Tucumán.

González Díaz, E.F. 1972. Descripción geológica de la Hoja 27d, San Rafael, provincia de Mendoza. Servicio Nacional Minero Geológico, Boletín 132: 127 p., Buenos Aires.

Gradstein, F.M. y OGG, J.G. Geologic Time Scale 2004 - why, how, y where next! Lethaia 37:175-181.

Groeber, P. 1952. Mesozoico, Ándico. En: Groeber, P., Stipanicic, P.N. y Mingramm, A.R.G. (Eds.) Geografía de la República Argentina. Sociedad Argentina de Estudios Geográficos GAEA 2: 349-541.

Haughton, P.D.W. 1993. Simultaneous dispersal of volcaniclastic y nonvolcaniclastic sediment in fluvial basins: examples from the Lower Old Red Systone, east-central Scotly. En: Alluvial Sedimentation. Marzo, M. y Puigdefabregas C. (Eds.) Special Publication International Association of Sedimentology $17: 451-472$.

Irvine, T. y Baragar, W. 1971. A guide to the chemical classification of the common volcanic rocks. Canadian journal of earth sciences 8 (5): 523-548.

Japas, M.S. y Kleiman, L.E. 2004. El ciclo Choiyoi en el bloque de San Rafael (Mendoza): de la orogénesis tardía a la relajación mecánica. Asociación Geológica Argentina, Publicación Especial 7: 89-100.

Japas, M.S., Cortés, J.M. y Pasini, M. 2008a. Tectónica extensional triásica en el sector norte de la Cuenca Cuyana: primeros datos cinemáticos. Revista de la Asociación Geológica Argentina 63 (2): 213-222.

Japas, M.S., Salvarredi, J.A. y Kleiman, L.E. 2008b. Control estructural en la distribución de las mineralizaciones de Uranio del Ciclo Choiyoi, Bloque de San Rafael, Mendoza. Revista de la Asociación Geológica Argentina 63 (2): 204-212.

Jenchen, U. y Rosenfeld, U. 2002. Continental Triassic in Argentina: response to tectonic activity. Journal of South American Earth Sciences 15 (4): 461479. 
Jones, D., Kokogian, D., Barzola G. y Ortiz, A. 1999. Sistemas Petroleros de la Cuenca Cuyana. $4^{\circ}$ Congreso de Exploración y Desarrollo de Hidrocarburos, Instituto Argentino del Petróleo y del Gas, Actas 1:127-143.

Keranen, K. y Klemperer, S.L. 2008. Discontinuous y diachronous evolution of the Main Ethiopian Rift: Implications for development of continental rifts. Earth y Planetary Science Letters 265 (1): 96-111.

Kleiman, L.E 1993. El vulcanismo permo-triásico y triásico del Bloque San Rafael (provincia de Mendoza): su potencial uranífero. $12^{\circ}$ Congreso Geológico Argentino y $2^{\circ}$ Congreso de Exploración de Hidrocarburos, Actas 5: 284-293, Mendoza.

Kleiman, L.E. 1999. Mineralogia y petrología del volcanismo Permo-Triásico y Triásico del Bloque de San Rafael en el área de Sierra Pintada, provincia de Mendoza y su relación con las mineralizaciones de uranio. Tesis Doctoral,, Universidad de Buenos Aires (Inédita), 286 p., Buenos Aires.

Kleiman, L.E., 2002. Magmatism y tectonic evolution of the Choiyoi y Puesto Viejo volcanics (Late Paleozoic-Early Mesozoic) at $34^{\circ}-35^{\circ} \mathrm{S}$ latitude, San Rafael, Mendoza, Argentina. $15^{\circ}$ Congreso Geológico Argentino, Actas 2: 15-16, El Calafate.

Kleiman, L.E. y Japas, M.S. 2009. The Choiyoi volcanic province at $34^{\circ} \mathrm{S}-36^{\circ} \mathrm{S}$ (San Rafael, Mendoza, Argentina): Implications for the Late Palaeozoic evolution of the southwestern margin of Gondwana. Tectonophysics 473: 283-299.

Kleiman, L.A. y Salvarredi, J.A. 1989. El volcanismo del Pérmico Inferior relacionado con la mineralización de uranio en el área de Sierra Pintada (Mendoza) Comisión de Energía Atómica, Informe Interno D:E:E 6-89 (Inédito): 113 p., Buenos Aires.

Kleiman, L.E y Salvarredi, J.A. 2001. Petrología, geoquímica e implicancias tectónicas del volcanismo triásico (Formación Puesto Viejo), Bloque de San Rafael. Revista de la Asociación Geológica Argentina 56 (4): 559-570.

Kokogián, D.A. y Boggetti, D.A. 1986. Estratigrafía y ambientes sedimentarios de los depósitos triásicos en la localidad de Potrerillos en la provincia de Mendoza. $1^{\circ}$ Reunión Argentina de Sedimentología. Resúmenes expyidos: 161-164, La Plata.

Kokogian, D.A. y Mancilla, O.H. 1989. Análisis estratigráfico secuencial de la cuenca Cuyana. En: Chebli, G. y Spalletti, L. (Eds.) Cuenca Sedimentarias Argentinas. Facultad de Ciencias Naturales, Universidad Nacional de Tucumán, Correlación Geológica Serie 6: 169-201, Tucumán.

Kokogián, D., Boggetti, D. y Rebay, G. 1989. Cuenca Cuyana. El análisis estratigráfico secuencial en la identificación de entrampamientos sutiles. $1^{\circ}$ Congreso Nacional Exploración de Hidrocarburos: 649-674. 
Kokogian, D.A., Seveso, F.F. y Mosquera, A. 1993. Las Secuencias Sedimentarias Triásicas. $12^{\circ}$ Congreso Geológico Argentino y $2^{\circ}$ Congreso de Exploración de Hidrocarburos. Relatorio 1 (7): 65-78.

Kokogian, D.A., Spalletti, L., Morel, E. y Artabe, A. 1999. Los Depósitos Continentales Triásicos. En: Caminos, R. (Ed.) Geología Argentina. Anales 29, Instituto de Geología y Recursos Minerales (15): 377-398.

Kokogian, D.A., Spalletti, L.A., Morel, E.M., Artabe, A.E., Martínez, R.N., Alcober, O.A., Milana, J.P. y Zavattieri, A.M. 2001. Estratigrafía del Triásico argentino. En: Artabe, A.E., Morel, E.M. y Zamuner, A.B. (Eds.) El Sistema Triásico en la Argentina. Fundación Museo de la Plata "Francisco Pascasio Moreno": 23-54, La Plata.

Kusiak, M. 1993. Nuevos afloramientos basales de la Formación Puesto Viejo al suroeste de la presa Valle Grye, río Atuel. San Rafael-Mendoza. $12^{\circ}$ Congreso Geológico Argentino y $2^{\circ}$ Congreso de Exploración de Hidrocarburos. Actas 2: 63-70, Mendoza.

Leeder, M.R. 1995. Continental rifts y proto-oceanic troughs. En: Busby, C.J. y Ingersol, R.V. (Eds.) Tectonics of Sedimentary Basins. Blackwell Scientific Publications, 119-148 p., Oxford, U.K.

Leeder, M.R. 1999. Sedimentology y sedimentary basins: from turbulence to tectonics. Blackwell Science Publishing, 592 p., Oxford, UK.

Llambías, E.J. 2003. Geología de los Cuerpos Ígneos. Asociación Geológica Argentina, 182 p., Buenos Aires.

Llambías, E.J., Kleiman, L.E. y Salvarredi, J.A. 1993. Magmatismo gondwánico. $12^{\circ}$ Congreso Geológico Argentino y $2^{\circ}$ Congreso de Exploración de Hidrocarburos. Relatorio 1 (6): 53-64.

López W., Rossello, E., Remuzgo, D., Guachallanqui, I., Romero, M., Ayala, L. 2013. Caracterización del abanico aluvial de la Quebrada Cueva en la localidade de Maramara Noreste de Lima. Revista del Instituto de Investigaciones de la Facultad de Geología, Minas, Metalurgia y Clencias Geográficas, Volumen 16, 32.

López Gamundi, O. 1994. Facies distribution in an asymmetric half graben: the northern Cuyo Basin (Triassic), western Argentina. International Sedimentological Congress $N^{\circ} 14$, Abstracts S1: 6-7, Recife.

López Gamundi, O.R. y Astini, R.A. 1992. Caracterización de facies lacustres en la sección basal del Triásico de El Alcázar-Agua de los Pajaritos, Provincia de San Juan, Argentina. $4^{\circ}$ Reunión Argentina de Sedimentología, Actas 3: 97-104, La Plata.

López Gamundi, O., Álvarez, L., Yrteis, R., Bossi, G.E., Espejo, I., Fernández Seveso, F., Legarreta, L., Kokogian, D.A., Limarino, C.O. y Sessarego, H.L. 1989. Cuencas intermontanas. En: Chebli, G.A. y Spalletti, L.A. (Eds.) 
Cuencas Sedimentarias Argentinas. INSUGEO, Serie Correlación Geológica 6: 123-167.

López-Gamundi, O.R., Limarino, C.O. y Cesari, S.N. 1992. Late Paleozoic paleoclimatology of central west Argentina. Palaeogeography, Palaeoclimatology y Palaeoecology 91 : 305-329.

Lluch, J.J. 1971. Sedimentología del Triásico en el área de PapagallosDivisadero Largo, Mendoza. Revista de la Asociación Argentina de Mineralogía, Petrología y Sedimentología (AMPS) 2: 91-116.

Lucas, S.G. 1998. Global Triassic tetrapod biostratigraphy y biochronology. Palaeogeography, Palaeoclimatology, Palaeoecology 143: 347-384.

Martin, W., Clavero, J., Mpodozis, C. 1999. Late Paleozoic to Early Jurassic tectonic development of the high Yean Principal Cordillera, El Indio Region, Chile (29-30 ${ }^{\circ}$ ). Journal of South American Earth Sciences 12: 33-49.

Martinelli, A.G. 2010. On the postcanine dentition of Pascualgnathus polanskii Bonaparte (Cynodontia, Traversodontidae) from the Middle Triassic of Argentina. Geobios 43 (6): 629-638.

Martinelli, A.G. y De La Fuente, M. 2008. Los cinodontes nomamaliaformes de la Formación Puesto Viejo, San Rafael, Mendoza. Encuentro Científico ICES 3. Actas: $67-74$, Malargüe.

Martinelli, A.G., de la Fuente, M. y Abdala, F. 2009. Diademodon tetragonus Seeley, 1894 (Therapsida: Cynodontia) in the Triassic of South America y its biostratigraphic implications. Journal of Vertebrate Paleontology 29: 852-862.

Malvicini, L. y Delpino, D. 1989. Metalogénesis de los complejos riolíticos de la provincia geológica sanrafaelino pampeana y la comarca norpatagónica, Argentina Procesos metalogenéticos. Universidad Nacional de Tucumán. Serie Correlación Geológica 3: 63-82.

Mazzarini, F. 2004. Volcanic vent self-similar clustering y crustal thickness in the northern Main Ethiopian Rift. Geophysical Research Letters 3: L04604, http://dx.doi.org/10.1029/2003GL018574.

McClay, K.R., Dooley, T., Whitehouse, P. y Mills, M. 2002. 4-D evolution of rift systems: Insights from scaled physical models. The American Association of Petroleum Geologists, AAPG bulletin 86 (6): 935-960.

McPhie, J., Doyle, M. y Allen, R. 1993. Volcanic textures: a Guide to the Interpretation of Textures in Volcanic Rocks. CODES Key Centre, University of Tasmania Center for Ore Deposit y Exploration Studies, 198 p., Hobart, Australia.

Miall, A.D., 1992. Alluvial deposits. En: Walker, R.G. y James, N.P. (Eds.) Facies Models: Response to Sea Level Change. Geological Association of Canada, pp. 119-142, Toronto. 
Miall, A.D. 1996. The Geology of Fluvial Deposits: Sedimentary Facies, Basin Analysis, y Petroleum Geology. Springer Verlag. 582 p., Berlín.

Middlemost, E.A. 1994. Naming materials in the magma/igneous rock system. Earth-Science Reviews 37 (3): 215-224.

Milana, J.P. y Alcober, O. 1995. Modelo tectosedimentario de la cuenca triásica de Ischigualasto (San Juan, Argentina). Revista de la Asociación Geológica Argentina 49 (3-4): 217-235

Moratello, J.H. 1993. Cuenca Cuyana. Geología y recursos naturales de Mendoza $12^{\circ}$ Congreso Geológico Argentino y $2^{\circ}$ Congreso Exploratorio de Hidrocarburos, Tomo 3 (1): 367-375.

Morel, E.M. y Artabe, A.E. 1993. Floras mesozoicas. En: Ramos, V.A. (Ed.) Geología y Recursos Naturales de Mendoza. $12^{\circ}$ Congreso Geológico Argentino y $2^{\circ}$ Congreso de Exploración de Hidrocarburos. Relatorio 2 (10): 317-324, Mendoza.

Morel, E.M. y Artabe, A.E. 1994. La "Flora de Pleuromeia" en la Formación Puesto Viejo (Triásico) de la Provincia de Mendoza, Argentina. $6^{\circ}$ Congreso Argentino de Paleontología y Bioestratigrafía. Resúmenes 4 . Trelew.

Morel, E.M., Artabe, A.E., Zavattieri, A.M. y Bonaparte, J.F. 2001. Cronología del Sistema Triásico. En: Artabe, A.E., Morel y E.M., Zamuner, A.B. (Eds.) El Sistema Triásico en la Argentina. Fundación Museo de la Plata "Francisco Pascasio Moreno": 227-253, La Plata.

Morel, E.M., Artabe, A.E. y Spalletti, L.A. 2003. Triassic floras of Argentina: biostratigraphy, floristic events y comparison with other areas of Gondwana y Laurasia. Alcheringa: An Australasian Journal of Palaeontology 27 (3): 231 243.

Moreno Peral, C.A. y Salvarredi J.A. 1984. Interpretación del origen de las estructuras anticlinales del Pérmico inferior en el bloque de San Rafael, Provincia de Mendoza. $9^{\circ}$ Congreso Geológico Argentino, Actas 2: 396-413, San Carlos de Bariloche.

Morley, C.K. 1995. Developments in the structural geology of rifts over the last decade y their impact on hydrocarbon exploration. Geological Society, London, Special Publications 80 (1): 1-32.

Morley, C.K. 1999a. Influence of Preexisting Fabrics on Rift Structure. En: Morley, C.K. (Ed.) Geoscience of Rift Systems - Evolution of East Africa, The American Association of Petroleum Geologists, AAPG Studies in Geology 44: 151-160.

Morley, C.K. 1999b. Aspects of Transfer Zone Geometry y Evolution in East African Rifts. En: Morley, C.K. (Ed.) Geoscience of Rift Systems - Evolution of East Africa, The American Association of Petroleum Geologists, AAPG Studies in Geology 44: 161- 171. 
Morley, C.K.., Haranya C., Phoosongsee W., Pongwapee S., Kornsawan A., Wonganan N. 2004. Activation of rift oblique and rift parallel pre-existing fabrics during extension and their effect on deformation style: examples from the rifts of Thailand. Journal of Structural Geology 26 (2004) 1803-1829.

Morley, C.K. 2010. Stress re-orientation along zones of weak fabrics in rifts: An explanation for pure extension in 'oblique'rift segments?. Earth y Planetary Science Letters 297 (3): 667-673.

Muravchik, M., Bilmes, A., D'Elia, L. y Franzese, J.R. 2014. Alluvial fan deposition along a rift depocentre border from the Neuquén Basin, Argentina. Sedimentary Geology, 301, 70-89.

Narciso, V., Zanettini, E., Sepúlveda, E., Mallimacci, H.S. 2001. Hoja Geológica 3769-Il Agua Escondida, provincias de Mendoza y La Pampa. Programa Nacional de Cartas Geológicas 1:250.000. Servicio Geológico Minero Argentino: 64p., Buenos Aires.

Nuñez, E. 1976. Descripción Geológica de la Hoja 28c El Nihuil (Provincia de Mendoza). Dirección Nacional de Minería, Inédita, Buenos Aires.

Ottone, E.G. y García, G.B. 1991. A Lower Triassic miosphere assemblage from the Puesto Viejo Formation, Argentina. Review of Paleobotany $y$ Palynology 68: 217-232.

Ottone, E.G, Monti, M., Marsicano, C., De la Fuente, M., Naipauer, M., Armstrong, R. y Mancuso, A. 2014a. Una edad U-Pb SHRIMP (Carniano) para el Gripo Puesto Viejo, depocentro de San Rafael. $19^{\circ}$ Congreso Geológico Argentino, Córdoba.

Ottone, E.G., Monti, M., Marsicano, C.A., Marcelo, S., Naipauer, M., Armstrong, R. y Mancuso, A.C. 2014b. A new Late Triassic age for the Puesto Viejo Group (San Rafael depocenter, Argentina): SHRIMP U-Pb zircon dating y biostratigraphic correlations across southern Gondwana. Journal of South American Earth Sciences 56: 186-199.

Pankhurst, R.J., Rapela, C.W., Caminos, R., Llambías, E.J. y Párica, C., 1992. A revised age for the granites of the central Somuncura batholith, North Patagonian Massif. Journal of South American Earth Sciences 5: 321-325.

Peacock, D.C.P. 2002. Propagation, interaction y linkage in normal fault systems. Earth-Science Reviews 58 (1): 121-142.

Petit, C., Déverchère, J., Houdry, F., Sankov, V. A., Melnikova, V. I. y Delvaux, D. 1996. Present-day stress field changes along the Baikal rift y tectonic implications. Tectonics 15 (6): 1171-1191.

Plint, A.G. y Browne, G.H. 1994. Tectonic event stratigraphy in a fluviolacustrine, strike-slip setting: the Boss Point Formation (Westphalian A), Cumberly Basin, Maritime Canada. Journal of Sedimentary Research 64 (3): 341-364. 
Posamentier, H. y Walker, R. 2006. Facies Models Revisited. Posamentier, H. y Walker, R. (Eds.) Society for Sedimentary Geology (SEPM), Special Publication 84: $527 \mathrm{p}$.

Putirka K., Jean M., Cousens B., Sharma R., Torrez G., Carlson C., 2012. Cenozoic volcanism in the Sierra Nevada y Walker lane, California, y a new model for lithosphere degradation: Geosphere (8). 265-29.

Ramos, V.A. 1992. Control geotectónico de las cuencas triásicas de Cuyo. Boletín de Informaciones Petroleras, Tercera época 9 (31): 2-9.

Ramos, V.A., 1993. Interpretación tectónica. En: Ramos, V. A. (Ed.) Geología y Recursos Naturales de Mendoza. $12^{\circ}$ Congreso Geológico Argentino, Relatorio: 257-266, Mendoza.

Ramos, V.A y Kay, S.M. 1991. Triassic rifting y associated basalts in the cuyo basin, Central Argentina. En: Harmon, R.S. y Rapela, C.W. (Eds.) Yean Magmatism y its Tectonics Settting. Geological Society of America, Special Paper 5 (265): 79-91.

Ramos, V., 2004. Cuyania, an Exotic Block to Gondwana: Review of a Historical Success and the Present Problems. Gondwana Research, V 7, No. 4, pp. 1009-1026.

Rapela, C.Q. y Alonso, G. 1991. Composición litológica y geoquímica del Batolito de la Patagonia Central. Em: Congreso Geológico Chileno №6, Actas 1: 236-240, Viña del Mar.

Rapela, C.W., Dias, G.F., Franzese, J.R., Alonso, G. y Benvenuto, A.R. 1991. El Batollto de la Patagonia Central: evidencias de un magmatismo TriasicoJurasico asociado a fallas transcurrentes. Yean Geology 18 (2): 121-138.

Rapela, C.W., Pankhurst, R.J. y Harrison, S.M. 1992. Triassic "Gondwana" granites of the Gastre district, north Patagonian massif. Geological Society of America Special Papers 272, 291-304.

Reading, H.G. 1978. Sedimentary Environments y Facies. Blackwell Scientific Publications, 576 p., Oxford, U.K.

Retallack, G.J. 1977. Reconstructing Triassic vegetation of eastern Australasia: a new approach for the biostratigraphy of Gondwanaly. Alcheringa 1: 247277.

Retallack, G.J. 2001. Cenozoic expansion of grasslys y climatic cooling. The Journal of Geology 109 (4): 407-426.

Rocha-Campos, A.C., Basei, M.A., Nutman, A.P., Kleiman, L.E, Varela, R., Llambias, E., Canile, F.M. y da Rosa, O.C.R. 2011. 30 million years of Permian volcanism recorded in the Choiyoi igneous province (W Argentina) y their source for younger ash fall deposits in the Paraná Basin: SHRIMP U-Pb zircon geochronology evidence. Gondwana Research 19: 509-523. Rudnick, 
R.L. y Gao, S. 2003. Composition of the continental crust. Treatise on geochemistry 3: 1-64.

Salvarredi, J. 1996. Caldera del Potrerito. Sección Superior del Grupo Choiyoi. Bloque de San Rafael (Mendoza). $13^{\circ}$ Congreso Geológico Argentino, Actas 1: 347.

Schlische, R.W. 1991. Half-graben basin filling models: new constraints on continental extensional basin development. Basin Research 3 (3): 123-141.

Schlische, R.W. 1995. Geometry y origin of fault-related folds in extensional settings. The American Association of Petroleum Geologists, AAPG bulletin 79 (11): 1661-1678.

Sepúlveda, E.G. 2001. Geología. En: Carpio, F. (Coord.) Metalogenia del Bloque de San Rafael, Mendoza. Recursos Minerales 20, Servicio Geológico Minero Argentino: 10-32, Buenos Aires.

Sepúlveda, E.G., Carpio, F.W., Regairaz, M.C., Zárate, M. y Zanettini, J.C.M. 2007. Boletín 321, Hoja Geológica 3569-2, San Rafael. Servicio Geológico Minero Argentino.

Smith, G.A. 1991. Facies sequences y geometries in continental volcaniclastic sediments. Sedimentatian in Volcanic Settings, Fisher, R.V. y Smith, G.A. (Eds.) Society for Sedimentary Geology (SEPM), Special Publication 45: 109-121.

Smith, G.A. y Lowe, D.R. 1991. Lahars; volcano-hydrologic events y deposition $y$ the debris flow-hyperconcentrated flow continuum. En: Sedimentation in Volcanic Settings. Fisher, R.V. y Smith, G.A. (Eds.) Special Publication of Society of Economic Paleontologists y Mineralogists 45: 59-70.

Spalletti, L.A., 1994. Evolución de los ambientes fluviales en el Triásico de la Sierra Pintada (Mendoza, Argentina): análisis sobre la influencia de controles intrínsecos y extrínsecos al sistema depositacional. Revista de la Asociación Argentina de Sedimentología 1: 125-142.

Spalletti, L.A. 1995. Controles sobre el desarrollo y evolución de los sistemas fluviales en el Triásico de la Sierra Pintada, Provincia de Mendoza, República Argentina.

Spalletti, L.A., 1999. Cuencas triásicas del Oeste argentino: origen y evolución. Acta Geológica Hispánica 32 (1-2): 29-50.

Spalletti, L.A., 2001. Evolución de las cuencas sedimentarias. En: Artabe, A.E., Morel, E.M., Zamuner, A.B. (Eds.), El Sistema Triásico en la Argentina. Fundación Museo de la Plata "Francisco Pascasio Moreno", La Plata, pp. 81101.

Spalletti, L.A., Artabe, A.E., Brea, M. y Ganuza, D.G. 1995. Ambientes de acumulación y paleoflora en capas rojas triásicas de la Cuenca Cuyana, Mendoza. Revista de la Asociación Geológica Argentina 50: 175-178. 
Spalletti, L.A., Merodio, J.C., Matheos, S.D. e Iñíguez Rodríguez, A.M. 1996. Petrología y geoquímica de sedimentitas silicoclásticas triásicas de la Sierra Pintada, Provincia de Mendoza. Revista de la Asociación Geológica Argentina 51 (1): 51-60.

Spalletti, L.A., Artabe, A.E., Morel, E.M. y Brea, M. 1999. Biozonación paleoflorística y cronoestratigrafía del Triásico Argentino. Ameghiniana 36: 419-451.

Spalletti, L.A., Morel, E.M., Artabe, A.E., Zavattieri, A. M. y Ganuza, D. 2005. Estratigrafía, facies y paleoflora de la sucesión triásica de Potrerillos, Mendoza, República Argentina. Revista geológica de Chile 32 (2): 249-272.

Spalletti, L.A., Fanning, C.M. y Rapela, C.W., 2008. Dating the Triassic continental rift in the southern Yes: the Potrerillos Formation, Cuyo Basin, Argentina. Geológica Acta 6: 267-283.

Stipanicic, P.N. 1969. Las sucesiones triásicas argentinas. $1^{\circ}$ Coloquio de la UICG: La estratigrafía del Gondwana. UNESCO, Ciencias de la Tierra 2: 1121-1149, Buenos Aires.

Stipanicic, P.N., 1979. El Triásico de valle del río de Los Patos (provincia de San Juan). En: Turner, J.C.M. (Ed.), $2^{\circ}$ Simposio de Geología Regional Argentina. Academia Nacional de Ciencias 1: 695-744, Córdoba.

Stipanicic, P.N. y Marsicano, C.A. 2002. En: Stipanicic, P.N. y Marsicano, C.A, (Eds.) Léxico Estratigráfico de la Argentina (8). Triásico. Asociación Geológica Argentina, Serie "B" (Didáctica y Complementaria) 26: 226-229, Buenos Aires.

Stipanicic, P.N., Bonaparte, J.F., Morel, E.M., Kleiman, L.E., 2002. Formación Puesto Viejo. En: Stipanicic, P.N. y Marsicano, C.A. (Eds.) Léxico Estratigráfico de la Argentina, Triásico 8. Asociación Geológica Argentina, Serie "B" (Didáctica y Complementaria) 26: 226-229, Buenos Aires.

Stipanicic, P.N., González Díaz, E.F. y Zavattieri, A.M. 2007. Grupo Puesto Viejo nom. transt. por Formación Puesto Viejo González Díaz (1994, 1967): nuevas interpretaciones paleontológicas, estratigráficas y cronológicas. Ameghiniana - Revista de la Asociación Paleontológica Argentina 44 (4): 759-761.

Sun, S.S. y McDonough, W. 1989. Chemical y isotopic systematics of oceanic basalts: implications for mantle composition y processes. Geological Society, London, Special Publications 42 (1): 313-345.

Tankard, A.J., Soruco, R.S., Welsink, H.J. 1995. Petroleum Basins of South America. American Association Petroleum Geologists. Memoria 62: 792 p.

Tassi, L.V., Monti, M., Gallego, O.F., Zavattieri, A.M., y Lara, M.B. 2013. The first spinicaudatan (Crustacea: Diplostraca) from Permo-Triassic continental sequences of South America y its palaeoecological context. Alcheringa: An Australasian Journal of Palaeontology 37 (2): 189-201. 
Tommasi, A. y Vauchez, A. 2001. Continental rifting parallel to ancient collisional belts: an effect of the mechanical anisotropy of the lithospheric mantle. Earth y Planetary Science Letters 185 (1): 199-210.

Tomezzoli, R.N., Kleiman, L., Salvarredi, J., Terrizzano, C. y Cristallini, E.O. 2005. Relaciones estratigráficas de volcanitas del Choiyoi Inferior sobre la base de estudios paleomagnéticos, Bloque de San Rafael, Mendoza, Argentina. $16^{\circ}$ Congreso Geológico Argentino. Actas 1:227-232, La Plata.

Trumpy, E. 1940. Probable extensión de la cuenca Rética de Mendoza. Y.P.F. Informe Interno (Inédito), Buenos Aires.

Truempy E. y Lhez R., 1937. División estratigráfica de los terrenos aflorantes en la región comprendida entre Luján de Cuyo, Potrerillos y Tupungato. Boletín de Informaciones Petroleras, 152: 39-56. Buenos Aires.

Tucker, M. 2001. Sedimentary Petrology. 3rd Blackwell Science, 262 p.

Uliana, M.A. y Biddle, K.T. 1987. Permian y late Cenozoic evolution of northern Patagonia. Main tectonic events, magmatic activity y depositional trends. En: McKenzie, G.D. (Ed.) Gondwana Six. Structure, tectonics, y geophysics. American Geophysical Union. Geophysical Monography 40: 271-286, Washington.

Uliana, M.A. y Biddle, K.T. 1988. Mesozoic- Cenozoic paleogeographic y geodynamic evolution of southern South America. Revista Brasileira de Geociências 18(2): 172-190.

Uliana, M.A., Biddle, K.T. y Cerdan, J. 1989, Mesozoic extension y the formation of Argentine sedimentary basins. American Association of Petroleum Geologists. Memoir 46: 599-614.

Uliana, M., Arteaga, M., Legarreta, L., Cerdán, J. y Peroni, G. 1995. Inversion structures y hydrocarbon occurrence in Argentina. En: Buchanan y Buchanan (Eds.): Basin Inversion. Geologic Society Special Publication 88: 211-233, Londres.

Valencio, D.A., Mendía, J.E. y Vilas, J.F. 1975. Paleomagnetism y K-Ar ages of triassic igneous rocks from the Ischigualasto-Ischichuca basin y Puesto Viejo Formation, Argentina. Earth y Planetary Science Letters 26: 319-330.

Vázquez, M.S., Ottone, E.G. y Zavattieri, A.M., 2012. Palinomorfos triásicos de la Formación Quebrada de los Fósiles, Grupo Puesto Viejo, en Río Seco de la Quebrada, Bloque de San Rafael, Mendoza. Ameghiniana 49: 120R.

Veiga, G.D. 2002. Evolución paleogeográfica y paleoambiental de los depósitos continentales del Jurásico Medio en el sector austral de la Cuenca Neuquina, República Argentina. Revista de la Asociación Argentina de Sedimentología 9 (1): 83-108.

Veiga, G.D., Spalletti, L.A. y Flint, S. 2002. Aeolian/fluvial interactions y high-resolution sequence stratigraphy of a non-marine lowsty wedge: the 
Avilé Member of the Agrio Formation (Lower Cretaceous), central Neuquén Basin, Argentina. Sedimentology 49 (5): 1001-1019.

Williams, H. y McBirney, A. R. 1979. Vulcanology. Freeman, Cooper y Company: 397 p., San Francisco, California.

Winchester, J.A. y Floyd, P.A. 1977. Geochemical discrimination of different magma series y their differentiation products using immobile elements. Chemical geology 20: 325-343.

Young, M.J., Gawthorpe, R.L. y Hardy, S. 2001. Growth y linkage of a segmented normal fault zone; the Late Jurassic Murchison-Statfjord North Fault, northern North Sea. Journal of Structural Geology 23 (12): 1933-1952.

Zavattieri, A. M., 2002. Aspectos biogeográficos y paleoclimáticos de las sucesiones triásicas de Argentina en base a registros palinológicos. Informe Interno. (Inédito).

Zavattieri, A.M. y Arcucci, A.B. 2007. Age y stratigraphic position of the tetrapods from the cerro Bayo at Potrerillos locality (Triassic), Mendoza, Argentina. Ameghiniana 44 (1): 133-142.

Zavattieri, A.M. y Batten, D.J. 1996. Miospores from Argentinian Triassic deposits $y$ their potential for intercontinental correlation. En: Jansonius, J. y McGregor, D.C. (Eds.) Palynology: principles y applications. American Association of Stratigraphic Palynologists Foundation 2, College Station: 767-778.

Zavattieri, A. y Rojo, L. 2005. Estudio microflorístico de las Formaciones Potrerillos y Cacheuta (Triásico) en el sur del cerro Cacheuta, Mendoza, Argentina. Parte 2. Ameghiniana 42 (3): 513-534.

Zamuner, A.B., Zavattieri, A.M., Artabe, A.E. y Morel, E.M. 2001. Paleobotánica. En: Artabe, A.E., Morel, E.M. y Zamuner, A.B. (Eds.) El Sistema Triásico en la Argentina. Fundación Museo de La Plata "Francisco Pascasio Moreno": 143-184, La Plata.

Zavattieri, A.M., Sepúlveda, E. Morel, E.M. y Spalletti, L.A. 2003. Límite Pérmico-Triásico para la base aflorante de la Formación Puesto Viejo, Mendoza (Argentina), en base a su contenido palinológico. Ameghiniana 40: $17 R$. 
ANEXOS

ANEXO 1

TABLA DE DATOS ESTRUCTURALES 
Fallas Principales de borde

\begin{tabular}{|c|c|c|c|c|c|c|c|}
\hline \multirow{2}{*}{\multicolumn{2}{|c|}{ Fallas de borde }} & \multirow[b]{2}{*}{ Coordenadas } & \multicolumn{5}{|c|}{ Medición } \\
\hline & & & Tipo & Azimut & RBZ & Inclinación & Raque (estriado) \\
\hline \multirow{8}{*}{$\begin{array}{c}\text { Margen } \\
\text { Este }\end{array}$} & \multirow{8}{*}{ Etapa I } & S $34^{\circ} 53,879^{\circ}$ & \multirow{8}{*}{$\begin{array}{c}\text { Fallas de } \\
\text { Rumbo } \\
\text { Sinestral }\end{array}$} & $\mathrm{N} 340^{\circ}$ & $250^{\circ}$ & $89^{\circ} \mathrm{SW}$ & \\
\hline & & W $68^{\circ} 53,150^{\circ}$ & & $\mathrm{N} 320^{\circ}$ & $230^{\circ}$ & $81^{\circ} \mathrm{SW}$ & \\
\hline & & S $44^{\circ} 54,068^{\prime}$ & & $\mathrm{N} 346^{\circ}$ & $256^{\circ}$ & $83^{\circ} \mathrm{SW}$ & \\
\hline & & W $68^{\circ} 22,998^{\prime}$ & & & & & \\
\hline & & $\mathrm{S} 34^{\circ} 54,083^{\prime}$ & & $\mathrm{N} 346^{\circ}$ & $256^{\circ}$ & $84^{\circ} \mathrm{SW}$ & $10^{\circ} \mathrm{SE}$ \\
\hline & & W $68^{\circ} 22,990^{\prime}$ & & & & & \\
\hline & & $S 34^{\circ} 54,137^{\prime}$ & & $\mathrm{N} 340^{\circ}$ & $250^{\circ}$ & $85^{\circ} \mathrm{SW}$ & $10^{\circ} \mathrm{SE}$ \\
\hline & & W $68^{\circ} 22,986^{\prime}$ & & & & & \\
\hline \multirow{4}{*}{$\begin{array}{c}\text { Margen } \\
\text { Oeste }\end{array}$} & \multirow{4}{*}{ Etapa I } & S $34^{\circ} 53,693^{\prime}$ & \multirow{4}{*}{$\begin{array}{c}\text { Fallas de } \\
\text { Rumbo } \\
\text { Sinestral }\end{array}$} & $\mathrm{N} 360^{\circ}$ & $90^{\circ}$ & $64^{\circ} \mathrm{E}$ & \\
\hline & & W $68^{\circ} 25,792^{\prime}$ & & $\mathrm{N} 355^{\circ}$ & $85^{\circ}$ & $70^{\circ} \mathrm{E}$ & \\
\hline & & S $34^{\circ} 55,069^{\prime}$ & & $\mathrm{N} 180^{\circ}$ & $90^{\circ}$ & $75^{\circ} \mathrm{E}$ & $10^{\circ} \mathrm{N}$ \\
\hline & & W $68^{\circ} 25,110^{\prime}$ & & & & & \\
\hline
\end{tabular}




\section{Fallas Internas}

\begin{tabular}{|c|c|c|c|c|c|c|}
\hline \multirow{2}{*}{$\begin{array}{l}\text { Fallas } \\
\text { internas }\end{array}$} & \multirow[b]{2}{*}{ Coordenadas } & \multicolumn{5}{|c|}{ Medición } \\
\hline & & Tipo & Azimut & RBZ & Inclinación & Raque (estriado) \\
\hline \multirow{25}{*}{ Etapa II } & S $34^{\circ} 53,458^{\prime}$ & \multirow{3}{*}{ Normal } & $\mathrm{N} 352^{\circ}$ & $82^{\circ}$ & $80^{\circ} \mathrm{NE}$ & \\
\hline & W $68^{\circ} 23,575^{\prime}$ & & $\mathrm{N} 354^{\circ}$ & $84^{\circ}$ & $80^{\circ} \mathrm{NE}$ & \\
\hline & & & $\mathrm{N} 352^{\circ}$ & $82^{\circ}$ & $80^{\circ} \mathrm{NE}$ & \\
\hline & $S 34^{\circ} 54,316^{\prime}$ & Normal & $\mathrm{N} 324^{\circ}$ & $234^{\circ}$ & $70^{\circ} \mathrm{SW}$ & \\
\hline & W 6823,190' & & & & & \\
\hline & S $34^{\circ} 54,749^{\prime}$ & \multirow[b]{4}{*}{ Normal } & $\mathrm{N} 300^{\circ}$ & $210^{\circ}$ & $55^{\circ} \mathrm{SW}$ & \\
\hline & W $68^{\circ} 23,152^{\prime}$ & & $\mathrm{N} 300^{\circ}$ & $210^{\circ}$ & $70^{\circ} \mathrm{SW}$ & \\
\hline & & & $\mathrm{N} 300^{\circ}$ & $210^{\circ}$ & $82^{\circ} \mathrm{SW}$ & \\
\hline & & & $\mathrm{N} 300^{\circ}$ & $210^{\circ}$ & $55^{\circ} \mathrm{SW}$ & \\
\hline & S $34^{\circ} 54,680^{\prime}$ & \multirow{2}{*}{ Normal-Sinestral } & $\mathrm{N} 224^{\circ}$ & $314^{\circ}$ & $86^{\circ} \mathrm{NW}$ & \\
\hline & W $68^{\circ} 23,259^{\prime}$ & & N342 ${ }^{\circ}$ & $252^{\circ}$ & $48^{\circ} \mathrm{SW}$ & \\
\hline & $\mathrm{S} 34^{\circ} 54,720^{\prime}$ & \multirow{2}{*}{ Normal } & $\mathrm{N} 125^{\circ}$ & $215^{\circ}$ & $49^{\circ} \mathrm{SW}$ & \\
\hline & W $68^{\circ} 23,451^{\prime}$ & & $\mathrm{N} 116^{\circ}$ & $26^{\circ}$ & $52^{\circ} \mathrm{NE}$ & \\
\hline & S $34^{\circ} 54,724^{\prime}$ & Normal & $\mathrm{N} 138^{\circ}$ & $228^{\circ}$ & $52^{\circ} \mathrm{SW}$ & \\
\hline & W $68^{\circ} 23,447^{\prime}$ & & & & & \\
\hline & S $34^{\circ} 54,657^{\prime}$ & Normal & $\mathrm{N} 332^{\circ}$ & & $90^{\circ}$ & \\
\hline & W $68^{\circ} 23,634^{\prime}$ & & & & & \\
\hline & $\mathrm{S} 34^{\circ} 55,131^{\prime}$ & Normal & $\mathrm{N} 140^{\circ}$ & $50^{\circ}$ & $25^{\circ} \mathrm{NE}$ & 30NW \\
\hline & W 68 25,509' & & & & & \\
\hline & S $34^{\circ} 55,037^{\prime}$ & Normal & $\mathrm{N} 142^{\circ}$ & $52^{\circ}$ & $82^{\circ} \mathrm{NE}$ & 30NW \\
\hline & W $68^{\circ} 23,335^{\prime}$ & & & & & \\
\hline & S $34^{\circ} 54,842^{\prime}$ & Normal & $\mathrm{N} 310^{\circ}$ & $40^{\circ}$ & $76 \% / 77^{\circ} \mathrm{NE}$ & $60^{\circ} / 50^{\circ} / 55^{\circ} \mathrm{NW}$ \\
\hline & W $68^{\circ} 24,534^{\prime}$ & & & & & \\
\hline & $\mathrm{S} 34^{\circ} 53,505^{\prime}$ & \multirow[b]{2}{*}{ Normal } & $\mathrm{N} 330^{\circ}$ & & $90^{\circ}$ & \\
\hline & W $68^{\circ} 23,633^{\prime}$ & & $\mathrm{N} 330^{\circ}$ & $240^{\circ}$ & $85^{\circ} \mathrm{SW}$ & \\
\hline
\end{tabular}




\begin{tabular}{|c|c|c|c|c|c|c|}
\hline \multirow{2}{*}{$\begin{array}{l}\text { Fallas } \\
\text { internas }\end{array}$} & \multirow[b]{2}{*}{ Coordenadas } & \multicolumn{5}{|c|}{ Medición } \\
\hline & & Tipo & \begin{tabular}{|l|} 
Azimut \\
\end{tabular} & RBZ & Inclinación & Raque (estriado) \\
\hline \multirow{24}{*}{ Etapa III } & S $34^{\circ} 53,465^{\circ}$ & Normal & $\mathrm{N} 192^{\circ}$ & $282^{\circ}$ & $80^{\circ} \mathrm{NW}$ & \\
\hline & W $68^{\circ} 23,790^{\circ}$ & & & & & \\
\hline & $S 34^{\circ} 53,492^{\circ}$ & \multirow{4}{*}{ Normal } & $\mathrm{N} 213^{\circ}$ & $303^{\circ}$ & $70^{\circ} \mathrm{NW}$ & \\
\hline & W $68^{\circ} 23,886^{\circ}$ & & $\mathrm{N} 220^{\circ}$ & $310^{\circ}$ & $77^{\circ} \mathrm{NW}$ & \\
\hline & & & $\mathrm{N} 230^{\circ}$ & $320^{\circ}$ & $85^{\circ} \mathrm{NW}$ & \\
\hline & & & $\mathrm{N} 222^{\circ}$ & $312^{\circ}$ & $70^{\circ} \mathrm{NW}$ & \\
\hline & S $34^{\circ} 53,458^{\prime}$ & Normal & N348 & $258^{\circ}$ & $80^{\circ} \mathrm{SW}$ & \\
\hline & W68 $23,698^{\prime}$ & & & & & \\
\hline & S $34^{\circ} 53,560^{\prime}$ & \multirow{4}{*}{ Normal } & $\mathrm{N} 327^{\circ}$ & $237^{\circ}$ & $70^{\circ} \mathrm{SW}$ & \\
\hline & W 68 $23,647^{\prime}$ & & $\mathrm{N} 320^{\circ}$ & $230^{\circ}$ & $77^{\circ} \mathrm{SW}$ & \\
\hline & & & $\mathrm{N} 310^{\circ}$ & $220^{\circ}$ & $85^{\circ} \mathrm{SW}$ & \\
\hline & & & $\mathrm{N} 318^{\circ}$ & $228^{\circ}$ & $70^{\circ} \mathrm{SW}$ & \\
\hline & S $34^{\circ} 53,647^{\prime}$ & Normal & $\mathrm{N} 332^{\circ}$ & $242^{\circ}$ & $55^{\circ} \mathrm{SW}$ & \\
\hline & $W^{\prime} 68^{\circ} 23,774^{\prime}$ & & & & & \\
\hline & S $34^{\circ} 53,977^{\circ}$ & \multirow{2}{*}{ Normal } & $\mathrm{N} 285^{\circ}$ & $15^{\circ}$ & $45^{\circ} \mathrm{NE}$ & $16^{\circ} / 17^{\circ} \mathrm{NW}$ \\
\hline & W $68^{\circ} 23,930^{\circ}$ & & $\mathrm{N} 315^{\circ}$ & $45^{\circ}$ & $29^{\circ} \mathrm{NE}$ & $45^{\circ} / 54^{\circ} \mathrm{NW}$ \\
\hline & $\mathrm{S} 34^{\circ} 54,150^{\prime}$ & Normal & $\mathrm{N} 285^{\circ}$ & $195^{\circ}$ & $75^{\circ} \mathrm{SW}$ & \\
\hline & W $68^{\circ} 23,299^{\prime}$ & & & & & \\
\hline & $\mathrm{S} 34^{\circ} 54,044^{\prime}$ & Normal & $\mathrm{N} 322^{\circ}$ & $232^{\circ}$ & $85^{\circ} \mathrm{SW}$ & \\
\hline & W $68^{\circ} 23,750^{\prime}$ & & & & & \\
\hline & $S 34^{\circ} 53,963^{\prime}$ & Normal Reactivada & $\mathrm{N} 155^{\circ}$ & $65^{\circ}$ & $69^{\circ} \mathrm{NE}$ & \\
\hline & $\begin{array}{c}\text { W } 68^{\circ} 25 \\
600^{\prime}\end{array}$ & & & & & \\
\hline & S $34^{\circ} 53,999^{\prime}$ & Normal & $\mathrm{N} 136^{\circ}$ & $46^{\circ}$ & $64^{\circ} \mathrm{NE}$ & $70^{\circ} \mathrm{NW}$ \\
\hline & W $68^{\circ} 25,622^{\prime}$ & & $\mathrm{N} 140^{\circ}$ & $50^{\circ}$ & $60^{\circ} \mathrm{NE}$ & \\
\hline \multirow{4}{*}{ Etapa IV } & S $34^{\circ} 54,005^{\prime}$ & Normal & $\mathrm{N} 254^{\circ}$ & $344^{\circ}$ & $56^{\circ} \mathrm{NW}$ & \\
\hline & W $68^{\circ} 24,640^{\prime}$ & & & & & \\
\hline & S $34^{\circ} 53,361^{\prime}$ & Normal & $\mathrm{N} 295^{\circ}$ & $25^{\circ}$ & $35^{\circ} \mathrm{NE}$ & \\
\hline & W 68 $25,178^{\prime}$ & & & & & \\
\hline
\end{tabular}




\section{Fallas menores}

\begin{tabular}{|c|c|c|c|c|c|}
\hline \multirow{2}{*}{$\begin{array}{l}\text { Fallas } \\
\text { menores }\end{array}$} & \multirow[b]{2}{*}{ Coordenadas } & \multicolumn{4}{|c|}{ Medición } \\
\hline & & Tipo & Azimut & RBZ & Inclinación \\
\hline \multirow{34}{*}{ Etapa II } & S $34^{\circ} 54,882^{\prime}$ & \multirow{8}{*}{ Normal } & $\mathrm{N} 240^{\circ}$ & $330^{\circ}$ & $60^{\circ} \mathrm{NW}$ \\
\hline & W $68^{\circ} 24,224^{\prime}$ & & $\mathrm{N} 258^{\circ}$ & $168^{\circ}$ & $50^{\circ} \mathrm{SE}$ \\
\hline & & & $\mathrm{N} 290^{\circ}$ & $200^{\circ}$ & $40^{\circ} \mathrm{SW}$ \\
\hline & & & $\mathrm{N} 284^{\circ}$ & $194^{\circ}$ & $60^{\circ} \mathrm{SW}$ \\
\hline & & & $\mathrm{N} 110^{\circ}$ & $20^{\circ}$ & $70^{\circ} \mathrm{NE}$ \\
\hline & & & $\mathrm{N} 272^{\circ}$ & $182^{\circ}$ & $35^{\circ} \mathrm{SW}$ \\
\hline & & & $\mathrm{N} 118^{\circ}$ & $28^{\circ}$ & $50^{\circ} \mathrm{NE}$ \\
\hline & & & $\mathrm{N} 292^{\circ}$ & $202^{\circ}$ & $60^{\circ} \mathrm{SW}$ \\
\hline & S $34^{\circ} 54,834^{\prime}$ & \multirow{3}{*}{ Normal } & N232 & $322^{\circ}$ & $55^{\circ} \mathrm{NW}$ \\
\hline & $\begin{array}{l}\text { W 68 23, } \\
881^{\prime}\end{array}$ & & $\mathrm{N} 304^{\circ}$ & $214^{\circ}$ & $70^{\circ} \mathrm{SW}$ \\
\hline & & & N308 ${ }^{\circ}$ & $218^{\circ}$ & $70^{\circ} \mathrm{SW}$ \\
\hline & S $34^{\circ} 54,798^{\prime}$ & \multirow{4}{*}{ Normal } & $\mathrm{N} 218^{\circ}$ & $308^{\circ}$ & $60^{\circ} \mathrm{NW}$ \\
\hline & W $68^{\circ} 23,778^{\prime}$ & & $\mathrm{N} 350^{\circ}$ & $260^{\circ}$ & $65^{\circ} \mathrm{SW}$ \\
\hline & & & $\mathrm{N} 348^{\circ}$ & $258^{\circ}$ & $85^{\circ} \mathrm{SW}$ \\
\hline & & & N332 ${ }^{\circ}$ & $242^{\circ}$ & $85^{\circ} \mathrm{SW}$ \\
\hline & S $34^{\circ} 54,787^{\prime}$ & \multirow{3}{*}{ Normal } & $\mathrm{N} 348^{\circ}$ & $258^{\circ}$ & $80^{\circ} \mathrm{SW}$ \\
\hline & $W^{\prime} 68^{\circ} 23,689^{\prime}$ & & $\mathrm{N} 236^{\circ}$ & $226^{\circ}$ & $60^{\circ} \mathrm{SW}$ \\
\hline & & & $\mathrm{N} 314^{\circ}$ & $224^{\circ}$ & $62^{\circ} \mathrm{SW}$ \\
\hline & S $34^{\circ} 54,773^{\prime}$ & \multirow{2}{*}{ Normal } & N262 ${ }^{\circ}$ & $352^{\circ}$ & $60^{\circ} \mathrm{SW}$ \\
\hline & W68 $23,681^{\prime}$ & & & & \\
\hline & S $34^{\circ} 54,756^{\prime}$ & \multirow{2}{*}{ Normal } & $\mathrm{N} 280^{\circ}$ & $190^{\circ}$ & $65^{\circ} \mathrm{SW}$ \\
\hline & W $68^{\circ} 23,669^{\prime}$ & & $\mathrm{N} 292^{\circ}$ & $202^{\circ}$ & $45^{\circ} \mathrm{SW}$ \\
\hline & $S 34^{\circ} 54,751^{\prime}$ & \multirow[b]{2}{*}{ Normal } & $\mathrm{N} 110^{\circ}$ & $20^{\circ}$ & $45^{\circ} \mathrm{NE}$ \\
\hline & $\begin{array}{l}\text { W 68 } 23 \\
664^{\prime}\end{array}$ & & & & \\
\hline & S $34^{\circ} 54,655^{\prime}$ & \multirow{10}{*}{ Normal } & N332 ${ }^{\circ}$ & $242^{\circ}$ & $55^{\circ} \mathrm{SW}$ \\
\hline & W $68^{\circ} 23,632^{\prime}$ & & $\mathrm{N} 300^{\circ}$ & $210^{\circ}$ & $50^{\circ} \mathrm{SW}$ \\
\hline & & & $\mathrm{N} 140^{\circ}$ & $50^{\circ}$ & $75^{\circ} \mathrm{NE}$ \\
\hline & & & N328 ${ }^{\circ}$ & $238^{\circ}$ & $75^{\circ} \mathrm{SW}$ \\
\hline & & & $\mathrm{N} 154^{\circ}$ & $64^{\circ}$ & $40^{\circ} \mathrm{NE}$ \\
\hline & & & $\mathrm{N} 324^{\circ}$ & $234^{\circ}$ & $72^{\circ} \mathrm{SW}$ \\
\hline & & & $\mathrm{N} 162^{\circ}$ & $72^{\circ}$ & $60^{\circ} \mathrm{NE}$ \\
\hline & & & $\mathrm{N} 200^{\circ}$ & $110^{\circ}$ & $78^{\circ} \mathrm{SE}$ \\
\hline & & & $\mathrm{N} 143^{\circ}$ & $53^{\circ}$ & $83^{\circ} \mathrm{NE}$ \\
\hline & & & $\mathrm{N} 146^{\circ}$ & $56^{\circ}$ & $72^{\circ} \mathrm{NE}$ \\
\hline
\end{tabular}




\begin{tabular}{|c|c|c|c|c|c|}
\hline \multirow{2}{*}{$\begin{array}{c}\text { Fallas } \\
\text { menores }\end{array}$} & \multirow[b]{2}{*}{ Coordenadas } & \multicolumn{4}{|c|}{ Medición } \\
\hline & & Tipo & Azimut & RBZ & Inclinación \\
\hline \multirow{14}{*}{ Etapa II } & S $34^{\circ} 54,718^{\prime}$ & \multirow{12}{*}{ Normal } & $\mathrm{N} 308^{\circ}$ & $218^{\circ}$ & $50^{\circ} \mathrm{SW}$ \\
\hline & W $68^{\circ} 23,461^{\prime}$ & & $\mathrm{N} 324^{\circ}$ & $234^{\circ}$ & $70^{\circ} \mathrm{SW}$ \\
\hline & & & $\mathrm{N} 322^{\circ}$ & $232^{\circ}$ & $65^{\circ} \mathrm{SW}$ \\
\hline & & & $\mathrm{N} 120^{\circ}$ & $30^{\circ}$ & $62^{\circ} \mathrm{NE}$ \\
\hline & & & $\mathrm{N} 318^{\circ}$ & $228^{\circ}$ & $65^{\circ} \mathrm{SW}$ \\
\hline & & & $\mathrm{N} 100^{\circ}$ & $10^{\circ}$ & $50^{\circ} \mathrm{NE}$ \\
\hline & & & $\mathrm{N} 104^{\circ}$ & $14^{\circ}$ & $50^{\circ} \mathrm{NE}$ \\
\hline & & & $\mathrm{N} 300^{\circ}$ & $210^{\circ}$ & $80^{\circ} \mathrm{SW}$ \\
\hline & & & $\mathrm{N} 114^{\circ}$ & $24^{\circ}$ & $52^{\circ} \mathrm{NE}$ \\
\hline & & & $\mathrm{N} 110^{\circ}$ & $20^{\circ}$ & $66^{\circ} \mathrm{NE}$ \\
\hline & & & $\mathrm{N} 104^{\circ}$ & $14^{\circ}$ & $46^{\circ} \mathrm{NE}$ \\
\hline & & & $\mathrm{N} 313^{\circ}$ & $223^{\circ}$ & $62^{\circ} \mathrm{SW}$ \\
\hline & S 34 $54,718^{\prime}$ & Normal & $\mathrm{N} 320^{\circ}$ & $230^{\circ}$ & $60^{\circ} \mathrm{SW}$ \\
\hline & W $68^{\circ} 23,451^{\prime}$ & & & & \\
\hline
\end{tabular}




\section{Inversión Cenozoica}

\begin{tabular}{|c|c|c|c|c|c|c|}
\hline \multirow{2}{*}{$\begin{array}{l}\text { Fallas } \\
\text { internas }\end{array}$} & \multirow[b]{2}{*}{ Coordenadas } & \multicolumn{5}{|c|}{ Medición } \\
\hline & & Tipo & Azimut & RBZ & Inclinación & Raque (estriado) \\
\hline \multirow{23}{*}{$\begin{array}{l}\text { Inversión } \\
\text { Cenozoica }\end{array}$} & S $34^{\circ} 55,037^{\prime}$ & Inversa & $\mathrm{N} 110^{\circ}$ & $20^{\circ}$ & $30^{\circ} \mathrm{NE}$ & \\
\hline & W $68^{\circ} 23,335^{\prime}$ & & & & & \\
\hline & $S 34^{\circ} 53,977^{\circ}$ & \multirow{7}{*}{ Inversa } & $\mathrm{N} 334^{\circ}$ & $64^{\circ}$ & $57^{\circ} \mathrm{NE}$ & $20^{\circ} / 15^{\circ} / 29^{\circ} \mathrm{NW}$ \\
\hline & W $68^{\circ} 23,930^{\circ}$ & & $\mathrm{N} 315^{\circ}$ & $45^{\circ}$ & $42^{\circ} \mathrm{NE}$ & $25^{\circ} / 27^{\circ} \mathrm{NW}$ \\
\hline & & & $\mathrm{N} 310^{\circ}$ & $40^{\circ}$ & $39^{\circ} \mathrm{NE}$ & $30^{\circ} / 29^{\circ} \mathrm{NW}$ \\
\hline & & & $\mathrm{N} 300^{\circ}$ & $30^{\circ}$ & $34^{\circ} \mathrm{NE}$ & $31^{\circ} / 32^{\circ} \mathrm{NW}$ \\
\hline & & & $\mathrm{N} 300^{\circ}$ & $30^{\circ}$ & $45^{\circ} \mathrm{NE}$ & $28^{\circ} / 27^{\circ} \mathrm{NW}$ \\
\hline & & & $\mathrm{N} 315^{\circ}$ & $45^{\circ}$ & $51^{\circ} \mathrm{NE}$ & $20 \% 15^{\circ} \mathrm{NW}$ \\
\hline & & & N315 & $45^{\circ}$ & $35^{\circ} \mathrm{NE}$ & $43^{\circ} \mathrm{NW}$ \\
\hline & S $34^{\circ} 54,150^{\prime}$ & Inversa y Dextral & N95 & $185^{\circ}$ & $65^{\circ} \mathrm{SW}$ & \\
\hline & W $68^{\circ} 23,299^{\prime}$ & & & & & \\
\hline & S $34^{\circ} 53,956^{\prime}$ & \multirow[b]{4}{*}{ Inversas } & $\mathrm{N} 102^{\circ}$ & $12^{\circ}$ & $36^{\circ} \mathrm{NE}$ & \\
\hline & W 68 $25,593^{\prime}$ & & $\mathrm{N} 127^{\circ}$ & $37^{\circ}$ & $40^{\circ} \mathrm{NE}$ & \\
\hline & & & $\mathrm{N} 135^{\circ}$ & $45^{\circ}$ & $39^{\circ} \mathrm{NE}$ & \\
\hline & & & $\mathrm{N} 122^{\circ}$ & $32^{\circ}$ & $40^{\circ} \mathrm{NE}$ & \\
\hline & S $34^{\circ} 53,963^{\prime}$ & Inversa & $\mathrm{N} 202^{\circ}$ & $292^{\circ}$ & $30^{\circ} \mathrm{SW}$ & \\
\hline & $\begin{array}{c}W 68^{\circ} 25 \\
600^{\prime}\end{array}$ & & & & & \\
\hline & S $34^{\circ} 52,876^{\prime}$ & Inversa & $\mathrm{N} 305^{\circ}$ & $35^{\circ}$ & $<30^{\circ} \mathrm{NE}$ & \\
\hline & W $68^{\circ} 24,999^{\prime}$ & & & & & \\
\hline & $\mathrm{S} 34^{\circ} 52,538$ & Normal Reactivada & $\mathrm{N} 25^{\circ}$ & $295^{\circ}$ & $30^{\circ} \mathrm{NW}$ & \\
\hline & W $68^{\circ} 23,966^{\prime}$ & & & & & \\
\hline & S $34^{\circ} 54,728^{\prime}$ & Inversa & $\mathrm{N} 280^{\circ}$ & $190^{\circ}$ & $80^{\circ} \mathrm{SW}$ & \\
\hline & W $68^{\circ} 23,668^{\prime}$ & & & & & \\
\hline
\end{tabular}




\section{ANEXO 2}

\section{PERFILES SEDIMENTOLÓGICOS}




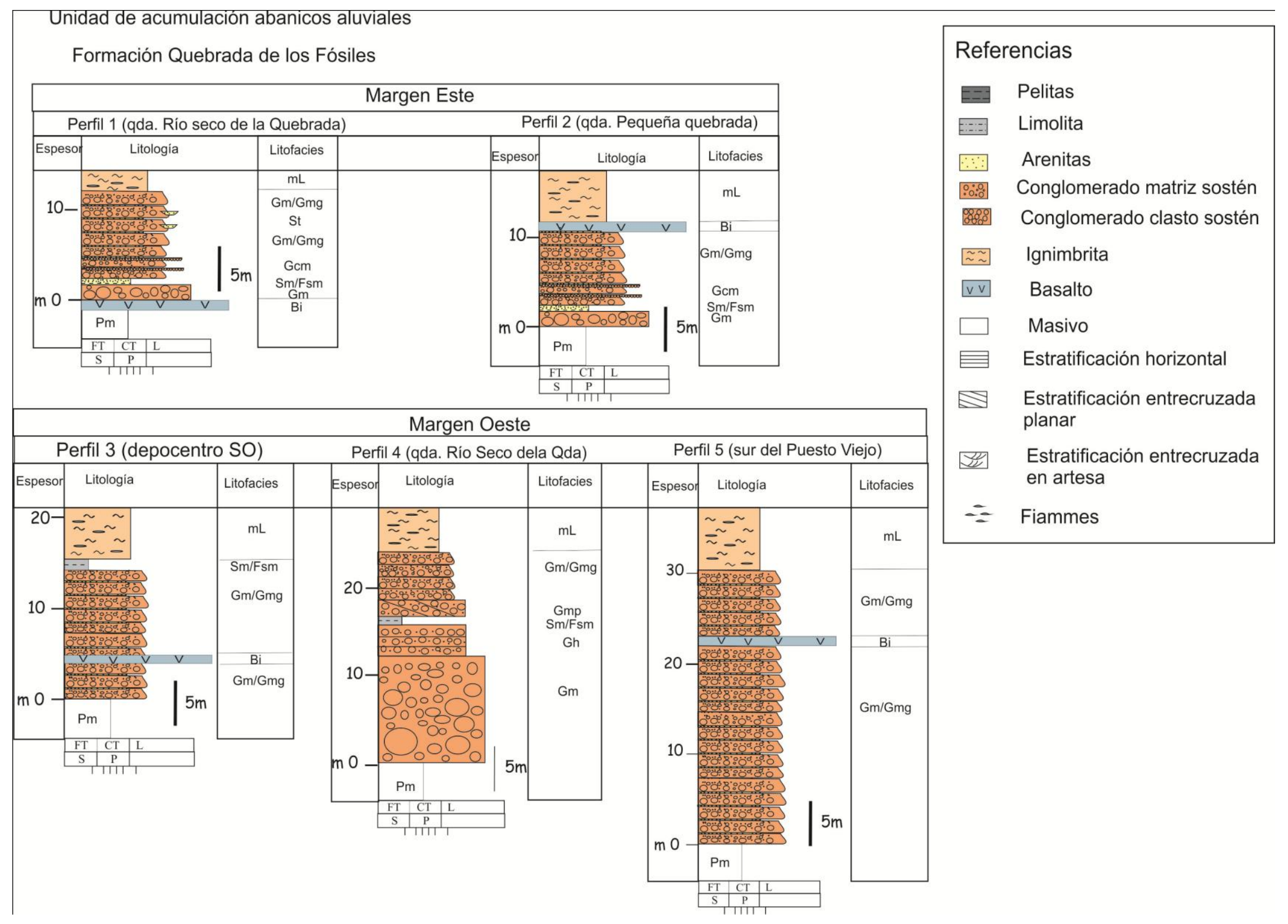




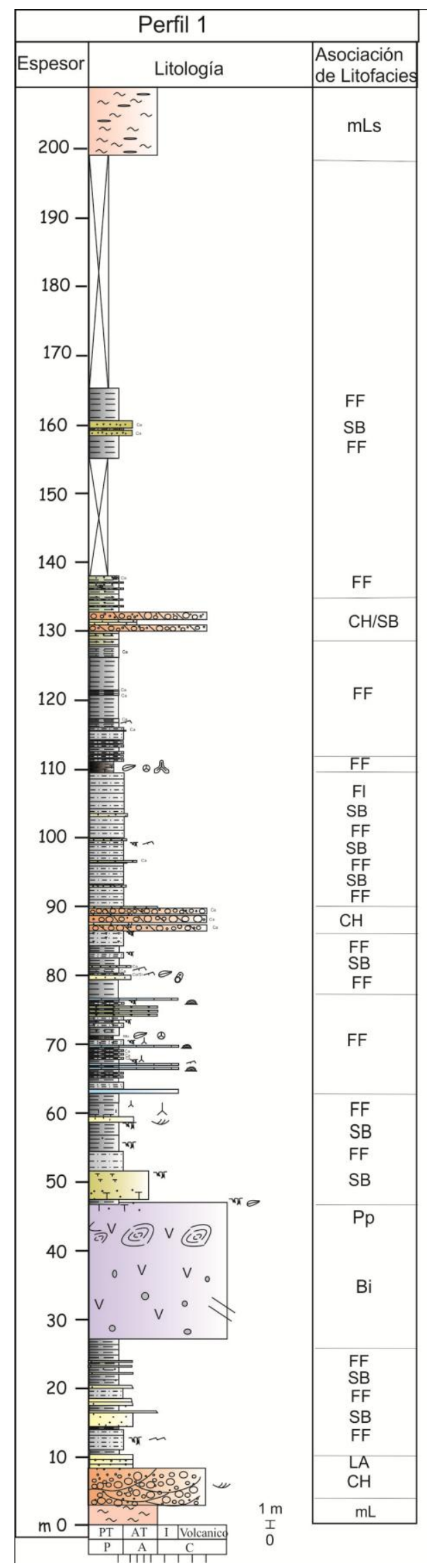

Unidad de acumulación

sist. meandroso de baja sinuosidad

Formación Quebrada de los Fósiles

Ubicación: qda. Agua de los Burros y Quebrada de los Fósiles

\begin{tabular}{|c|c|}
\hline \multicolumn{2}{|c|}{ Referencias } \\
\hline 国 & Arcillita \\
\hline$E=\exists$ & Fangolita \\
\hline EIF & Fangolita Tobácea \\
\hline$=-$ & Limolita \\
\hline$\because$ & Arensica \\
\hline$\because \because$ & Arenisca tobácea \\
\hline$\because \because: 0$ & Conglomerado \\
\hline$\approx \approx$ & Ignimbrita \\
\hline ए1 & Caliza \\
\hline $\mathrm{vv}$ & Basalto \\
\hline $\mathrm{T}^{\mathrm{T}} \mathrm{T}$ & Toba \\
\hline & Masiva \\
\hline 㞔 & Estratificación horizontal \\
\hline$\approx$ & $\begin{array}{l}\text { Estrtificación } \\
\text { entrecruzada planar }\end{array}$ \\
\hline स्य & $\begin{array}{l}\text { Estrtificación } \\
\text { entrecruzada en artesa }\end{array}$ \\
\hline 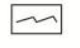 & Ondulitas \\
\hline$\therefore$ & Amigdolas \\
\hline & Fiammes \\
\hline & Vesículas enlongadas \\
\hline 旬 & Fractura perlítica \\
\hline & Leaves \\
\hline & Tronco \\
\hline & Paleosuelo \\
\hline ำ & Marca de raíces \\
\hline$\pi$ & Bioturbación \\
\hline @ & Stromatolitos \\
\hline Q & Microesporas \\
\hline
\end{tabular}




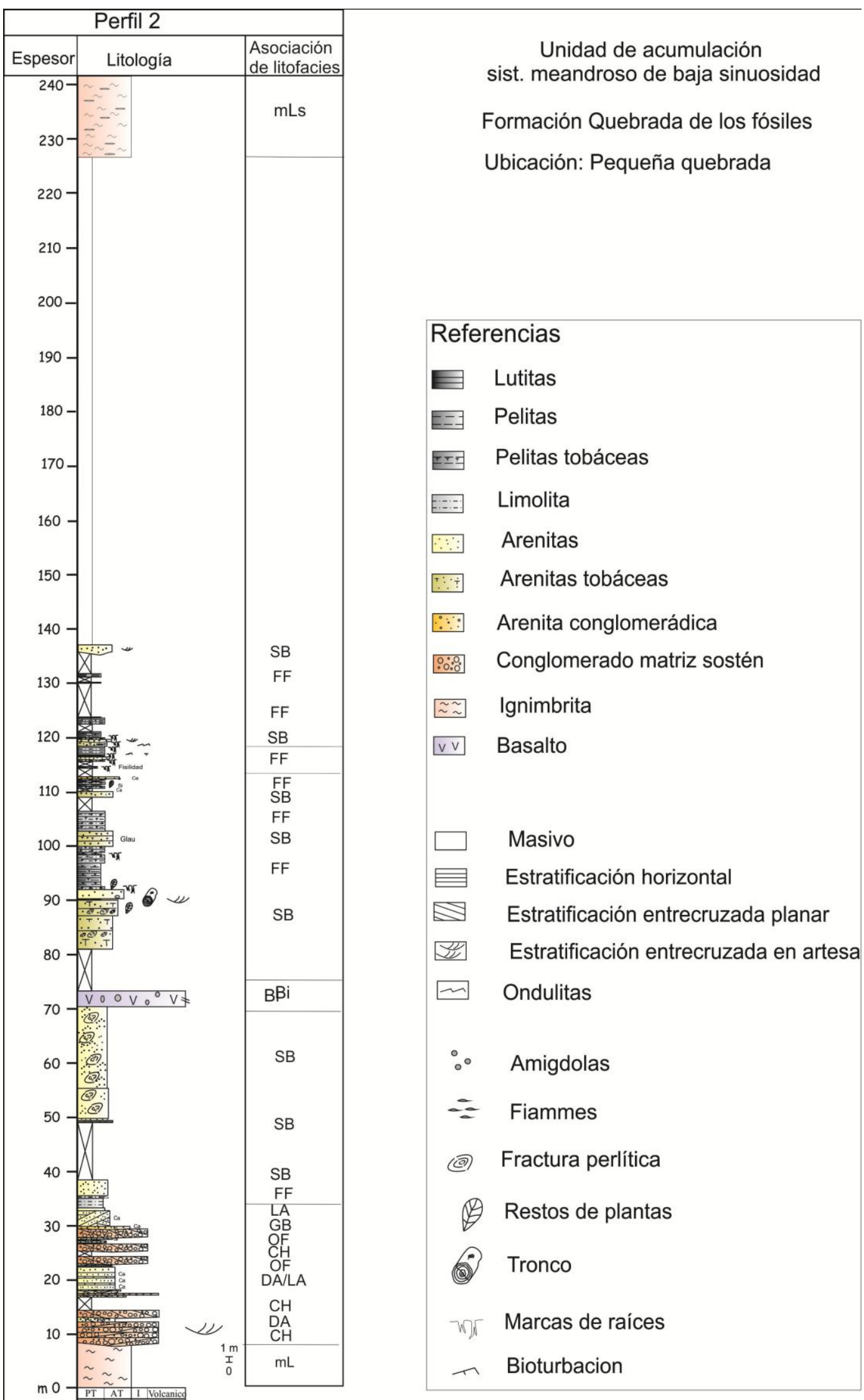




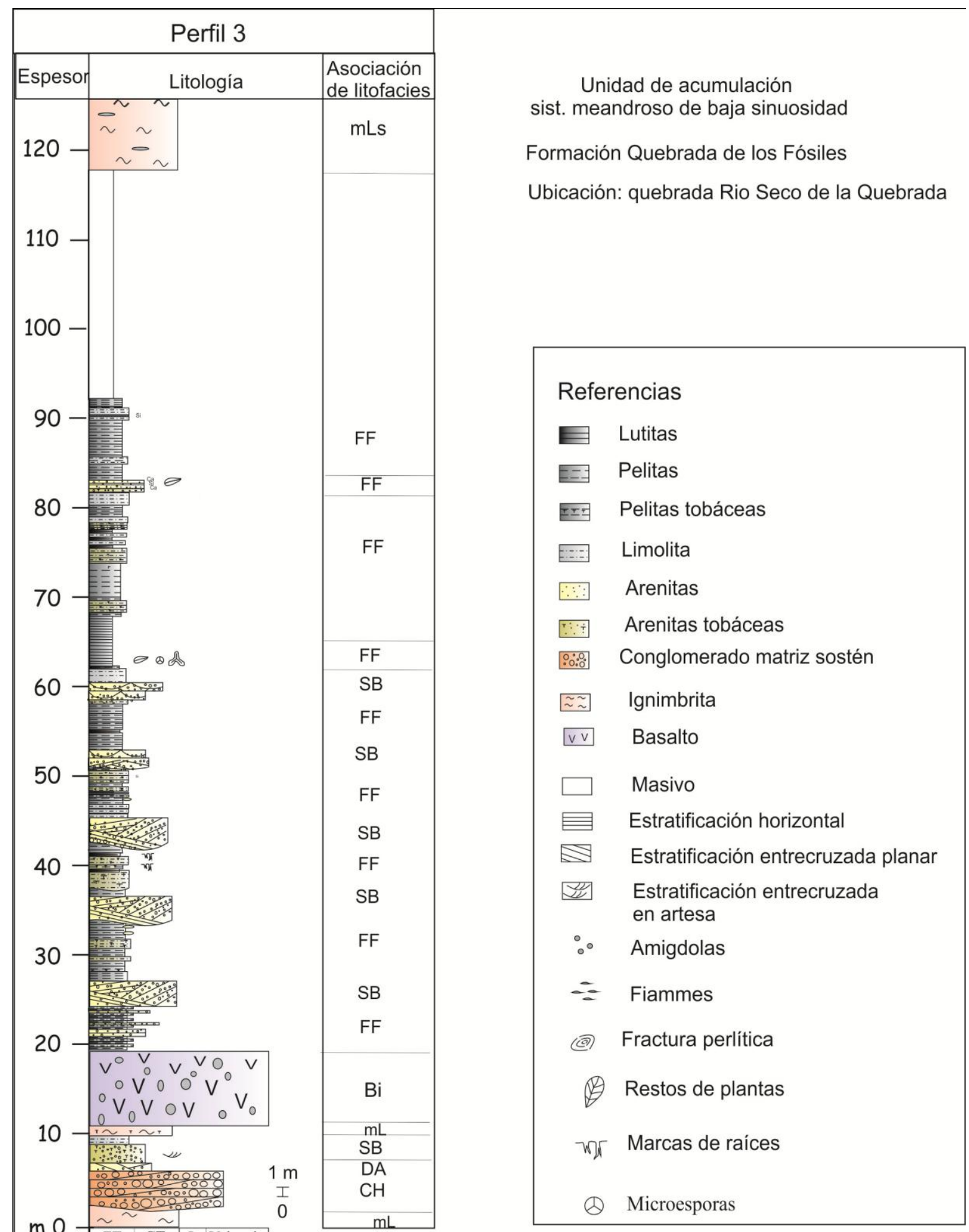




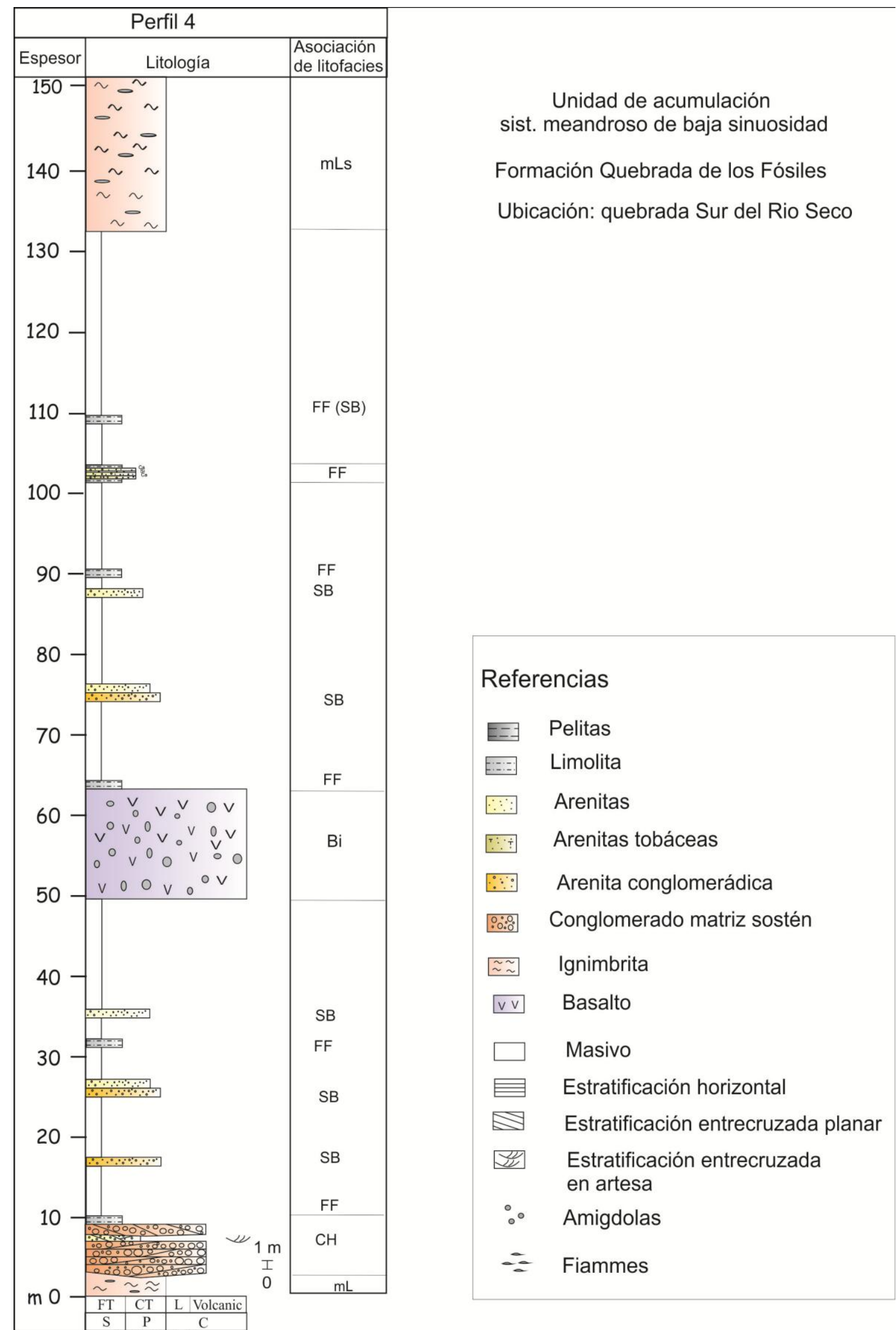




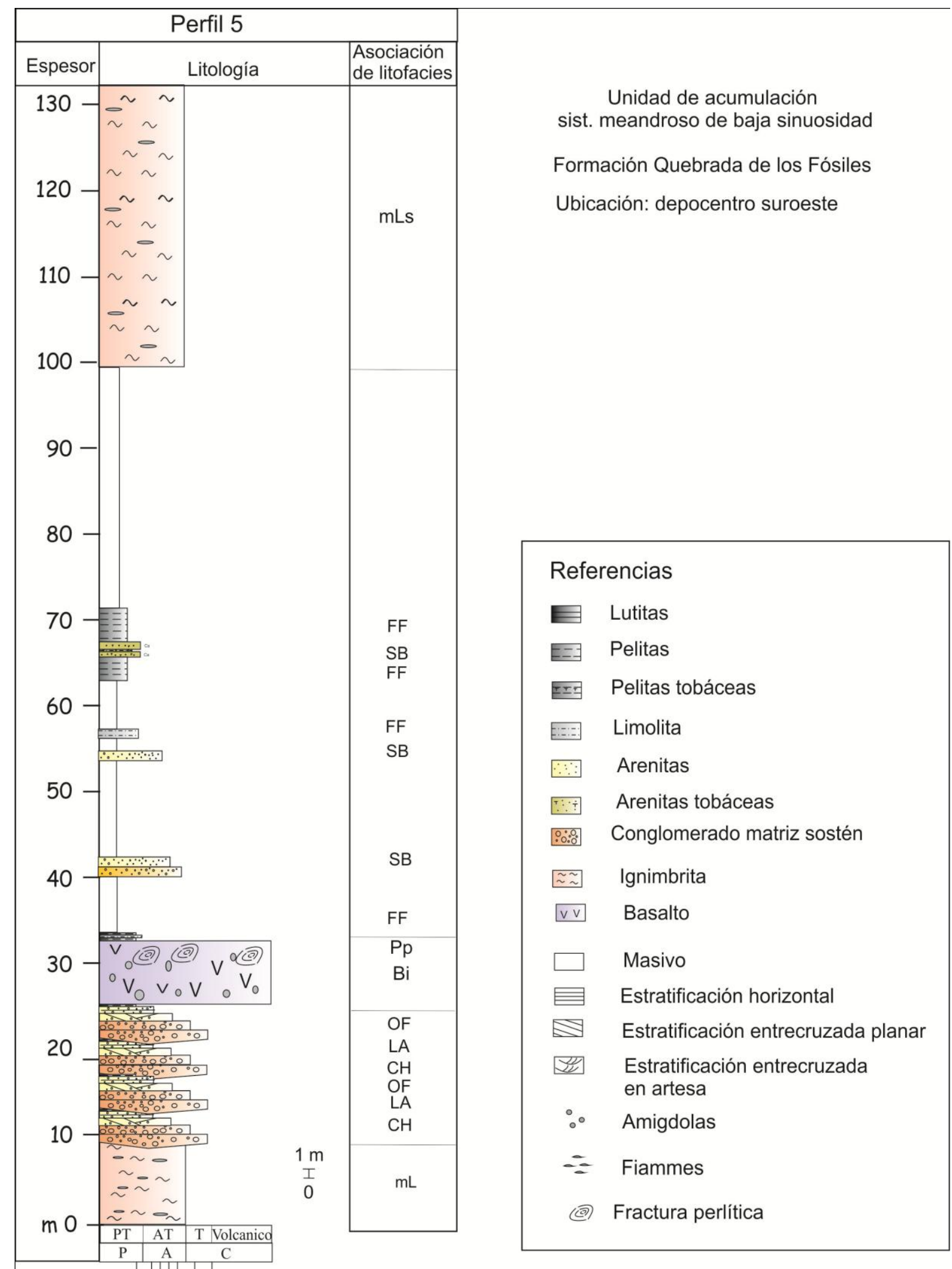




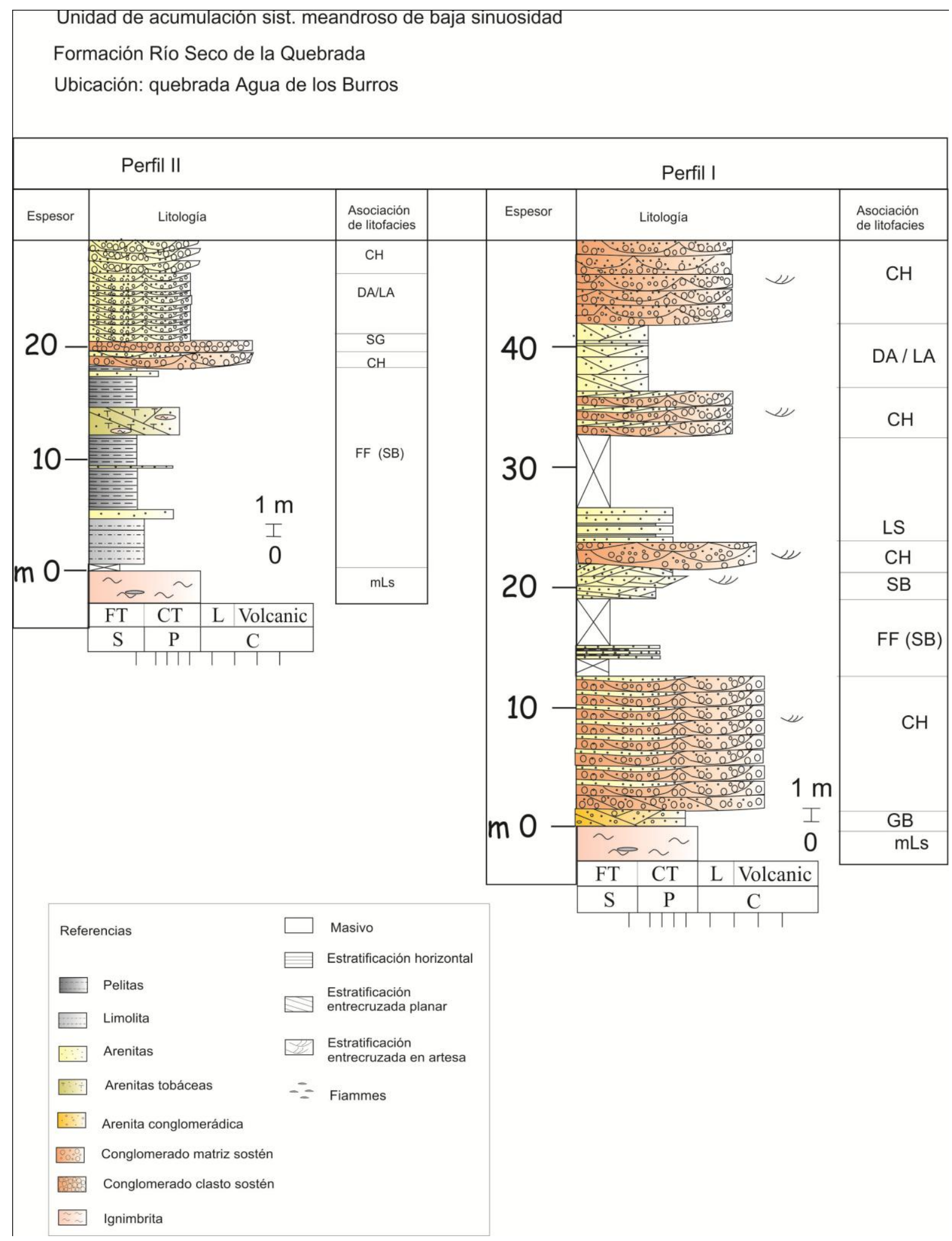


Unidad de acumulación sist. meandroso de baja sinuosidad

Formación Río Seco de la Quebrada

Ubicación: quebrada EI Puntano

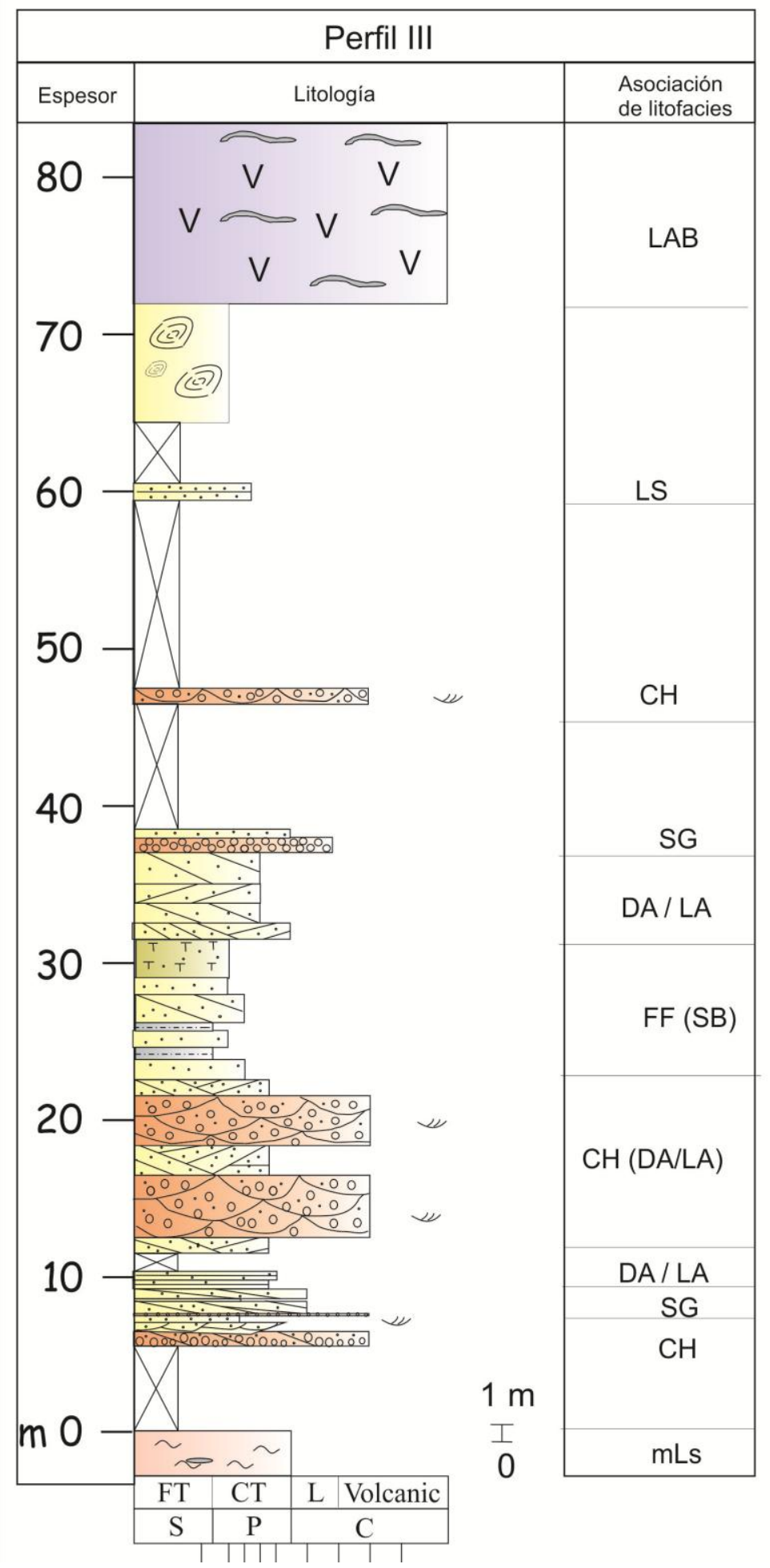




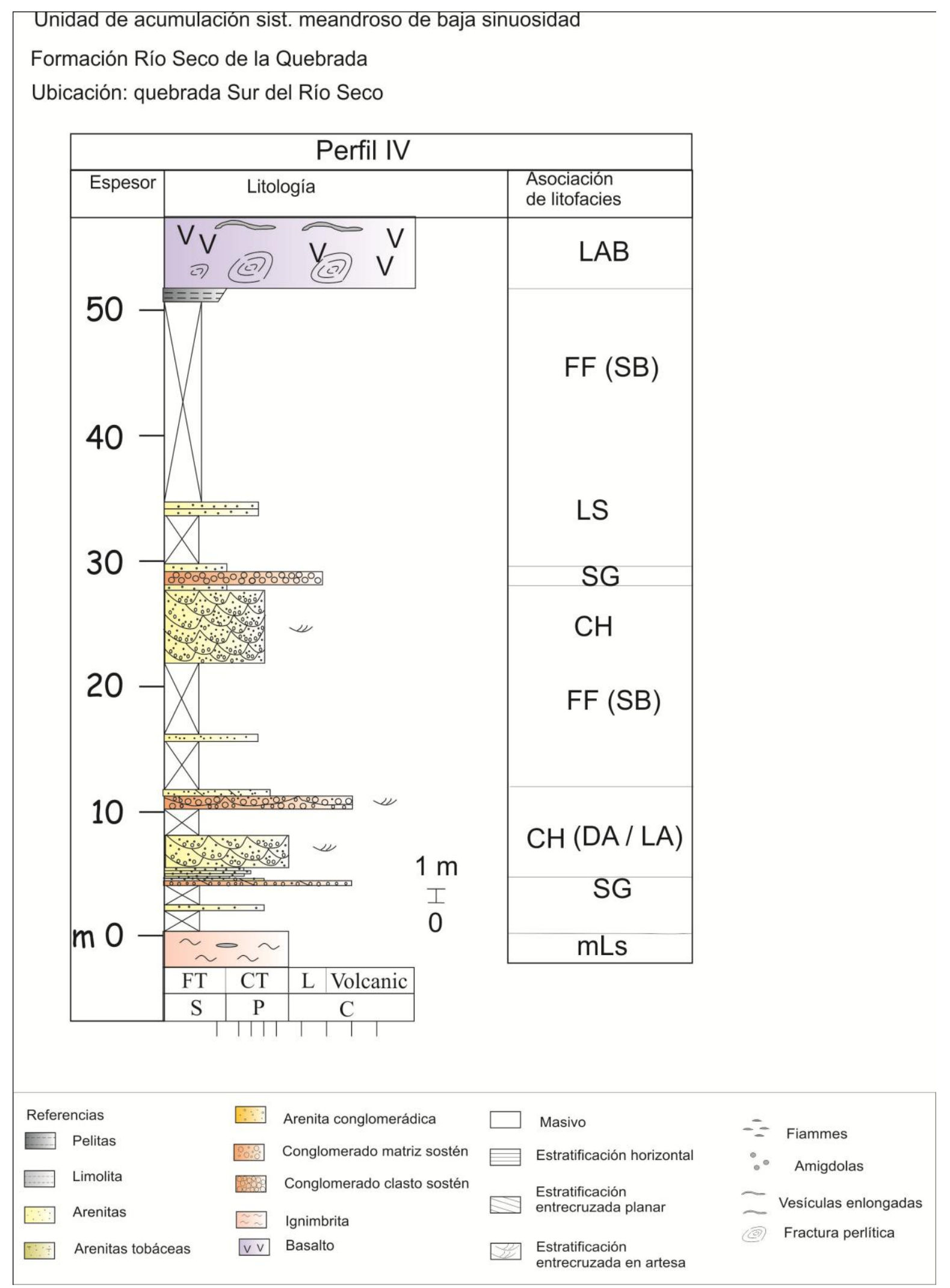


Unidad de acumulación sist. meandroso de baja sinuosidad Formación Río Seco de la Quebrada

Ubicación: quebrada El Durazno

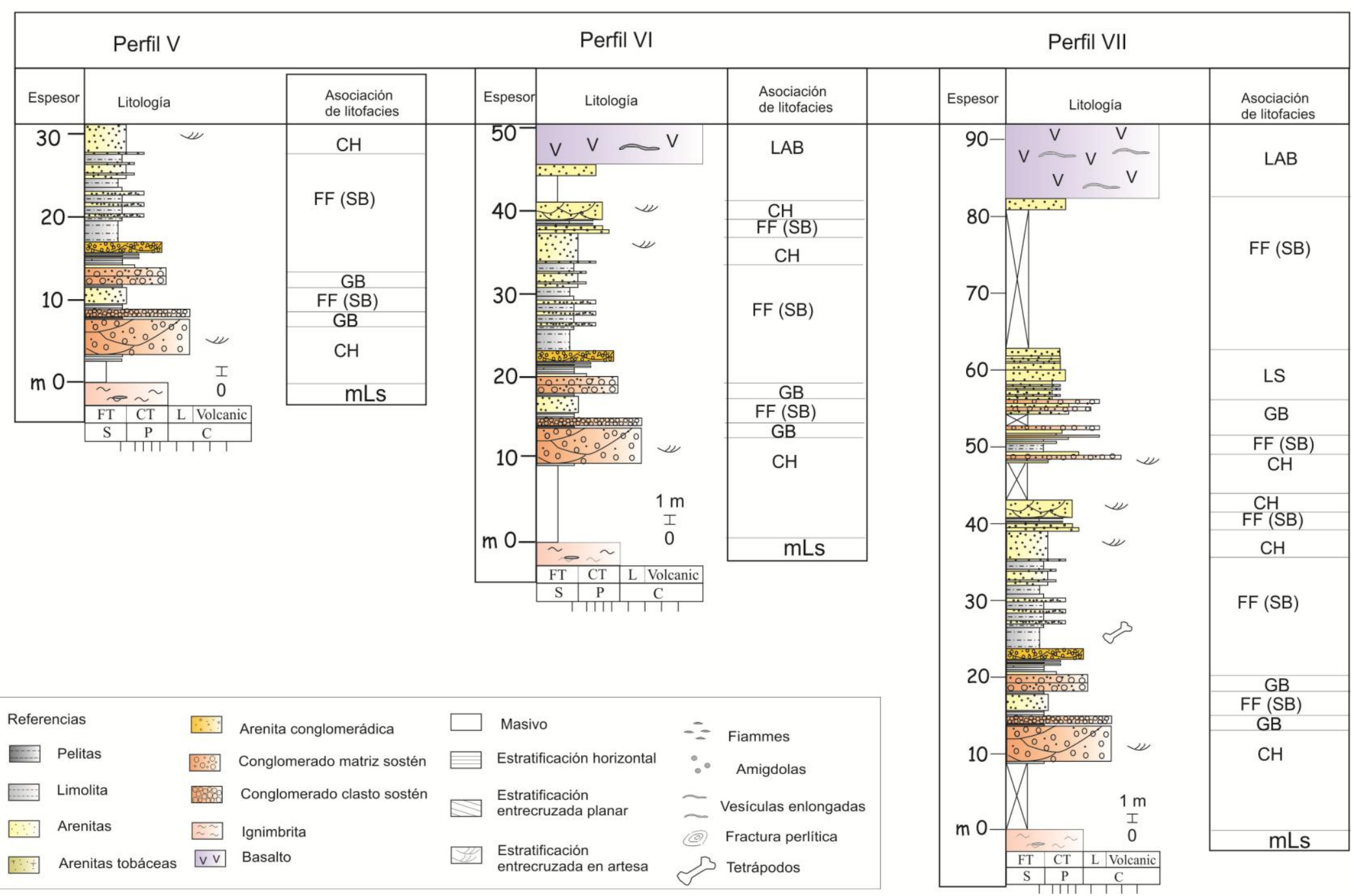




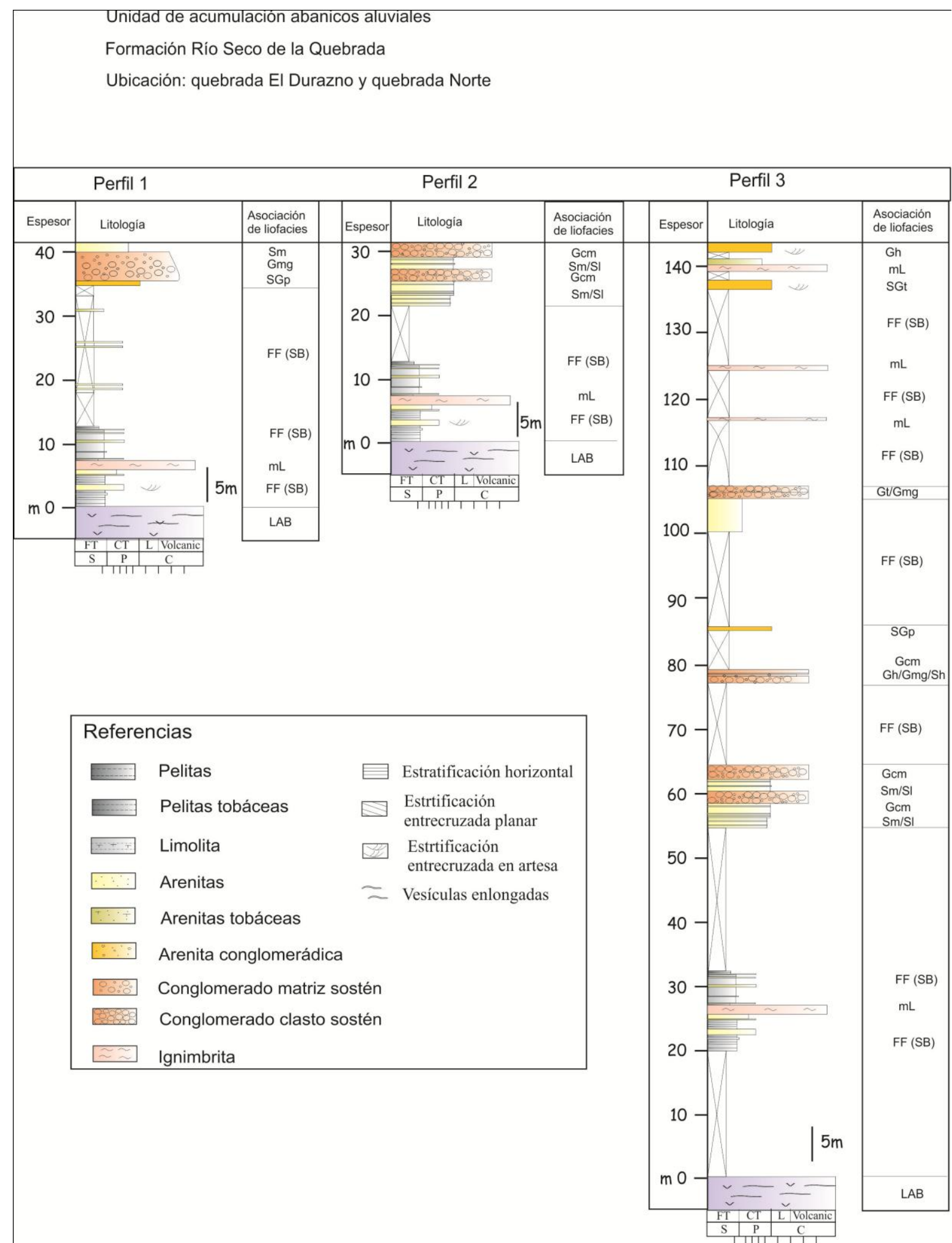




\section{ANEXO 3}

\section{ANÁLISIS GEOQUÍMICOS}




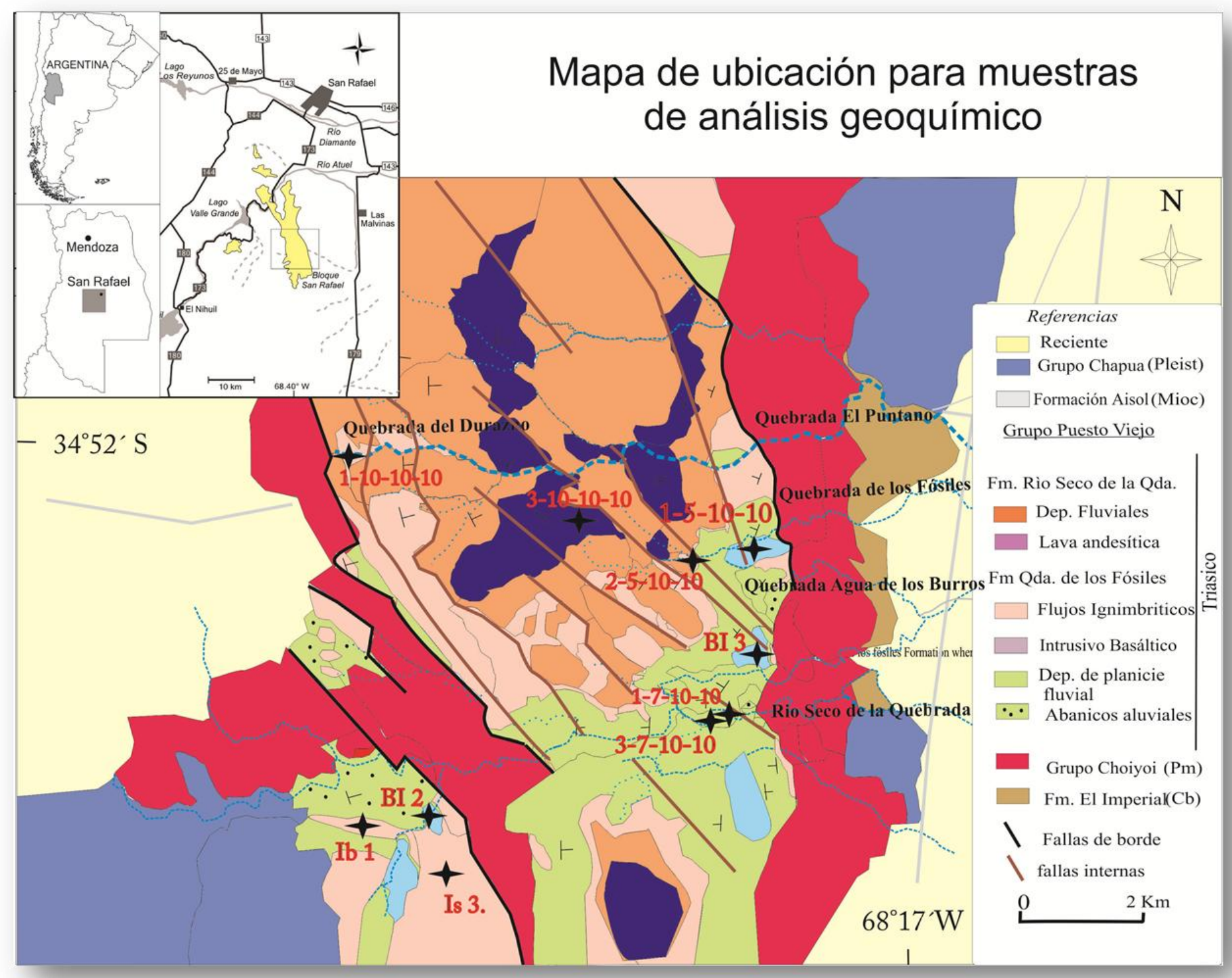


Tabla de datos de análisis geoquímico

\begin{tabular}{|c|c|c|c|c|c|c|c|c|c|c|c|c|c|c|}
\hline & & \multicolumn{7}{|c|}{ BASALTOS } & \multicolumn{6}{|c|}{ IGNIMBRITAS } \\
\hline & & \multicolumn{5}{|c|}{ TESIS } & \multicolumn{2}{|c|}{ KLEMA,N, 2001} & \multicolumn{5}{|c|}{ TESIS } & \multirow[b]{2}{*}{$52 / 88$} \\
\hline & & PV3.7.10.10 & PV3.10.10.10 & PV1.5.10.10 & BINT 3 & B1.2 & $53 / 88$ & $146 / 92$ & PV2.5.10.10 & IS. 3 & PV1.10.10.10 & Ib.1 & PV1.7.10.10 & \\
\hline MAYORITARIOS & $\mathrm{SiO} 2$ & 48,39 & 48,33 & 51,29 & 52,42 & 47,77 & 62,97 & 50,11 & 77,22 & 75,56 & 84,61 & 76,08 & 76,39 & 77,19 \\
\hline \multirow[t]{9}{*}{$\%$} & $\mathrm{Al} 2 \mathrm{O} 3$ & 14,34 & 14,95 & 12,8 & 12,05 & 15,05 & 11,88 & 17,59 & 10,36 & 11,32 & 6,94 & 11,15 & 9,46 & 12,31 \\
\hline & $\mathrm{Fe} 2 \mathrm{O} 3(\mathrm{~T})$ & 15,62 & 15,55 & 13,64 & 12,93 & 14,03 & 10,47 & 4,37 & 1,73 & 2,48 & 1,62 & 1,02 & 2,14 & 1,5 \\
\hline & $\mathrm{MnO}$ & 0,12 & 0,11 & 0,25 & 0,2 & 0,21 & 0,17 & 0,2 & 0,03 & 0,02 & 0,01 & 0,02 & 0,02 & 0,02 \\
\hline & $\mathrm{MgO}$ & 1,86 & 0,53 & 0,67 & 0,52 & 2,89 & 1,31 & 3,37 & 0,2 & 0,12 & 0,06 & 0,15 & 1,14 & 0,12 \\
\hline & $\mathrm{CaO}$ & 3,71 & 5,15 & 7,25 & 7,98 & 6,61 & 3,57 & 5,11 & 0,23 & 0,38 & 0,12 & 1,01 & 0,78 & 0,6 \\
\hline & $\mathrm{Na} 2 \mathrm{O}$ & 2,82 & 4,17 & 2,83 & 3,1 & 4,04 & 3,44 & 4,36 & 1,48 & 2,1 & 0,71 & 1,9 & 1,13 & 2,78 \\
\hline & K2O & 4,69 & 4,24 & 3,48 & 1,82 & 1,87 & 2,83 & 2,26 & 7,18 & 6,83 & 4,72 & 6,18 & 3,45 & 4,86 \\
\hline & TiO2 & 3,34 & 2,63 & 2,96 & 2,66 & 3,47 & 1,72 & 2,78 & 0,15 & 0,18 & 0,09 & 0,18 & 0,22 & 0,09 \\
\hline & P205 & 1,11 & 2,09 & 1,04 & 0,92 & 1,12 & 1,2 & 1,03 & 0,04 & 0,04 & 0,03 & 0,03 & 0,03 & 0,24 \\
\hline LOI & & 3,97 & 2,24 & 3,78 & 5,42 & 2,93 & 0,46 & 2.05 & 1,38 & 0,96 & 1,06 & 2,34 & 5,25 & 0,44 \\
\hline Total & & 100 & 100 & 100 & 100 & 100 & 100 & 100 & 100 & 100 & 100 & 100 & 100 & 100 \\
\hline REE & La & 49,3 & 75,4 & 45,8 & 39,7 & 49,6 & 50,1 & 49,93 & 54,8 & 72,5 & 34,9 & 85 & 56,6 & \\
\hline \multirow{7}{*}{ ppm } & $\mathrm{Ce}$ & 111 & 165 & 102 & 89,7 & 112 & 117,29 & 117,29 & 118 & 136 & 71,6 & 169 & 124 & \\
\hline & Nd & 65,8 & 99 & 62,2 & 55,2 & 68,1 & 65,84 & 65,07 & 57,9 & 71,4 & 37 & 78,8 & 55,5 & \\
\hline & $\mathrm{Sm}$ & 13,7 & 19,9 & 14 & 12 & 15,2 & 14,31 & 14,67 & 13 & 13,3 & 8,4 & 15 & 10,5 & \\
\hline & Eu & 3,73 & 5,7 & 3,8 & 3,27 & 4,32 & 4,11 & 4,09 & 0,26 & 0,47 & 0,14 & 0,41 & 0,56 & \\
\hline & $\mathrm{Tb}$ & 1,9 & 2,3 & 1,8 & 1,5 & 2 & & 2,42 & 1,9 & 1,9 & 1,3 & 2 & 1,6 & \\
\hline & $\mathrm{Yb}$ & 5 & 5,2 & 5,3 & 4,8 & 5,8 & 4,54 & 7,15 & 7,4 & 7 & 4,9 & 7,8 & 7 & \\
\hline & Lu & 0,75 & 0,73 & 0,71 & 0,69 & 0,88 & 0,7 & 1,03 & 1,03 & 1,02 & 0,73 & 1,17 & 1,17 & \\
\hline
\end{tabular}


Tabla de datos de análisis geoquímico (continuación)

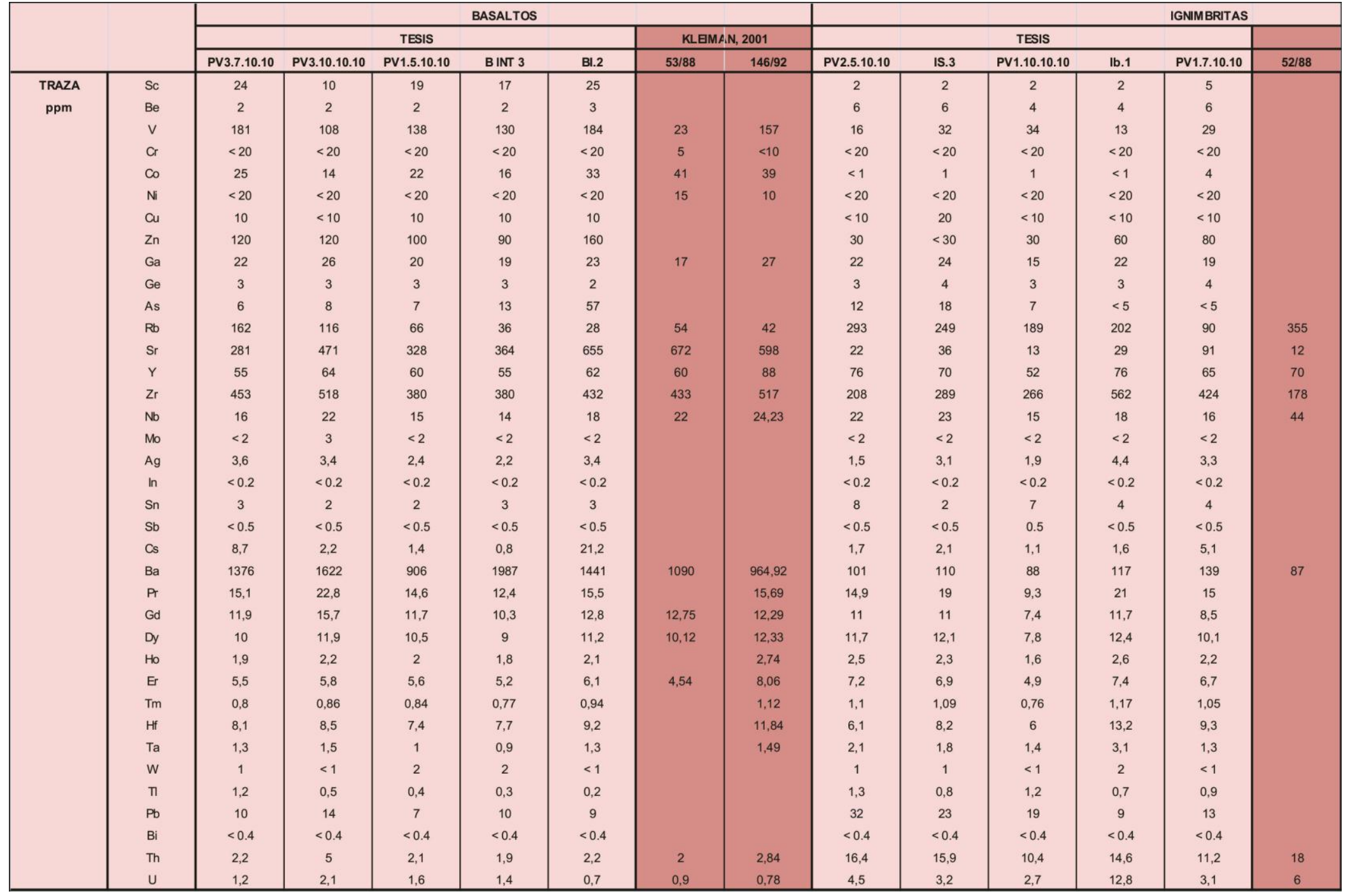

